\title{
Puget Sound Dissolved Oxygen Modeling Study: Development of an Intermediate Scale Water Quality Model
}

by $\mathrm{T}$ Khangaonkar and $\mathrm{W}$ Long

of the Pacific Northwest National Laboratory

and B Sackmann, T Mohamedali, and M Roberts of the Washington State Department of Ecology

November 2012 
This page is purposely left blank 


\title{
DISCLAIMER
}

This report was prepared as an account of work sponsored by an agency of the United States Government. Neither the United States Government nor any agency thereof, nor Battelle Memorial Institute, nor any of their employees, makes any warranty, express or implied, or assumes any legal liability or responsibility for the accuracy, completeness, or usefulness of any information, apparatus, product, or process disclosed, or represents that its use would not infringe privately owned rights. Reference herein to any specific commercial product, process, or service by trade name, trademark, manufacturer, or otherwise does not necessarily constitute or imply its endorsement, recommendation, or favoring by the United States Government or any agency thereof, or Battelle Memorial Institute. The views and opinions of authors expressed herein do not necessarily state or reflect those of the United States Government or any agency thereof.

\author{
PACIFIC NORTHWEST NATIONAL LABORATORY \\ operated by \\ BATTELLE \\ for the \\ UNITED STATES DEPARTMENT OF ENERGY \\ under Contract DE-AC05-76RL01830
}

Printed in the United States of America
Available to DOE and DOE contractors from the Office of Scientific and Technical Information,
P.O. Box 62, Oak Ridge, TN 37831-0062;
ph: (865) 576-8401
fax: $(865)$ 576-5728
email: reports@adonis.osti.gov

\begin{abstract}
Available to the public from the National Technical Information Service, U.S. Department of Commerce, 5285 Port Royal Rd., Springfield, VA 22161 ph: (800) 553-6847 fax: $(703) 605-6900$ email: orders@ntis.fedworld.gov online ordering: http://www.ntis.gov/ordering.htm
\end{abstract}

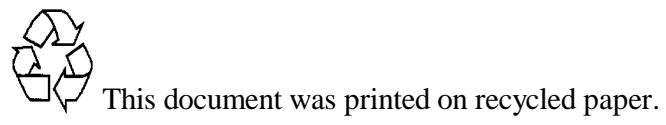


This page is purposely left blank 


\section{Puget Sound Dissolved Oxygen Modeling Study: Development of an Intermediate Scale Water Quality Model}

by

T Khangaonkar and W Long

of the Pacific Northwest National Laboratory

B Sackmann, T Mohamedali, and M Roberts

of the Washington State Department of Ecology

October 2012

Prepared for

the Washington State Department of Ecology

under an Interagency Agreement with

the U.S. Department of Energy

Contract DE-AC05-76RL01830

Pacific Northwest National Laboratory

Richland, Washington 99352

Any use of product or firm names in this publication is for descriptive purposes only and does not imply endorsement by the authors or the Department of Ecology.

If you need this document in a format for the visually impaired, call 360-407-6764. Persons with hearing loss can call 711 for Washington Relay Service.

Persons with a speech disability can call 877-833-6341. 
This page is purposely left blank 


\section{Summary}

The Salish Sea, including Puget Sound, is a large estuarine system bounded by over seven thousand miles of complex shorelines, consists of several subbasins and many large inlets with distinct properties of their own. Pacific Ocean water enters Puget Sound through the Strait of Juan de Fuca at depth over the Admiralty Inlet sill. Ocean water mixed with freshwater discharges from runoff, rivers, and wastewater outfalls exits Puget Sound through the brackish surface outflow layer. Nutrient pollution is considered one of the largest threats to Puget Sound. There is considerable interest in understanding the effect of nutrient loads on the water quality and ecological health of Puget Sound in particular and the Salish Sea as a whole.

The Washington State Department of Ecology (Ecology) contracted with Pacific Northwest National Laboratory (PNNL) to develop a coupled hydrodynamic and water quality model. The water quality model simulates algae growth, dissolved oxygen, (DO) and nutrient dynamics in Puget Sound to inform potential Puget Sound-wide nutrient management strategies. Specifically, the project is expected to help determine 1) if current and potential future nitrogen loadings from point and non-point sources are significantly impairing water quality at a large scale and 2) what level of nutrient reductions are necessary to reduce or control human impacts to DO levels in the sensitive areas. The project did not include any additional data collection but instead relied on currently available information. This report describes model development effort conducted during the period 2009 to 2012 under a U.S. Environmental Protection Agency (EPA) cooperative agreement with PNNL, Ecology, and the University of Washington awarded under the National Estuary Program.

The development of a predictive nutrients and DO model of Puget Sound consisted of two major components: 1) a three-dimensional coastal hydrodynamic model and 2) an offline water quality model of Puget Sound. Offline water quality model refers to the approach in which water quality computations are conducted using a previously computed hydrodynamic solution. In this study, a water quality model of Puget Sound was developed with a focus on simulating nutrient loading, phytoplankton primary productivity, and subsequent effects on DO in Puget Sound and the Northwest Straits (Salish Sea) using data from Year 2006.

The model was constructed using the unstructured grid Finite Volume Coastal Ocean Model (FVCOM) framework and the integrated compartment model (CE-QUAL-ICM) for biogeochemical water quality kinetics developed by U.S. Army Corps of Engineers. In this offline linkage, the hydrodynamic outputs (domain-wide temperature, salinity, free surface heights and elevations, velocity components, and boundary fluxes) were first calculated using the FVCOM model. Outputs were then used to drive the CEQUAL-ICM kinetic equations. A total of 19 state variables, including two species of algae, dissolved and particulate carbon, and nutrients, were simulated as part of the carbon cycle to calculate algal production and decay and the impact on dissolved oxygen.

The model domain includes all of Puget Sound and Georgia Basin divided into a three-dimensional grid. The model grid is an unstructured mesh and uses triangular cells with higher resolution in narrower regions of the Sound, growing coarser in the Strait of Juan de Fuca. The grid resolution is on average 250 meters in the inlets and bays and approximately 800 meters inside Puget Sound main basin, and it consists of approximately 14,000 grid cells in the horizontal plane and 10 layers in the vertical direction with thinner layers near the surface. This grid resolution is insufficient to resolve nearfield dilution and mixing at the wastewater outfalls. Similarly residence time in some of the inner secluded narrow and 
shallow channels and inlets may not be adequately captured. It is therefore sometimes referred to as the Intermediate Grid Model of Puget Sound. However, this scale does allow sufficient resolution of the various major river estuaries and the larger fjordal subbasins and their interaction with the main basin of Puget Sound. This scale was selected specifically to enable efficient year-long simulations. The model runs in a parallel mode on a 184-core computer cluster, with a computer run time of approximately 24 hours for a one-year simulation of water quality, using 35 cores per simulation.

The FVCOM hydrodynamic model was calibrated using Year 2006 data. The setup includes loads (nutrient, phytoplankton, and DO) from the open ocean boundaries, 64 river inflows, and 99 wastewater treatment plants. Meteorological forcing includes the same wind stress and solar irradiance used in the hydrodynamic model for 2006. Phytoplankton primary production, inorganic and organic carbon fluxes, and nutrient (nitrogen and phosphorus) sources and sinks were specified as the key water quality parameters. The model was calibrated against observed data of chlorophyll a (a proxy for phytoplankton biomass), nutrients (phosphate, nitrate + nitrite), and DO at various stations within the study domain.

Model results were consistent with the generally accepted understanding of how Puget Sound circulation and transport processes affect algae, nutrients, and DO kinetics. Nutrient and DO concentrations in the Puget Sound water column below the pycnocline, which is where the density gradient is highest in the water column, reflect Pacific Ocean water, which enters Puget Sound at depth over the Admiralty Inlet sill. The concentrations in the mixed outflow layer occupying approximately 5-20 $\mathrm{m}$ of the upper water column correspond to the exchange flow mixed with the freshwater discharges from the rivers or wastewater discharges. As expected, observations and model results from 2006 showed that little or no algal activity occurs during the winter months because of reduced sunlight and low water temperatures. As temperatures and sunlight availability increased in 2006, Puget Sound experienced a spring bloom of algae in April and May 2006. A slightly larger summer bloom followed during the months of June, July, and August. In many shallow areas, surface algal production coupled with re-aeration contributes to DO levels that exceed $10 \mathrm{mg} / \mathrm{L}$, sometimes reaching supersaturated levels. These spring and summer blooms resulted in depletion of nutrients to low levels in many of these shallow bays and surface layers of the fjordal subbasins. The end of the summer algal bloom coincided with incoming Pacific Ocean waters with lowest levels of DO during the months of September and October. By late fall 2006, with reduced sunlight availability and decreasing temperatures, the algal chlorophyll $a$ levels dropped back to very low levels.

The bottom layer of Puget Sound, however, experienced the opposite. A steady inflow of low DO water modulated by mixing with biologically active surface layer outflow in the Strait of Juan de Fuca and Admiralty Inlet was observed. This was particularly noticeable during the late spring and continued through the end of summer and the fall months. This is a well-known phenomenon associated with coastal upwelling during which higher salinity and nutrient- rich waters enter the Strait of Juan de Fuca. By November and December, the low DO waters at the bottom, along with other water column constituents of interest, were flushed out and renewed with wintertime Pacific Ocean water that contains higher DO levels. Alongside the natural processes that affect DO, human activities in the region released nutrients into the Sound, potentially affecting DO levels.

Simulating water quality in a waterbody as complex as Puget Sound is a significant technical challenge. In its present state of development the model generally captures many of the spatial and temporal patterns for phytoplankton, nutrients, and DO seen in the water quality data for 2006. Further efforts could refine estimates of impacts from human activities on water quality in Puget Sound and the Salish Sea, particularly in the shallow inlets where the model resolution is lowest. 


\section{Abbreviations and Acronyms}

2-D

3-D

$\mathrm{ADCP}$

CTD

DFO

DIN

DO

DOC

DOM

DOP

Ecology

EPA

FVCOM

JEMS

LIDAR

MAE

NAD

NARR

NAVD88

NCEP

NOAA

NPDES

PAR

PNNL

POC

PON

PSDEM

RME

RMSE

USGS

UTM

UW

WSE

XTide two-dimensional

three-dimensional

acoustic Doppler current profiler

conductivity/temperature/depth

Department of Fisheries and Oceans Canada

dissolved inorganic nitrogen

dissolved oxygen

dissolved organic carbon

dissolved organic matter

dissolved organic phosphate

Washington State Department of Ecology

U.S. Environmental Protection Agency

Finite Volume Coastal Ocean Model

Joint Effort to Monitor the Straits (joint project of Ecology and University of Washington)

light detection and ranging

absolute mean error

North American Datum

North American Regional Reanalysis

North American Vertical Datum of 1988

National Center for Environmental Prediction

National Oceanic and Atmospheric Administration

National Pollutant Discharge Elimination System

photosynthetically active radiation

Pacific Northwest National Laboratory

particulate organic carbon

particulate organic nitrogen

Puget Sound Digital Elevation Model

relative mean error

root mean square error

U.S. Geological Survey

Universal Transverse Mercator

University of Washington

water surface elevation

harmonic tide clock and tide predictor 
This page is purposely left blank 


\section{Contents}

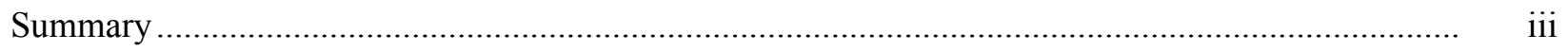

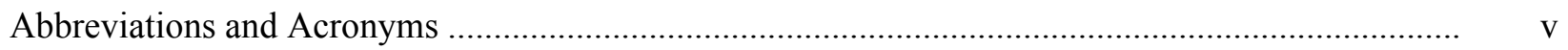

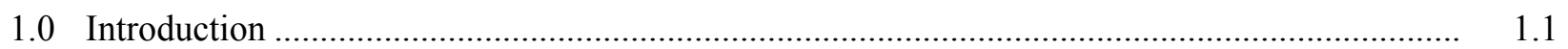

$2.0 \quad$ Water Quality Model Description and Setup ...................................................................... 2.1

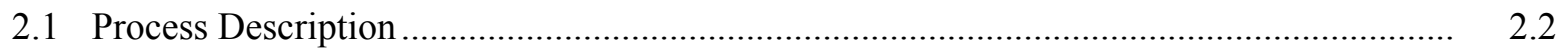

2.2 Model Domain and Grid ..................................................................................... 2.5

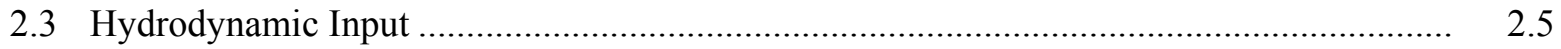

2.4 Initial Condition Data - Water Quality ................................................................... 2.14

2.5 River, Wastewater Treatment Plant, and Watershed Discharge Boundary Data ............... 2.16

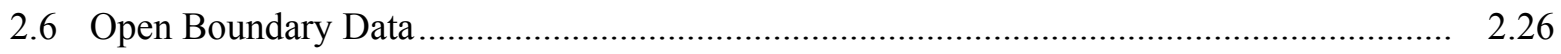

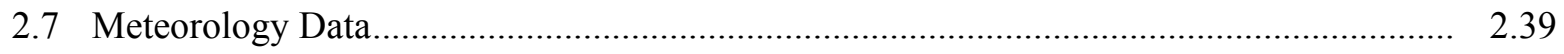

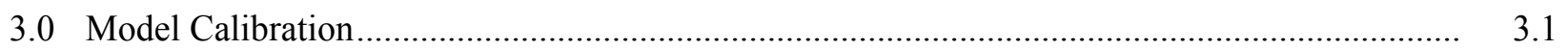

3.1 Calibration Approach - Parameterization through Sensitivity Testing ............................. 3.1

3.2 Model Calibration - Profiles of Dissolved Oxygen and Nutrients................................... 3.7

3.2.1 Dissolved Oxygen Profiles............................................................................. 3.7

3.2.2 Nutrient Profiles (Nitrate + Nitrite - Nitrogen) …................................................ 3.12

3.2.3 Nutrient Profiles (Phosphate - Phosphorus) …..................................................... 3.13

3.3 Model Calibration - Surface Concentrations of Algal Chlorophyll a, Profiles of Dissolved Oxygen, and Nutrients............................................................................... 3.17

3.4 Model Calibration - Surface and Bottom Nutrients...................................................... 3.20

3.5 Model Calibration - Surface and Bottom Dissolved Oxygen ........................................ 3.26

3.6 Model Error Statistics............................................................................................ 3.29

4.0 Summary and Discussion of Model Limitations ..................................................................

4.1 Summary of Model Development .............................................................................. 4.1

4.2 Model Limitations and Uncertainty ........................................................................... 4.2

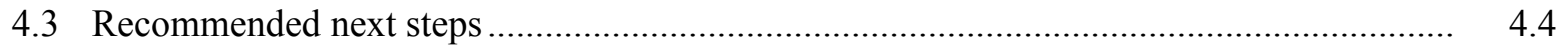

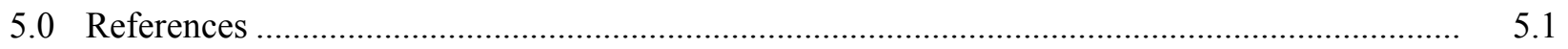

Appendix A - Development and Evaluation of a Coupled Hydrodynamic (FVCOM) and Water Quality Model (CE-QUAL-ICM) .................................................................................. A.1

Appendix B - Dissolved Oxygen Profiles Comparison of Year 2006 Monthly Profile Data with Predicted Results

Appendix C - (Nitrate + Nitrite) Profiles Comparison of Year 2006 Monthly Profile Data with Predicted Results

Appendix D - Phosphate Profiles Comparison of Year 2006 Monthly Profile Data with Predicted Results

Appendix E - User Instructions and Guide - Puget Sound Hydrodynamic and Water Quality Models 


\section{Figures}

1.1 Study Domain - Puget Sound, Strait of Juan de Fuca, and Georgia Strait ............................. 1.3

2.1 Representative Carbon, Phosphorus, Nitrogen, and Dissolved Oxygen Cycles in the Puget

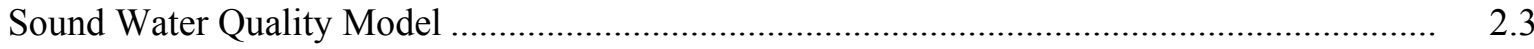

2.2 Study Domain and Oceanographic Data Monitoring Stations - Puget Sound Water Quality Model.

2.3 Computational Grid - Puget Sound Water Quality Model

2.4 Ocean Boundary Tidal Elevations, and River Inflows, Wind Speed, and Net Heat Flux from Year 2006 Used in the Hydrodynamic Model Setup .

2.5 Hydrodynamic Model Calibration Example - (a) Water Surface Elevation at Seattle, and (b) Currents in Skagit Bay.

2.6 Salinity and Temperature Calibration - (a) Profiles during High Flow and (b) Time Histories of Salinity and Temperature from Surface and Bottom (2006)

2.7 Ecology's Puget Sound Ambient Monitoring - Marine Flight Program: Station Locations ......

2.8 Wastewater Treatment Plant Locations - Puget Sound Basin, Point Source Loads .....

2.9 Wastewater Treatment Plant Flows - Puget Sound Basin, Point Source Loads

2.10 River and Watershed Discharge Locations (Pour Points) - Puget Sound Basin, Point Source Loads

2.11 Individual River Inflow in the Straits and North Sound, Whidbey Basin, and Main Basin........

2.12 Individual River Inflow in Hood Canal and South Sound

2.13 River Temperature Distributions - Puget Sound Basin

2.14 River Discharge Constituents, Year 2006 Average - Ammonia - N, (Nitrate +Nitrite -N), Phosphate - P, DOC, DON, DOP, and Flow

2.15 Wastewater Treatment Plant Discharge Constituents, Year 2006 Average - Ammonia, (Nitrate +Nitrite), Phosphate, DOC, DON, DOP, and Flow.

2.16 Locations of Boundary Water Quality Stations (yellow stars) Together with all Gauged and Ungauged River Pour Points in the Model Domain

2.17 Nitrate + Nitrite and Phosphate Profiles at Georgia Strait and Strait of Juan de Fuca Boundaries

2.18 Dissolved Oxygen and Algal Carbon at Georgia Strait and Juan de Fuca Boundaries

2.19 Nitrite + Nitrate and Phosphate Profiles, Strait of Juan de Fuca, Year 2006

2.20 Dissolved Oxygen Profiles - Strait of Juan de Fuca, Year 2006 Boundaries

2.21 Composite Time History of Near-Bed Constituent Concentrations at the Strait of Juan de Fuca and Georgia Strait Boundaries from DFO and JEMs Data - 2006.

2.22 Temperature and Salinity Profiles at Strait of Juan de Fuca Open Boundary - Year 2006

2.23 Temperature and Salinity Profiles at Georgia Strait Open Boundary - Year 2006

2.24 Daily Integrated Photosynthetically Active Radiation Calculated from WRF Shortwave Dataset near Seattle

3.1 Observed Data Station Locations Used for Water Quality Calibration 
3.2 Salinity and Velocity in a Transect over Admiralty Inlet to Puget Sound - Year 2006 Model Average

3.3 Dissolved Oxygen Profiles - Comparison of Measured Data with Model Results for the Summer of Year 2006

3.4 (Nitrate + Nitrite) Profiles - Comparison of Measured Data with Model Results for the Summer of Year 2006

3.5 Phosphate Profiles - Comparison of Measured Data with Model Results for the Summer of Year 2006.

3.6 Algal Carbon Time History - Comparison of Measured Surface Data with Model Results for Year 2006

3.7 Nitrate+Nitrite Time History - Comparison of Measured Surface Data with Model Results for Year 2006

3.8 Nitrate+Nitrite Time History - Comparison of Measured Bottom Data with Model Results for Year 2006

3.9 Phosphate Time History - Comparison of Measured Surface Data with Model Results for Year 2006

3.10 Phosphate Time History - Comparison of Measured Bottom Data with Model Results for Year 2006

3.11 Dissolved Oxygen Time History - Comparison of Measured Surface Data with Model Results for Year 2006.

3.12 Dissolved Oxygen Time History - Comparison of Measured Bottom Data with Model Results for Year 2006.

3.13 Aggregated goodness-of-fit statistics for Dissolved Oxygen (DO, mg/L), Nitrate+Nitrite (NO3, mg/L), Salinity (PPT), and Temperature (deg C) for 36 stations distributed throughout model domain.

\section{Tables}

2.1 Model Calibration Error Statistics for Water Surface Elevation.......................................... 2.10

2.2 Model Calibration Error Statistics for Velocity .................................................................. 2.11

2.3 Model Calibration Error Statistics for Salinity .

2.4 Model Calibration Error Statistics for Temperature

2.5 Initial Water Quality Concentrations for 2006 for the spin-up simulation from Puget Sound Main Basin Station PSB003 and Hood Canal Station HCB003 (December 7, 2005)

2.6 Summary of River Inflows (*Percentage is relative to the total inflows in Puget Sound)

2.7 Benthic Sediment Fluxes (5-cm depth) - Nutrients and Dissolved Oxygen throughout the Puget Sound Model Domain

3.1 Ecology Puget Sound Ambient Monitoring Stations

3.2 Mean annual inflows to Salish Sea and Puget Sound subbasins along with residence times estimated for selected locations from analysis of the year 2006 model simulation

3.3 Listing of Key Model Parameters

3.4 Biogeochemical model calibration error statistics at selected locations in Puget Sound (2006) 
This page is purposely left blank 


\subsection{Introduction}

The Salish Sea, including Puget Sound, is a large estuarine system bounded by over seven thousand miles of complex shorelines, consists of several subbasins and many large inlets with distinct properties of their own (Figure 1.1). Pacific Ocean water enters the Puget Sound estuary system and the Georgia Strait through the Strait of Juan de Fuca. The Strait of Juan de Fuca is also the outlet for most of the freshwater discharged to the Puget Sound and from the Fraser River in British Columbia.

Geographically, Puget Sound is defined by the water body that is southeast of Admiralty Inlet, east of Deception Pass, and south of the Swinomish Channel.

Nutrient pollution is considered a potential threat to the ecological health of Puget Sound. There is considerable interest in understanding the hydrodynamics and the effect of nutrient loads entering Puget Sound. As part of the mandates under the Clean Water Act (1987) to manage pollutant loading to meet water quality standards, the U.S. Environmental Protection Agency (EPA) has provided grant funding to the Washington State Department of Ecology (Ecology) to initiate a Puget Sound water quality model development project. + NEP standard language here

Ecology has contracted with Pacific Northwest National Laboratory (PNNL) to develop an offline linked hydrodynamic and water quality model. The model simulates biogeochemical processes including algae growth and nutrient dynamics, and will be used to evaluate the effects of current and potential future nutrient loads on DO levels in Puget Sound. Results will inform potential Puget Sound-wide nutrient management strategies and decisions. The model domain encompasses the entire Salish Sea, but Puget Sound is the primary area of emphasis.

For this study, the intermediate-scale grid was sized to provide sufficient resolution to describe the shape of Puget Sound subbasins, including river mouths and surrounding waters, while allowing reasonable run times of 1-2 days per year's simulation on Ecology's multiprocessor cluster computer. Typical grid elements vary in size between 250 and $800 \mathrm{~m}$. Sackmann (2009b) described the approach to intermediate model development. A related effort described in Sackmann (2009a) is developing a largescale model, which is coarser than the intermediate-scale model.

Much of our current understanding of circulation in Puget Sound is based on analysis and interpretation of a considerable historical record of moored current meter and salinity profile data collected since the 1950s and insights gained from the application of a physical scale model of Puget Sound at the University of Washington (Rattray and Lincoln 1955). Using this information, Ebbesmeyer and Barnes (1980) developed a conceptual model of Puget Sound that describes circulation in the main basin of Puget Sound as that in a fjord with deep sills (landward sill zone at Tacoma Narrows and a seaward sill zone at Admiralty Inlet) embracing a large basin, outflow through the surface layers, and inflow at depth. This behavior may be recognized as a transition between a fjord and partially mixed estuary and is a characteristic feature of Puget Sound circulation. Ability of the model to simulate this hydrodynamic behavior is essential for simulating reasonable biogeochemical behavior and water quality response observed in Puget Sound.

Systematic monitoring of nutrients, DO, and algae in Puget Sound was initiated by Ecology in 1967 and continues today through Ecology's Marine Waters Monitoring Program designed to measure ambient water quality conditions in Puget Sound and the coastal estuaries of Washington State. Ecology has 
maintained a database of marine water quality data since 1973 and was the primary source of data used in this study. Ecology also provided marine water quality data from the Joint Effort to Monitor the Strait (JEMS) program, a collaborative effort between Ecology and University of Washington, along with freshwater riverine, runoff, and wastewater load estimates for 2006. Water quality in Puget Sound, as indicated by conventional parameters such as $\mathrm{DO}$, nutrients [(nitrate + nitrite)-nitrogen $\left(\mathrm{NO}_{3}+\mathrm{NO}_{2}\right)$ and phosphate-phosphorus $\left.\left(\mathrm{PO}_{4}\right)\right]$, algae, and fecal coliform bacteria, is generally considered to be good. However, there are several specific locations where water quality appears reduced due to low DO and fecal coliform bacteria contamination. The areas of lowest DO are southern Hood Canal, Budd Inlet, Penn Cove, Commencement Bay, Elliott Bay, Possession Sound, Saratoga Passage, and Sinclair Inlet (Ecology ambient monitoring program).

Historical observations of primary production suggest that phytoplankton growth in Puget Sound is closely coupled to the circulation characteristics. This was demonstrated through the early work by Winter et al. (1975). Using biweekly data collected from the main basin off Seattle from September 1963 through 1965, they conducted numerical model simulations of the dynamics of spring algae blooms in the main basin of Puget Sound. Subsequent studies and review of historic data show that although spring and summer blooms occur regularly, the potential for eutrophication impacts in the main basin is only moderate due to the presence of strong residual circulation and water renewal from freshwater discharges and inflow of water from the Pacific Ocean. However, poorly flushed inner basins and shallow embayments, particularly in the southern end of Puget Sound, show depleted surface nitrate concentrations during the summer and very low oxygen concentrations at depth (Harrison et al. 1994; Newton and Van Voorhis 2002).

Nutrient loading to Puget Sound occurs through natural sources such as inflow of Pacific Ocean waters through the Admiralty Inlet as well as natural river runoff. Anthropogenic sources include nonpoint sources, industrial, and wastewater discharges. In the spring and summer, Puget Sound experiences algae blooms, during which nutrient concentrations drop down to near zero levels in the surface layers, suggesting nutrient limitation in several basins (e.g., Bernhard and Peele, 1997; Newton et al. 1995, 1998; Newton and Van Voorhis 2002). Ecology has developed a biogeochemical model of South Puget Sound to simulate DO in response to phytoplankton primary production, oxidation of organic material, and sediment flux (Albertson et al. 2002). Similarly, the University of Washington has developed a model of Hood Canal in connection with hypoxia concerns as part of the Hood Canal Dissolved Oxygen Program (Banas 2009, Kawase and Bahng, 2011). However, modeling studies of this nature, covering the entire Puget Sound and domain, and attempts to reproduce observed nutrients and algal concentration are sparse.

This effort by Ecology is an attempt to develop a tool that can reproduce the observed water quality behavior in the entire Salish Sea domain consisting of Puget Sound south of Admiralty Inlet and the Strait of Juan de Fuca and Georgia Strait extending into the Canadian waters. The Puget Sound Water Quality Model (or Biogeochemical Model) developed through this project is expected to answer the following questions regarding nutrient management:

- Are human sources of nutrients in and around Puget Sound significantly impacting water quality?

- How much nutrient reduction is necessary to reduce human impacts in sensitive areas? 


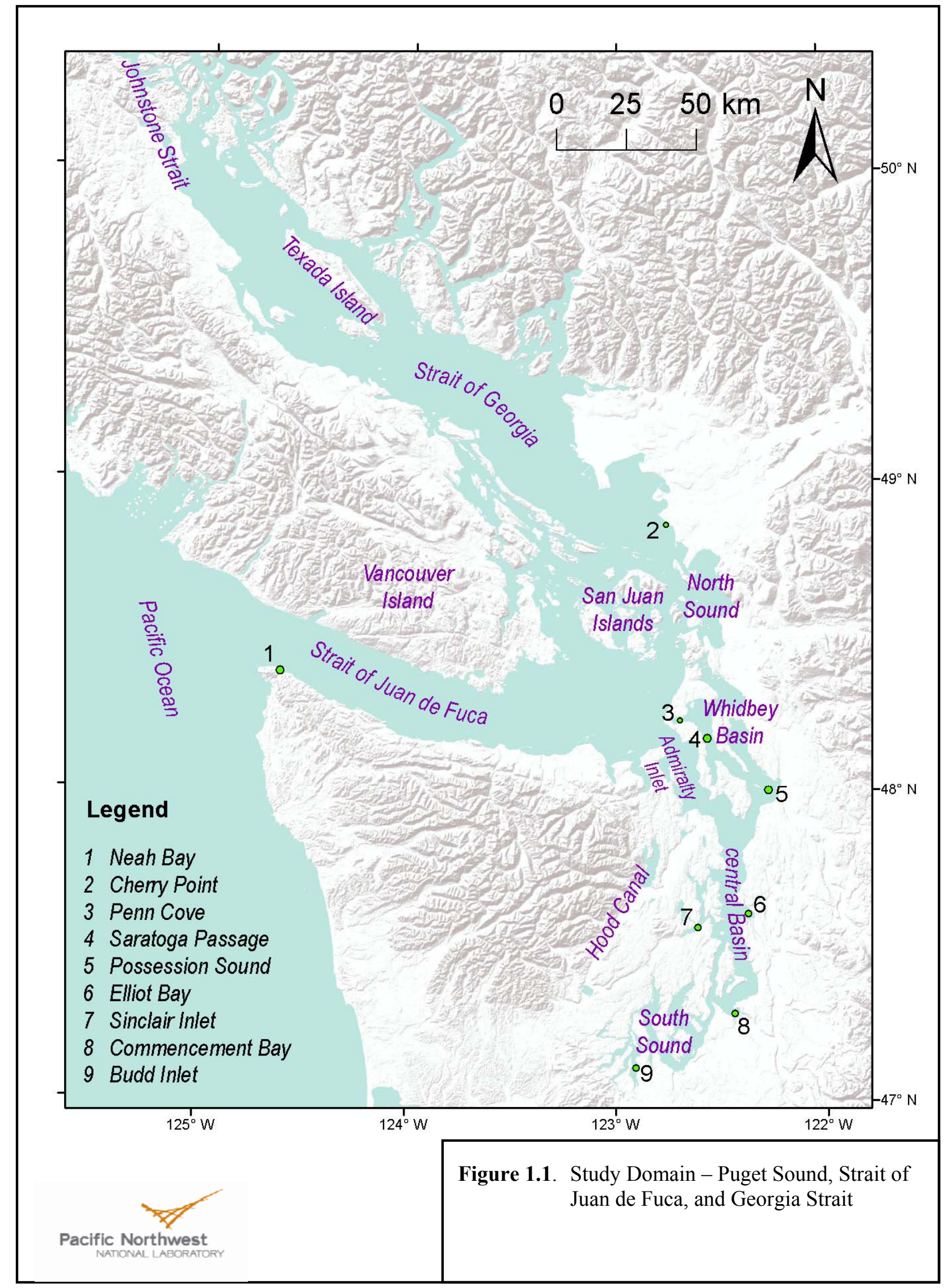


The overall approach of this project by Ecology and PNNL is to work collaboratively with the EPA and the advisory committee for the Puget Sound Water Quality Model project to simulate DO and nutrient kinetics throughout Puget Sound to support management initiatives. The project did not include any additional data collection but instead relied on currently available information. The effort described in this report focused on building a tool to help address the fundamental question related to human nutrient contributions. Subsequent phases will apply the Puget Sound circulation and biogeochemical models to evaluate potential effects of climate cycles, climate change, and population growth on water quality. The results will be used to refine our understanding of the effects of human-caused nutrient enrichment on DO across Puget Sound now and into the future. This model will help inform potential Puget Sound-wide management strategies and support site-specific detailed work that may be completed beyond this project.

The development of the hydrodynamic and water quality model of Puget Sound consisted of two major components: 1) a 3-D coastal hydrodynamic model and 2) an offline linked water quality model. The hydrodynamic model was developed previously (Yang et al. 2010) and was further improved during the course of this work (Khangaonkar et al. 2011). The water quality model development included a major effort to link the hydrodynamic output and FVCOM scalar transport routine to the CE-QUAL-ICM kinetic equations. This task included updating the open boundary routines, point source and river loading routines, initial condition and restart file routines, output routines, and many other pieces of code critical to the proper functioning of the model. The technical details describing the development of the offline coupling of FVCOM and CE-QUAL-ICM are provided in detail by Kim and Khangaonkar (2011) and also summarized in Appendix A. After the linkage development, the model was optimized to increase stability and speed and was fully parallelized. All routines were checked for proper array declaration, allocation, and de-allocation, appropriately passed among the compute nodes, and input routines were parallelized such that input data were distributed properly and output data were gathered correctly. Finally, the ecosystem model kinetic routines were set up.

Section 2 describes the setup of the water quality model of Puget Sound. Section 2 includes a brief description of the biogeochemical model kinetics in CE-QUAL-ICM, the hydrodynamic conditions input from FVCOM for 2006 conditions in Puget Sound, various river and point source loads, and boundary conditions. Section 2 also describes the water quality monitoring data used in this study to select initial conditions and to calibrate the model.

Section 3 describes model calibration. The calibration effort described in this report corresponds to setting up the circulation and transport processes using available data from the selected year (2006), sensitivity tests to identify key model parameters and processes affecting results, and adjustment of the parameters until a reasonable match with observed data was achieved. Initial model parameters were specified based on literature values and then adjusted using professional judgment ensuring that major processes and phenomena, such as tidally averaged circulation and exchange, bottom water renewal, and spring and summer algal blooms, were reproduced. Comparison of simulated DO, nutrients (nitrate + nitrite and phosphate) and chlorophyll $a$ (converted to algal carbon) to measured data in the form of discrete vertical profiles, and surface and bottom time series plots are presented.

Section 4 summarizes model performance and limitations, and recommendations for potential improvements are discussed. 


\subsection{Water Quality Model Description and Setup}

The tidally averaged long-term circulation in Puget Sound shows three dimensional (3-D) characteristics with mean outflow in the surface layers and inflow in the lower layers. Overall water quality in Puget Sound is dependent on the flushing of the basin provided in large part by the tidal exchange flow that occurs between Puget Sound and the Pacific Ocean primarily through Admiralty Inlet. The Strait of Juan de Fuca, located across the mouth of Admiralty Inlet, is a high-tidal energy waterway that connects the estuarine system to the eastern Pacific Ocean and is the main outlet of freshwater to the Pacific Ocean. The large freshwater discharges from the Fraser River and other rivers to Georgia Strait are thought to affect nutrient and DO balance between the Pacific Ocean and the adjacent waters of the Strait of Juan de Fuca and Georgia Strait. This also includes waters around the San Juan Islands and the Cherry Point coastline near the United States/Canada border. The model domain therefore extends beyond Puget Sound into Georgia Strait north to Johnstone Strait and east to Neah Bay at the entrance to the Strait of Juan de Fuca.

Summertime winds from the north drive coastal upwelling along the Pacific coast, bringing cold, salty and nutrient-rich deepwater to the surface. These high-nutrient low-DO waters are frequently swept north up the coast of Washington into Strait of Juan de Fuca during periods of weak or southerly winds (Snover et al. 2005). This can have a significant influence on the total nutrient load intruding into Puget Sound at depth or entrained at the surface during periods of strong upwelling and relaxation. However the model domain does not extend to the edge of the continental shelf and the coastal upwelling and other events are treated as specified boundary conditions. Near the heads of inlets within Puget Sound, there is stratification due to freshwater discharges which are also typically high in nutrients and can promote phytoplankton bloom formation in Puget Sound. These discharges are also sources of nutrient and carbon loads to the Sound.

The biogeochemical model selected in this study must simulate the influence of nutrients and carbon on phytoplankton primary productivity and dissolved oxygen concentrations within the Sound. PNNL and Ecology consulted with modeling experts and selected the unstructured-grid Finite Volume Coastal Ocean Model (FVCOM) developed by the University of Massachusetts (Chen et al. 2003) with CEQUAL-ICM, a state-of-the-art biogeochemical code developed by the U.S. Army Corps of Engineers (Cerco and Cole 1995), as described in the quality assurance plan for intermediate-scale model development (Sackmann 2009b).

To set up the water quality model, the following types of data were required:

- Nutrient concentrations [nitrate + nitrite - nitrogen $\left(\mathrm{NO}_{3}+\mathrm{NO}_{2}\right)$, and phosphate - phosphorus $\left(\mathrm{PO}_{4}\right)$, dissolved and particulate organic nitrogen, dissolved and particulate organic phosphorous], phytoplankton biomass, and dissolved oxygen concentrations as initial conditions and for calibration purposes

- Nutrient, phytoplankton biomass, and dissolved oxygen profiles at the open boundaries

- River nutrient, dissolved and particulate organic carbon, and dissolved oxygen loads

- Meteorological parameters such as wind, heat flux, and solar radiation

- Hydrodynamic solution - currents, tides, salinity, and temperature in the 3-D domain. 
In total, the following 19 state variables were simulated:

1. Algae Species 1 - diatom

2. Algae Species 2 - dinoflagellates

3. Dissolved organic carbon (DOC) - labile

4. DOC - refractory

5. Particulate organic carbon (POC) - labile

6. $\mathrm{POC}-$ refractory

7. Ammonium $\left(\mathrm{NH}_{4}\right)$

8. Nitrate + nitrite $\left(\mathrm{NO}_{3}+\mathrm{NO}_{2}\right)$

9. Dissolved organic nitrogen (DON) - labile

10. DON - refractory

11. Particulate organic nitrogen (PON) - labile

12. PON - refractory

13. Phosphate $\left(\mathrm{PO}_{4}\right)$

14. Dissolved organic phosphorus (DOP) - labile

15. DOP - refractory

16. Particulate organic phosphate (POP) - labile

17. POP - refractory

18. Particulate inorganic phosphate

19. Dissolved oxygen.

\subsection{Process Description}

The Puget Sound Water Quality Model includes biogeochemical routines to calculate algal production and decay as well as bacterial breakdown of organic matter entering the Sound from tributaries and point sources. The kinetics simulated by the model are briefly described here and schematically represented in Figure 2.1.

Organic carbon is transformed in many ways within the simulated water column. The carbon cycle as shown in Figure 2.1 in the model comprises phytoplankton production and excretion, predation on phytoplankton by zooplankton, dissolution of particulate carbon, heterotrophic respiration, denitrification, and settling. Carbon, as a representative currency in the model, is incorporated into phytoplankton biomass, and algal production is the primary source of carbon in the model. The change in biomass at each time step is computed using the specific growth rate of each phytoplankton, which is converted into a primary production rate from the phytoplankton-specific carbon to chlorophyll ratio. 
Model Carbon Cycle

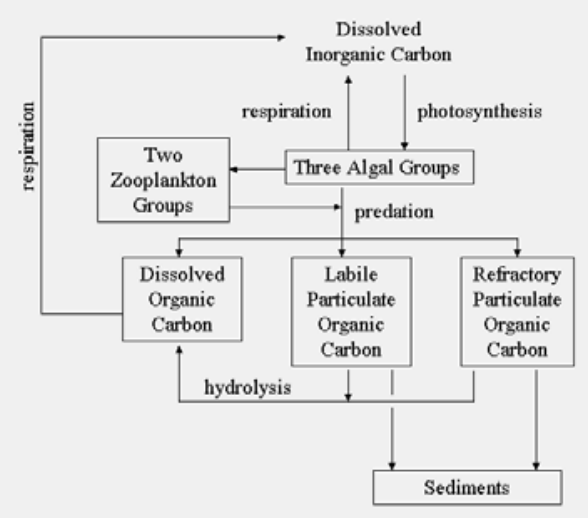

Model Nitrogen Cycle

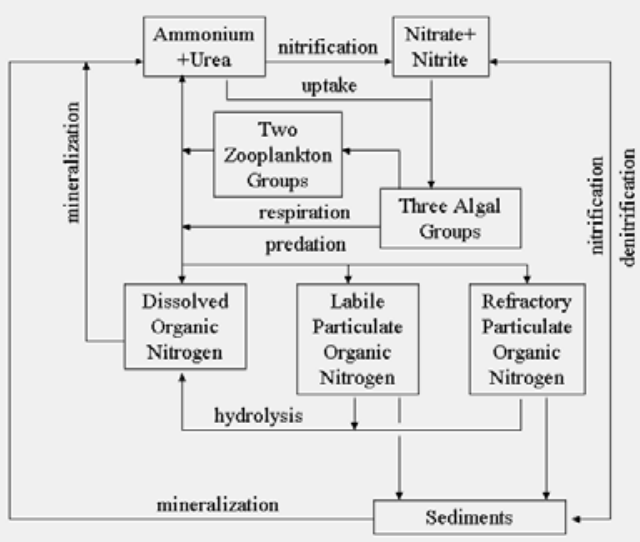

Model Phosphorus Cycle

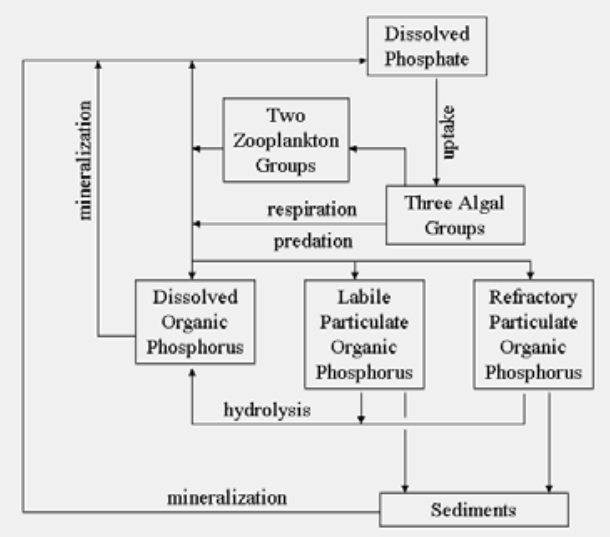

Model Dissolved Oxygen Cycle

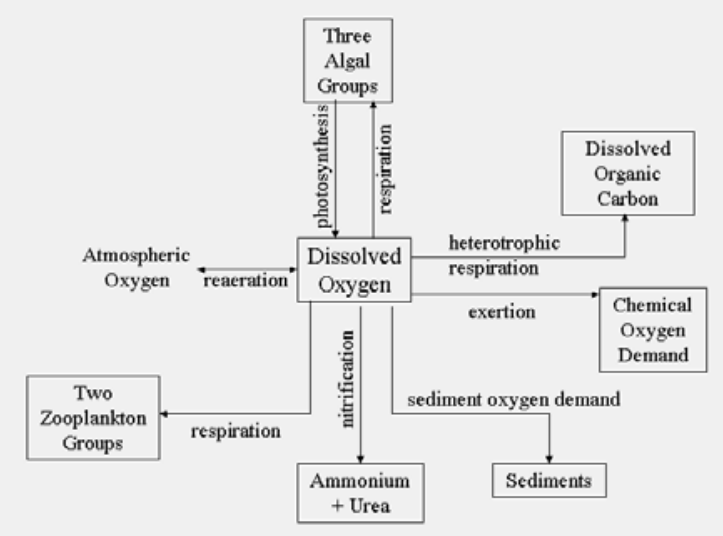

Source: Cerco and Cole (1995)

Note:

1. Although CE-QUAL-ICM allows 3 groups of algae, in this Phase 1 effort we are only considering 2 species (diatoms and dinoflagellates)

2. Although CE-QUAL-ICM allows 2 zooplankton groups, in this Phase 1 effort, zooplanktons were not simulated explicitly but zooplankton grazing is included in the form of $1^{\text {st }}$ order decay rate.

Figure 2.1. Representative Carbon, Phosphorus, Nitrogen, and Dissolved Oxygen Cycles in the Puget Sound Water Quality Model 
Nutrient concentrations, temperature, and light intensity within the water column determine the growth rate used in the above calculations. Silica concentrations which also affect growth rates were not explicitly simulated as silica is not considered a factor limiting growth rate in Puget Sound. The calculated change in phytoplankton carbon-based biomass is then reallocated into zooplankton biomass, using the calculated grazing and growth rates for zooplankton (in the case of the simulations described here, zooplankton grazing is represented as a first-order loss rate). Grazed material is converted using the appropriate pathways into dissolved and particulate inorganic carbon, nitrogen, and phosphorus. Losses due to predation and excretion are divided into labile and refractory pools of dissolved and particulate organic carbon. Through hydrolysis, particulate organic carbon is converted into dissolved forms. The remaining particulate matter settles to sediment. In this model setup the sediment diagenesis processes are not simulated and as a simplification the sediment fluxes are held constant independent of the amount of organic matter that settled out. From each carbon pool, nutrient pools are calculated given the ratios of nitrogen, phosphorus, to carbon for each. Loss rates from nutrient pools represent uptake by phytoplankton. Sinking of phytoplankton redistributes phytoplankton throughout the water column. While it would be possible to setup diel vertical migration driven by light through specification of negative settling rates for each species, it has not been incorporated in this model setup.

Temperature is an important parameter which affects algal growth. Algal production increases as an exponential function of temperature until an optimum temperature or temperature range is reached. Above the optimum, production declines until a temperature lethal to the organisms is attained. The maximum growth rate $\left(\mathrm{G}_{\max }\right)$ is calculated as the ratio of maximum production, Pmax, $\left(\mathrm{g} \mathrm{C} \mathrm{g}^{-1} \mathrm{Chl} \mathrm{d}^{-1}\right)$ and carbonto-chlorophyll ratio, $\mathrm{C}$ : Chl, modified by the exponential form of temperature function which decays with temperatures above or below the optimum.

Phytoplankton growth is predicated on nutrient and light availability in the water column and temperature. The growth limitation of algae can be through "Liebig's law of the minimum" (Odum 1971), where either light or one major nutrient can limit growth, whichever is most limiting at that point in time or in combination (currently used in the calibration), where light limitation is factored in together with nutrient limitation (nutrient limitation is used first to decrease growth rate and then is multiplied by the light limitation factor). In this current configuration of the model, Michaelis-Menten kinetics (e.g., Eppley et al. 1969) were used to determine nutrient limitation for dissolved inorganic nitrogen (DIN), ammonium, and phosphate $\left(\mathrm{PO}_{4}\right)$, while the square root formula was used for light limitation (Jassby and Platt 1976). Although preference for reduced forms of nitrogen is encoded in the model, suppression of growth rates of phytoplankton by the presence of ammonium is not considered. Light in the water column is attenuated based on scattering and absorption of constituents in the water column, including chlorophyll $a$. Spectral absorption was used in the model; however, only a generalized chlorophyll $a$ based spectrum was used, due to limited available data for Puget Sound.

Nitrogen fluxes include nitrification, denitrification, benthic flux rates, conversion of algal material into dissolved and particulate organic forms, and boundary loads. Similarly, phosphate fluxes include transformations of algal material and boundary fluxes. Dissolved oxygen is affected by saturation state (calculated from salinity and temperature), re-aeration due to wind stress, algal photosynthesis and respiration, nitrification, and heterotrophic respiration and sediment oxygen demand. Organic carbon concentrations (particulate and dissolved, refractory and labile) are calculated from algal production and excretion, and predation of algae and carbon kinetics (dissolution of particulate organic carbon, heterotrophic respiration, and settling). 
In CE-QUAL-ICM, all organic matter entering the model domain from the open boundaries and from point sources is tracked directly in the form of dissolved or particulate organic carbon, organic nitrogen, and organic phosphorous. This differs from the approach of tracking dissolved organic matter (DOM) and detritus separately prior to breakdown into nutrients and carbon as conducted in other water quality models such as CE-QUAL-W2 (Cole and Buchak 1995). In its current configuration no distinction is made in the properties of organic matter entering the model domain from different sources. Fluxes of organic carbon, nitrogen, and phosphorous (subdivided into labile/refractory and particulate/ dissolved forms) are specified at individual point source locations.

The following subsections describe all the components used to drive the model described above in the model setup.

\subsection{Model Domain and Grid}

The model domain along with the oceanographic data monitoring stations is shown in Figure 2.2, and comprises the entire Salish Sea including the Puget Sound and the Strait of Juan de Fuca, Haro Strait, Georgia Strait, and San Juan Islands. The ocean side open boundary is located just west of the Strait of Juan de Fuca, while the second open boundary is located near the northernmost point of the Georgia Strait (Canadian waters) near Johnstone Strait. The model grid (Figure 2.3) is an unstructured mesh and uses triangular cells with higher resolution in narrower regions of the Salish Sea, growing coarser in the Strait of Juan de Fuca with up to $3 \mathrm{~km}$ resolution near the open boundary. The grid resolution is on average 250 $\mathrm{m}$ in the inlets and bays and approximately $800 \mathrm{~m}$ inside the Puget Sound main basin.

\subsection{Hydrodynamic Input}

The Puget Sound Water Quality Model was forced with a 1-year long hydrodynamic solution generated from a 10-layer FVCOM model (also referred to as Puget Sound Circulation and Transport Model). A detailed description of hydrodynamic model setup and calibration is provided in a companion report (Yang et al. 2010).

Continuing efforts improved the model performance and efficiency, particularly the use of 10 vertical, terrain-following sigma layers distributed using a power law function with an exponent of 1.5. The thinner layers resulting from the higher density of layers near the surface allowed vertical salinity and temperature gradients to be resolved while reducing the computational load relative to a 30-layer simulation with uniform layer distribution described in Yang et al. (2010). The hydrodynamic model was also improved with smoothing of the bathymetry to ensure hydrostatic consistency (Mellor et al. 1994), and the Georgia Strait boundary was refined to obtain a reasonable match with historical records of tidally averaged currents (Khangaonkar et al. 2011). The associated slope-limiting ratio (maximum permitted slope between two neighboring nodes) varying from $\delta \mathrm{H} / \mathrm{H}=0.1$ to 0.2 was specified within each grid element following guidance provided by Mellor et al. (1994) and using site-specific experience from Foreman et al. (2009), where $\mathrm{H}$ is the local depth at a node and $\delta \mathrm{H}$ is change in depth to the nearest neighbor. The smoothing results in alteration of the bathymetry, resulting in a domain-wide volume error of $\approx+4 \%$ but as high as $\approx+37 \%$ in some locations with narrow deep channels such as Hood Canal or south Puget Sound. Therefore a bathymetric depth (reduction) adjustment was applied to all nodes with depths greater than $50 \mathrm{~m}$ to ensure that individual basin volume as well as the total volume in the smoothed grid remained within $1 \%$ of the original values. The $50 \mathrm{~m}$ depth limit on the adjustment helped 


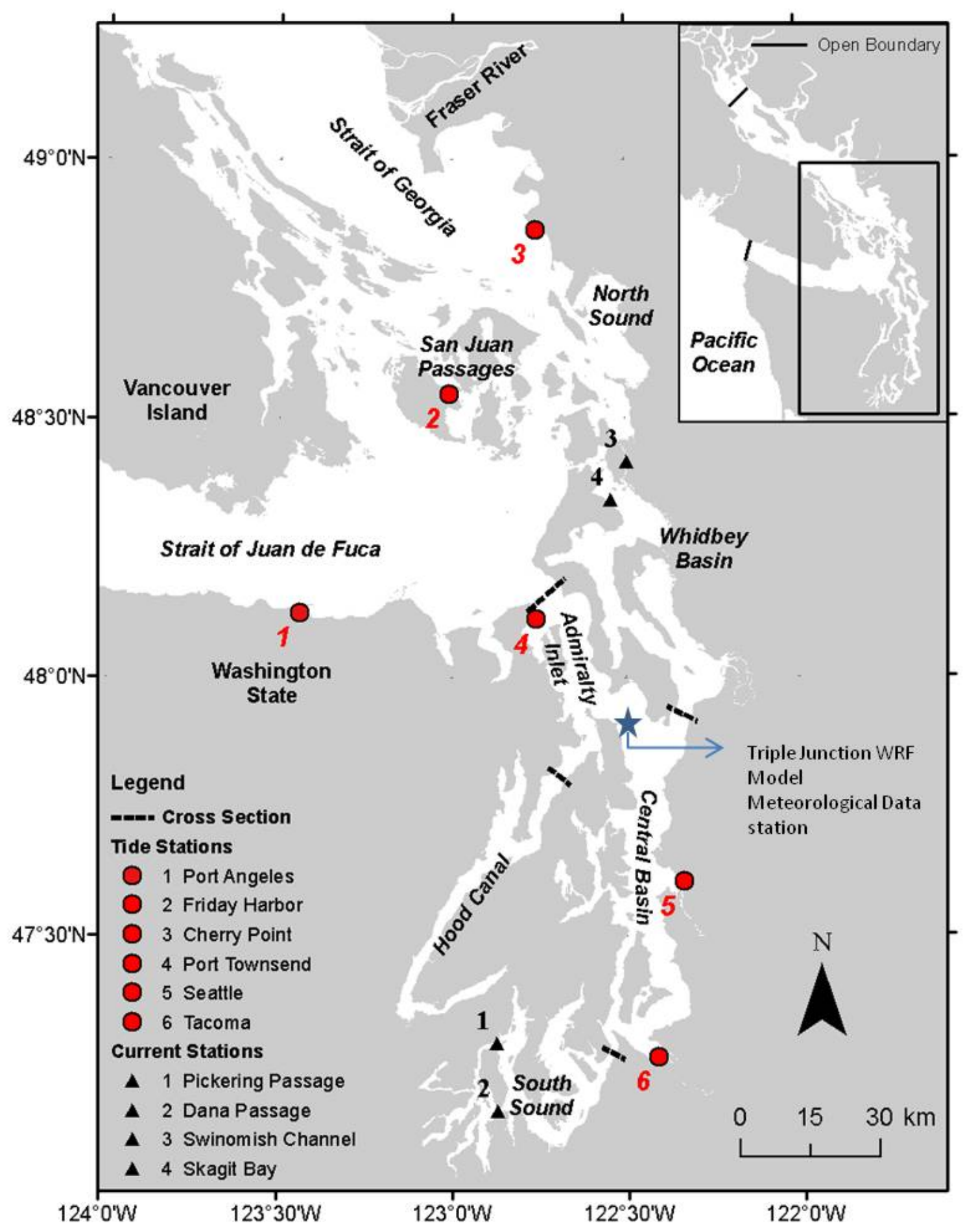

Figure 2.2. Study Domain and Oceanographic Data Monitoring Stations - Puget Sound Water Quality Model 


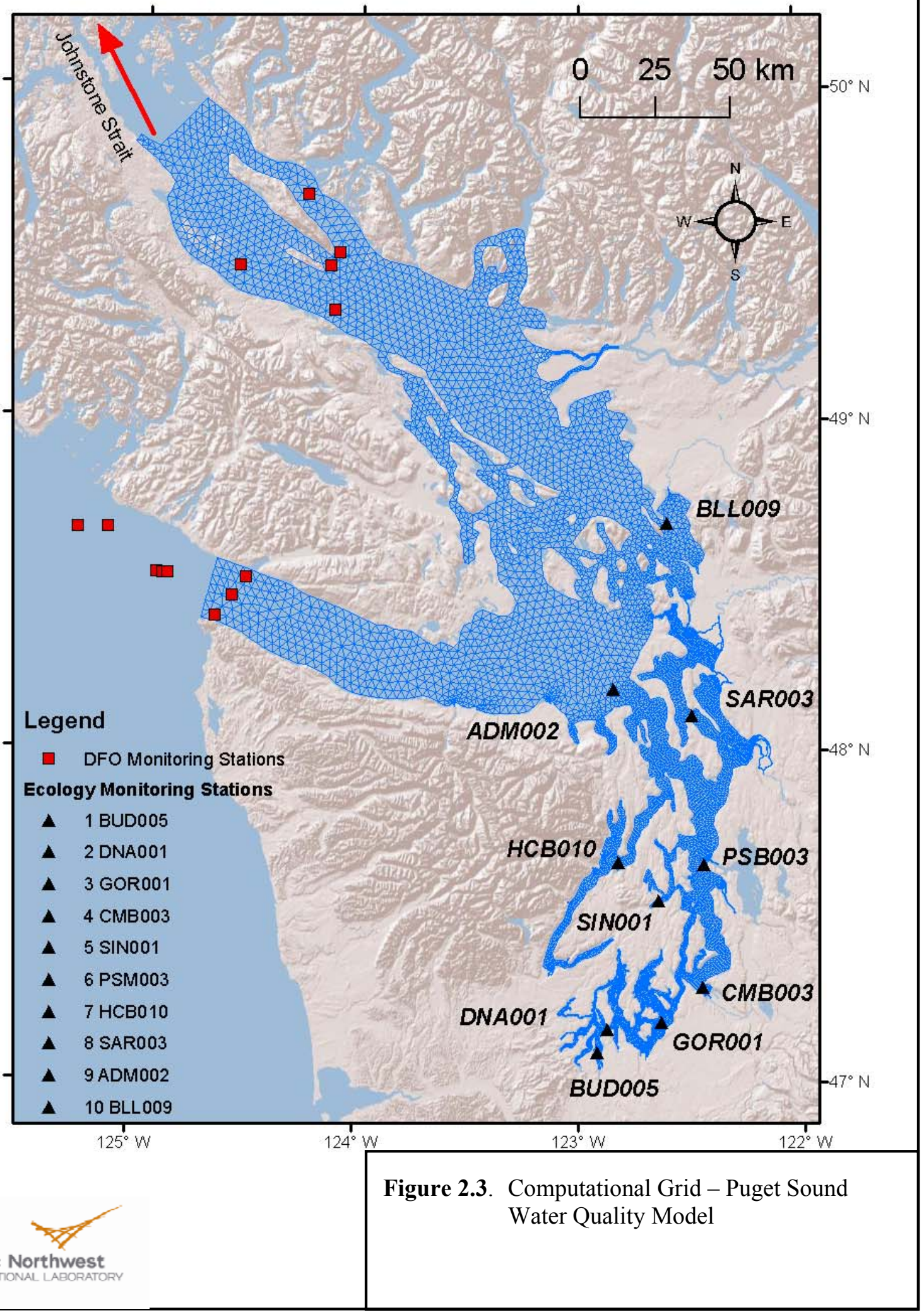


maintain the hydraulic controls exerted by the Admiralty Inlet, Hood Canal, and Tacoma Narrows sills to $50 \mathrm{~m}$ or greater depths. A summary of the hydrodynamic model setup, calibration, and the predicted solution (water surface elevations, velocity, salinity, and temperature values) used in water quality computations is provided below.

The model setup was conducted using Year 2006 as the basis because it was a data-rich year for salinity, temperature, and water quality information from Puget Sound. Tidal elevations were specified along the open boundaries using predictions from XTide, a harmonic tide clock and tide predictor (Flater 1996) at the Tatoosh Island station located at the entrance of the Strait of Juan de Fuca and at the Campbell River station at the mouth of Johnstone Strait.

Figure 2.4 (a) shows tidal elevations specified at the open boundaries to force the model. In this study, temperature and salinity profiles along the open boundaries were estimated based on monthly observations conducted by the Department of Fisheries and Oceans Canada. To obtain the final initial condition for the Year 2006 model run, at first the model was applied for one year with Year 2005 forcing inputs. Subsequently as a simplification, Year 2006 was run twice. The first run was considered as the spin-up run. For the first run, in the entire model domain, initial temperature and salinity conditions were specified uniformly as $9^{\circ} \mathrm{C}$ and $31 \mathrm{psu}$, respectively, and water surface and velocities were set to zero. The output at the end of the spin-up run was recycled and used as the initial condition for the 2006 calibration run. Sensitivity tests using constant tidal forcing and steady freshwater flows showed that dynamic steady state with respect to velocity and salinity profiles was achieved in 6-7 months of simulation over most of Puget Sound confirming that 1-year long simulation would be an adequate spin up period.

The model includes complete watershed inflow contributions, represented as 64 pour points in the model. Inflows were aggregated based on gauged flows that were extrapolated to the total nearby watershed area using relative area and annual precipitation. These pour points include 19 river mouths that are incorporated into the model along with the associated estuaries. Pour points for the remaining 45 inflows were located at nodes nearest to the largest river in the subwatershed. Also included are flows from the 99 industrial and municipal wastewater treatment plants. Inflow development and results are summarized further in Section 2.5 and detailed in Mohamedali et al. (2011).

The Puget Sound region experienced a significant flood event in November 2006, which is reflected in the river discharge time series. In general, river flows in Puget Sound peak during the high precipitation winter months of November, December, January, and February. In contrast, the Fraser River inflow on the Canadian side of the domain, which is significantly larger than the rest of the inflows into Puget Sound and the Straits combined, shows a very different seasonal distribution pattern - high flow in the late spring and summer dominated by snowmelt and low flow in the fall and winter. Figure 2.4 (b) shows a plot of basin-wide freshwater discharges grouped by their discharge basins. The Whidbey Basin consists of the three largest rivers in Puget Sound (Skagit River, Snohomish River, and Stillaguamish River) and accounts for almost $70 \%$ of the total freshwater flow into Puget Sound.

Meteorological parameters for calculation of net heat flux in FVCOM include 1) downward and upward shortwave radiation, 2) downward and upward longwave radiation, 3) latent heat flux, and 4) sensible heat flux. These meteorological parameters were obtained from the weather research forecasting (WRF) mode reanalysis data generated by the University of Washington. Available data were on a $12-\mathrm{km}$ grid with limited stations over water. Data from an open-water location at the Triple Junction 


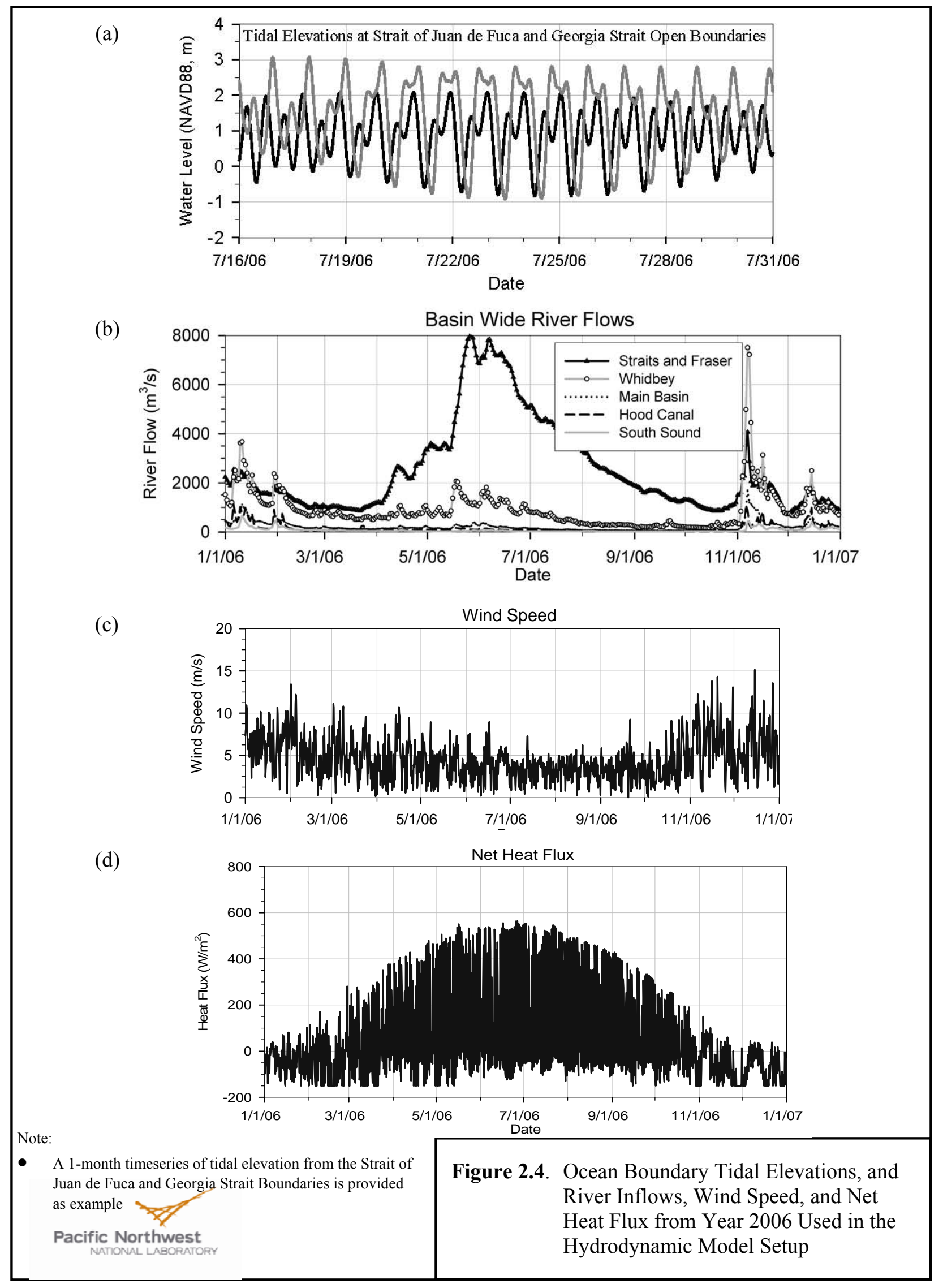


near the center of model domain just north of Kingston (see Figure 2.2) were selected for use in model calibration and required $20 \%$ reduction in net heat flux to account for different albedo over water. Wind stress within FVCOM is calculated based on the well-known Large and Pond (1981) method. In general, winds are mostly southwesterly within Puget Sound with low speeds during summer (around $5 \mathrm{~m} / \mathrm{s}$ ) and high speeds during winter (as high as $15 \mathrm{~m} / \mathrm{s}$ ). Winds can reach gale-force easterly speeds, $17-24 \mathrm{~m} / \mathrm{s}$ or higher, in the Strait of Juan de Fuca (Holbrooke et al. 1980). Wind speed and computed net heat flux time histories for 2006 are shown in Figures 2.4 (c) and (d) respectively. Use of a single station to represent meteorological conditions for the entire Puget Sound domain is a simplification especially for wind data which may vary based on site specific topography.

Hydrodynamic model calibration through numerous sensitivity tests focused on refining and smoothing the bathymetry; averaging specified boundary forcing salinity and temperature profiles; and adjusting bed friction until achieving a stable model operation and best fit of predicted water surface elevation (WSE), velocity, salinity, and temperature to observed data at selected stations in Puget Sound. There are six real-time tidal stations maintained by NOAA throughout the Straits and Puget Sound. Velocity data are quite limited in Puget Sound. Acoustic Doppler current profiler (ADCP) data in South Puget Sound (Roberts et al. 2008) as well as Skagit Bay and Swinomish Channel (Yang and Khangaonkar 2009) were used for model calibration. Monthly salinity and temperature profiles collected by the Washington State Department of Ecology as part of their ambient monitoring program throughout Puget Sound were also used.

Examples of time series comparisons for WSE and velocity at selected stations are shown in Figures 2.5 (a) and 2.5 (b), respectively, to illustrate the quality of match in phase and magnitude. A detailed model skill assessment is not the focus of this section, but error statistics at all stations analyzed are listed in Tables 2.1 and 2.2 and provide a quantitative assessment of the model's ability to reproduce observed oceanographic parameters. These reflect the switch from the 30-layer to the 10-layer hydrodynamic model and supersede the plots and error statistics presented in Yang et al. (2010).

Table 2.1. Model Calibration Error Statistics for Water Surface Elevation

\begin{tabular}{lcccc}
\hline \multicolumn{1}{c}{ Station } & MAE $(\mathrm{m})$ & RMSE $(\mathrm{m})$ & RME $(\%)$ & Correlation $(\mathrm{R})$ \\
\hline Port Angeles & 0.26 & 0.33 & 8.88 & 0.92 \\
Friday Harbor & 0.17 & 0.22 & 5.77 & 0.97 \\
Cherry Point & 0.25 & 0.31 & 7.33 & 0.97 \\
Port Townsend & 0.28 & 0.35 & 8.93 & 0.95 \\
Seattle & 0.34 & 0.43 & 9.50 & 0.95 \\
Tacoma & 0.36 & 0.46 & 10.21 & 0.95 \\
Mean & $\mathbf{0 . 2 8}$ & $\mathbf{0 . 3 5}$ & $\mathbf{8 . 4 4}$ & $\mathbf{0 . 9 5}$ \\
\hline
\end{tabular}

Note: Table 3-2 in the hydrodynamic model calibration report (Yang et al 2010) included additional stations with data from XTide predictions. Comparisons shown above are between model results and measured data only. 
Table 2.2. Model Calibration Error Statistics for Velocity

\begin{tabular}{lccccccccc}
\hline & \multicolumn{3}{c}{ MAE $(\mathrm{m} / \mathrm{s})$} & \multicolumn{3}{c}{ RMSE $(\mathrm{m} / \mathrm{s})$} & \multicolumn{3}{c}{ Correlation $(\mathrm{R})$} \\
\cline { 2 - 10 } \multicolumn{1}{c}{ Station } & Surface & Middle & Bottom & Surface & Middle & Bottom & Surface & Middle & Bottom \\
\hline Pickering Passage & 0.16 & 0.1 & 0.09 & 0.2 & 0.13 & 0.12 & 0.65 & 0.90 & 0.81 \\
Dana Passage & 0.28 & 0.26 & 0.23 & 0.34 & 0.29 & 0.28 & 0.89 & 0.93 & 0.90 \\
Swinomish Channel & 0.23 & 0.16 & 0.09 & 0.27 & 0.19 & 0.11 & 0.96 & 0.96 & 0.96 \\
Skagit Bay & 0.23 & 0.16 & 0.17 & 0.28 & 0.19 & 0.2 & 0.82 & 0.90 & 0.88 \\
\hline Mean & \multicolumn{3}{c}{$\mathbf{0 . 1 8}$} & \multicolumn{3}{c}{$\mathbf{0 . 2}$} & & & $\mathbf{0 . 8 8}$ \\
\hline
\end{tabular}

As shown in Table 2.1, mean absolute errors (MAE) and root mean square errors (RMSE) for WSE of all the stations average $0.28 \mathrm{~m}$ and $0.35 \mathrm{~m}$, respectively. Relative mean errors (RME), defined as the ratio of MAE to the mean of daily tidal ranges, were within $10 \%$. Some of this error is associated with error in specified tidal elevations at the Georgia Strait boundary. The tidal elevations at the open boundary were based on predictions from the XTide harmonic tide clock and tide predictor while the errors were computed relative to measured data.

Velocity data available for model calibration in 2006 were limited. The ADCP data obtained at Dana Passage and Pickering Passage in South Puget Sound were collected by the Washington State Department of Ecology, while Skagit Bay and Swinomish Channel data were obtained from the Skagit River System Cooperative. These stations are located within narrow, long channels with dominant longitudinal characteristics. For simplicity, comparisons were made between the model results and observed data along the major axis of tidal currents at the surface, middle, and bottom layers of the water column, as shown in Figure 2.5 (b). The errors are relatively higher in the surface layer, and smallest in the bottom layer. This could be due to the fact that surface layers are thinner and more easily affected by the resolution of available wind data. The overall mean MAE and RMSE for all four stations are $0.18 \mathrm{~m} / \mathrm{s}$ and $0.20 \mathrm{~m} / \mathrm{s}$, respectively, as shown in Table 2.2. These results supersede those presented in Yang et al. (2010).

Although surface temperature and salinity are dependent on freshwater discharge influenced surface outflow and meteorological forcing to Puget Sound, sensitivity tests showed that deeper waters of Puget Sound were primarily controlled by salinity and temperature of the inflowing water from the Strait of Juan de Fuca over the Admiralty Inlet sill. These values near the mouth of Admiralty Inlet were in turn dependent on the salinity and temperatures at depth specified at the boundaries, which set up the interaction and mixing between inflowing Pacific Ocean water through the mouth of the Strait of Juan de Fuca and deeper water of Georgia Strait. A review of the data from monthly profiles collected at the boundaries showed that seasonal salinity and temperature variations were notable in only the upper $50 \mathrm{~m}$ of the water column and relatively unchanged in deeper waters throughout the year. Although year-long time histories were not available, salinity and temperature profiles were collected on a monthly basis at 25 monitoring stations within Puget Sound. In this study, we selected 11 stations representing the subbasins in Puget Sound for temperature and salinity profile comparisons.

Figure 2.6 (a) shows a comparison between simulated and observed salinity and temperature profiles (February 2006, high-flow condition). Tables 2.3 and 2.4 show mean absolute errors for temperature and salinity profiles at all stations. The overall MAE for salinity is less than $1 \mathrm{ppt}$ and overall MAE for temperature is less than $1^{\circ} \mathrm{C}$. Figure 2.6 (b) compares predicted and observed salinity in the form of time series data from Saratoga Passage, Hood Canal, and East Passage subbasins. 
(a)

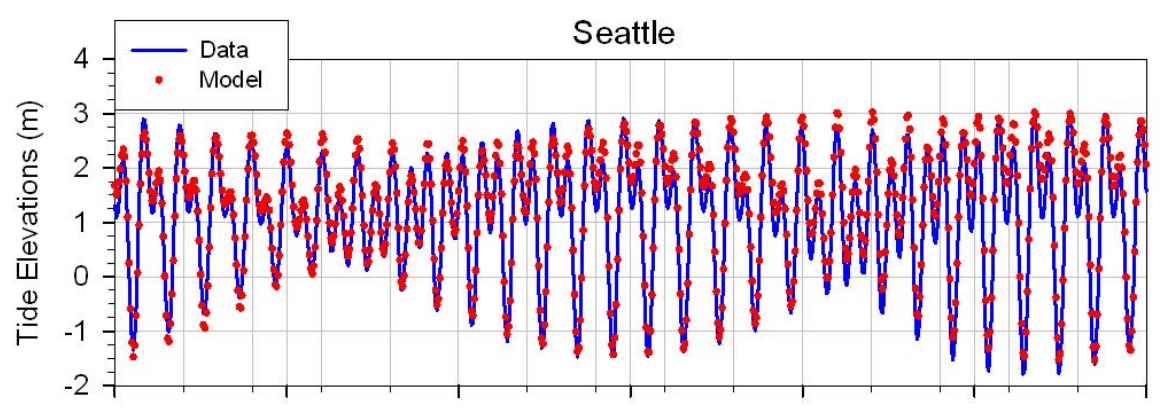

(b)
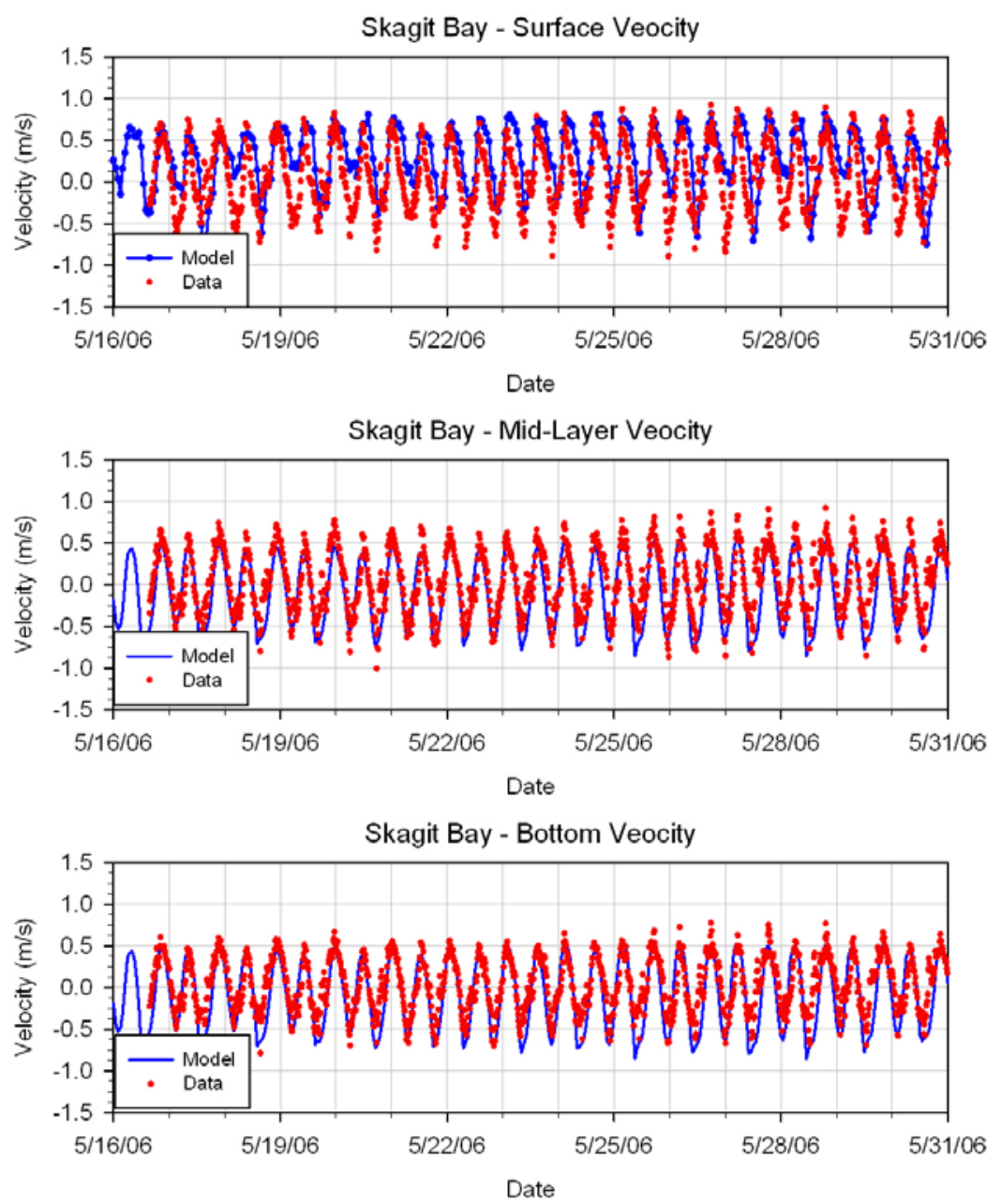

Figure 2.5. Hydrodynamic Model Calibration Example - (a) Water Surface Elevation at Seattle, and (b) Currents in Skagit Bay 
(a)

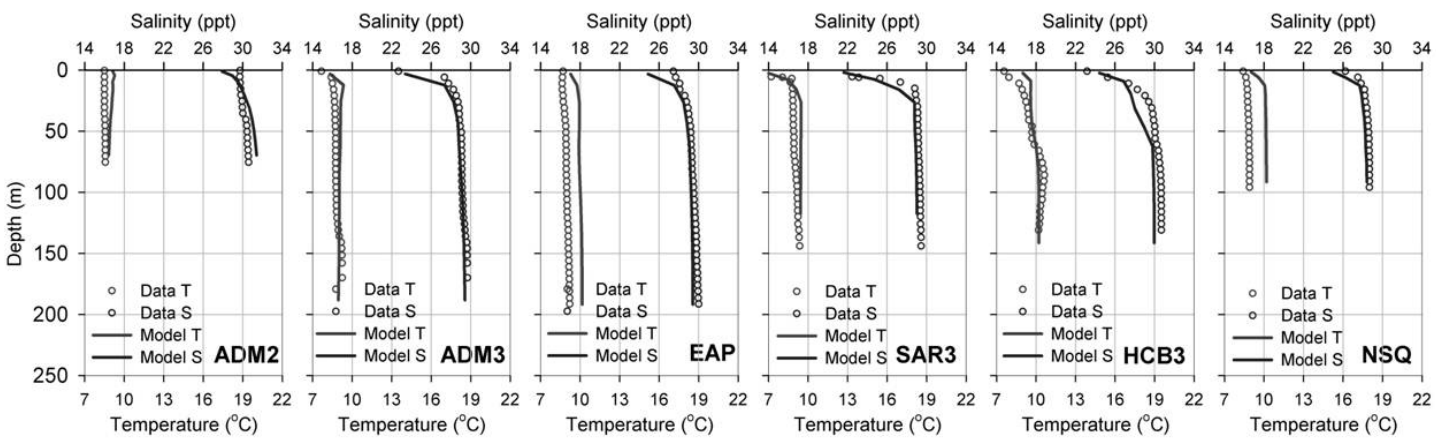

(b)

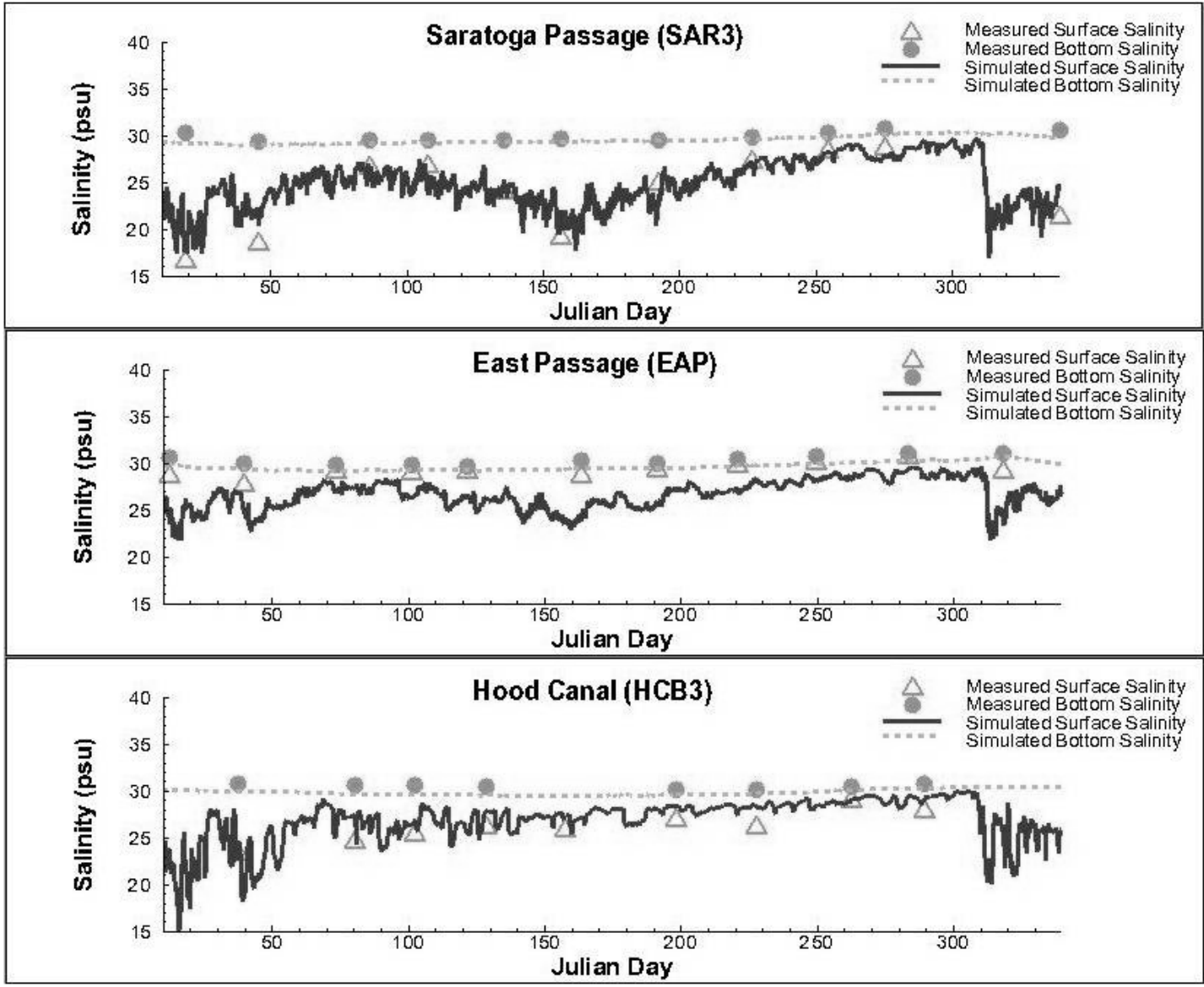

Note:

- $\quad$ Salinity and temperature profile comparison is from February of 2006

Figure 2.6. Salinity and Temperature Calibration -

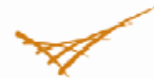

(a) Profiles during High Flow and

(b) Time Histories of Salinity and

Pacific Northwest

Temperature from Surface and Bottom

NATIONAL LABORATORY (2006) 
Tables 2.1, 2.2, and 2.4, show that the errors with the 10-layer version, despite being slightly higher, are still reasonable and similar in magnitude to the 30-layer version reported earlier (Yang et al. 2010). The tradeoff is that the 10-layer version with modifications to the grid and the bathymetry provides an improved performance (residual circulation matches the historical patterns and stratification is well developed) while providing significantly improved computational efficiency.

Note: Error statistics presented in Tables 2.3 and 2.4 were computed based on water column data collected at different depths at each site compared to model predictions at the corresponding depth, resulting in an aggregate value for the station.

Table 2.3. Model Calibration Error Statistics for Salinity

\begin{tabular}{lcc}
\hline \multicolumn{1}{c}{ Station } & MAE (ppt) & RMSE (ppt) \\
\hline Admiralty Inlet Entrance (ADM2) & 0.68 & 0.96 \\
Admiralty Inlet North (ADM1) & 0.85 & 0.97 \\
Admiralty Inlet South (ADM3) & 0.73 & 1.04 \\
Puget Sound Main Basin (PSB) & 1.27 & 2.15 \\
East Passage (EAP) & 0.79 & 1.19 \\
Gordon Point/Tacoma Narrows (GOR1) & 0.81 & 1.09 \\
Hood Canal (HCB003) & 0.74 & 0.88 \\
Saratoga Passage (SAR003) & 0.71 & 1.08 \\
Nisqually Reach (NSQ) & 0.64 & 0.74 \\
Dana Passage (DNA) & 0.63 & 0.76 \\
\hline Mean & $\mathbf{0 . 7 8}$ & $\mathbf{1 . 0 9}$ \\
\hline
\end{tabular}

Table 2.4. Model Calibration Error Statistics for Temperature

\begin{tabular}{lcc}
\hline \multicolumn{1}{c}{ Station } & $\mathrm{MAE}\left({ }^{\circ} \mathrm{C}\right)$ & $\mathrm{RMSE}\left({ }^{\circ} \mathrm{C}\right)$ \\
\hline Admiralty Inlet Entrance (ADM2) & 0.62 & 0.72 \\
Admiralty Inlet North (ADM1) & 0.63 & 0.74 \\
Admiralty Inlet South (ADM3) & 0.57 & 0.75 \\
Puget Sound Main Basin (PSB) & 0.83 & 0.94 \\
East Passage (EAP) & 0.8 & 0.89 \\
Gordon Point/Tacoma Narrows (GOR1) & 1 & 1.11 \\
Hood Canal (HCB003) & 0.8 & 1.13 \\
Saratoga Passage (SAR003) & 0.89 & 1.12 \\
Nisqually Reach (NSQ) & 1.08 & 1.18 \\
Dana Passage (DNA) & 1.26 & 1.43 \\
\hline Mean & $\mathbf{0 . 8 5}$ & $\mathbf{1}$ \\
\hline
\end{tabular}

\subsection{Initial Condition Data - Water Quality}

Our approach was to conduct a first round of calibration using observed data to initialize the model. Data for specifying initial conditions in the model corresponding to January of 2006 were selected from the Ecology Puget Sound Ambient Monitoring Marine Overflight Program, ${ }^{a}$ fully quality-assured andcontrolled for the years up through 2006. Figure 2.7 shows the stations from the marine overflight database from which data were obtained from 2006 for setting up the model initial conditions and later for validation.

\footnotetext{
${ }^{\mathrm{a}}$ http://www.ecy.wa.gov/apps/eap/marinewq/mwdataset.asp (March 2011).
} 


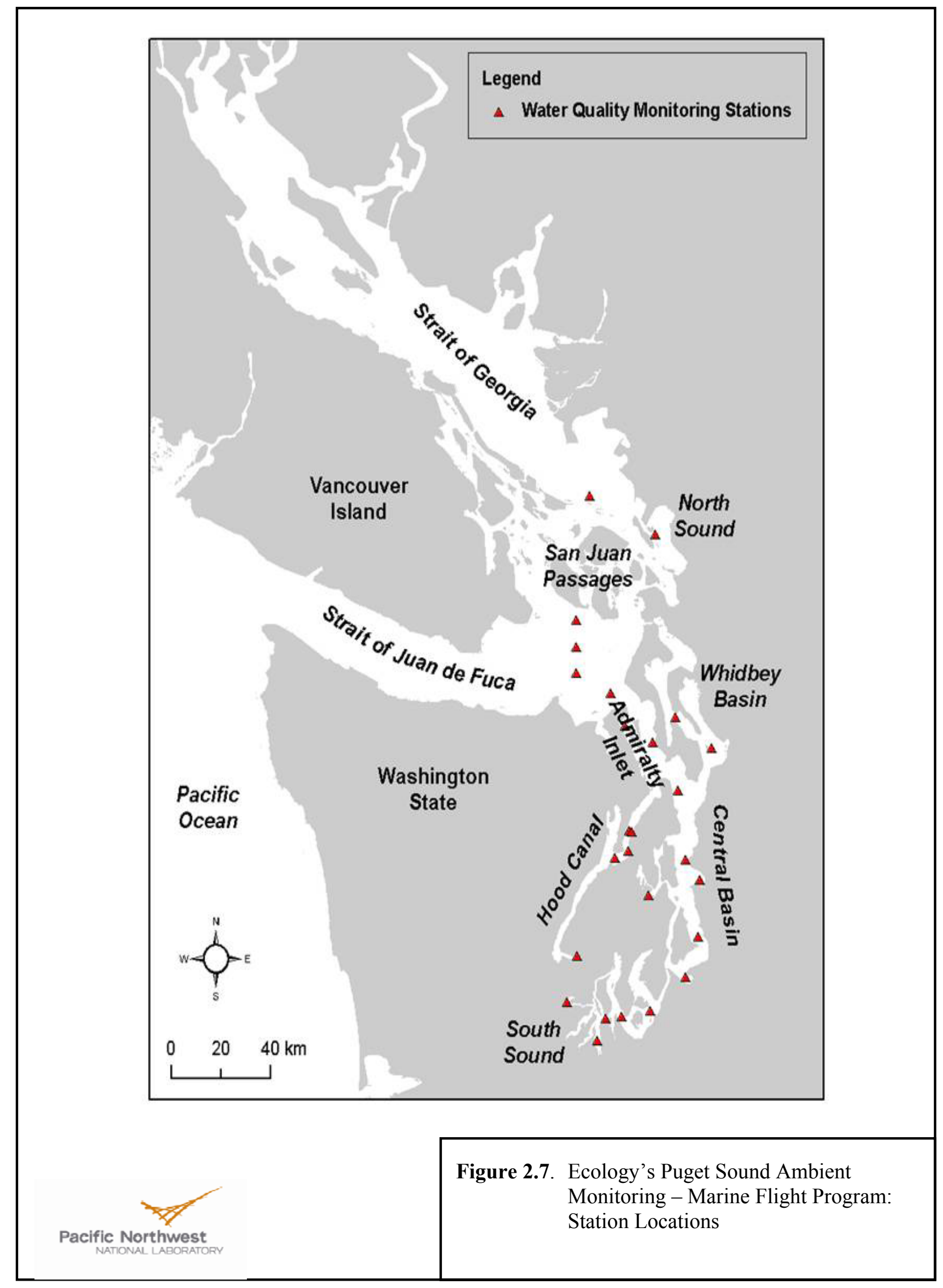


After a review of the available water quality monitoring data, it was determined that the water column was relatively homogeneous and fully mixed in winters of 2005 and 2006, and because December 2005 was the month with the most complete winter dataset, the available data from station PSB003 (Puget Sound Main Basin) were used to initialize the model throughout the domain. Nutrients (inorganic $\mathrm{N}$ and P), chlorophyll a (converted to carbon using a carbon to chlorophyll a ratio of 50), and dissolved oxygen from the dataset were used to initialize the model. Table 2.5 provides values that were used to specify initial conditions for five of the major constituents in the model. Due to limited availability of data, the remaining constituents were set to zero. For simplicity, uniform initial conditions were chosen for initializing the model spin-up run. This initial approach assumes that during the winter, biological activity is low and, by the time spring bloom occurs, the remaining constituents will be internally updated, filled via boundary fluxes and transformation from the other pools.

The exceptions to well-mixed conditions in Puget Sound in the winter were the long and narrow fjordal basins of Hood Canal and Saratoga Passage, which remained stratified in winter. The stratification in Hood Canal and Saratoga Passage is driven by high freshwater inflow during the winter months relative to basin volume. In Hood Canal, the circulation is complex and influenced by the hydraulic control exerted by $\mathrm{a} \approx 10$-km-long sill near the entrance to Hood Canal (Gregg and Pratt 2010). The basin is therefore known to have flushing times considerably longer than other subbasins in Puget Sound, which is reflected in the vertical salinity, temperature, and DO gradients throughout the year. To accommodate this difference from the rest of Puget Sound, the initial conditions for Hood Canal were specified using data from the Hood Canal station HCB010 and are also listed in Table 2.5. HCB010 was selected because it is centrally located and representative of Hood Canal basin but may not completely reflect water quality of the inner-most portions of Hood Canal.

The results at the end of 1-year would be treated as pre-conditioning or spin-up to initialize the model for calibration. The simulation for year 2006 would then be repeated.

Table 2.5. Initial Water Quality Concentrations for 2006 for the spin-up simulation from Puget Sound Main Basin Station PSB003 and Hood Canal Station HCB003 (December 7, 2005)

\begin{tabular}{lccccc}
\hline \multicolumn{1}{c}{ Basin } & $\begin{array}{c}\mathrm{DO} \\
\mathrm{mg} / \mathrm{L}\end{array}$ & $\begin{array}{c}\mathrm{NO}_{3}+\mathrm{NO}_{2} \\
\mathrm{mg} / \mathrm{L}^{\mathrm{a}}\end{array}$ & $\begin{array}{c}\mathrm{NH}_{4} \\
\mathrm{mg} / \mathrm{L}^{\mathrm{b}}\end{array}$ & $\begin{array}{c}\mathrm{PO}_{4} \\
\mathrm{mg} / \mathrm{L}^{\mathrm{c}}\end{array}$ & $\begin{array}{c}\text { Algae } \\
\mathrm{mg} / \mathrm{L}\end{array}$ \\
\hline $\begin{array}{l}\text { Puget Sound } \\
\text { Domain (except }\end{array}$ & 8.0 & 0.43 & 0.002 & 0.08 & 0.026 \\
$\begin{array}{l}\text { Hood Canal) } \\
\text { Hood Canal }\end{array}$ & $\begin{array}{l}\text { Surface (9.0) } \\
\text { Bottom (4.0) }\end{array}$ & 0.43 & 0.002 & 0.08 & 0.026 \\
\hline
\end{tabular}

a $-1 \mathrm{mg} / \mathrm{L}$ of $\left(\mathrm{NO}_{3}+\mathrm{NO}_{2}-\mathrm{N}\right)=71.43 \mu \cdot \mathrm{mol} / \mathrm{L}$ of $\left(\mathrm{NO}_{3}+\mathrm{NO}_{2}-\mathrm{N}\right)$

b $-1 \mathrm{mg} / \mathrm{L}$ of $\left(\mathrm{NH}_{4}-\mathrm{N}\right)=71.43 \mu \cdot \mathrm{mol} / \mathrm{L}$ of $\left(\mathrm{NH}_{4}-\mathrm{N}\right)$

c $-1 \mathrm{mg} / \mathrm{L}$ of $\left(\mathrm{PO}_{4}-\mathrm{P}\right)=32.29 \mu \cdot \mathrm{mol} / \mathrm{L}$ of $\left(\mathrm{PO}_{4}-\mathrm{P}\right)$

\subsection{River, Wastewater Treatment Plant, and Watershed Discharge Boundary Data}

A total of 64 streams, including 19 major rivers with permanent USGS gages and 45 watershed discharges enter the model domain, as well as 99 municipal wastewater treatment plant flows. Most of the major river flows were obtained from the USGS real-time stream flow gauges. Watershed discharges correspond to water runoff to Puget Sound that occurs through streams without permanent gauging 
stations in place. Some of the watershed discharges were based on measurements, and others were estimated using a scaling method based on watershed areas and areal precipitation. The daily flow rates and constituent concentrations for each inflow were developed by Ecology through a combination of hydrologic analysis and regression techniques that are described in detail in Mohamedali et al. (2011). Similarly, the wastewater treatment plant flows were developed by Ecology through multiple regression analysis using information from the monitoring conducted by various treatment plants under the National Pollutant Discharge Elimination System (NPDES) requirement. The locations of various wastewater treatment plant and relative flow magnitudes are shown in Figures 2.8 and 2.9, respectively. Although wastewater flow magnitudes are small relative to tidal exchange and not expected to affect tidal circulation, a fundamental question for the study is whether they affect water quality locally or could cumulatively result in significant effects on the biogeochemistry of Puget Sound. Therefore, in this study all major wastewater plants that discharge directly to Puget Sound are included. Municipal plants that discharge to tributaries are implicitly included in the tributary loadings. The watershed discharges (red dots) and gauged river inflows (blue triangles) locations are shown in Figure 2.10.

Figures 2.11 and 2.12 show river flows for each basin, including the Fraser River in Canada. All river inflows in the U.S. portion of the domain show similar patterns, with high flow events occurring in late fall and winter months while relatively low flow is recorded in late spring and summer months. In contrast, the Fraser River inflow in the Canadian portion of the domain is significantly higher and shows a very different seasonal distribution pattern, with high flow in the late spring and summer and low flow in the fall and winter. The river flows are grouped by their discharge basins, and the annual mean flows are summarized in Table 2.6. The Skagit River is the largest river discharging into Puget Sound. The Whidbey Basin consists of the three largest rivers (Skagit River, Snohomish River, and Stillaguamish River) in Puget Sound and accounts for almost $70 \%$ of the total freshwater flow into Puget Sound.

Unlike flow, continuous temperature monitoring data are not available at all stations. Comparisons of monthly river temperatures from different rivers indicated that they were similar and the differences among rivers within Puget Sound were relatively small (upper panel in Figure 2.13 (Ecology, personal communication). Salinity exerts a much stronger influence on stratification than temperature. Surface Puget Sound temperatures are more strongly influenced by solar radiation than the heat load of rivers except adjacent to river mouths. Therefore, river inflow temperatures for all rivers except the Fraser River were represented using the Cedar River temperature time history that was available for 2006 in the model setup. Figure 2.13 shows the temperature distributions for the Cedar River in the United States and the Fraser River in Canada for 2006.

For the water quality simulation, daily average nutrient, carbon, and DO concentrations were provided for each of the 19 rivers for the period 2006-2007 (Mohamedali et al., 2011). A similar dataset was also developed for the 45 ungauged inflows for the United States and Canada as concentrations along with associated flows. These data were converted into daily mass loadings. Likewise, Mohamedali et al. (2011) also developed a comparable dataset for the almost 100 wastewater treatment plants, which also included daily mass loadings. For wastewater loads, per guidance provided by Ecology, the DO was set to a constant $5.9 \mathrm{mg} / \mathrm{L}$. 


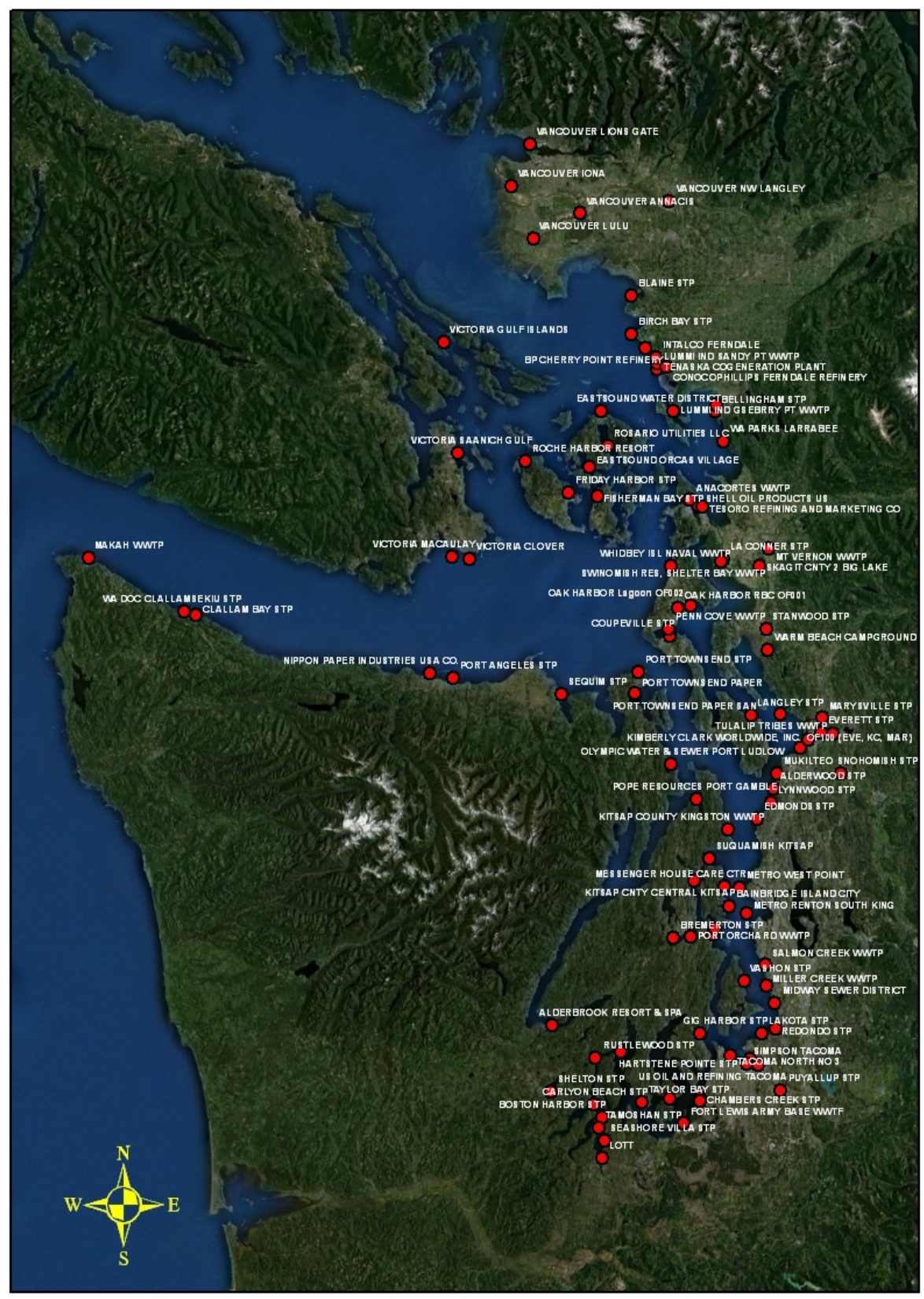

Figure 2.8. Wastewater Treatment Plant Locations - Puget Sound Basin, Point Source Loads 


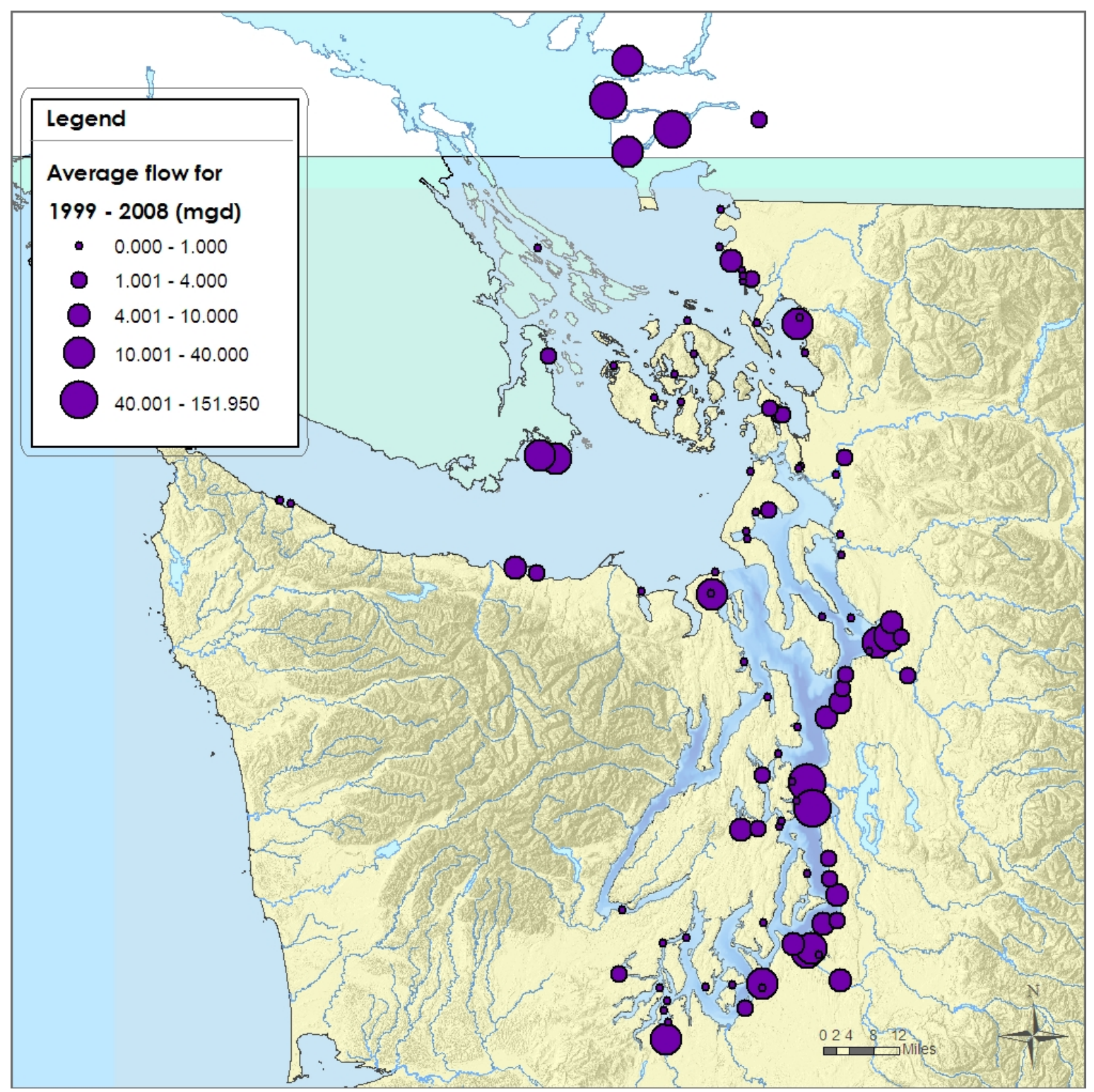

Figure 2.9. Wastewater Treatment Plant Flows Puget Sound Basin, Point Source Loads 


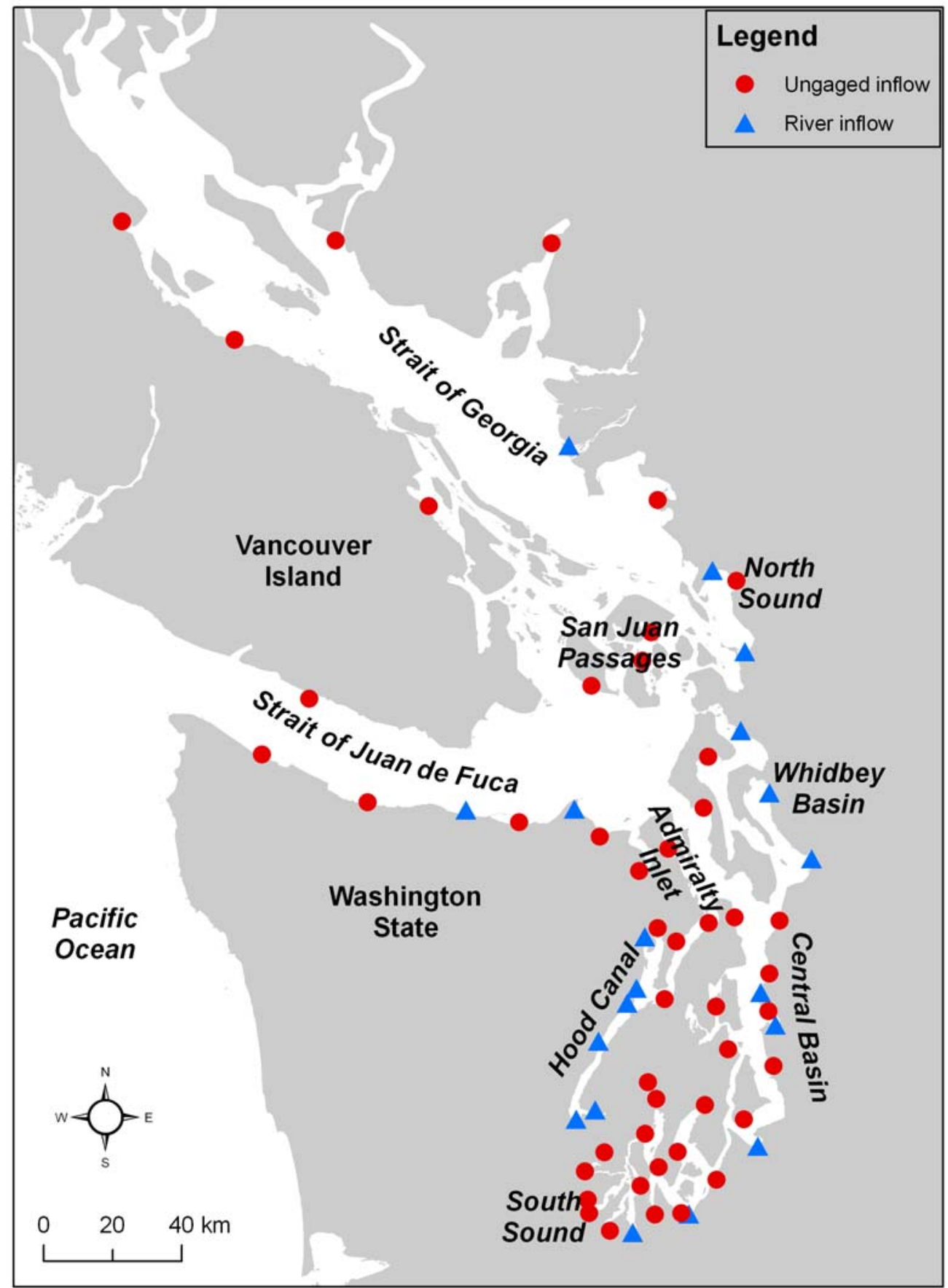

Figure 2.10. River and Watershed Discharge Locations (Pour Points) - Puget Sound Basin, Point Source Loads 

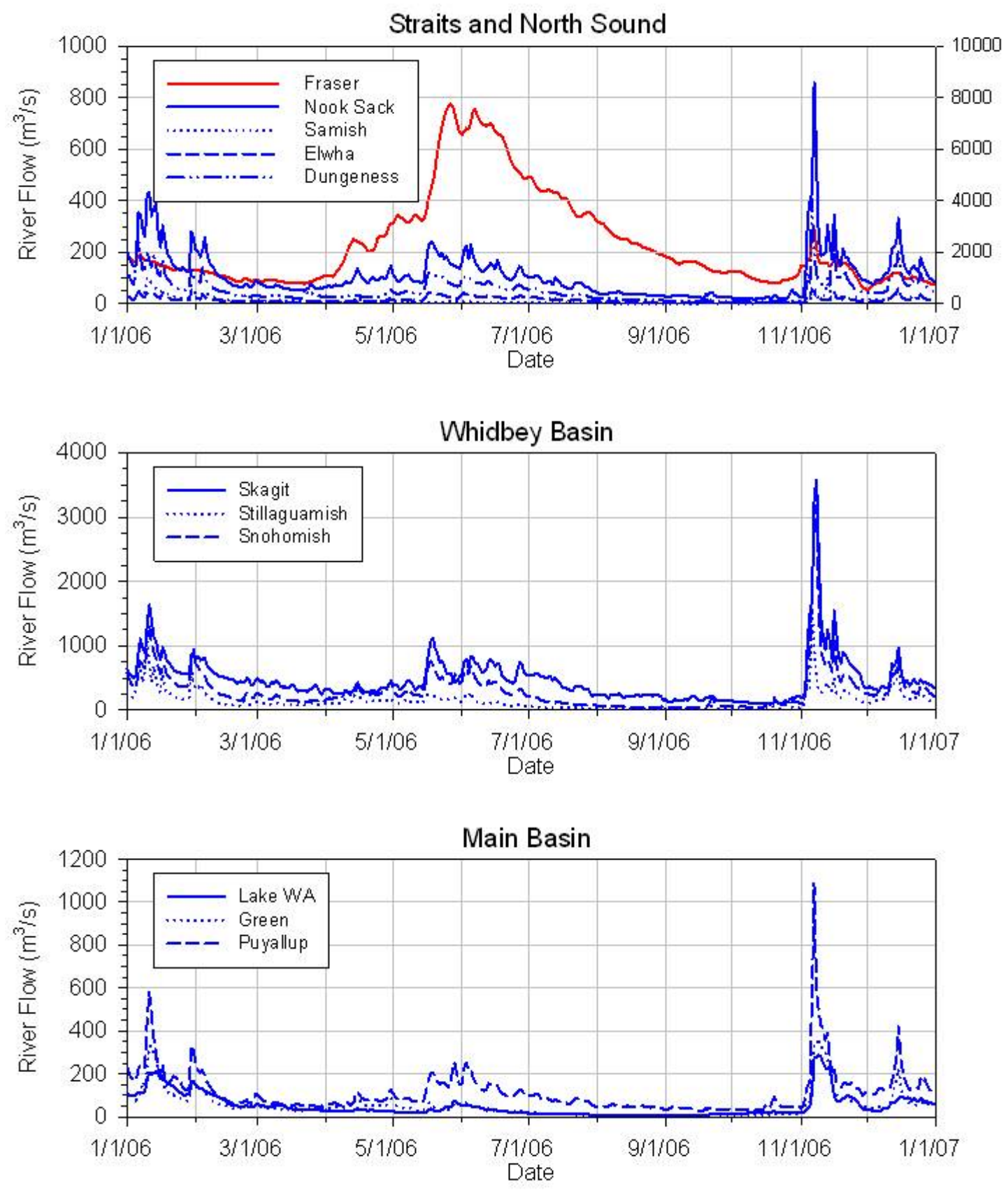

Figure 2.11. Individual River Inflow in the Straits and North Sound, Whidbey Basin, and Main Basin 

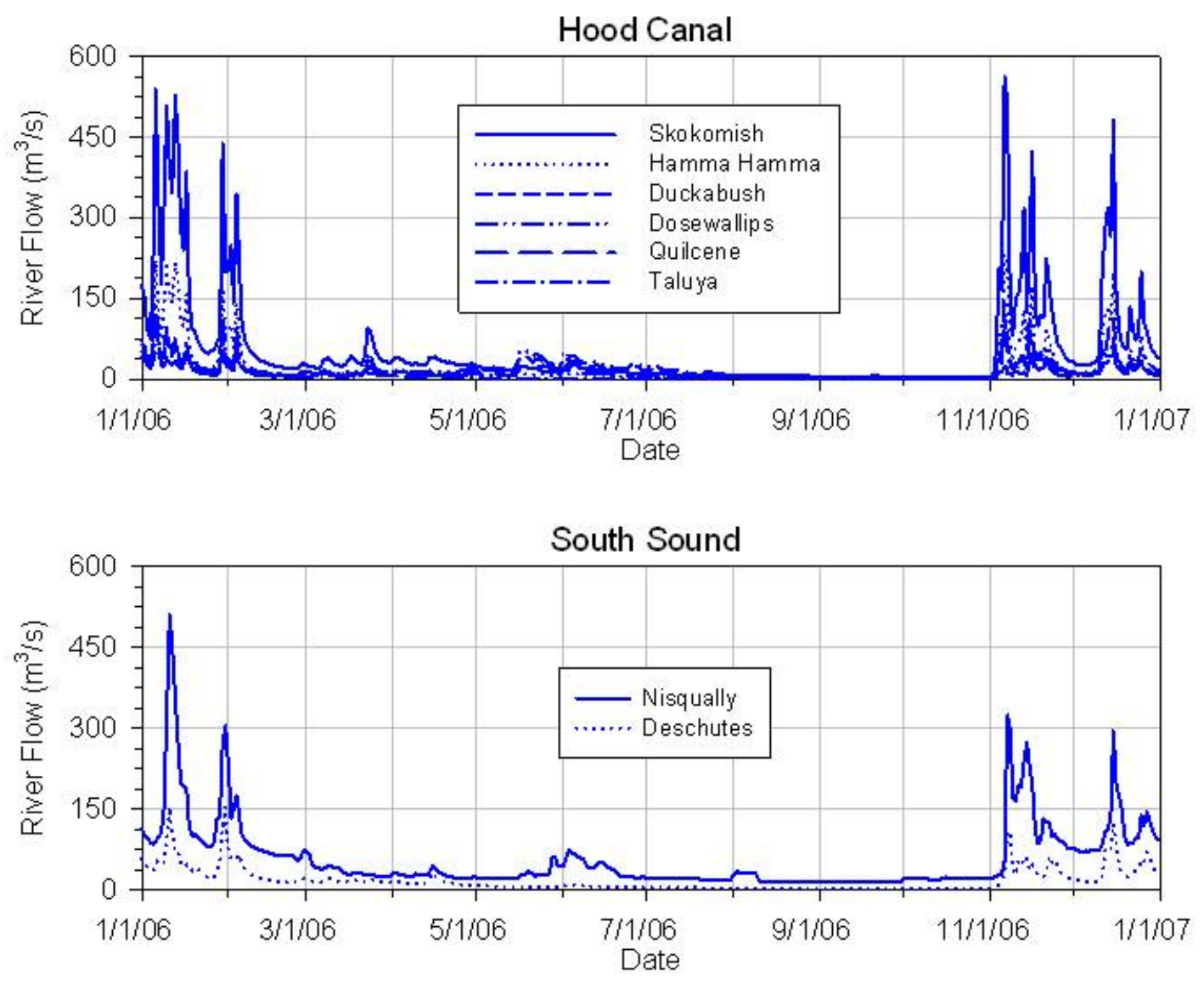

Figure 2.12. Individual River Inflow in Hood Canal and South Sound 

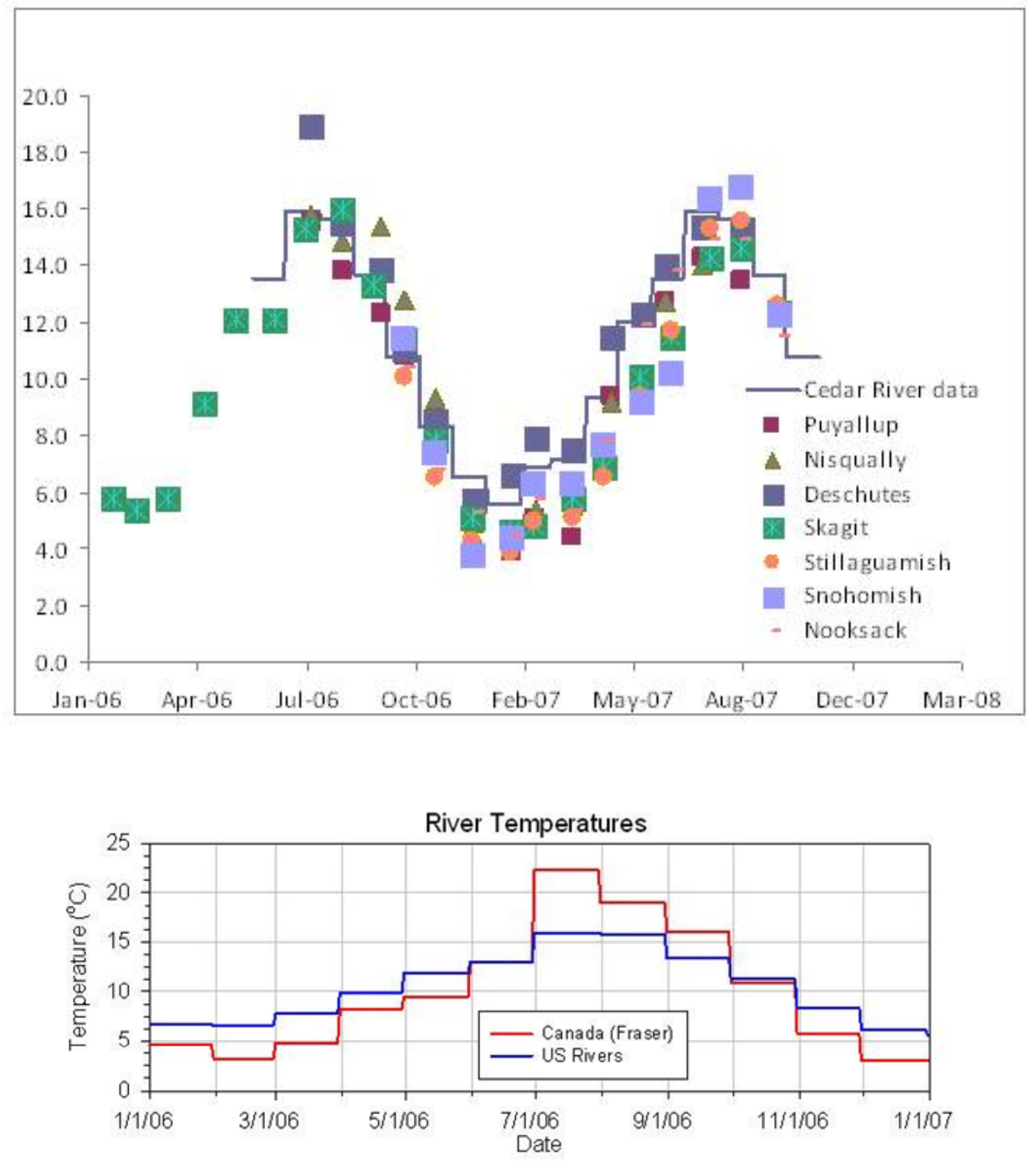

Figure 2.13. River Temperature Distributions Puget Sound Basin 
Table 2.6. Summary of River Inflows (*Percentage is relative to the total inflows in Puget Sound)

\begin{tabular}{|c|c|c|}
\hline River/Basin Name & $\begin{array}{l}\text { Annual Mean Flow } \\
\qquad\left(\mathrm{m}^{3} / \mathrm{s}\right)\end{array}$ & Station ID \\
\hline Straits and North Sound & 2541 & \\
\hline Fraser (Canada) & 2351.6 & WSC08MF005 \\
\hline Dungeness & 14.8 & USGS12048000 \\
\hline Elwha & 52.1 & USGS12045500 \\
\hline Nooksack & 109.8 & USGS12213100 \\
\hline Samish & 12.5 & USGS12201500 \\
\hline Whidbey Basin & $919(68 \%)^{*}$ & \\
\hline Skagit & 475.5 & USGS12200500 \\
\hline Stillaguamish & 144.6 & USGS12167000 \\
\hline Snohomish & 298.8 & USGS12150800 \\
\hline Main Basin & $214(16 \%)^{*}$ & \\
\hline Lake Washington & 48.8 & USGS12119000 \& USGS12125200 \\
\hline Duwamish & 52.3 & USGS12113000 \\
\hline Puyallup & 112.7 & USGS12101500 \\
\hline Hood Canal & $139(10 \%)^{*}$ & \\
\hline Tahuya & 10.6 & \\
\hline Skokomish & 56.9 & USGS12061500 \\
\hline Duckabush & 16.7 & USGS12054000 \\
\hline Dosewallips & 20.9 & \\
\hline Big Quilcene & 10.0 & USGS12052210 \\
\hline South Sound & $76(6 \%)^{*}$ & \\
\hline Nisqually & 58.3 & USGS12089500 \\
\hline Deschutes & 17.8 & USGS12080010 \\
\hline
\end{tabular}

Initially, as a simplification, the wastewater treatment plant and ungauged inflows were not included in the hydrodynamic calibration based on the fact that their flow rates are low relative to Puget Sound tidal exchange flows (Yang et al, 2010). Although local effects may occur near the point source discharges, it was assumed that the freshwater characteristics of wastewater effluents do not impact basinwide hydrodynamic circulation and salinity stratification of Puget Sound. Yet there is still some concern that local effects may be important, especially in selected locations such as the smaller shallow subbasins. All point sources are now included in the hydrodynamic solution explicitly.

The loads from the 19 major rivers, 45 watershed discharges, and 99 wastewater inflows were introduced directly into water quality calculations in the form of constituent mass flux loads. Wastewater treatment plant constituent loads were generally added to the bottom layer of the model. However, for the four largest inputs (METRO West Point, METRO South King, Tacoma Central, and Pierce County Chambers Creek), the wastewater loads were added to the water column where the plume traps, based on information provided by King County (Nairn, personal communication) and Ecology (Ahmed, personal communication) and are consistent with the approach used in the South Puget Sound Dissolved Oxygen Study. 
Marine phytoplankton loadings in rivers and point sources were set to zero. Although rivers provide phytoplankton, the species are not expected to survive and thrive in saltwater conditions. Their contributions to the carbon and nitrogen pools are included in the organic components. The loadings and river concentrations were derived from stream measurements and watershed analyses. Briefly, nutrients, carbon, and dissolved oxygen loadings were scaled from monitored watersheds with comprehensive measurements to those where such measurements were sparse. Mohamedali et al. (2011) describes the multiple linear regressions used to develop daily time series from monthly concentration data by considering patterns in flow and seasonality.

Daily average loadings (concentrations of 13 of the 19 constituents) and flows were provided by Ecology for the period of 2006 to 2007. Nutrients, carbon and dissolved oxygen were also provided by Ecology for major Canadian rivers, including the Fraser River. Watershed discharges computed using hydrologic analysis based on watershed size and rainfall provided by Ecology are also included and specified at the pour points. In river loads, dissolved organic carbon (DOC) was moderately high for a subset of rivers (up to $4.23 \mathrm{mg} / \mathrm{L}$, significant when considering that flows are much higher than wastewater treatment plant levels (Figure 2.14), while dissolved oxygen was typically much higher than dissolved oxygen in the wastewater flows.

Daily average concentrations for all major wastewater treatment plant inputs were also provided by Ecology. Notably, relative to typical Puget Sound ambient, wastewater treatment plant inputs universally contain large concentrations of DOC (with a maximum of $70 \mathrm{mg} / \mathrm{L}$ ) and ammonium $(>20 \mathrm{mg} / \mathrm{L}$ for most flows and with a maximum of $41.2 \mathrm{mg} / \mathrm{L})$. The maximum values of (nitrate + nitrite) nitrogen $(\approx 5 \mathrm{mg} / \mathrm{L}$ or $357 \mu \mathrm{mol} / \mathrm{L}$ ) in the wastewater flows are nearly an order of magnitude higher than the (nitrate + nitrite) concentrations of near bottom inflows of Pacific Ocean waters to Puget Sound discussed in Section 2.5.

Figures 2.14 and 2.15 show plots of loads to Puget Sound from the major rivers and wastewater treatment plants in the form of bar charts of average nitrate, phosphate, carbon, and DO concentrations for 2006.

In addition to river inputs, benthic sediment fluxes were specified for dissolved oxygen, ammonium, nitrate and nitrite, and phosphate, using data provided by Ecology (Table 2.7; Roberts et al. 2008). These data are conservative (higher fluxes than would be expected on average throughout the Sound), since they include data collected during the summer in shallow regions of Puget Sound such as Budd Inlet. Constant fluxes were used for nitrate+nitrite, ammonia, and phosphate. However for DO, a spatially varying benthic flux with high demand of $2.0 \mathrm{gm} \mathrm{m}^{-2} \mathrm{~d}^{-1}$ was specified in selected shallow areas of Puget Sound with known occurrences of low DO conditions corresponding to the upper end of the range for estuarine mud (Thomann and Mueller 1987). A representative value of $0.1 \mathrm{gm} \mathrm{m}^{-2} \mathrm{~d}^{-1}$ was specified for the rest of Puget Sound domain. 
Table 2.7. Benthic Sediment Fluxes (5-cm depth) - Nutrients and Dissolved Oxygen throughout the Puget Sound Model Domain

\begin{tabular}{lcccc}
\hline \multicolumn{1}{c}{ Constituent } & $\begin{array}{c}\text { Nitrate } \\
\left(\mathrm{NO}_{3}+\mathrm{NO}_{2}\right)\end{array}$ & $\begin{array}{c}\text { Ammonium } \\
\left(\mathrm{NH}_{4}\right)\end{array}$ & $\begin{array}{c}\text { Phosphate } \\
\left(\mathrm{PO}_{4}\right)\end{array}$ & \begin{tabular}{c} 
Dissolved Oxygen \\
\hline $\begin{array}{l}\text { Benthic Flux } \\
\left(\mathrm{g} \mathrm{m}^{-2} \mathrm{~d}^{-1}\right)\end{array}$
\end{tabular} \\
$\begin{array}{l}\text { Range } \\
\left(\mathrm{g} \mathrm{m}^{-2} \mathrm{~d}^{-1}\right)\end{array}$ & -0.011 & 0.064 & 0.02 & $\begin{array}{l}-0.1^{\mathrm{a}} \\
-2.0^{\mathrm{b}}\end{array}$ \\
\hline
\end{tabular}

${ }^{\mathrm{a}}$ Value specified in most of Salish Sea domain, ${ }^{\mathrm{b}}$ Value specified in selected shallow regions of Puget Sound known for low values of near bed DO

\subsection{Open Boundary Data}

To simulate nutrient, phytoplankton, and dissolved oxygen distributions in Puget Sound, time series of these constituents along the open boundaries are required. These data provide boundary forcing to Puget Sound and the Straits via the incoming Pacific Ocean water. Nutrient, phytoplankton, and dissolved oxygen monitoring data collected at the open boundaries by Fisheries and Oceans Canada (DFO) and monthly profile data collected by Ecology and UW as part of the Joint Effort to Monitor the Strait of Juan de Fuca (JEMS) program were considered for specification of appropriate boundary values. Figure 2.16 shows locations of pour points (gauged rivers and ungauged inflow locations), and the DFO and JEMS stations.

Boundary data are relatively sparse close to Neah Bay and Johnstone Strait. The DFO data stations are nearest to the model boundaries but available only at a quarterly interval. JEMS data were collected at a higher monthly frequency but are located in the Strait of Juan de Fuca, interior to the model domain just southeast of San Juan Islands. The nutrient (nitrate + nitrite and phosphate), algal carbon, and dissolved oxygen profiles at the entrance of the Strait of Juan de Fuca and northern Georgia Strait are presented in Figures 2.17 and 2.18, taken from the most complete sampling stations available.

Strait of Juan de Fuca nitrate + nitrite concentrations are approximately $0.4 \mathrm{mg} / \mathrm{L}$ at depth throughout the year, with concentrations approximately half of this value $(0.1-0.2 \mathrm{mg} / \mathrm{L})$ at the surface during the summer. Inorganic phosphate follows a similar pattern. In the Georgia Strait, the nutrient concentrations are similar at depth, but reach zero for nitrate and near zero for phosphate in the surface during the summer months (Figure 2.17). This strongly suggests effects of local primary productivity and consumption of nutrients from the surface layers during the summer. These data collected by DFO are the closest available to the model grid boundary located in the channel south of Texada Island but still about $50 \mathrm{~km}$ away from the model boundary. Therefore, results near the northern boundary, which receives inflow from Johnstone Straits at a considerable distance north of Texada Island, must be interpreted with care. Tidally averaged inflow to the model domain at depth through the Strait of Juan de Fuca boundary is considerably higher than the surface freshwater discharges that affect stratification, primary productivity, and nutrient concentrations. Measurements of near-surface waters inside the Salish Sea domain correspond to properties of mixed outflow waters and are likely not representative of the Pacific Ocean boundary conditions. 

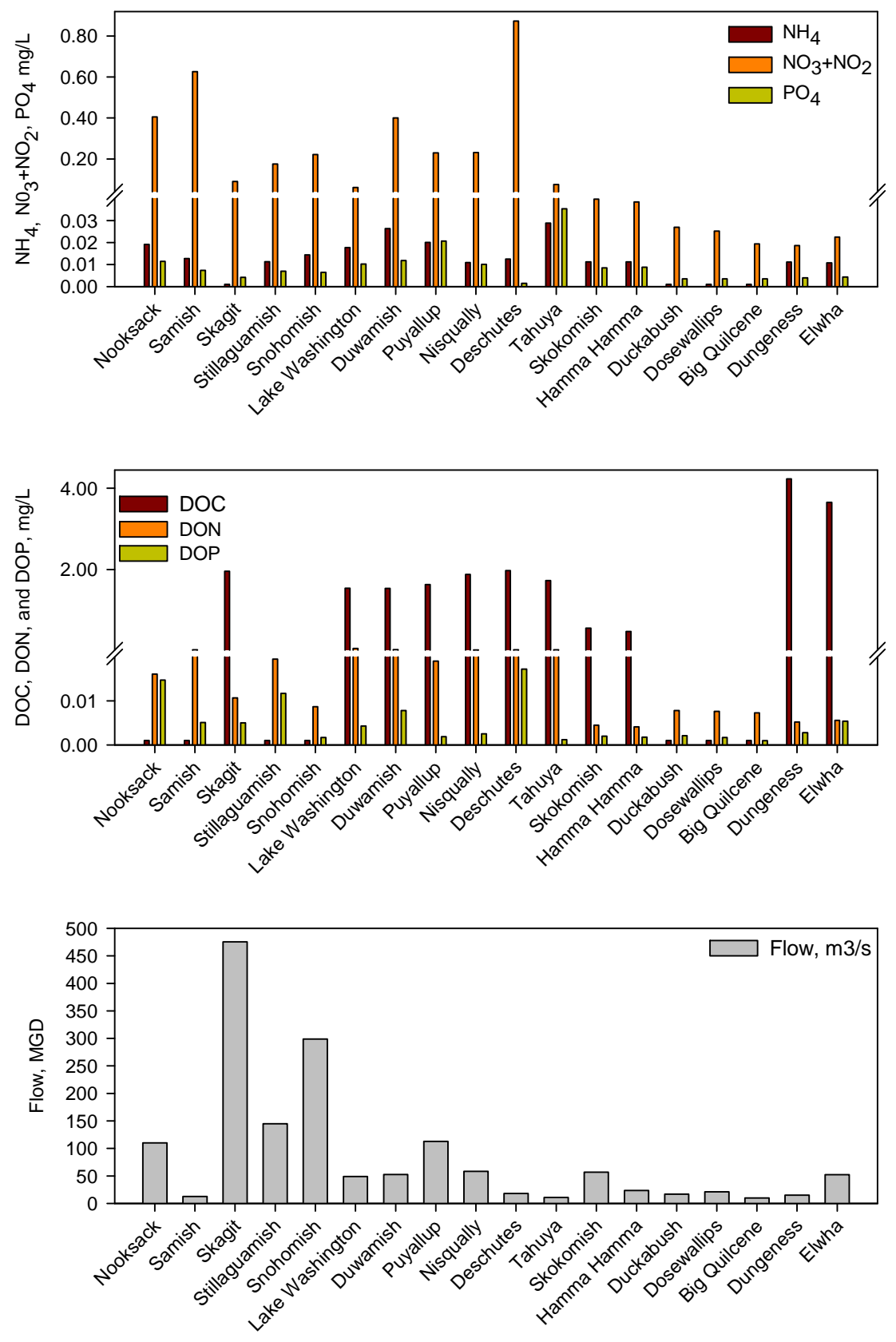

Figure 2.14. River Discharge Constituents, Year 2006 Average - Ammonia - N, (Nitrate + Nitrite $-\mathrm{N})$, Phosphate $-\mathrm{P}$, DOC, DON, DOP, and Flow 

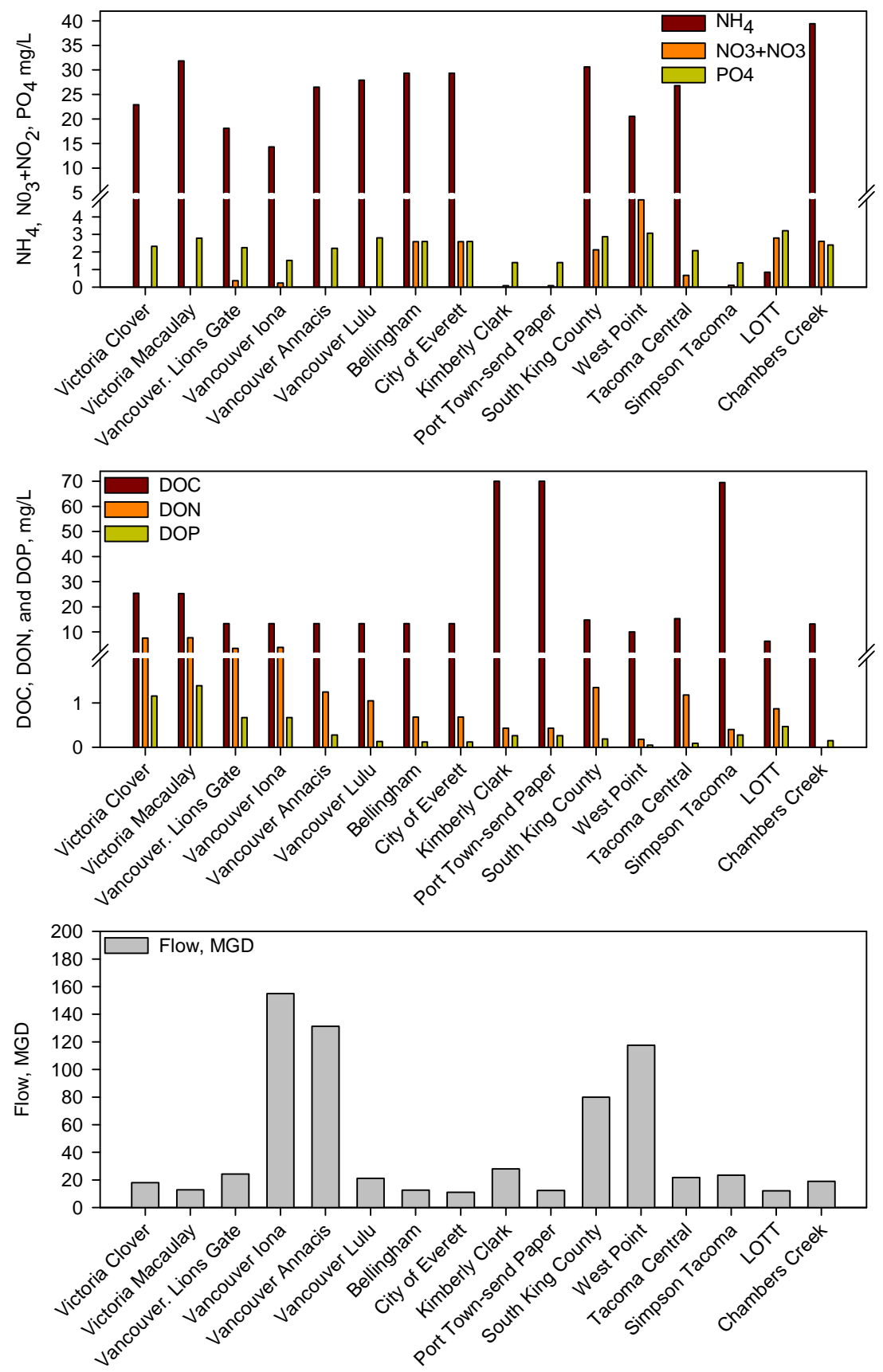

Figure 2.15. Wastewater Treatment Plant Discharge Constituents, Year 2006 Average Ammonia, (Nitrate +Nitrite), Phosphate, DOC, DON, DOP, and Flow 


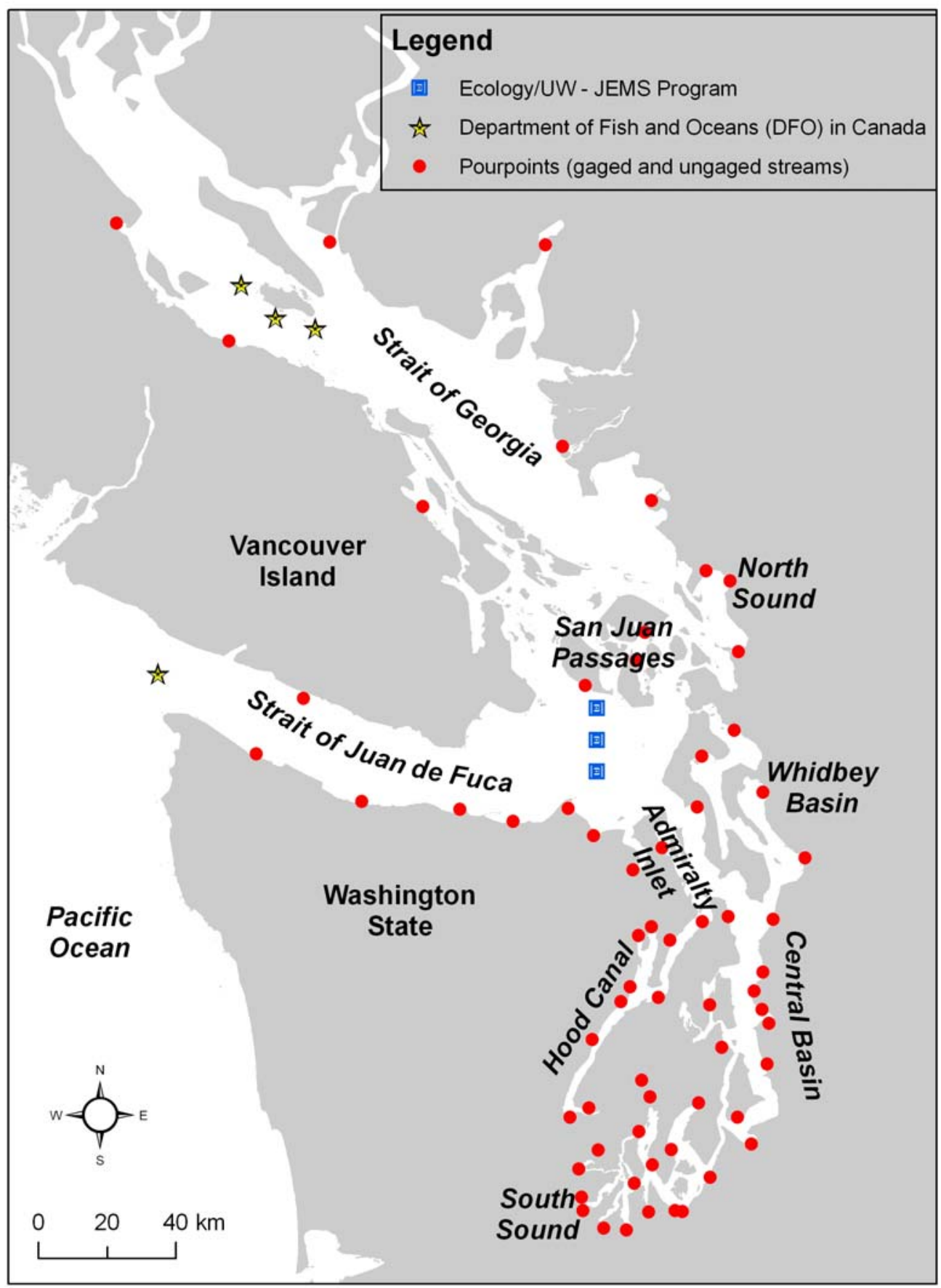

Figure 2.16. Locations of Boundary Water Quality Stations (yellow stars) Together with all Gauged and Ungauged River Pour Points in the Model Domain 

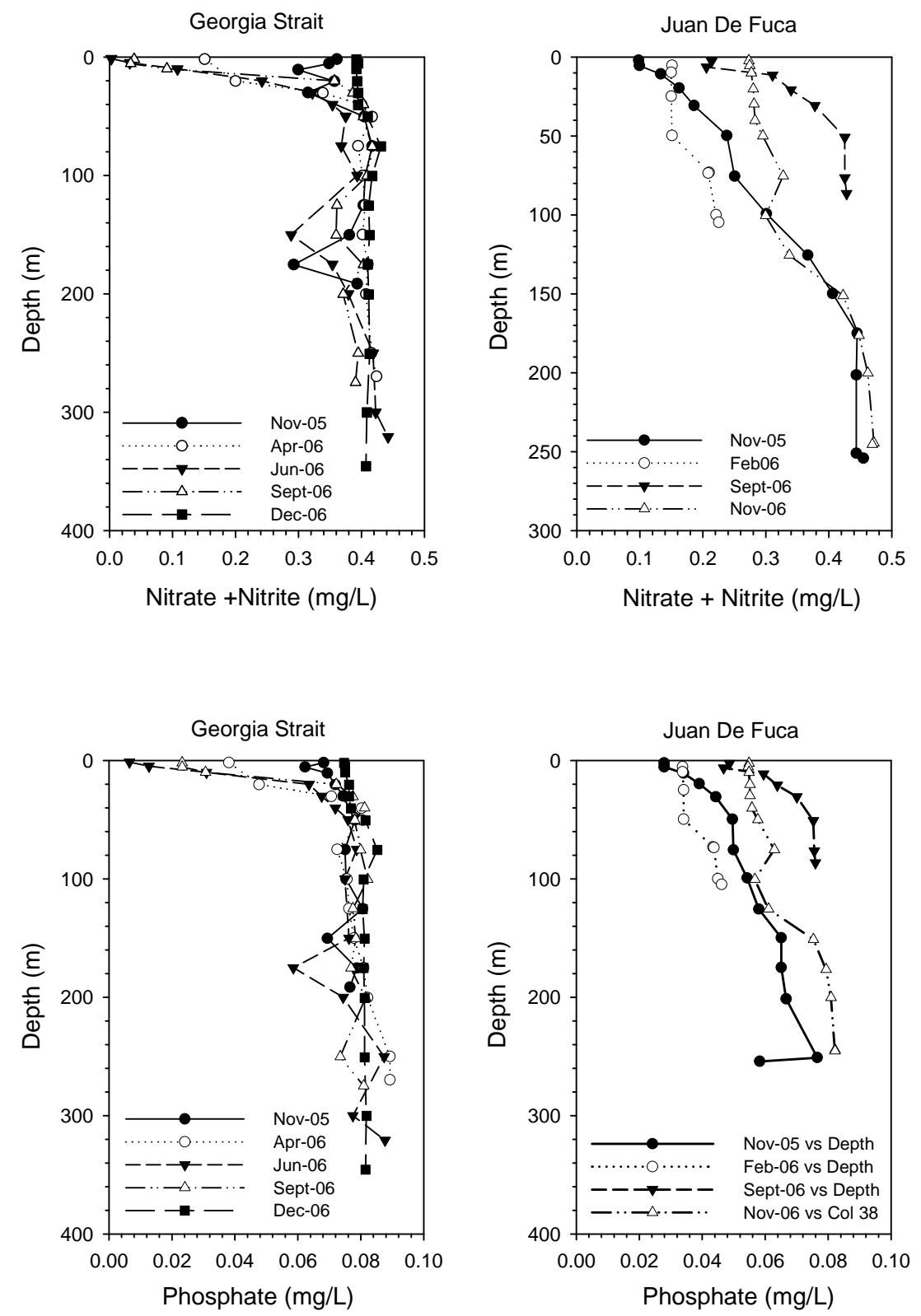

Source: Department of Fisheries and Oceans Canada (http://www.pac.dfompo.gc.ca/index-eng.htm

Figure 2.17. Nitrate + Nitrite and Phosphate Profiles at Georgia Strait and Strait of Juan de Fuca Boundaries 

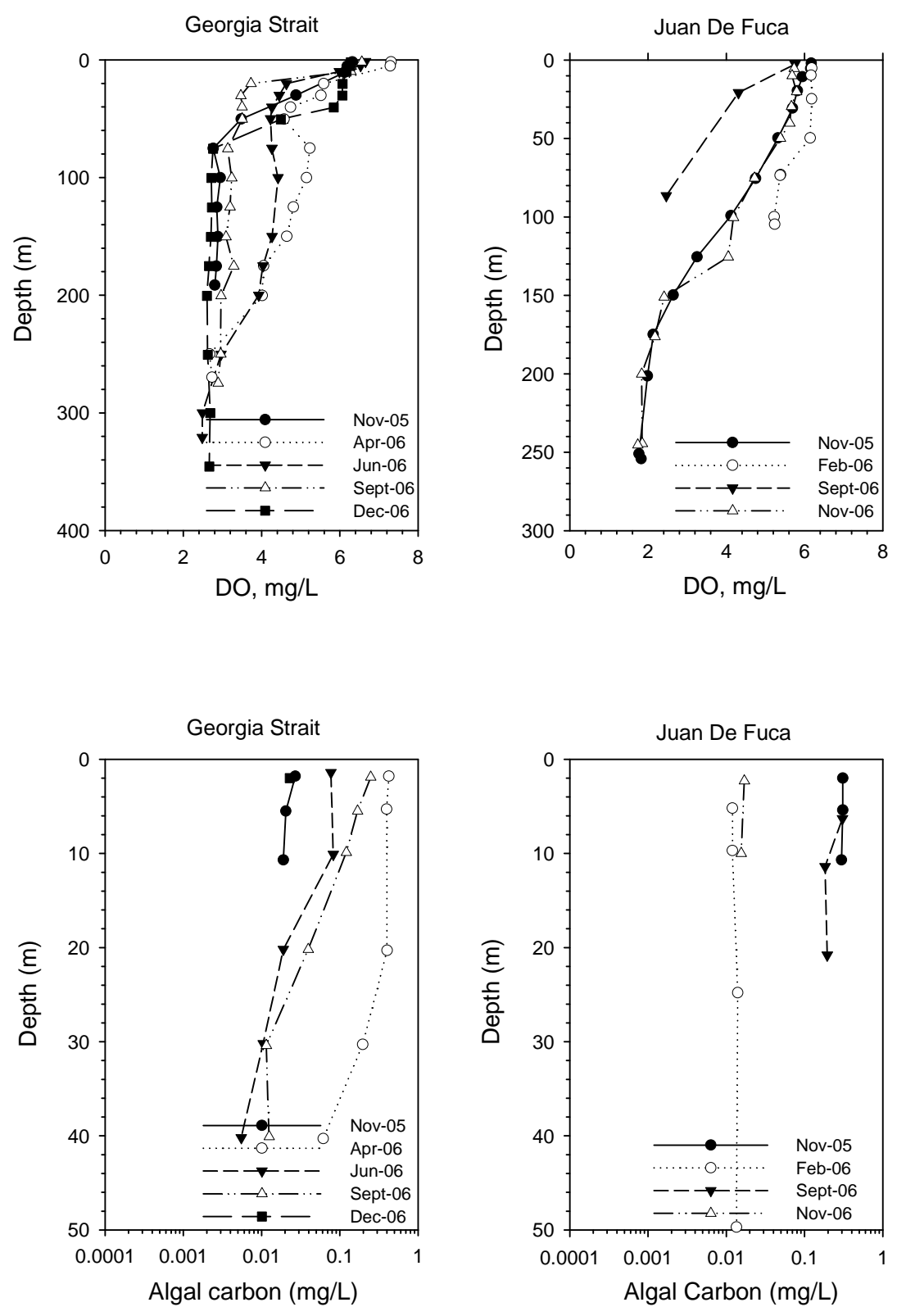

Source: Department of Fisheries and Oceans Canada (http://www.pac.dfompo.gc.ca/index-eng.htm

Figure 2.18. Dissolved Oxygen and Algal Carbon at Georgia Strait and Juan de Fuca Boundaries 
Dissolved oxygen is relatively high in the surface $(\sim 7 \mathrm{mg} / \mathrm{L})$ during the spring and winter months (reflecting algal growth in the spring and mixing and reaeration in the winter months). In late summer and autumn, dissolved oxygen decreases in the surface slightly to $6-7 \mathrm{mg} / \mathrm{L}$, with concentrations decreasing much more quickly with depth than at other times of year, such that concentrations reach $\sim 4 \mathrm{mg} / \mathrm{L}$ at $50 \mathrm{~m}$ in autumn (this concentration occurs around $100 \mathrm{~m}$ during the rest of the year). Dissolved oxygen is quite low at depth, $2-5 \mathrm{mg} / \mathrm{L}$ throughout the year in waters deeper than $100 \mathrm{~m}$.

At both Strait of Juan de Fuca and Georgia Strait stations, the waters contain more oxygen in the spring (April-June) in the upper and middle water column, which also likely reflects algal production during the spring bloom or stratification after mixing events. The algal carbon is converted from chlorophyll $a$ using a ratio of $50 \mathrm{~g} \mathrm{C:1} \mathrm{g}$ chlorophyll $a$, which is an average concentration developed from Steinbuck et al. (2010). Profiles display some seasonality, with higher concentrations during spring and fall and lower magnitudes in the winter. In addition, there is some interannual variability, with higher concentrations in November 2005 compared to November 2006. Deep algal maxima are not seen in the available data. The profiles at each model time step are linearly interpolated to the model internal time step (100 seconds).

An attempt was first made to conduct the model simulations based on boundary water quality data (nutrients, algae, and dissolved oxygen) directly from the profiles provided in Figures 2.17 and 2.18. The model response showed a strong sensitivity to the specified near bed concentrations at the boundaries and indicated that nutrients and DO concentrations in Puget Sound were strongly affected by the exchange flow entering the model domain from the Strait of Juan de Fuca boundary and into Puget Sound over Admiralty Inlet. While the surface layers within the model domain showed influence of primary productivity and loading from local discharges, the bulk of the water column characteristics were controlled by constituent concentrations in the inflow over Admiralty Inlet.

The temporal resolution (quarterly) of the profiles from DFO was not sufficient for direct use in specifying the model boundary conditions. It was decided that the data collected by Ecology and University of Washington as part of their JEMS program (Figure 2.16, blue squares) would be incorporated into the data set for specifying the boundary concentrations of nutrients and DO for the missing months of boundary values. Figure 2.19 and 2.20 show profiles of nutrients, DO, and algae collected at a monthly frequency in the Strait of Juan de Fuca station SJF000 that were used in specifying the boundary conditions for months and depths where data was not available from DFO stations. Also available at this stations were concentrations of dissolved inorganic nitrogen (DIN), silica $\left(\mathrm{SiOH}_{4} ;\right.$ not simulated), and ammonium-N. Figure 2.21 shows Time history of near bed constituent concentrations at the Strait of Juan de Fuca and Georgia Strait boundaries estimated from DFO and JEMs data - 2006. Available data at these boundaries is limited and does not allow detailed characterization of variation in quality of upwelled water.

Profiles of temperature and salinity from the Georgia Strait and Juan de Fuca boundaries from 2006 also required at the boundaries are provided in Figures 2.22 and 2.23. 

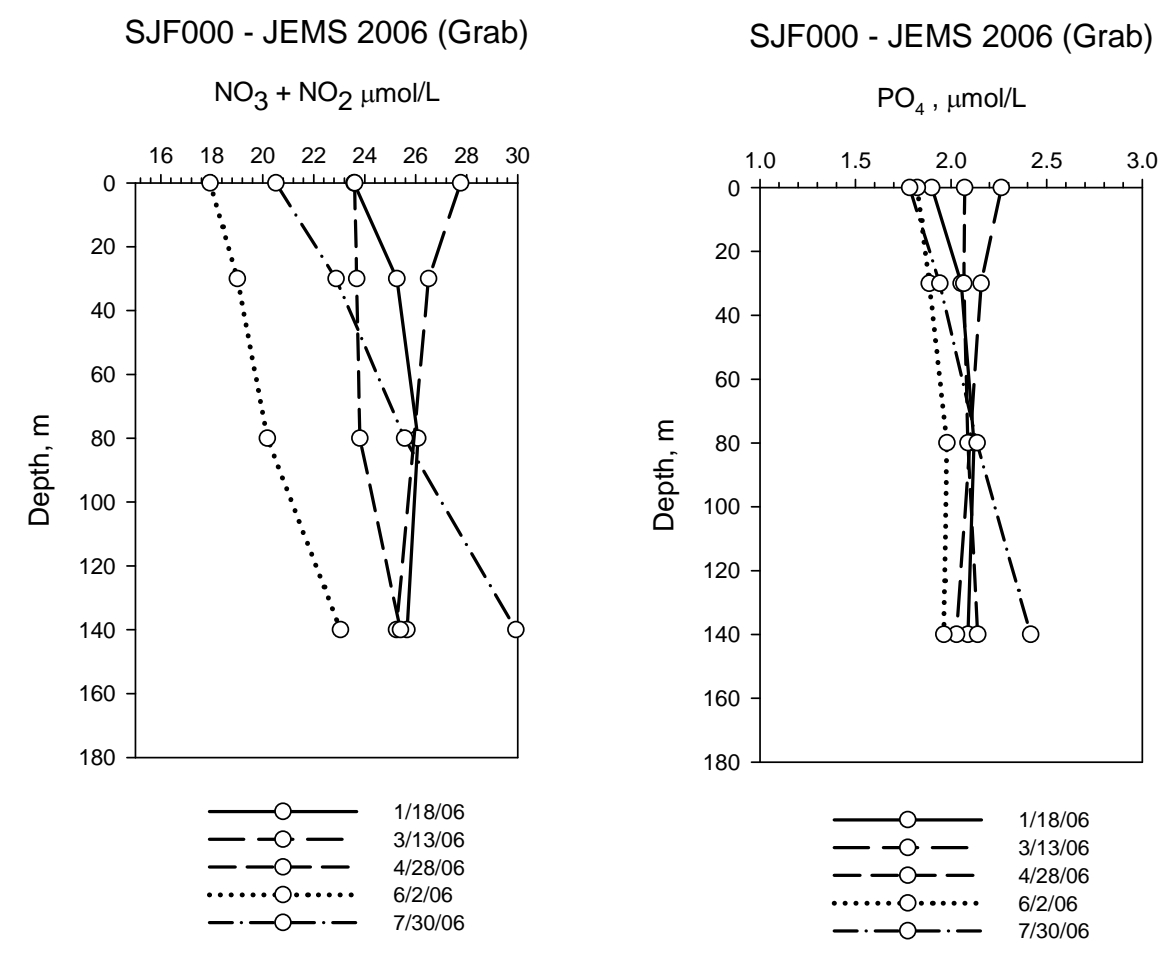

Source: Ecology / UW- Joint Effort to Monitor the Strait of Juan de Fuca

(JEMS), station SJF000

Figure 2.19. Nitrite + Nitrate and Phosphate Profiles, Strait of Juan de Fuca, Year 2006 

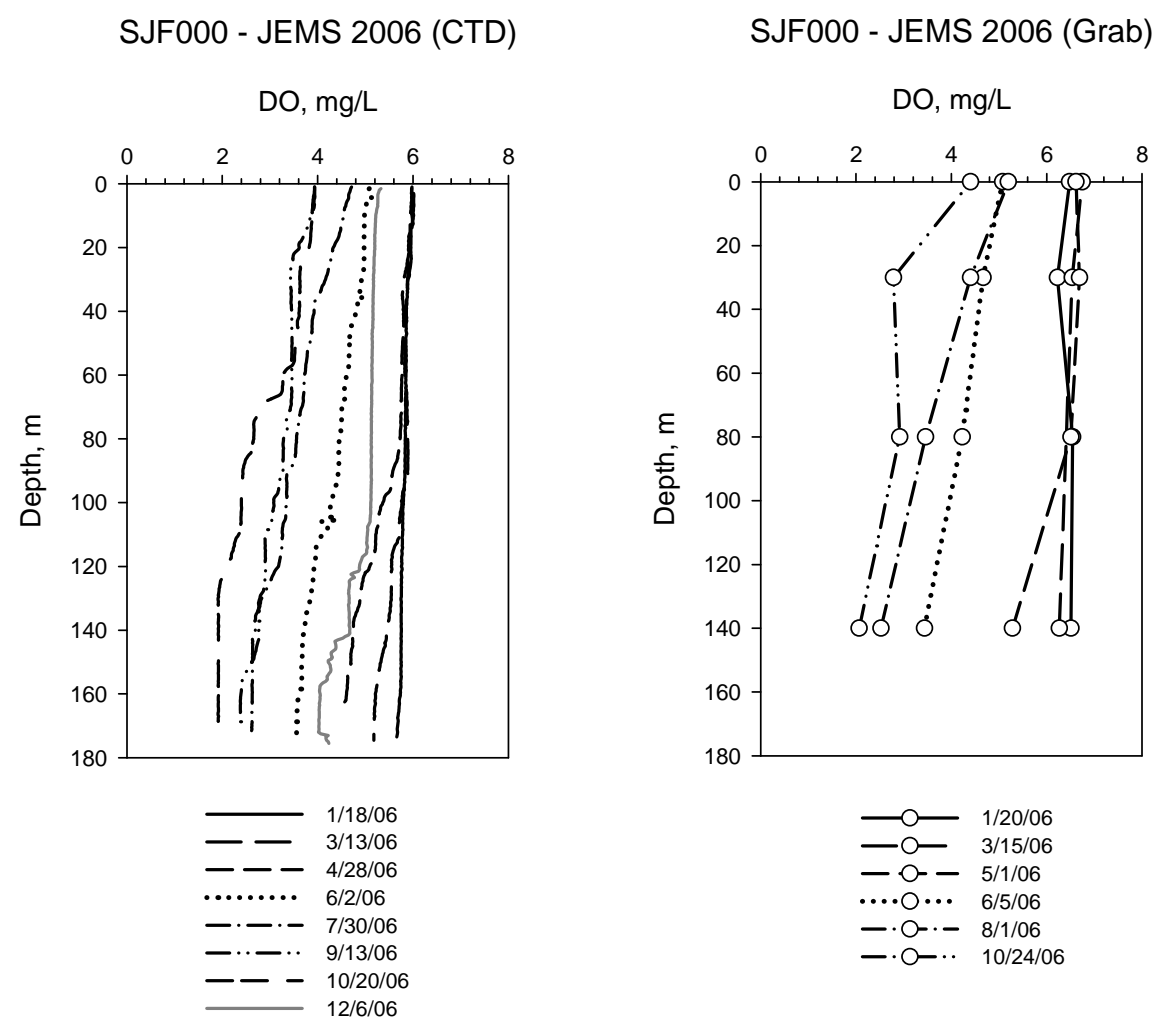

Source: Ecology / UW- Joint Effort to

Monitor the Strait of Juan de Fuca

(JEMS), station SJF000

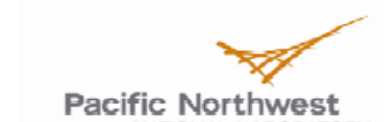

Figure 2.20. Dissolved Oxygen Profiles - Strait of Juan de Fuca, Year 2006 Boundaries 

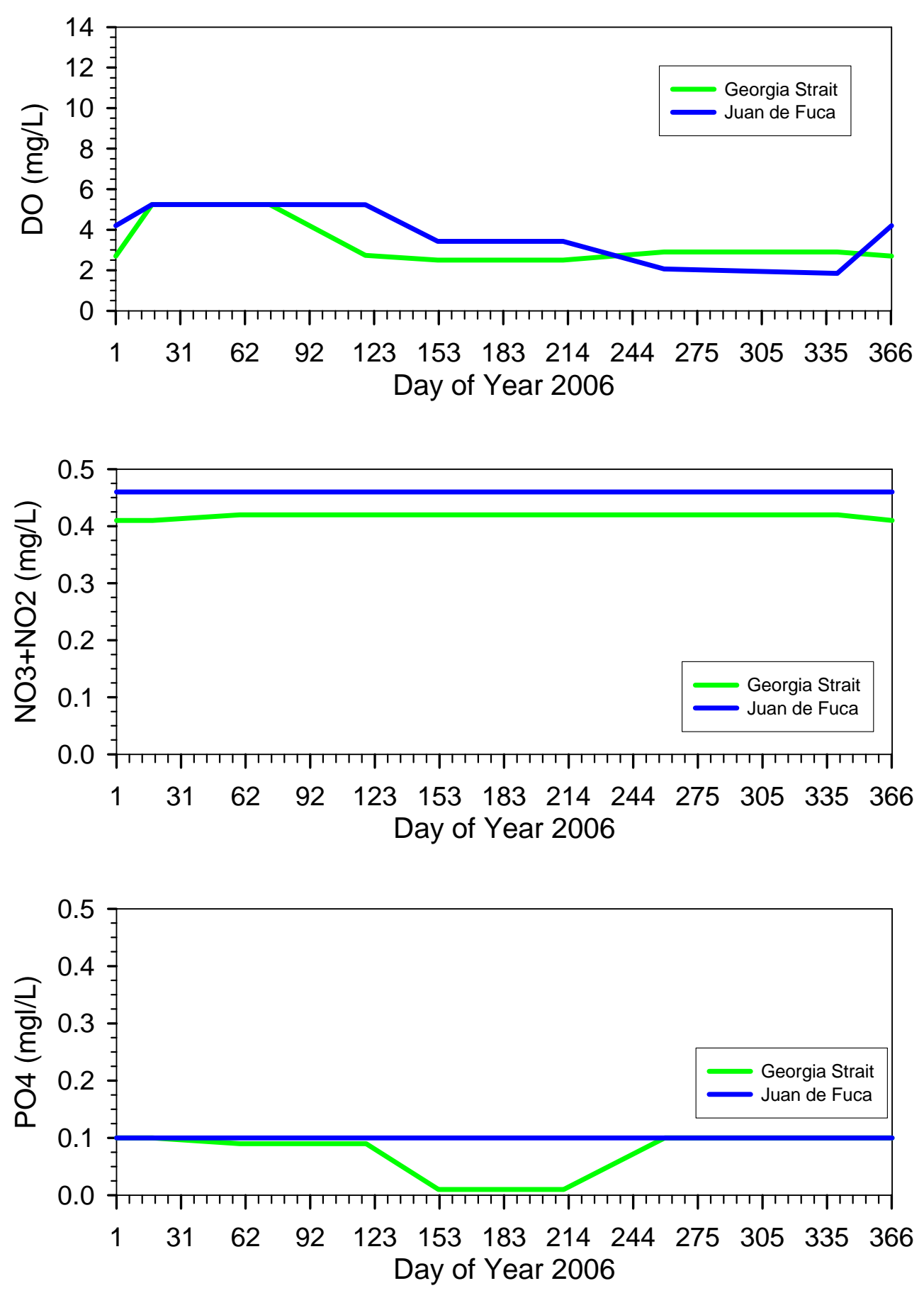

Figure 2.21. Composite Time History of Near-Bed Constituent Concentrations at the Strait of Juan de Fuca and Georgia Strait Boundaries from DFO and JEMs Data 2006 


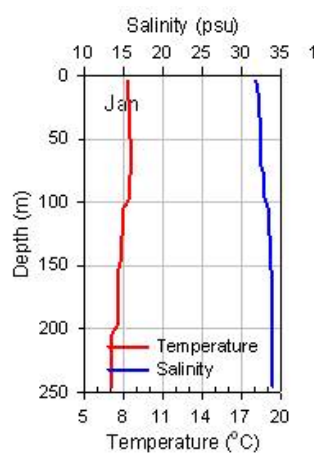

Salinity (psu)

Salinity (psu)

Salinity ( $\mathrm{psu}$ )

Salinity (psu)

Salinity (psu)
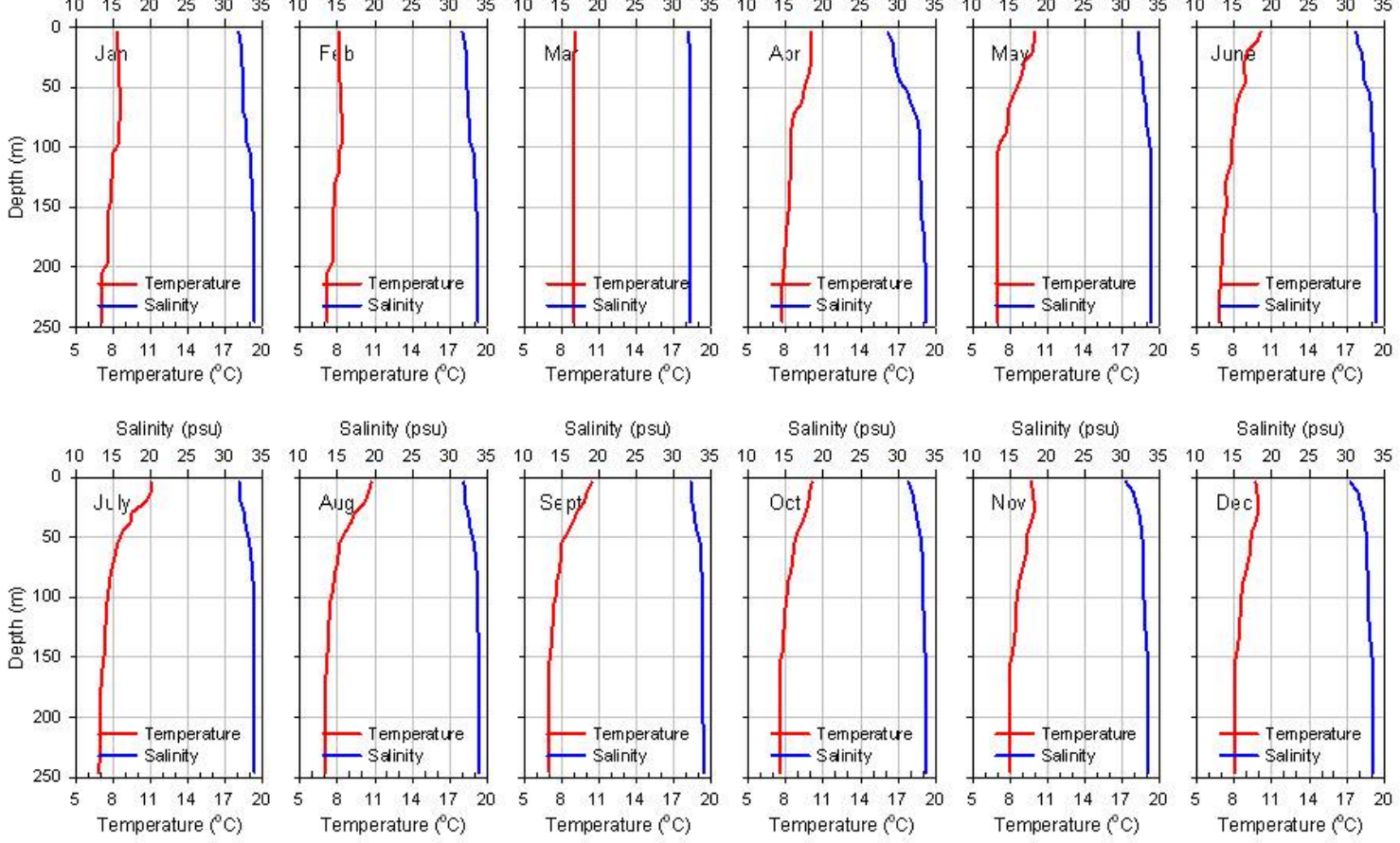

Salinity (psu)

Salinity ( $\mathrm{psu}$ )

Salinity (psu)

Salinity (psu)

Salinity (psu)
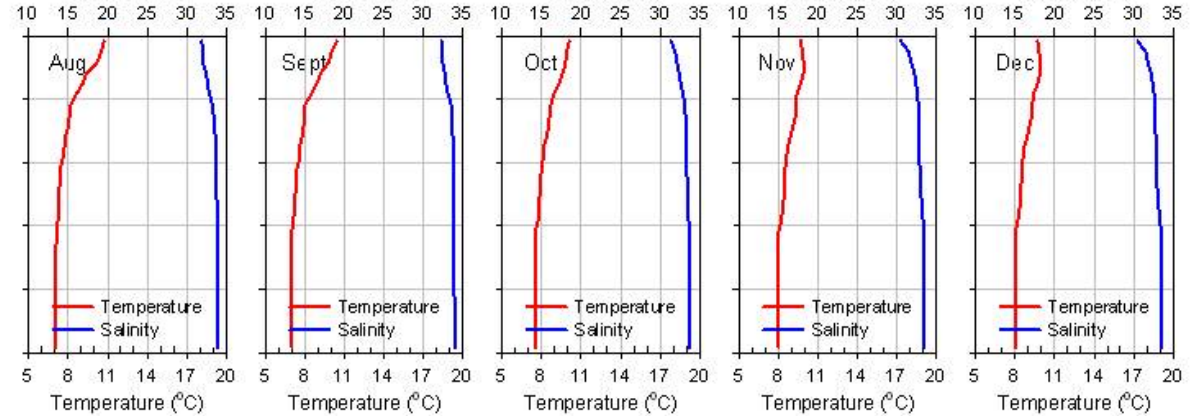

Source: Department of Fisheries and Oceans Canada (DFO) (http://www.pac.dfo-mpo.gc.ca/index-eng.htm )

Figure 2.22. Temperature and Salinity Profiles at Strait of Juan de Fuca Open Boundary Year 2006 


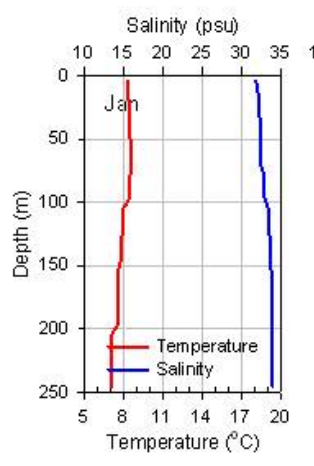

Salinity (psu)

Salinity (psu)

Salinity (psu)

Salinity (psu)

Salinity (psu)
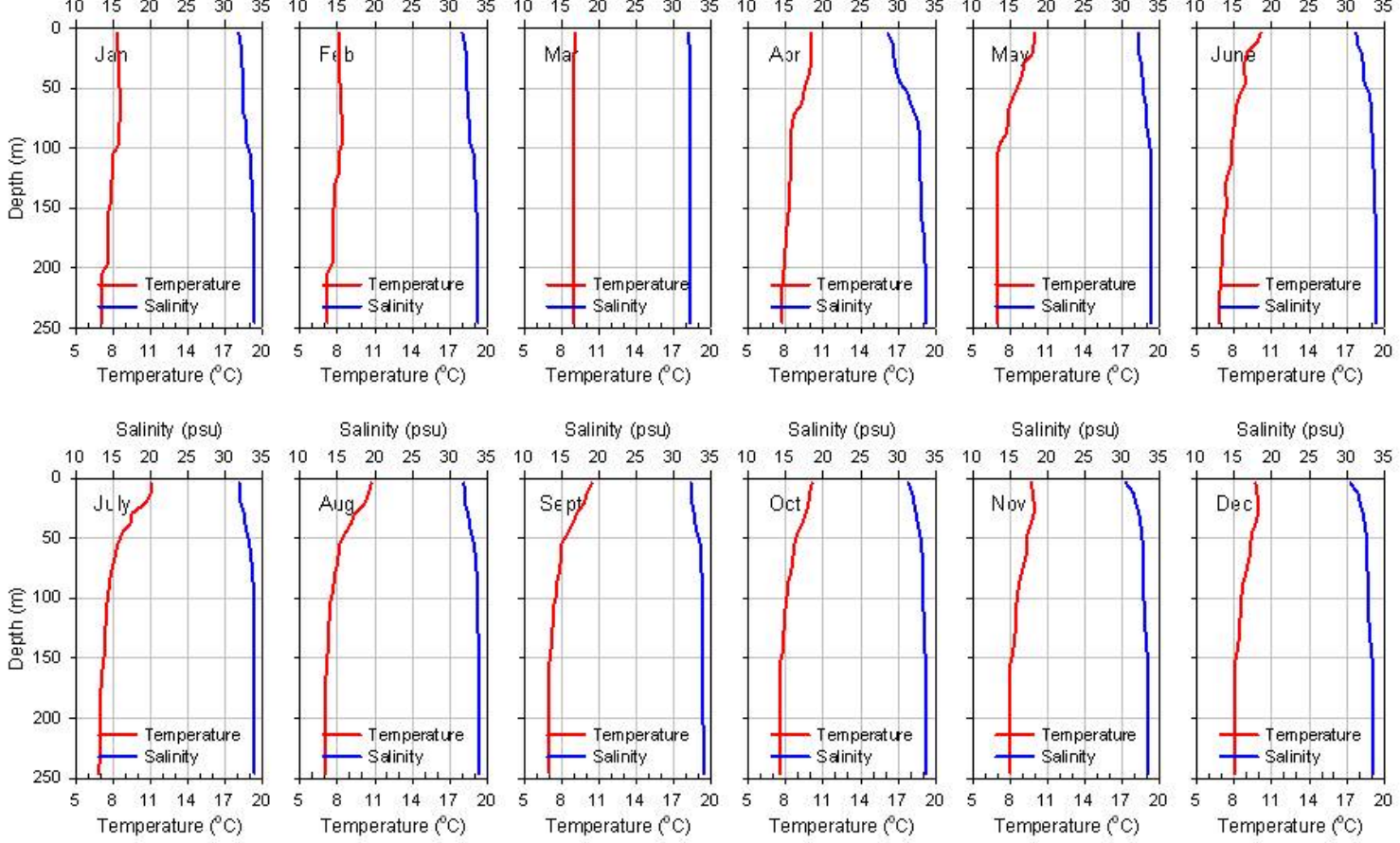

Salinity (psu)

Salinity ( $\mathrm{psu}$ )

Salinity (psu)

Salinity (psu)

Salinity (psu)
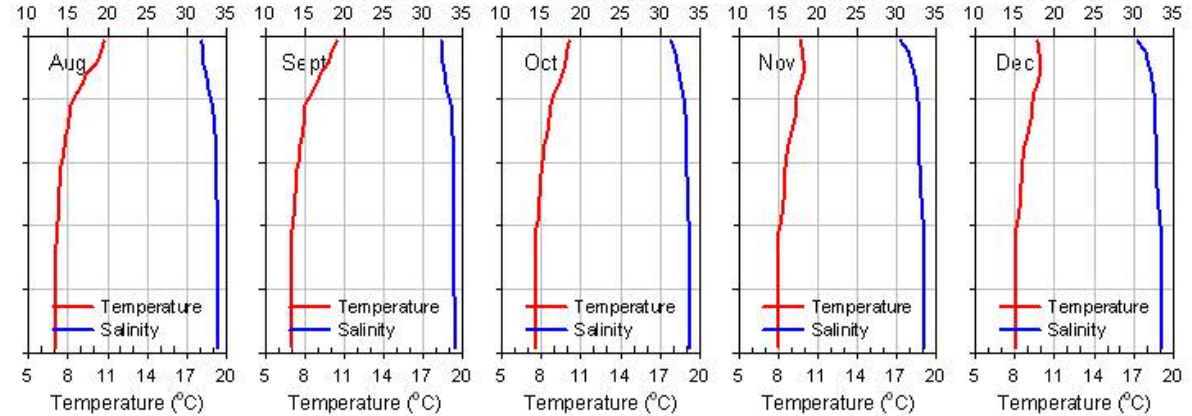

Source: Department of Fisheries and Oceans Canada (http://www.pac.dfo-mpo.gc.ca/index-eng.htm )

Figure 2.23. Temperature and Salinity Profiles at Georgia Strait Open Boundary Year 2006 


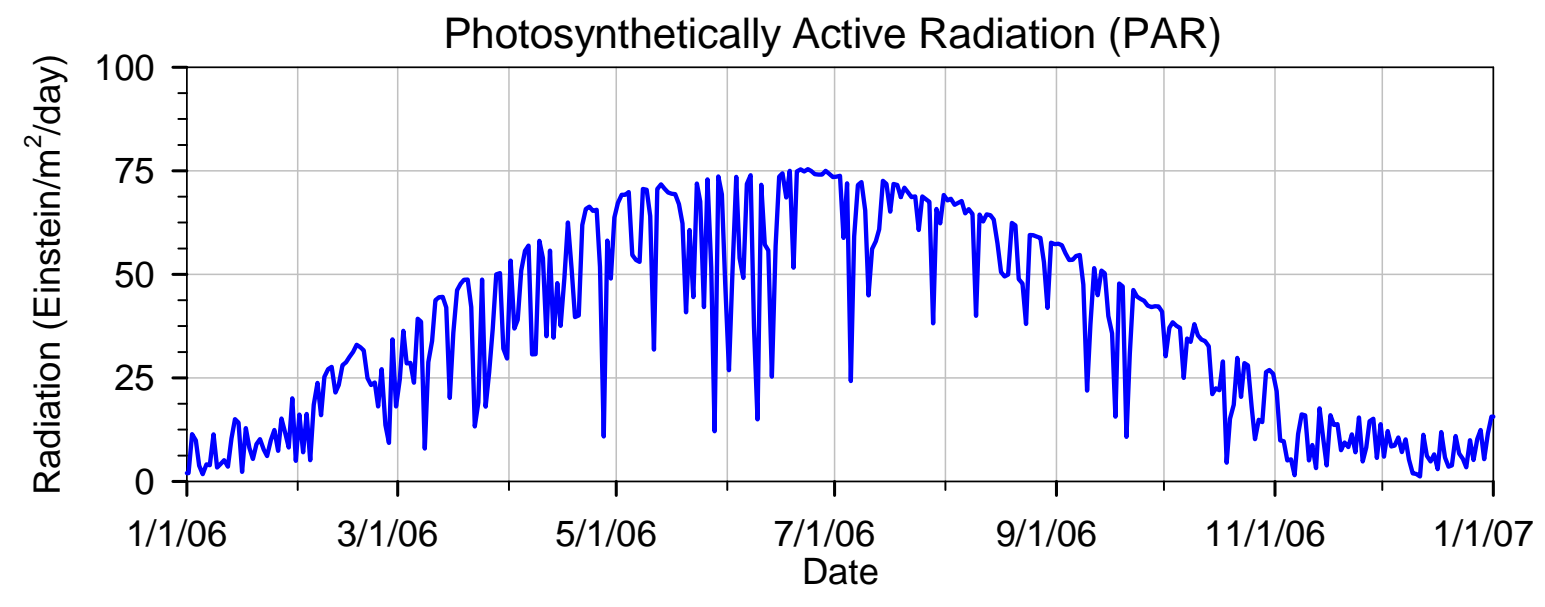

Figure 2.24. Daily Integrated Photosynthetically Active Radiation Calculated from WRF Shortwave Dataset near Seattle 


\subsection{Meteorology Data}

To simulate the effect of wind stress on reaeration/gas flux and calculate photosynthetically active radiation (PAR) distributions in Puget Sound, meteorological forcing is required. Specifically, the meteorological inputs for the Puget Sound Water Quality Model include 1) wind speed, 2) irradiance, and 3) day length. WRF data sets provided all meteorological inputs required in the Puget Sound Water Quality Model and were converted to model inputs at daily intervals (per the model configuration). The data were then subset over the day at the model time step, according to algorithms internal to the model, corrected for spectral quality over the day, and attenuated through the water column given the scatter and absorption properties of the water calculated by the model (Cerco and Cole 1995).

PAR (Figure 2.24) was calculated from shortwave heat flux using the assumptions of Kaduk and Heimann (1996), where it was approximated that half of the total downward shortwave radiation is PAR. To convert between energy $\left(\mathrm{W} / \mathrm{m}^{2}\right)$ and number of photons $\left(\mu \operatorname{Ein} / \mathrm{m}^{2} / \mathrm{s}\right)$, a conversion factor for the average energy for PAR wavelengths $(4.6 \mu \mathrm{Ein} / \mathrm{J})$ was applied, thus:

$$
\mathrm{PAR}=0.5 * \mathrm{SWdown} * 4.6
$$

Day length was similarly calculated directly from the WRF data. Hours with zero irradiance were subtracted from the rest of the day and remaining hours were summed. 



\subsection{Model Calibration}

Model calibration was conducted for the entire Year 2006, which was selected for this effort because it was identified as a recent data-rich period. Salinity, temperature, and water quality constituents are measured by Ecology as part of its ambient water monitoring program. Additional short-term focused studies were also under way in South Puget Sound (Roberts et al. 2008) and Hood Canal (Newton et al. 2007). In general, 2006 late-summer oxygen levels represented somewhat average conditions over the past 10 years (Krembs 2012).

Initially, the location used to guide the overall calibration effort was the Puget Sound Main Basin (PSB 003 station). Subsequently, calibration focused on Commencement Bay, the Hood Canal basin (inland from the sill), and Saratoga Passage, due to their strong fjordal circulation characteristics. South Puget Sound subbasins located farthest away from the boundary (south of the Tacoma Narrows sill) also show behavior distinct from that of the main basin. Markedly higher levels of biological activity, including nutrient consumption, algal growth, and DO production, were recorded in the shallow subbasins of Bellingham Bay, Sinclair Inlet, and Budd Inlet, which distinguished them from the rest of Puget Sound. Therefore, stations in these areas were selected for calibration to represent this variability within the Puget Sound subbasins and allow synoptic examination of the entire domain.

There are 25 monitoring stations regularly sampled at a monthly frequency throughout the Straits and Puget Sound. Of these, 15 were found to have complete, quality-controlled, and quality-assured datasets for 2006; 9 of these, representing key subbasins of Puget Sound (Table 3.1), were used for comparison and validation of nutrients, algal carbon (surface only, primarily) and dissolved oxygen. The observed data locations used in model calibration are presented in Table 3.1 and shown in Figure 3.1. Comparisons of model results and observed data for nutrients, dissolved oxygen, and algal carbon are discussed in the following three sections.

\subsection{Calibration Approach - Parameterization through Sensitivity Testing}

Initial model setup was conducted using literature values for the model parameters. A multitude of model runs were then conducted to identify the parameters which affected predicted nutrients, algal carbon, and DO concentrations most strongly. The parameters were then adjusted using best professional judgment until predicted results best reproduced observed DO, nutrients, and algal carbon data. Since the inception of the model calibration effort in fall 2009 (following completion of the model setup, and finalization of hydrodynamic model input), more than 500 model runs have been conducted to reach the level of calibration presented in this report.

Residual circulation (tidally averaged inflow of Pacific Ocean water and outflow of mixed water with Puget Sound freshwater discharges including flows from rivers and wastewater) has a strong influence on establishing tidally averaged background concentrations of various constituents of interest, especially at depths below the stratified layer varying in depth from $\approx 5-20 \mathrm{~m}$. Much of our current understanding of tidally averaged circulation in Puget Sound is based on analysis and interpretation of considerable data collected since the 1950s and insights gained from the application of a physical scale model of Puget Sound at the University of Washington (Rattray and Lincoln 1955). 
Table 3.1. Ecology Puget Sound Ambient Monitoring Stations

\begin{tabular}{|c|c|c|c|c|c|}
\hline Location & $\begin{array}{l}\text { Grid } \\
\text { Node }\end{array}$ & $\begin{array}{l}X \\
\mathrm{~m}\end{array}$ & $\begin{array}{l}\mathrm{Y} \\
\mathrm{m}\end{array}$ & Station Number & $\begin{array}{c}\text { Depth at Model } \\
\text { Node }(\mathrm{m})\end{array}$ \\
\hline Bellingham $^{(a)}$ & 1935 & 529565.2 & 5392707 & BLL009 & 52 \\
\hline Admiralty Inlet, Quimper Pt ${ }^{(a)}$ & 752 & 511765.6 & 5337153 & ADM002 & 57 \\
\hline Port Townsend & 1408 & 517628.3 & 5325586 & PTH005 & 40 \\
\hline Saratoga Passage $^{(a)}$ & 4451 & 537964 & 5328463 & SAR003 & 6 \\
\hline Admiralty Inlet South & 3075 & 538745.5 & 5303004 & ADM003 & 54 \\
\hline Hood Canal Send Creek, Bangor ${ }^{(a)}$ & 4741 & 513513.4 & 5279306 & HCB010 & 102 \\
\hline Sinclair Inlet ${ }^{(a)}$ & 5962 & 526959.2 & 5266349 & SIN001 & 6.00 \\
\hline PS Main Basin ${ }^{(a)}$ & 4581 & 541919.5 & 5278663 & PSB003 & 50 \\
\hline Elliott Bay & 5333 & 547488 & 5271670 & ELB015 & 9 \\
\hline East Passage & 6112 & 546768.1 & 5251659 & EAP001 & 48 \\
\hline Hood Canal Great Bend & 6950 & 498240.4 & 5244805 & HCB004 & 45 \\
\hline Commencement Bay $^{(a)}$ & 6601 & 541715.8 & 5237539 & CMB003 & 6 \\
\hline Gordon Point $^{(a)}$ & 7315 & 527783.1 & 5225599 & GOR001 & 40 \\
\hline Dana Passage & 8200 & 509853.5 & 5223142 & DNA001 & 30 \\
\hline Budd Inlet $^{(a)}$ & 8491 & 506322.1 & 5215358 & BUD005 & 6 \\
\hline
\end{tabular}

(a) A subset of 9 diverse stations is presented. $\mathrm{X}$ and $\mathrm{Y}$ coordinates of the nearest model node in meters are in Universal Transverse Mercator (UTM) North American Datum 83 (NAD83) (Zone 10).

Historical records of moored current meter and salinity profile observations are extensive and date back to 1930. Cox et al. (1981) tabulated known current observations, including periods of intensive monitoring from 1951 to 1956 and in the 1970s and 1980s. Ebbesmeyer et al. (1984) and Cox et al. (1984) provided a synthesis of these current measurements in Puget Sound and interpretation. Using this information, Ebbesmeyer and Barnes (1980) developed a conceptual model of Puget Sound which describes circulation in the main basin of Puget Sound as that in a fjord with deep sills (landward sill zones at Tacoma Narrows and northern Hood Canal and a seaward sill zone at Admiralty inlet) separating large basins, outflow through the surface layers, and inflow at depth. The hydrodynamic model developed as part of this effort (Yang et al. 2010; Khangaonkar et al. 2011) was shown to generate the tidally averaged circulation pattern as described in the literature above, and matched the composite dataset from previously analyzed historical records.

In well mixed estuaries, flushing time (defined as the ratio of basin volume to net inflow) offers a first order comparison to time scales of biogeochemical processes. However in highly stratified estuaries with interconnected basins such as Puget Sound, residence time calculated using a tracer or Lagrangian particles provides a more accurate measure. 


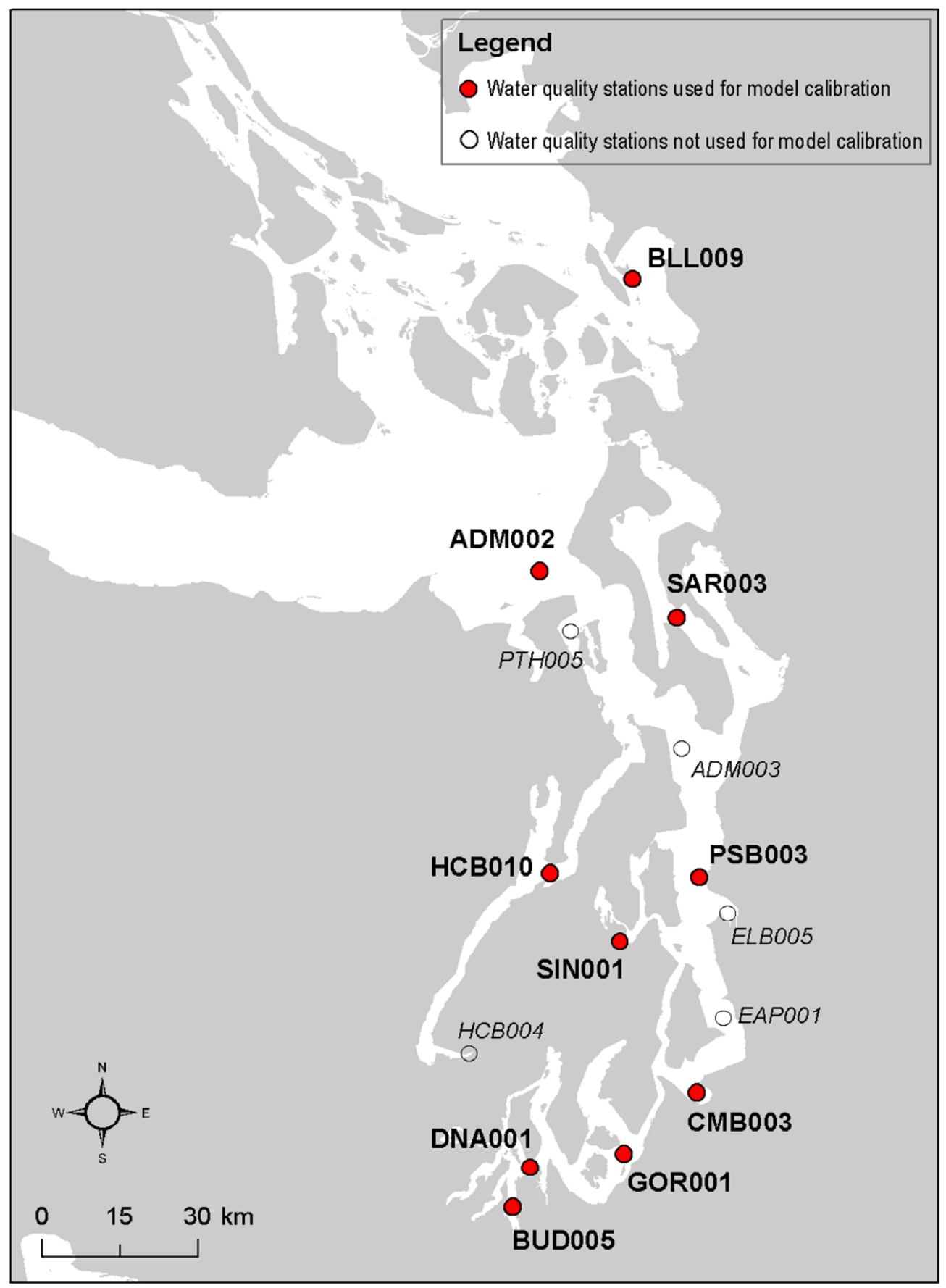

Figure 3.1. Observed Data Station Locations Used for Water Quality Calibration 
Average Salinity - Transect over Admiralty Inlet

Time Averaged Salinity - Transect SJF-PSB-SS

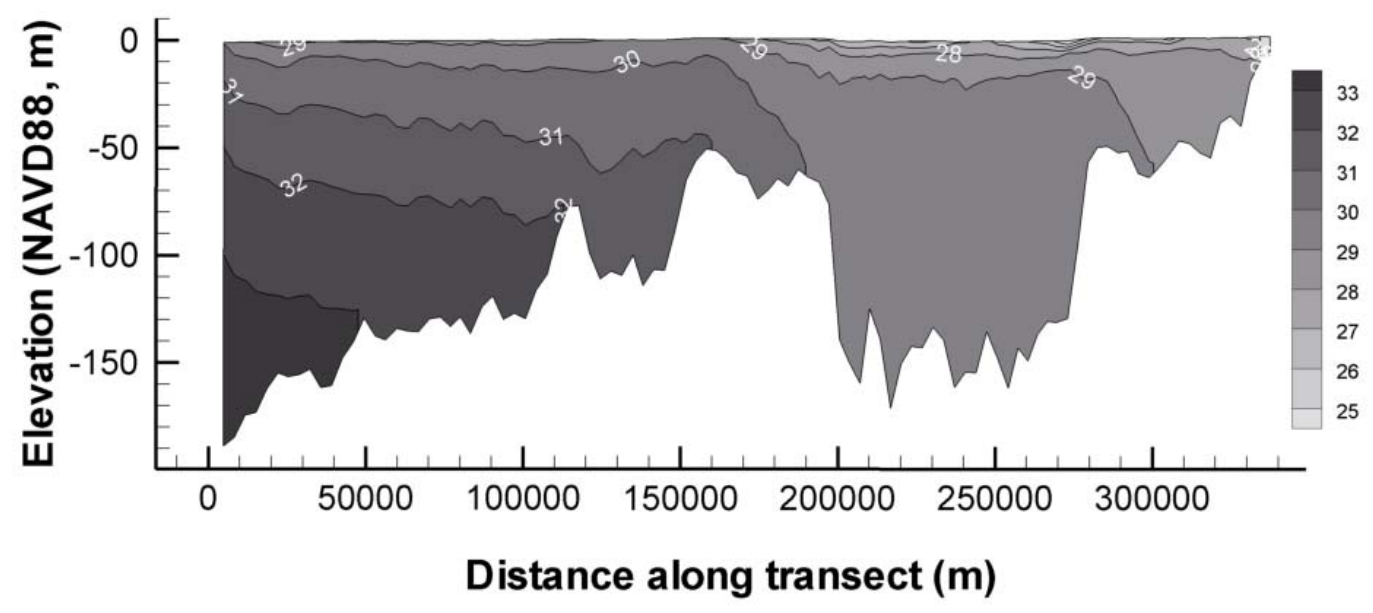

Average Velocity - Transect over Admiralty Inlet

Time Averaged Along Transect Velocity - Transect SJF-PSB-SS

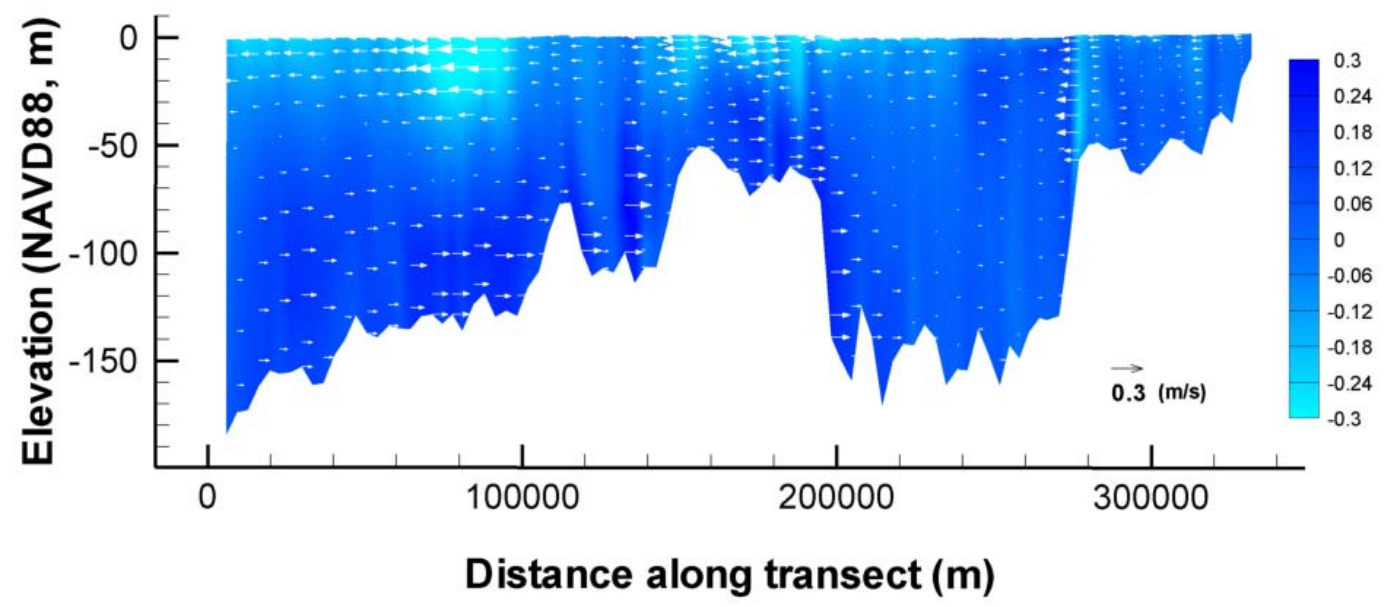

Note: The above contour plots of salinity and velocity vectors represent a 365-day average of Year 2006 model results.

Figure 3.2. Salinity and Velocity in a Transect over Admiralty Inlet to Puget Sound Year 2006 Model Average 
Figure 3.2 shows salinity contour and velocity vector profile plots representing the 365 -day average for 2006. Computed tidally averaged inflows to various basins are listed in Table 3-2. Also shown in Table 3-2 are computed "e-folding" residence times for each basin, defined as the time taken for the initial concentration in the individual basins ( 1 unit) to dilute to $1 / \mathrm{e}$ level $(37 \%$ of the original concentration) over the water column. For this analysis, the constituent was introduced into the domain after a spin-up period of 1 year and allowed to flush out. For the year 2006, the computed tidally averaged inflow rate of $17 \times 10^{3} \mathrm{~m} 3 / \mathrm{s}$ (through Admiralty Inlet to Puget Sound) is within the range of $10-20 \times 10^{3} \mathrm{~m}^{3} / \mathrm{s}$ reported in literature (Cokelet et al. 1990; Babson et al. 2006; Sutherland et al. 2011). The results show that inner basins such as Hood Canal and South Puget Sound, sheltered behind their individual sills, have the longest residence times.

Table 3.2. Mean annual inflows to Salish Sea and Puget Sound subbasins along with residence times estimated for selected locations from analysis of the year 2006 model simulation

\begin{tabular}{cccc}
\hline Subbasin and reach & $\begin{array}{c}\text { Mean annual tidal inflow } \\
\left(\mathrm{m}^{3} / \mathrm{s}\right)\end{array}$ & Station name & $\begin{array}{c}\text { Residence time } \\
\text { (days) }\end{array}$ \\
\hline $\begin{array}{c}\text { Strait of Juan de Fuca } \\
\text { Admiralty Inlet } \\
\text { to Puget Sound }\end{array}$ & 129,300 & Pillar Point & 61 \\
Main Basin - Puget Sound & 16,931 & Admiralty Inlet & 160 \\
$\begin{array}{c}\text { Whidbey Basin } \\
\text { (inflow through Possession } \\
\text { Sound) }\end{array}$ & 12,342 & Jefferson Point & 257 \\
$\begin{array}{c}\text { Hood Canal } \\
\text { (inflow over the sill) }\end{array}$ & 6,098 & Saratoga Passage & 228 \\
$\begin{array}{c}\text { South Puget Sound } \\
\text { (inflow over Tacoma } \\
\text { Narrows sill) }\end{array}$ & 4,589 & Eldon Point & 282 \\
\hline
\end{tabular}

The offline linked water quality model developed here uses the above previously generated Puget Sound hydrodynamic information from 2006 for conducting the constituent transport and kinetics. The model therefore shows a response consistent with the residual circulation characteristics of Puget Sound consisting of inflow of Pacific Ocean waters at depth over the Admiralty Inlet sill, and outflow in the surface layers mixed with the freshwater discharges to the basin.

As described in Section 2.5, initially attempts were made to use available nutrients and DO profiles directly from the stations nearest to Strait of Juan de Fuca and Georgia Strait model boundaries. The composite DFO and JEMS boundary conditions based on both datasets were found to provide nutrients and DO conditions in Puget Sound with reasonable accuracy, especially in the deeper layers. The surface layers of Puget Sound, on the other hand, are affected by various freshwater and wastewater discharges and dominant biogeochemical reactions, including algal production and decay, the impact of other organic matter on dissolved oxygen, and nutrient kinetics. 
After selecting and setting up appropriate boundary conditions, we conducted model parameter sensitivity tests with a particular focus on DO, algal carbon, and nutrients response to change in rates, constants, and boundary conditions. The model results were most sensitive to maximum photosynthetic rate for algae $\left(\mathrm{P}_{\max }\right)$, carbon to chlorophyll ratios, grazing loss rate, reaeration parameterizations, and settling rates, and half saturation coefficients for nitrogen and phosphorous uptake. In addition to parameter testing, different model configurations were also tested, including a configuration where nitrogen was presumed the limiting nutrient for simplicity, and where nitrogen and phosphorus were both considered as potentially limiting nutrients. In this calibration effort, algal nutrient ratios have been kept static at the Redfield ratios (106:16:1 for $\mathrm{C}: \mathrm{N}: \mathrm{P})$, but note that ratios can vary, depending upon the ecological niche of the phytoplankton taxon of interest (see, e.g., Klausmeier et al. 2004).

The calibration is limited to some degree by a paucity of primary production and other rate and kinetic data for Puget Sound. Of the few data reported, ranges for primary production vary from 265 and $465 \mathrm{~g} \mathrm{C} \mathrm{m}^{-2} \mathrm{y}^{-1}$ (Winter et al. 1975; South Sound and main basin of Puget Sound, respectively) to 694-1241 $\mathrm{g} \mathrm{C} \mathrm{m}^{-2} \mathrm{y}^{-1}$ in South Puget Sound (Ruef et al. 2003). Puget Sound $\mathrm{P}_{\max }$ rates were reported in Winter et al. (1975) to range from $96-120 \mathrm{mg} \mathrm{C} \mathrm{mg} \mathrm{Chl}^{-1} \mathrm{~d}^{-1}$. Some work has been done to quantify the phytoplankton contributors to the carbon pool, with diatom bloom during the late winter to early spring period and summer bloom by other species (Connell and Jacobs 1998; Horner et al. 2005; Rensel 2007). Integrated chlorophyll $a$ over the water column has ranged over the past 40 years of sampling between $10-400 \mathrm{mg} \mathrm{Chl} \mathrm{m}^{-2}$; typically spring integrated chlorophyll $a$ is $\sim 250 \mathrm{mg} \mathrm{m}^{-2}$ (Horner et al. 2005). $\mathrm{P}_{\max }$ rates varying from 200-350 $\mathrm{g} \mathrm{C} \mathrm{g}^{-1} \mathrm{Chl} \mathrm{d}^{-1}$ were used in this model study and are discussed further in section 3.3 .

Grazing rates for copepods typically range from 0.2 to $0.4 \mathrm{~d}^{-1}$ (e.g., McAllister 1970). Grazing rates of microzooplankton varying from $0-1.48 \mathrm{~d}^{-1}$ in fall and winter and 0.32 to $2.1 \mathrm{~d}^{-1}$ have been observed in north Puget Sound (Strom et al. 2001). Zooplankton were not explicitly simulated but the effect of grazing has been included using a base predation rate of $.01 \mathrm{~d}^{-1}$ for diatoms and $0.5 \mathrm{~d}^{-1}$ for dinoflagellates derived as part of model calibration in combination with a basal metabolism rate parameter of $0.1 \mathrm{~d}^{-1}$ for both species to limit the algae growth.

For nutrient uptake, general ranges surrounding the estuarine half saturation constants were tested during the calibration, with the best fit at the upper end of the half-saturation constant range for $\mathrm{N}$ and $\mathrm{P}$. The half-saturation constants based on data from 17 species of marine phytoplankton have been reported in the range from 0.001 to $0.144 \mathrm{~g} \mathrm{~N} \mathrm{~m}^{-3}$ (Eppley et al. 1969; Herndon and Cochlan 2007). However, there are numerous additional phytoplankton species in Puget Sound, such that half-saturation constants for nitrogen can be much higher, with maxima of $4.34 \mathrm{~g} \mathrm{~N} \mathrm{~m}^{-3}$ (Bowie et al. 1985). Phosphorus half-saturation constants for dinoflagellates range from 0.0003 to $0.195 \mathrm{~g} \mathrm{P} \mathrm{m}^{-3}$ and for diatoms range from 0.001 to 0.163 $\mathrm{g} \mathrm{P} \mathrm{m}^{-3}$ (Bowie et al. 1985). Final values of half saturation constants derived as part of model calibration was $0.06 \mathrm{~g} \mathrm{~N} \mathrm{~m}^{-3}$ and $0.02 \mathrm{~g} \mathrm{P} \mathrm{m}^{-3}$ respectively.

The parameters known to influence algal growth and oxygen depletion in the water column may actually vary considerably in different parts of Puget Sound. In this model we simulate a static carbon to chlorophyll $a$ ratio $(\mathrm{C}: \mathrm{Chl})$ with a base ratio of 37 for diatoms and 50 for dinoflagellates. In reality, this value varies with nutrient and light availability in the water column, and phytoplankton can respond by changing their light harvesting structures on the order of hours (see e.g., Kirk, 1994; Steinbuck et al. 2010). Typical ranges recorded in Dabob Bay, Puget Sound, were 25-65 (Horner et al. 2005). 
One of the key parameters of algal growth is the optimum temperature at which algal growth rate is highest assuming appropriate light and nutrients are available. The values of optimum temperatures may vary depending on the location based on site specific conditions and acclimatization. For example, optimum temperature may range from 20 to $35^{\circ} \mathrm{C}$ in tropical waters (Bowie et al. 1985). But optimum temperatures may be much lower in higher latitudes where waters are naturally cooler. For example, the water temperature in Puget Sound is usually less than $20^{\circ} \mathrm{C}$ and some of the phytoplankton species (like Heterosigma carterae) proliferate when the water temperature becomes 16 to $18^{\circ} \mathrm{C}$. Similarly the spring bloom of diatoms is known to occur during March-April period when water temperatures are $10-12^{\circ} \mathrm{C}$. The optimum temperature parameter was evaluated during the calibration to adjust the timing of the spring and summer algae bloom onset and separation of peaks.

Table 3.2 provides a listing of all model parameters used in the calibration along with rages of values found in literature (Bowie et al. 1985; Cerco and Cole 1994; Bunch et al. 2000; Cerco et al. 2000; Tillman et al. 2004).

This report presents model setup and calibration optimized over the entire Puget Sound domain using a 3-D hydrodynamic and biogeochemical model. The goal was to develop a model capable of reasonably simulating broad features and properties of Puget Sound over a 1-year cycle such that it may be used to conduct sensitivity analysis and planning level scenario tests. To accomplish this goal, many complex biological processes have been simplified and the model may not represent individual embayments as well as the overall domain. See Section 4 for recommended improvements to model kinetics and calibration to consider in subsequent efforts.

\subsection{Model Calibration - Profiles of Dissolved Oxygen and Nutrients}

\subsubsection{Dissolved Oxygen Profiles}

Dissolved oxygen profiles simulated by the model were compared with measured profiles at the representative stations listed in Table 3.1 around Puget Sound. An example of the comparison is shown in Figure 3.3 for September of 2006, representative of low-river flow summer conditions. Measured data and model results show that the DO concentrations in the lower water column below approximately $40 \mathrm{~m}$ depth in most basins are well mixed and uniform, and vary between 4 and $6 \mathrm{mg} / \mathrm{L}$. In shallower embayments, such as Bellingham Bay, Budd Inlet, and Sinclair Inlet, data show DO in surface waters sometimes reaching supersaturated levels as high as $12 \mathrm{mg} / \mathrm{L}$ indicative of high levels of primary productivity, with very strong near-surface gradients.

Comparison with monthly profile data collected at each station with predicted DO profiles over the entire Year 2006 are presented in Appendix B. At most stations used in this calibration, measured data show that the winter DO profiles (at the start of model simulation) were relatively high in DO at approximately 6-8 $\mathrm{mg} / \mathrm{L}$ at depth and 8-10 $\mathrm{mg} / \mathrm{L}$ near the surface, with the exception of Hood Canal where DO levels near the bottom were around $5 \mathrm{mg} / \mathrm{L}$ in February 2006. The DO levels declined progressively with time as incoming water with lower DO levels from Admiralty Inlet mixed with surface outflow prior to entering Puget Sound over Admiralty Inlet. By September of 2006, DO concentrations at depth ranged between 4 to $6 \mathrm{mg} / \mathrm{L}$ at most stations. This observed DO variation mostly controlled by advection of water from the Strait of Juan de Fuca into Puget Sound was reproduced by the model. A closer examination of model results in the inner shallow reaches of the model domain and sensitivity tests 
show that further depletion of DO can occur near the bed with increased in sediment oxygen demand and respiration rates. The effect of primary productivity in the surface layer $(0-20 \mathrm{~m})$ is seen in all stations, especially in September where DO levels of $8 \mathrm{mg} / \mathrm{L}$ are common and nearly twice as high as bottom DO.

The available monthly profiles at Budd Inlet and Sinclair Inlet (Figures B.4 and B.8) show that simulated surface dissolved oxygen during the summer bloom period is much lower in the simulation than in the data; this indicates that the simulated bloom was not strong enough in these subbasins, was not sustained for sufficient duration, or over-mixing near the surface could not resolve surface productivity and strong gradients. Further site specific adjustment of growth-related parameters along with improvement in mixing, layering, residence time, or flushing characteristics may be needed for improving model performance in these subbasins. It is also noted that Budd Inlet and Sinclair Inlet are shallow basins with strong sediment influences, warm water temperatures, and multiple storm and wastewater discharges, all of which can contribute to higher primary productivity. 
Table 3.3. Listing of Key Model Parameters

\begin{tabular}{|c|c|c|c|c|}
\hline Symbol & Value & Unit & $\begin{array}{l}\text { Literature } \\
\text { Range }\end{array}$ & Definition \\
\hline $\mathrm{G}_{\mathrm{dia}}$ & calculated & $\mathrm{d}^{-1}$ & - & growth rate of diatom \\
\hline $\mathrm{G}_{\text {fla }}$ & calculated & $\mathrm{d}^{-1}$ & - & growth rate of dinoflagellates \\
\hline$P_{\mathrm{m} \text { dia }}$ & $200-350^{\mathrm{a}}$ & $\mathrm{g} \mathrm{C} \mathrm{g}^{-1} \mathrm{Chl} \mathrm{d}^{-1}$ & $200-350$ & maximum photosynthetic rate of diatom \\
\hline $\mathrm{P}_{\mathrm{m} \text { dino }}$ & $250-350^{\mathrm{a}}$ & $\mathrm{g} \mathrm{C} \mathrm{g}^{-1} \mathrm{Chl} \mathrm{d}^{-1}$ & $200-350$ & maximum photosynthetic rate of dinoflagellates \\
\hline $\mathrm{T}_{\text {opt dia }}$ & 12 & ${ }^{\circ} \mathrm{C}$ & up to 35 & optimal temperature for growth of diatom \\
\hline $\mathrm{T}_{\text {opt dino }}$ & 18 & ${ }^{\circ} \mathrm{C}$ & up to 35 & optimal temperature for growth of dinoflagellates \\
\hline $\mathrm{BM}_{\mathrm{dia}}$ & 0.1 & $d^{-1}$ & $0.01-0.1$ & basal metabolic rate of diatom \\
\hline $\mathrm{BM}_{\text {dino }}$ & 0.1 & $\mathrm{~d}^{-1}$ & $0.01-0.1$ & basal metabolic rate of dinoflagellates \\
\hline $\mathrm{W}_{\mathrm{a} \text { dia }}$ & 0.4 & $\mathrm{~m} \mathrm{~d}^{-1}$ & $0-30$ & settling velocity of diatom \\
\hline $\mathrm{W}_{\mathrm{a} \operatorname{dino}}$ & 0.2 & $\mathrm{~m} \mathrm{~d}^{-1}$ & $0-30$ & settling velocity of dinoflagellates \\
\hline $\mathrm{BPR}_{\mathrm{dia}}$ & 1.0 & $\mathrm{~d}^{-1}$ & $0.05-1.0$ & base predation rate of diatom \\
\hline $\mathrm{BPR}_{\text {dino }}$ & 0.5 & $\mathrm{~d}^{-1}$ & $0.05-1.0$ & base predation rate of dinoflagellates \\
\hline $\mathrm{CChl}_{\text {dia }}$ & 37 & $\mathrm{~g} \mathrm{C} \mathrm{g}^{-1} \mathrm{Chl}$ & $30-143$ & carbon-to-chlorophyll ratio for diatoms \\
\hline $\mathrm{CChl}_{\text {dino }}$ & 50 & $\mathrm{~g} \mathrm{C} \mathrm{g}^{-1} \mathrm{Chl}$ & $30-143$ & carbon-to-chlorophyll ratio for dinoflagellates \\
\hline $\mathrm{PN}_{\mathrm{dia}}$ & calculated & $0 \leq \mathrm{PN} \leq 1$ & $0-1$ & preference for ammonium uptake of diatom \\
\hline $\mathrm{PN}_{\text {dino }}$ & calculated & $0 \leq \mathrm{PN} \leq 1$ & $0-1$ & preference for ammonium uptake of dinoflagellates \\
\hline $\mathrm{NT}_{\mathrm{m}}$ & 0.4 & $\mathrm{~g} \mathrm{~N} \mathrm{~m} \mathrm{~d}^{-3}$ & $0.01-0.7$ & maximum nitrification rate \\
\hline $\mathrm{T}_{\mathrm{mnt}}$ & 30 & ${ }^{\circ} \mathrm{C}$ & $25-35$ & optimal temperature for nitrification \\
\hline Denit & calculated & $d^{-1}$ & 0.0 & denitrification rate \\
\hline Kldc & 0.025 & $d^{-1}$ & $0.005-0.25$ & minimum respiration rate of $\mathrm{LDOC}$ \\
\hline Krdc & 0.0015 & $\mathrm{~d}^{-1}$ & - & minimum respiration rate of $\mathrm{RDOC}$ \\
\hline Klpc & 0.05 & $\mathrm{~d}^{-1}$ & $0.005-1.5$ & dissolution rate of LPOC \\
\hline Krpc & 0.0015 & $\mathrm{~d}^{-1}$ & $0.001-0.005$ & dissolution rate of RPOC \\
\hline $\mathrm{KH}_{\text {odoc }}$ & 0.5 & $\mathrm{~g} \mathrm{O}_{2} \mathrm{~m}^{-3}$ & 0.5 & $\begin{array}{l}\text { half-saturation concentration of dissolved oxygen } \\
\text { required for oxic respiration }\end{array}$ \\
\hline $\mathrm{KHn}_{\text {dia }}$ & 0.06 & $\mathrm{~g} \mathrm{~N} \mathrm{~m}^{-3}$ & $0.003-0.923$ & $\begin{array}{l}\text { half-saturation concentration for nitrogen uptake by } \\
\text { diatoms }\end{array}$ \\
\hline $\mathrm{KHn}_{-}$dino & 0.06 & $\mathrm{~g} \mathrm{~N} \mathrm{~m}^{-3}$ & $0.005-0.589$ & $\begin{array}{l}\text { half-saturation concentration for nitrogen uptake by } \\
\text { dinoflagellates }\end{array}$ \\
\hline $\mathrm{KHp}_{\text {dia }}$ & 0.02 & $\mathrm{~g} \mathrm{P} \mathrm{m}^{-3}$ & $0.001-0.163$ & $\begin{array}{l}\text { half-saturation concentration for phosphorus uptake by } \\
\text { diatoms }\end{array}$ \\
\hline $\mathrm{KHp}_{\text {dino }}$ & 0.02 & $\mathrm{~g} \mathrm{P} \mathrm{m}^{-3}$ & $0.0003-0.195$ & $\begin{array}{l}\text { half-saturation concentration for phosphorus uptake by } \\
\text { dinoflagellates }\end{array}$ \\
\hline $\mathrm{K}_{\mathrm{r}}$ & calculated & & - & reaeration coefficient \\
\hline $\mathrm{FT}_{\mathrm{SOD}}$ & $0.1-2.0^{\mathrm{b}}$ & $\mathrm{g} \mathrm{m}^{-2} \mathrm{~d}^{-1}$ & - & SOD coefficient \\
\hline Presp_dia & 0.25 & $0 \leq$ Presp $\leq 1$ & $0-1$ & photo-respiration fraction of diatom \\
\hline Presp_dino & 0.25 & $0 \leq$ Presp $\leq 1$ & $0-1$ & photo-respiration fraction of dinoflagellates \\
\hline FCLDP & 0.1 & $0 \leq \mathrm{FCLDP} \leq 1$ & $0-1$ & fraction of algal predation released as LDOC \\
\hline
\end{tabular}


Table 3.3. (cont.)

\begin{tabular}{|c|c|c|c|c|}
\hline Symbol & Value & Unit & $\begin{array}{c}\text { Literature } \\
\text { Range }\end{array}$ & Definition \\
\hline FCRDP & 0.2 & $0 \leq \mathrm{FCRDP} \leq 1$ & $0-1$ & fraction of algal predation released as RDOC \\
\hline FCLP & 0.5 & $0 \leq \mathrm{FCLP} \leq 1$ & $0-1$ & fraction of algal predation released as LPOC \\
\hline FCRP & 0.2 & $0 \leq \mathrm{FCRP} \leq 1$ & $0-1$ & fraction of algal predation released as RPOC \\
\hline $\mathrm{W}_{1}$ & 0.25 & $\mathrm{~m} \mathrm{~d}^{-1}$ & $0.03-0.8$ & settling velocity of labile particles \\
\hline $\mathrm{W}_{\mathrm{r}}$ & 0.25 & $\mathrm{~m} \mathrm{~d}^{-1}$ & $0.03-0.8$ & settling velocity of refractory particles \\
\hline FNI & 0.55 & $0 \leq \mathrm{FNI} \leq 1$ & $0-1$ & fraction of algal metabolism released as $\mathrm{NH}_{4}$ \\
\hline FNL & 0.2 & $0 \leq \mathrm{FNL} \leq 1$ & $0-1$ & fraction of algal metabolism released as LPON \\
\hline FNR & 0.05 & $0 \leq \mathrm{FNR} \leq 1$ & $0-1$ & fraction of algal metabolism released as RPON \\
\hline FNLD & 0.18 & $0 \leq \mathrm{FND} \leq 1$ & $0-1$ & fraction of algal metabolism released as LDON \\
\hline FNRD & 0.02 & $0 \leq \mathrm{FND} \leq 1$ & $0-1$ & fraction of algal metabolism released as RDON \\
\hline FNIP & 0.4 & $0 \leq \mathrm{FNIP} \leq 1$ & $0-1$ & fraction of algal predation released as $\mathrm{NH}_{4}$ \\
\hline FNLP & 0.3 & $0 \leq \mathrm{FNLP} \leq 1$ & $0-1$ & fraction of algal predation released as LPON \\
\hline FNRP & 0.1 & $0 \leq \mathrm{FNRP} \leq 1$ & $0-1$ & fraction of algal predation released as RPON \\
\hline FNLDP & 0.18 & $0 \leq \mathrm{FNLDP} \leq 1$ & $0-1$ & fraction of algal predation released as LDON \\
\hline FNRDP & 0.02 & $0 \leq \mathrm{FNRDP} \leq 1$ & $0-1$ & fraction of algal predation released as RDON \\
\hline Klpn & 0.075 & $\mathrm{~d}^{-1}$ & $0.03-0.08$ & minimum hydrolysis rate of LPON \\
\hline Krpn & 0.0025 & $d^{-1}$ & $0.001-0.005$ & minimum hydrolysis rate of RPON \\
\hline Kldn & 0.050 & $d^{-1}$ & $0.02-2.0$ & minimum mineralization rate of LDON \\
\hline Krdn & 0.0025 & $d^{-1}$ & - & minimum mineralization rate of $\mathrm{RDON}$ \\
\hline FPI & 0.75 & $0 \leq \mathrm{FPI} \leq 1$ & $0-1$ & fraction of algal metabolism released as $\mathrm{PO}_{4}$ \\
\hline FPL & 0.0 & $0 \leq \mathrm{FPL} \leq 1$ & $0-1$ & fraction of algal metabolism released as LPOP \\
\hline FPR & 0.0 & $0 \leq \mathrm{FPR} \leq 1$ & $0-1$ & fraction of algal metabolism released as RPOP \\
\hline FPLD & 0.2 & $0 \leq \mathrm{FPLD} \leq 1$ & $0-1$ & fraction of algal metabolism released as LDOP \\
\hline FPRD & 0.05 & $0 \leq \mathrm{FPRD} \leq 1$ & $0-1$ & fraction of algal metabolism released as RDOP \\
\hline FPIP & 0.5 & $0 \leq \mathrm{FPIP} \leq 1$ & $0-1$ & fraction of algal predation released as $\mathrm{PO}_{4}$ \\
\hline FPLP & 0.07 & $0 \leq \mathrm{FPD} \leq 1$ & $0-1$ & fraction of algal predation released as LDOP \\
\hline FPRP & 0.03 & $0 \leq \mathrm{FPD} \leq 1$ & $0-1$ & fraction of algal predation released as RDOP \\
\hline FPLDP & 0.36 & $0 \leq \mathrm{FPLP} \leq 1$ & $0-1$ & fraction of algal predation released as LPOP \\
\hline FPRDP & 0.04 & $0 \leq \mathrm{FPRP} \leq 1$ & $0-1$ & fraction of algal predation released as RPOP \\
\hline Kldp & 0.1 & $\mathrm{~d}^{-1}$ & $0.05-0.2$ & minimum mineralization rate of LDOP \\
\hline Krdp & 0.01 & $\mathrm{~d}^{-1}$ & - & minimum mineralization rate of RDOP \\
\hline Klpp & 0.075 & $d^{-1}$ & $0.075-0.12$ & minimum hydrolysis rate of LPOP \\
\hline Krpp & 0.005 & $d^{-1}$ & $0.001-0.005$ & minimum hydrolysis rate of RPOP \\
\hline
\end{tabular}

${ }^{\text {a }}$ Value specified in subbasins - Hood Canal, Whidbey Basin, Bellingham Bay, and South Puget Sound
${ }^{\mathrm{b}}$ Value specified in selected shallow regions of Puget Sound known for low values of near bed DO 

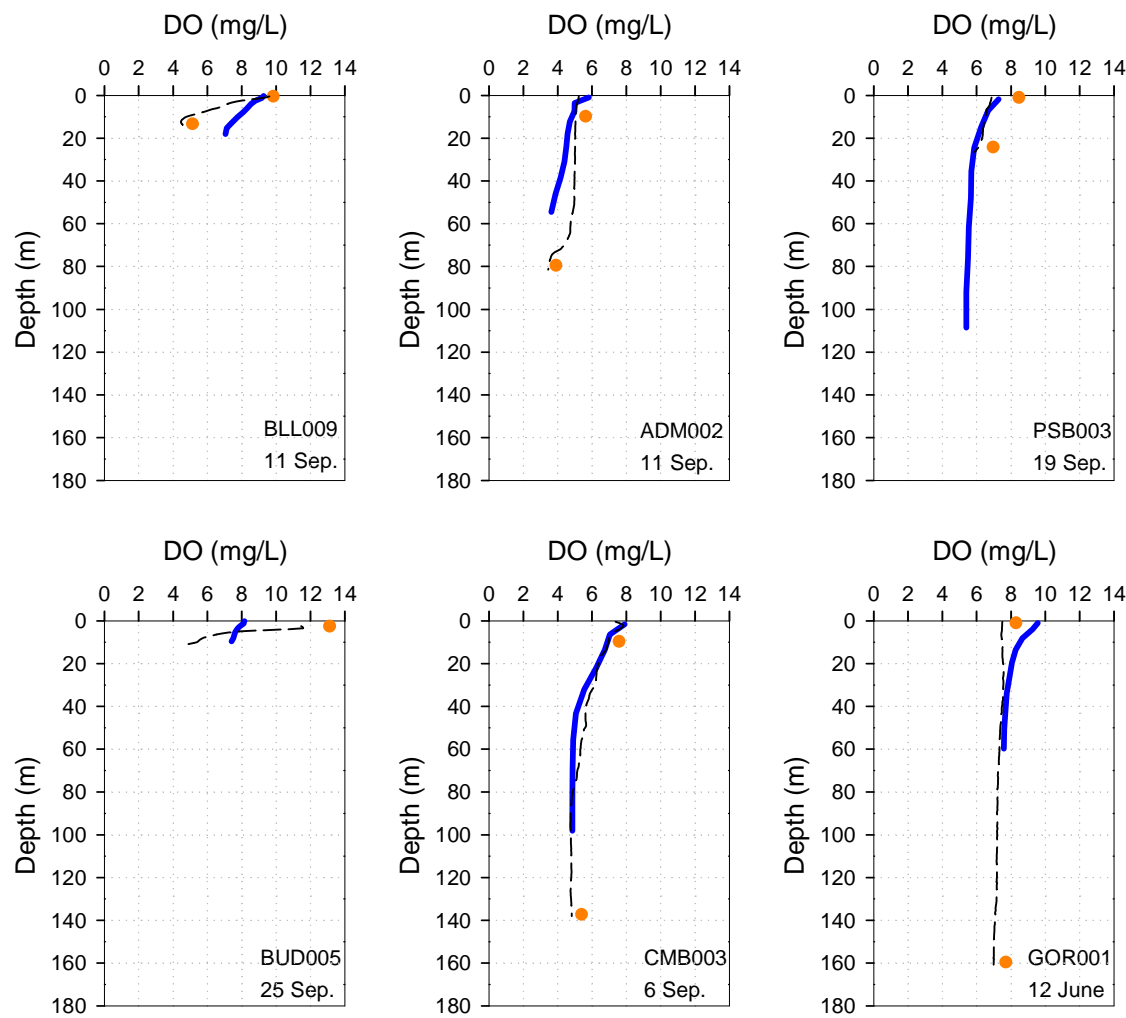

$\mathrm{DO}(\mathrm{mg} / \mathrm{L})$

$\mathrm{DO}(\mathrm{mg} / \mathrm{L})$
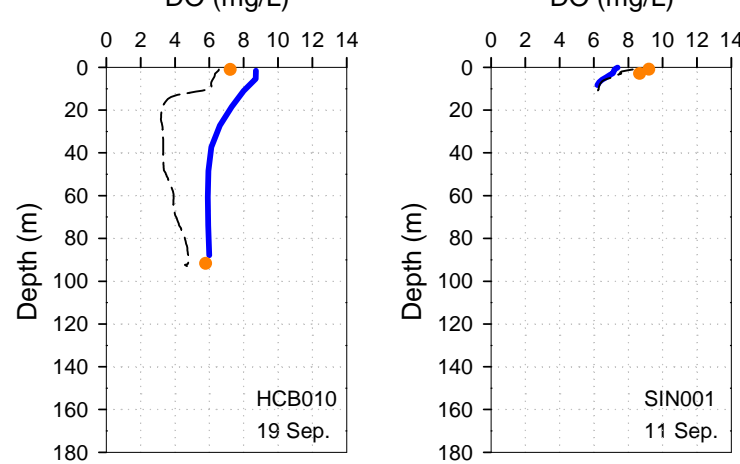

$\mathrm{DO}(\mathrm{mg} / \mathrm{L})$

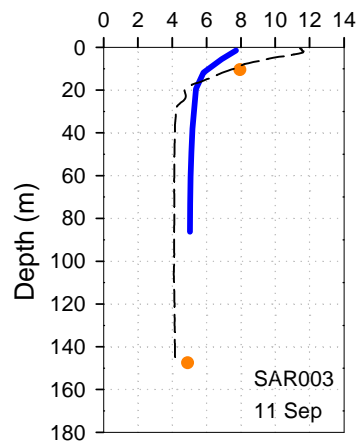

Note:

- Circles represent the discretely measured data, and dashed black line is the conductivity/temperature/depth probe

- Depths at nearest nodes in the model (eg. Saratoga Passage and Gordon point) are lower (due to limited resolution and smoothing) than the actual depth at the measurement station (see section 2.3)

Figure 3.3. Dissolved Oxygen Profiles - Comparison of Measured Data with Model Results for the Summer of Year 2006 
The Main Basin station (PSB003) is representative of a large region of Puget Sound (also known as Central Basin). The corresponding DO profile shown in Figure 3.3 shows gradients near surface induced by summer bloom of algae in the brackish surface layer over a deep water column with lower DO (5-6 $\mathrm{mg} / \mathrm{L}$ ) influenced by the inflow over Admiralty Inlet. The near bottom DO in the Main Basin station is higher than incoming water due to reflux of and mixing with surface waters induced by the Admiralty Inlet sill. This pattern continues to the south along the deeper regions of the main basin and a similar response is obtained at Commencement Bay (CMB003) and Gordon Point (GOR001) stations.

In Hood Canal, the inner reaches near Lynch Cove have experienced hypoxia in the past and have been the subject of much attention from various researchers (e.g., Hood Canal Dissolved Oxygen Program - University of Washington). Calibrated buoy data were not available for model comparison. Examination of the 2006 data from the inner Hood Canal station HCB004 showed unusually strong depletion of oxygen near the bed (relative to other basins), and strong stratification and DO gradient in the upper layers throughout the year. The gradient near the surface aligns with the salinity stratification seen at this station and could be influenced by the freshwater plumes containing higher DO from Tahuya and Skokomish Rivers. Persistent low DO levels at depth indicate that other local mechanisms such as sediment oxygen demand, organic matter decay in the water column and poor flushing of bottom layers may be occurring. For this Puget Sound-scale calibration effort, we focused on Hood Canal station HCB010, a station located approximately near the midpoint of the basin. The results show a reasonable match with observed surface and bottom DO in most basins but the near bottom DO are distinctly lower in Hood Canal relative to the rest of Puget Sound. It is possible that this is a unique feature of Hood Canal where the bottom water trapped behind the sill resides even longer than the currently simulated e-folding period (292 days) in the model.

Saratoga Passage is also an inland fjord, and the model has shown good capability of simulating stratification and circulation in the Saratoga Passage (Khangaonkar et al. 2011). The simulated DO gradients near the surface match the observed data as seen in Figure 3.3 summer profile comparison and strong gradients near the surface similar to those seen in measured data are reproduced as shown in Figure B.9.

Further adjustment of model parameters enabling higher late summer algal growth and increased DO production in shallow basins of Budd Inlet and Sinclair Inlet will likely improve the calibration as part of continuing improvement. At Gordon Point station in South Puget Sound, no DO data were available in August or September; hence, model results were plotted along with data that were available from June 2006.

\subsubsection{Nutrient Profiles (Nitrate + Nitrite - Nitrogen)}

The simulated profiles of nitrate + nitrite during August 2006 corresponding to the summer 2006 period in Puget Sound are plotted along with measured data in (Figure 3.4). A sharp drop in nutrient concentration is observed in the summer months especially in the shallow basins such as Bellingham Bay, Budd Inlet, and Sinclair Inlet and data indicate nutrients are nearly completely depleted in the surface layer. This is also seen in fjordal basins of Hood Canal and Saratoga Passage, where the shallow surface layer does not mix with the bottom water and algae growth and nutrient uptake occur in approximately the upper $20 \mathrm{~m}$ of the water column. The model predicts this pattern but does not indicate such strong drawdown at the surface in shallow inlets, consistent with under predicting dissolved oxygen. The effect 
of primary productivity and nitrate + nitrite consumption by algae is also seen in the Main Basin and other deeper stations within Puget Sound. The surface concentrations of nitrate + nitrite in the Main Basin reduced to approximately $15 \mu-\mathrm{mol} / \mathrm{L}$.

In general, lower algal biomass is observed in the larger deeper and open basins in this study area relative to the protected shallow subbasins in measured data. Algae growth was restricted in the main basin of Puget Sound, Admiralty Inlet and the Straits of Juan de Fuca and Georgia as part of model calibration through spatial variation of maximum primary productivity $\left(\mathrm{P}_{\max }\right)$ and basal metabolism $(\mathrm{BM})$ rates. However this also results in lower than observed uptake of nitrate+nitrite in the main basin especially during the summer. A higher summer bloom would further improve, model match to measure surface nutrient data. At the Commencement Bay and Gordon Point stations, the surface concentrations reduced to about $10 \mu-\mathrm{mol} / \mathrm{L}$ in the summer.

The concentrations of nitrate + nitrite simulated by the model in the lower water column below the stratified layer are controlled by a combination of incoming nutrient levels over Admiralty Inlet and the reflux of surface waters on the southern side of the sill zones consistent with the description in Ebbesmeyer and Barnes (1980). The simulated nitrate + nitrite levels at depth in the summer, as seen in Saratoga Passage and Hood Canal basins in Figure 3.4 are lower than incoming concentrations and match observed data well. This is likely due to nutrient consumption in the surface layer of main basin of Puget Sound and intrusion of this water into deeper parts of main and interconnected basins through refluxing at the Admiralty Inlet sill.

As also inferred from DO profiles, algal growth and associated nitrate + nitrite uptake simulated in the model is lower than that observed in September in shallow subbasins of Budd Inlet and Sinclair Inlet. Consequently, sharp gradients in nitrate + nitrite near the surface observed in data are not seen in the model results shown in Figure 3.4. Further model calibration could focus on enabling stronger summer algal growth and uptake of near surface nitrite + nitrate.

Comparison with monthly profile data collected at each station with predicted nitrate + nitrite profiles over Year 2006 are presented in Appendix C. The data show that nitrate + nitrite concentrations at the Admiralty Inlet station (Figure C.2) in the lower water column varied approximately between 20 and $30 \mu-\mathrm{mol} / \mathrm{L}$ throughout the year in 2006. The concentrations in the Strait of Juan de Fuca just outside the Admiralty Inlet were also in this range $(22-30 \mu-\mathrm{mol} / \mathrm{L})$, as shown in Figure 2.19. The effect of inflow concentrations is reflected in Puget Sound profiles at most stations, especially in the winter months prior to initiation of biological activity. January 2006 profiles at all stations show nitrate + nitrite concentrations at these background levels $(20-30 \mu-\mathrm{mol} / \mathrm{L})$.

\subsubsection{Nutrient Profiles (Phosphate - Phosphorus)}

Figure 3.5 shows a comparison of predicted phosphate profiles with measured data at representative stations in Puget Sound during the summer of 2006. The phosphate concentrations are nearly an order of magnitude lower than the nitrate + nitrite levels at all stations and range approximately between 1-3 $\mu$-mol/L. There is evidence of summertime phosphate consumption in the surface layers. The drop in concentration is small $(\approx 1 \mu-\mathrm{mol} / \mathrm{L})$ but large as a relative percentage drop and is noticeable in shallow and fjordal subbasins such as Bellingham Bay, Budd Inlet, Sinclair Inlet, and Saratoga Passage (e.g., 50\% phosphate reduction in the surface layer in Sinclair Inlet in the summer). 

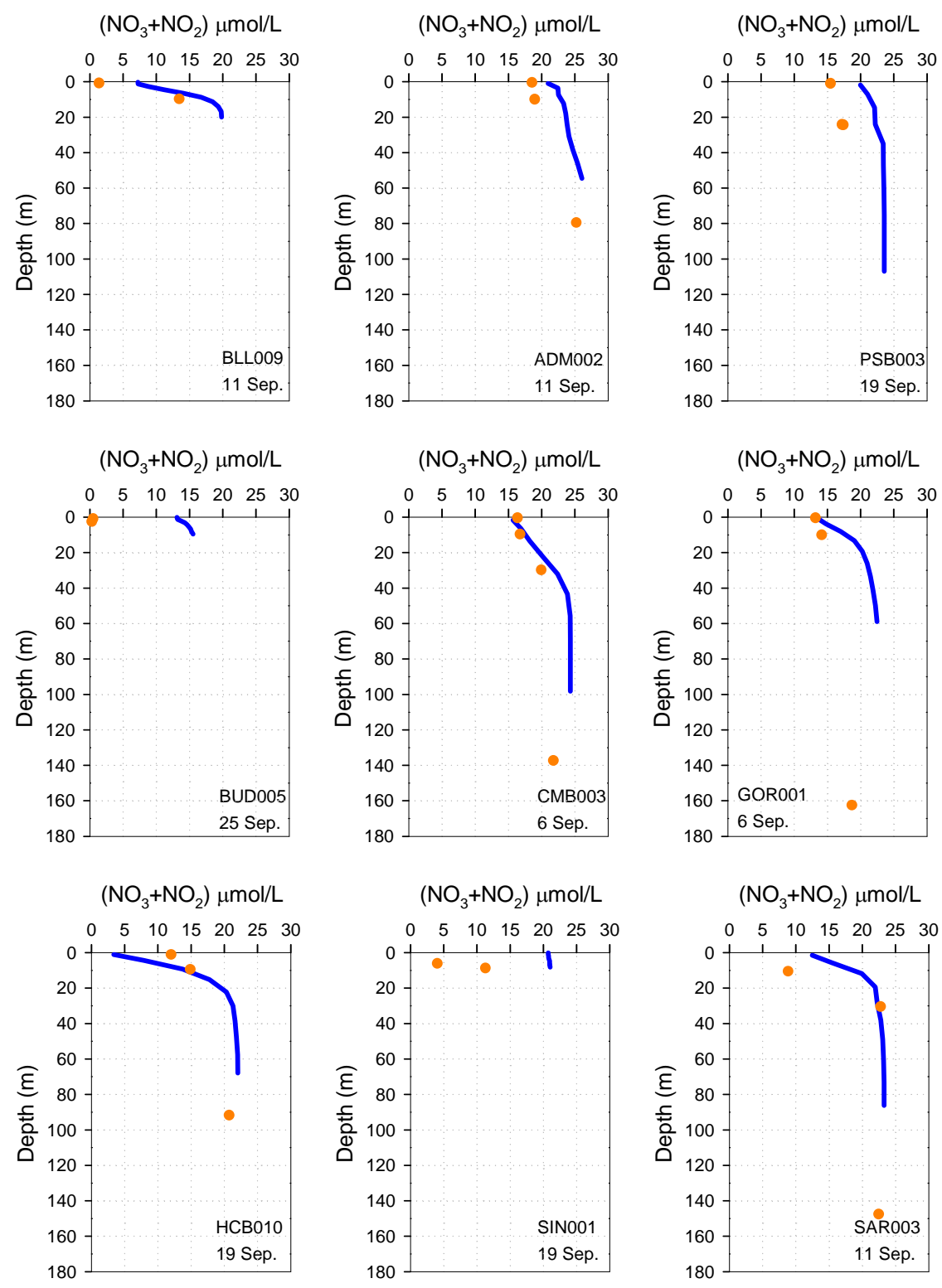

Note: Circles represent the discretely measured data

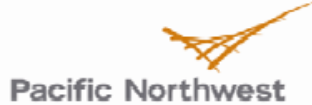

Figure 3.4. (Nitrate + Nitrite) Profiles - Comparison of Measured Data with Model Results for the Summer of Year 2006 
These stations where phosphate was depleted to 0.5 to $1.0 \mu-\mathrm{mol} / \mathrm{L}$ are the same locations where nitrate + nitrite were also strongly reduced.

Simulated phosphate profiles in the summer, similar to data at most stations, range approximately between 1-3 $\mu-\mathrm{mol} / \mathrm{L}$. The model does not reproduce near-surface gradients seen in the data. This indicates that the phosphate uptake rate in the model by algae is lower than that observed in the data or the model over mixes near the surface. Further evaluation could improve the performance. Comparison of monthly profile data collected at each station with predicted phosphate profiles over Year 2006 are presented in Appendix D. The phosphate concentration of incoming water through Admiralty Inlet increased from about $2.0 \mu-\mathrm{mol} / \mathrm{L}$ in the winter to $2.5 \mu-\mathrm{mol} / \mathrm{L}$. Hood Canal basin station shows an interesting feature in that near bed phosphate concentrations at Hood Canal station HCB010 shown Figure D.7 are higher than $3.0 \mu-\mathrm{mol} / \mathrm{L}$. This could be due sediment diagenesis related release or initial condition from the previous year not being flushed out. Hood Canal and Saratoga Passage also show evidence of phosphate consumption from the surface layer. As noted with nitrate, stations in shallow basins such as Bellingham Bay and Budd Inlet and fjordal basin of Saratoga Passage and Hood Canal also show concentration gradients near the surface indicating phosphate consumption. 

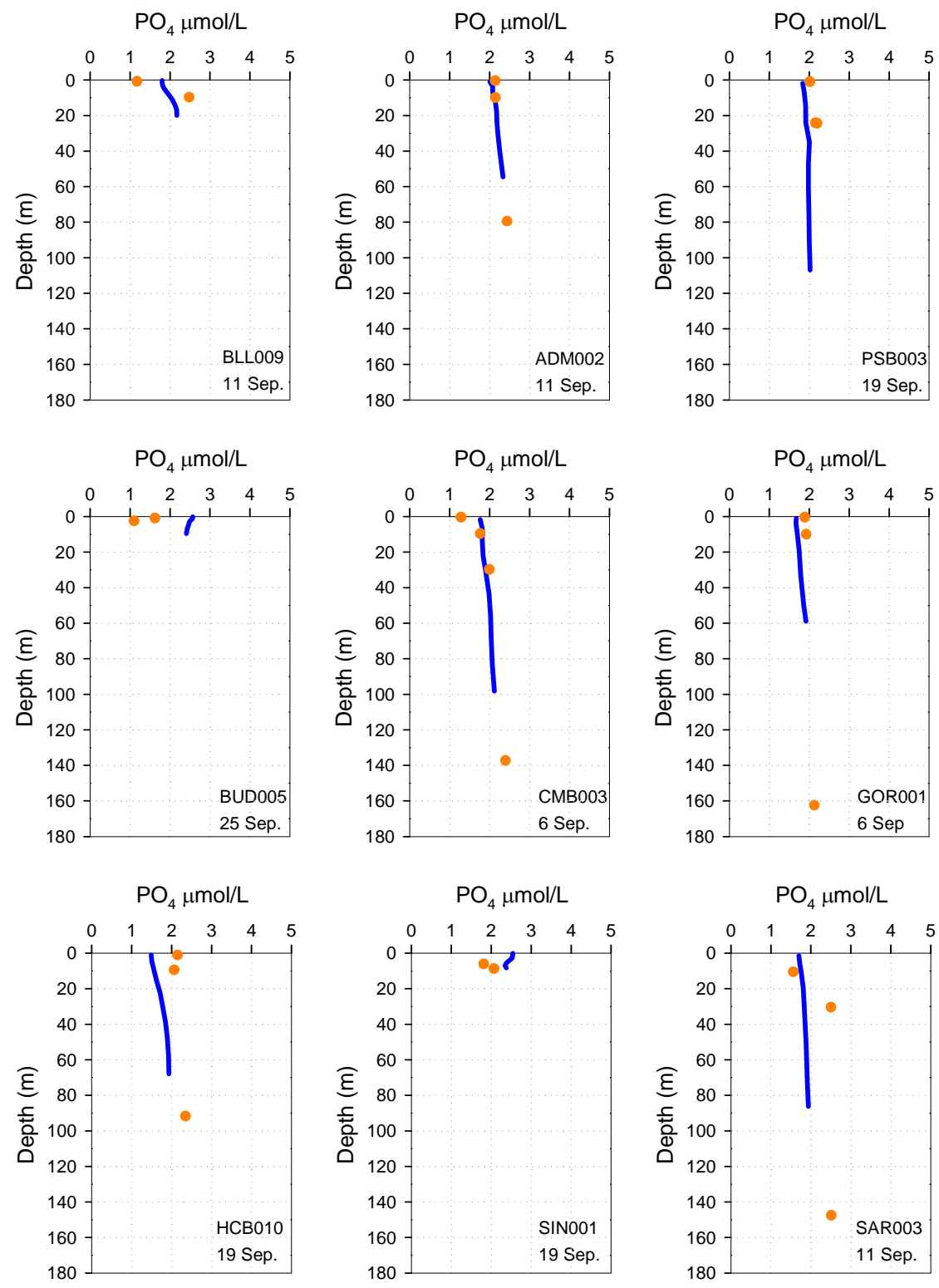

Note: Circles represent the discretely measured data

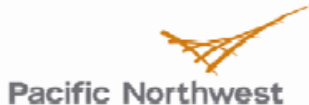

Figure 3.5. Phosphate Profiles - Comparison of Measured Data with Model Results for the Summer of Year 2006 


\subsection{Model Calibration - Surface Concentrations of Algal Chlorophyll a, Profiles of Dissolved Oxygen, and Nutrients}

Figure 3.6 provides a comparison between measured and predicted algal carbon concentration in Puget Sound as time histories at the same stations listed in Table 3.1. Surface data were collected at $1 \mathrm{~m}$ depth. As mentioned in Section 3.1, the model simulates two species of algae-diatoms and dinoflagellates. The spring bloom in Puget Sound is simulated using the diatoms algal group and peaks during April and May. The summer bloom is simulated using the dinoflagellates algal group that peaks during July and August.

Of the nine stations, algal biomass is highest in the interior inlets and passages, including Budd Inlet, Sinclair Inlet, and Hood Canal and Saratoga Passage. The stations within the main basin and near the Strait of Juan de Fuca showed lower biomass levels. It is possible that algal blooms are initiated and occur first along the shoreline closer to many nutrient sources and warmer waters resulting in faster growth. Tidal currents then dilute and transport the nearshore bloom across Puget Sound, which could explain why Main Basin and Admiralty Inlet stations have lower algal carbon concentrations. Other mechanisms which likely control algal biomass, in addition to nutrient and light availability and boundary fluxes are the residence time or flushing time for each basin. Another possible explanation for this variation in algal biomass may be temperature variability among the basins with surface waters in the main deeper basins of Puget Sound and Admiralty Inlet being a little cooler than the shallow subbasins.

Assuming this spatial variation in biological response is tied to various physical processes, a spatially varying $\mathrm{P}_{\max }$ was specified. As described in section 3.2.2, for the South Puget Sound region landward of Tacoma Narrows, the Whidbey Basin, and Hood Canal region landward of Hood Canal sill, a higher $\mathrm{P}_{\max }$ of $350 \mathrm{~g} \mathrm{C} \mathrm{g}^{-1} \mathrm{Chl} \mathrm{d}{ }^{-1}$ was used for both species of algae. A lower rate $200 \mathrm{~g} \mathrm{C} \mathrm{g}^{-1} \mathrm{Chl} \mathrm{d}^{-1}$ for diatoms and $250 \mathrm{~g} \mathrm{C} \mathrm{g}^{-1} \mathrm{Chl} \mathrm{d}^{-1}$ for dinoflagellates was used over the rest of the domain. While the predation rate of $1 \mathrm{~d}^{-}$ ${ }^{1}$ for diatoms and $0.5 \mathrm{~d}^{-1}$ for dinoflagellates, the basal metabolism rate was set to $0.1 \mathrm{~d}^{-1}$ was kept the same for both species. Although results and model response appear reasonable, it is noted that the above combination of parameters was derived through numerous sensitivity tests and professional judgment as part of the calibration process and may not be unique. Direct measurements of some these kinetic rates would help reduce the associated uncertainty.

The algal concentration is likely much higher in the nearshore regions and smaller bays and inlets or in concentrated patches as sometimes reported through Ecology's Eyes Over Puget Sound (EOPS) program. Measured data show that algal chlorophyll $a$ concentrations in Puget Sound generally vary between 0 and $20 \mu \mathrm{g} / \mathrm{L}$ based on Ecology's ambient monitoring stations. Budd Inlet is an exception where Chlorophyll $a$ data show that peak concentrations are over 4 times higher than other basins in Puget Sound. Other similar inlets do not have ambient monitoring data but may exhibit similar patterns in productivity. The current model predictions do not reflect this pattern. Capitol Lake/Deschutes River system at the head waters of Budd Inlet is known to reach eutrophic levels of algal production in the summer. Although freshwater algae from Capitol Lake in the discharge to Budd Inlet are not likely to survive in marine waters, there is a possibility that they may be influencing algal biomass measurements and the intense patchy blooms seen in Budd Inlet.

As described in the calibration approach section, key parameters limiting algal growth were optimum temperature, half saturation constants for nitrogen, and light availability. Increase in available light and 
use of optimum temperatures for growth $12^{\circ} \mathrm{C}$ to $18^{\circ} \mathrm{C}$ provided the best match for the timing of spring bloom of diatoms and summer bloom of dinoflagellates. Separation between spring and summer blooms was accomplished through adjustment of the exponential shape of the temperature dependence function. Algal production increases as an exponential function of temperature until an optimum temperature or temperature range is reached. Above the optimum, production declines until a temperature lethal to the organisms is attained. These parameters in combination with nutrient limitation imposed through the half saturation constants $0.06 \mathrm{~g} \mathrm{~N} \mathrm{~m}^{-3}$ for nitrogen allowed best reproduction of the observed spring and summer blooms and the die-off in late fall. 

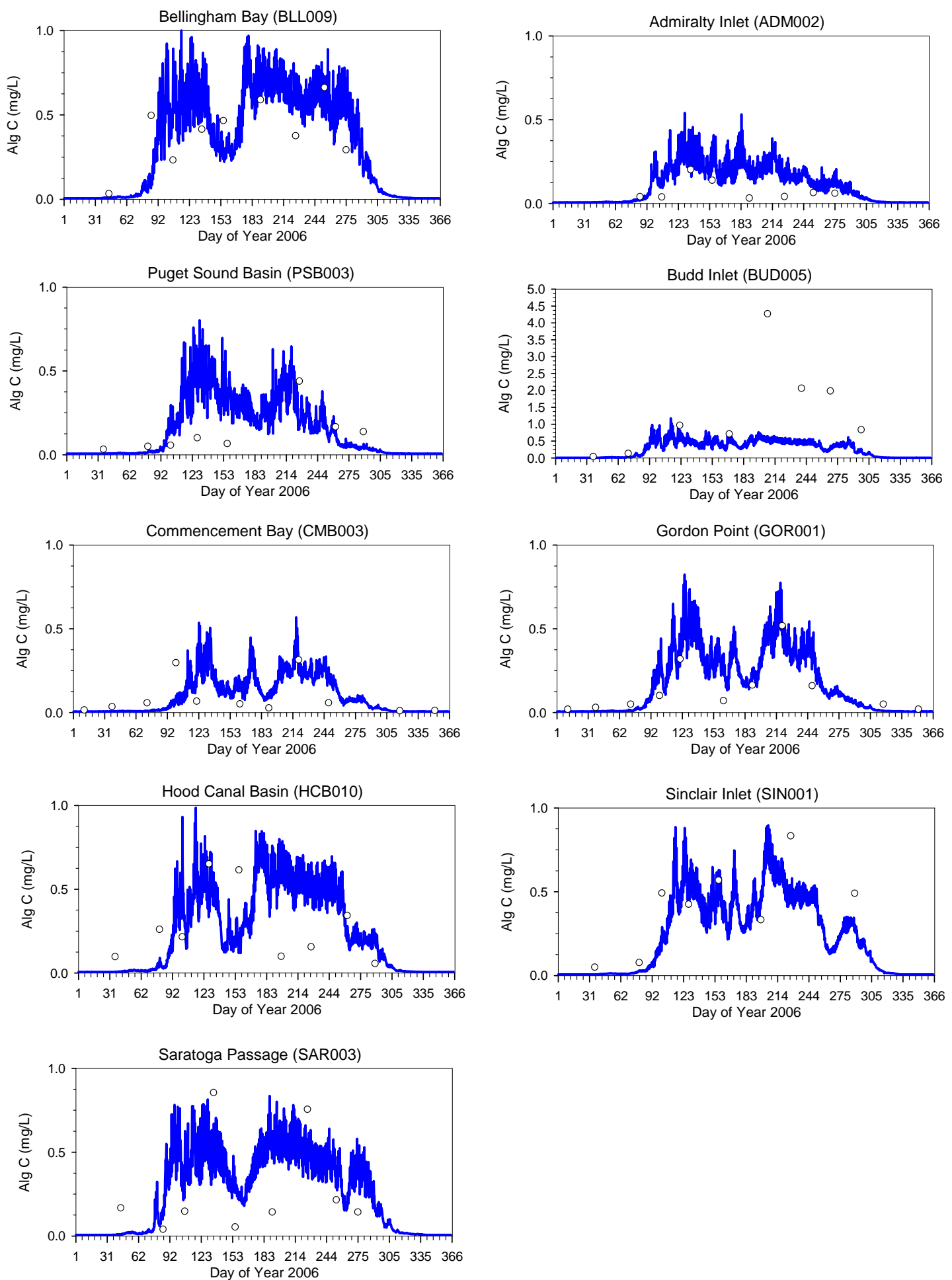

Figure 3.6. Algal Carbon Time History - Comparison of Measured Surface Data with Model Results for Year 2006 


\subsection{Model Calibration - Surface and Bottom Nutrients}

In this section, concentrations of nutrients (dissolved nitrate + nitrite and phosphate) in the surface and bottom waters are discussed. The surface concentrations are from analyses of samples collected at $1 \mathrm{~m}$ depth from the photosynthetically active, brackish surface outflow layer of Puget Sound which varies between 5-20 m in thickness (Cannon 1983; Cokelet et al. 1990; Khangaonkar et al. 2011). Algal blooms are known to occur in this layer just above the pycnocline, and their effects on nutrient concentrations such as consumption for growth are easily discernible and correlate well with measured algae data.

Surface concentrations of nitrite + nitrate at the Admiralty Inlet station shown in Figure 3.7 represent nutrient concentration of mixed surface outflow water, which is transported out into the Strait of Juan de Fuca. The cumulative effects of the spring and summer blooms from the various basins are seen in the mixed outflow waters as the concentrations dip from about $25-30 \mu-\mathrm{mol} / \mathrm{L}$ in the winter to about $18 \mu-$ $\mathrm{mol} / \mathrm{L}$ in the spring and summer periods. Similar response but with higher reduction in concentrations of nitrite + nitrate levels is seen at Puget Sound Main Basin $(15 \mu-\mathrm{mol} / \mathrm{L})$, Gordon Point $(13 \mu-\mathrm{mol} / \mathrm{L})$, and Commencement Bay $(11 \mu-\mathrm{mol} / \mathrm{L})$, respectively.

Due to high levels of algal growth associated with spring and summer blooms, the surface concentrations of Nitrite + Nitrate in the shallow embayments (Bellingham Bay, Sinclair Inlet, and Budd Inlet), and fjordal subbasins (Hood Canal and Saratoga Passage) are nearly completely depleted and drop to less than $2 \mu-\mathrm{mol} / \mathrm{L}$.

In contrast and as discussed in Section 3.2, the bottom water concentrations of nutrients in the main basin of Puget Sound are dominated by the quality of incoming water through the Admiralty Inlet over the sill. The annual tidal exchange between the main basin and Admiralty Inlet is nearly 10 times the inflow from all rivers based on information presented in Babson et al. (2006). However, as also pointed out in the previous section, reflux of surface waters into lower layers at the Admiralty Inlet sill for the Puget Sound Main Basin and Hood Canal reduces the near bottom concentrations relative to the incoming water from the Strait of Juan de Fuca (Ebbesmeyer and Barnes 1980, Cokelet et al 1990, Moore et al 2008).

Bottom concentrations of nitrite + nitrate are shown in Figure 3.8. Incoming concentrations of nitrite + nitrate at the Admiralty Inlet station vary approximately between 20-30 $\mu-\mathrm{mol} / \mathrm{L}$. Main Basin concentration time history was only available from the $30 \mathrm{~m}$ depth level. It reflects the effects of mixing and the decrease from the initial levels of $\approx 30 \mu-\mathrm{mol} / \mathrm{L}$ to $18 \mu-\mathrm{mol} / \mathrm{L}$ in the spring and summer. The bottom nitrate+ nitrite levels at Hood Canal and Saratoga Passage are similar to incoming waters varying between $20-30 \mu-\mathrm{mol} / \mathrm{L}$.

In shallow basins such as Bellingham Bay, Budd Inlet, and Sinclair Inlet, there could be sufficient light penetration to the bottom as all layers show the effects of biological activity and changes in nutrient concentrations. In Bellingham Bay, Budd Inlet, and Sinclair Inlet, likely due to mixing in the water column and light penetration, the effect of nutrient consumption is seen in the entire water column including deeper layers indicated by the sharp drops in nutrient concentrations corresponding to the spring and summer blooms. Model results at Bellingham Bay and Budd Inlet and Sinclair Inlet show nitrogen uptake at depth. This is expected in the shallow basins, as algal activity is indicated throughout the water column. 

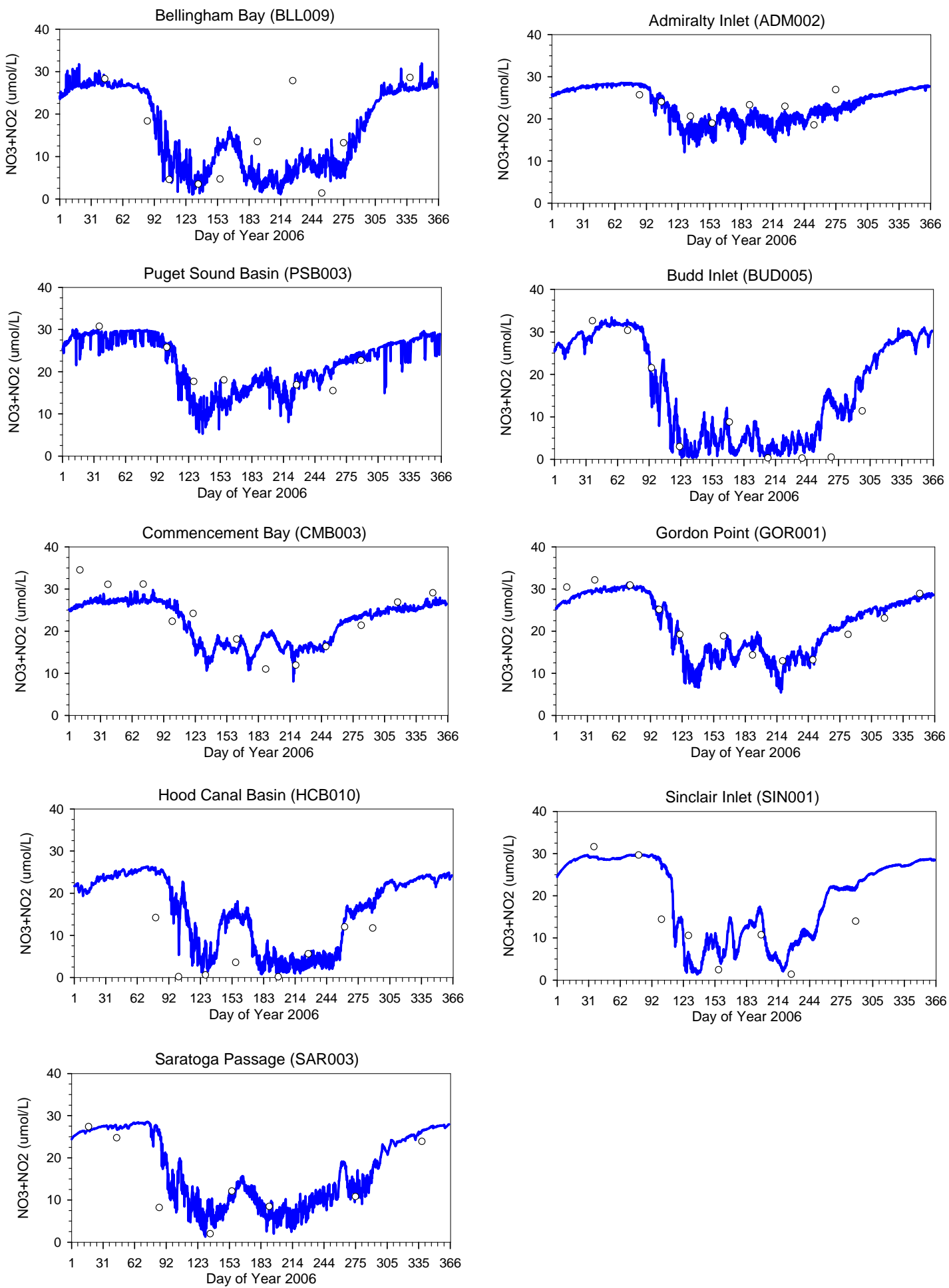

Figure 3.7. Nitrate+Nitrite Time History - Comparison of Measured Surface Data with Model Results for Year 2006 

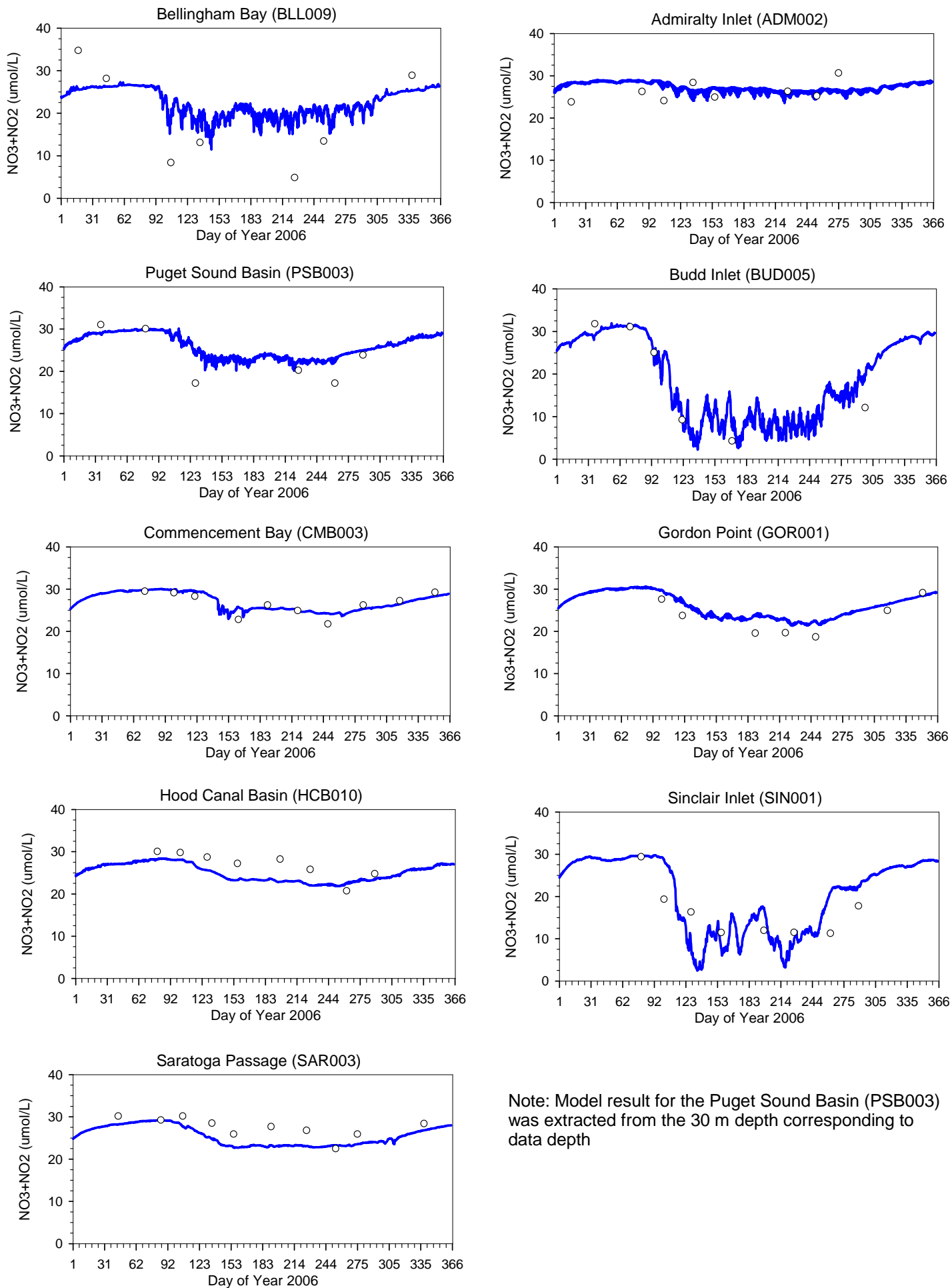

Note: Model result for the Puget Sound Basin (PSB003) was extracted from the $30 \mathrm{~m}$ depth corresponding to data depth

Figure 3.8. Nitrate + Nitrite Time History - Comparison of Measured Bottom Data with Model Results for Year 2006 
The model results at deeper basins of Puget Sound, Commencement Bay, and Gordon Point also show reduction in nitrate levels in bottom waters than observed data. This may be due to the reflux of nitrogen depleted surface waters mixing into lower layers of Puget Sound.

Comparisons with surface and bottom concentrations of phosphate are provided in Figures 3.9 and 3.10, respectively. Incoming phosphate over Admiralty Inlet varies between $2-3 \mu-\mathrm{mol} / \mathrm{L}$. As in the case of nitrates, trends in phosphate kinetics in the deeper basin are difficult to interpret due to complex mixing among the basins. However, phosphate consumption associated with spring and summer blooms are noticeable in the shallow embayments and the fjordal basins as discussed in the previous sections. It is noted that the simulated uptake of phosphate from the surface layer in fjordal basins of Hood Canal and Whidbey Basin (Saratoga Passage) is lower than measured data and that predicted concentrations higher but the simulated phosphate concentrations near the bottom in these basins are lower than measured data.

As in the case of DO, bottom concentrations of phosphate in Hood Canal appear to be an exception. The sustained high concentrations of $\approx 3 \mu$-mol/L measured in the bottom waters of Hood Canal through July of 2006 appear to be higher than the phosphate concentrations of bottom water entering Puget Sound over Admiralty Inlet. The hypothesis presented in section 3.2.1 that points to the possibility that the flushing of bottom water may actually be longer than the current estimate of 292 days (e-folding residence time estimated for 2006) is one possible explanation.

Further adjustment of phosphate uptake rate accounting for spatial variability and interconnection with the main basin may help improve the model performance. Particulate organic phosphorus (POP, labile and refractory) constituents are included in the model. However their partitioning and adsorption with suspended solids and dissolution to dissolved organic phosphorus (DOP) constituent have not been explicitly calibrated. Considering that the phosphate uptake in model is of significantly lower magnitude relative to Nitrate+Nitrite, phosphorus limitation likely plays a relatively small role compared to nitrogen limitation. The simplified approach of using constant bottom $\mathrm{PO}_{4}$ flux of $0.02 \mathrm{~g} \mathrm{P} \mathrm{m}^{-2} \mathrm{~d}^{-1}$, with the current model provides reasonable results. Half constant of $\mathrm{PO}_{4}$ concentration for $\mathrm{P}$ uptake is set to $0.02 \mathrm{~g} \mathrm{P} \mathrm{m}^{-3}$ for both species of algae over the entire domain. 

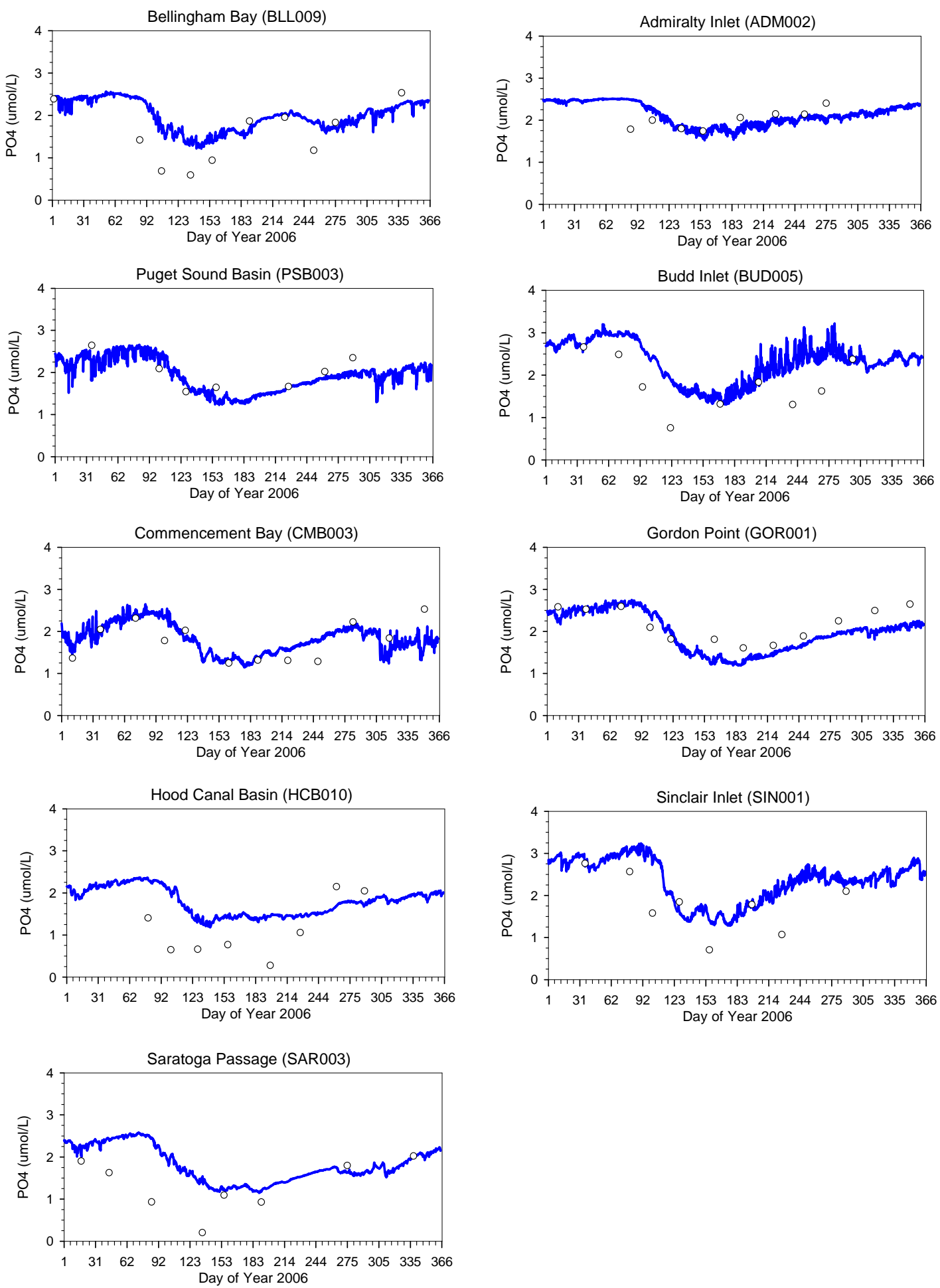

Figure 3.9. Phosphate Time History - Comparison of Measured Surface Data with Model Results Pacific Northwest 

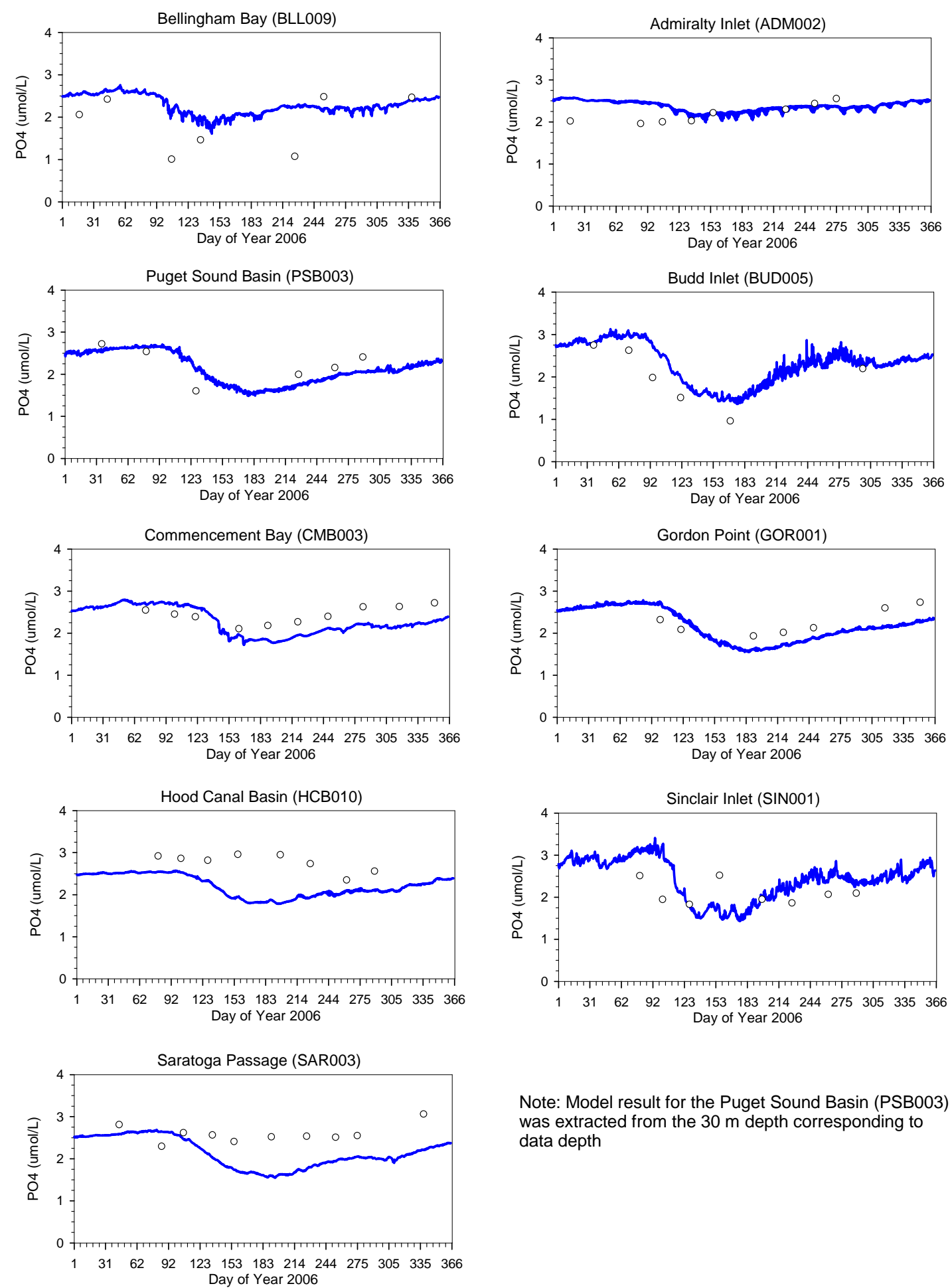

Note: Model result for the Puget Sound Basin (PSB003) was extracted from the $30 \mathrm{~m}$ depth corresponding to data depth

Figure 3.10. Phosphate Time History - Comparison of Measured Bottom Data with Model Results for Year 2006 


\subsection{Model Calibration - Surface and Bottom Dissolved Oxygen}

The ability to reproduce observed drawdown of nutrient concentrations from the surface layers of the model and corresponding DO response is dependent on adjustment of parameters controlling the growth, die-off, and succession between the diatoms and dinoflagellate species of algae. As described in Sections 3.1 and 3.2, two algal groups are currently simulated in the model, a diatom and a dinoflagellate. The diatom simulated is an idealized spherical diatom that has adapted to its estuarine environment. Therefore, it is well adapted to grow under moderate light, high nutrient, and turbulent well mixed conditions. In contrast, the dinoflagellates are better adapted to grow under high light conditions and are smaller and slightly less adapted to high nutrient conditions than the diatom. Dinoflagellates also tend to favor more stratified conditions. Bienfang and Harrison (1984) noted in their study that the settling rates of large centric diatoms were higher than dinoflagellates $(0.96 \mathrm{~m} / \mathrm{d}$ and $0.22 \mathrm{~m} / \mathrm{d}$, respectively). In this study we also we used a higher settling rate of $0.4 \mathrm{~m} / \mathrm{d}$ for diatoms and $0.2 \mathrm{~m} / \mathrm{d}$ for dinoflagellates. It is noted that settling velocities may vary over a large range especially towards the end of diatom blooms where aggregation of cells similar to coagulation of organic particles can result in higher settling velocities. Detailed parameterizations of each algal group were provided in Table 3.3.

Phytoplankton succession is important in the Puget Sound. As discussed in section 3.3, the year 2006 included a significant dinoflagellate bloom, which affected many of the subbasins of Puget Sound. We have focused calibration on phytoplankton succession of 2006 in terms of the magnitude and timing of the blooms. A diatom bloom occurred in the early spring, followed by a bloom from late spring throughout the summer of dinoflagellates.

The magnitudes of dissolved oxygen throughout the Sound were simulated, with deviations mostly due to offsets in the timing of phytoplankton blooms. Dissolved oxygen in the surface around the Sound (Figure 3.11) was generally high, reflecting reaeration, phytoplankton primary production, and river input, especially during the winter months. In some locations that were quite productive, including Hood Canal year-round and Budd Inlet in summer, dissolved oxygen concentrations were near saturation or super-saturated at ambient temperatures, as would be expected with a strong phytoplankton bloom.

Dissolved oxygen concentration at depth (Figure 3.12) simulated in the model reflects a downward trend strongly influenced by the incoming low DO water from the Pacific Ocean via Admiralty Inlet. The near bed DO concentrations in the fjordal basins show low DO concentrations which vary between $4-6 \mathrm{mg} / \mathrm{L}$ but do not reflect strongly the trend seen in the Admiralty Inlet data. The near bottom DO levels simulated by the model in Hood Canal are considerably higher than observed data and require further improvement. 

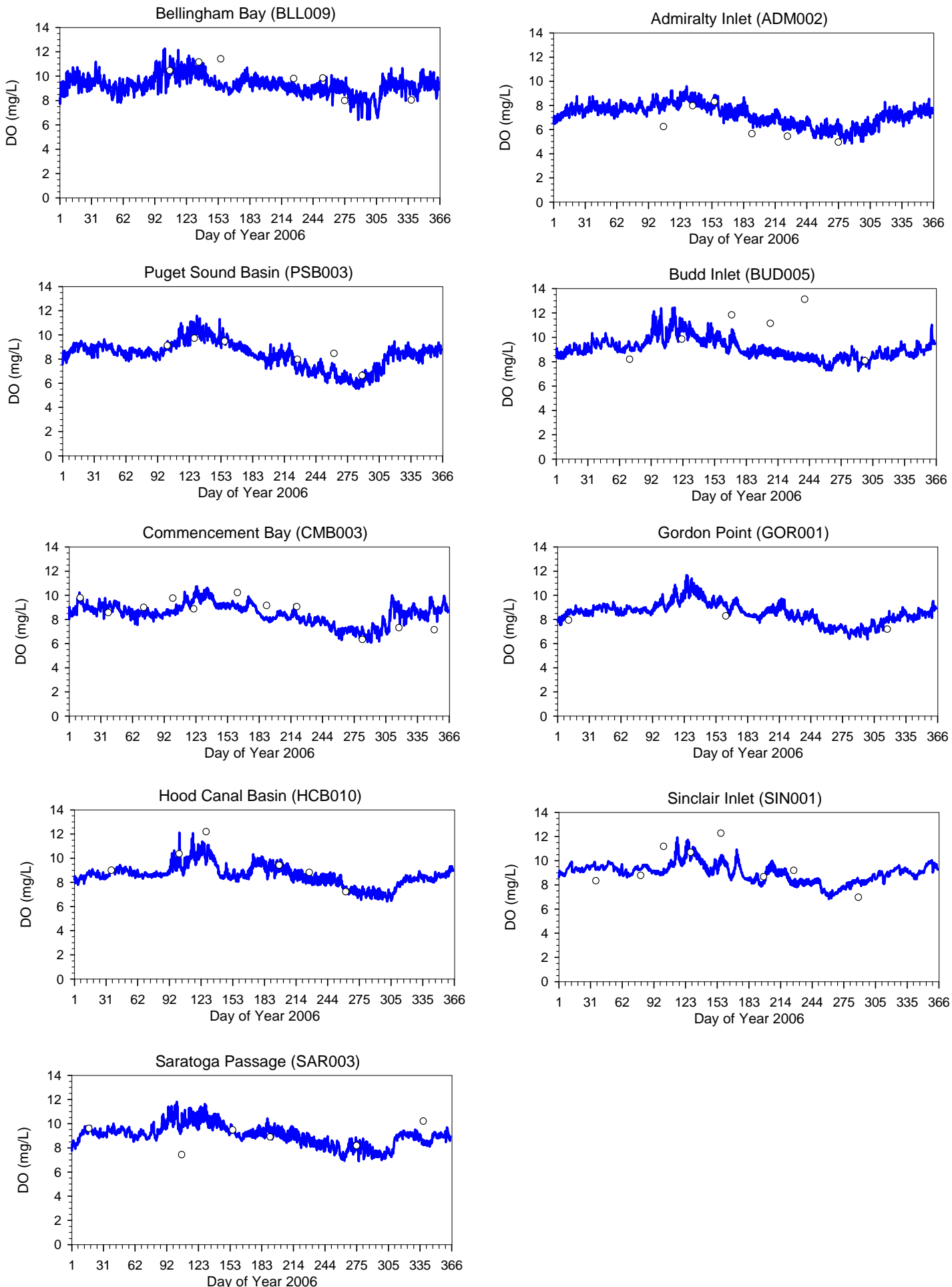

Figure 3.11. Dissolved Oxygen Time History Comparison of Measured Surface Data with Model Results for Year 2006 

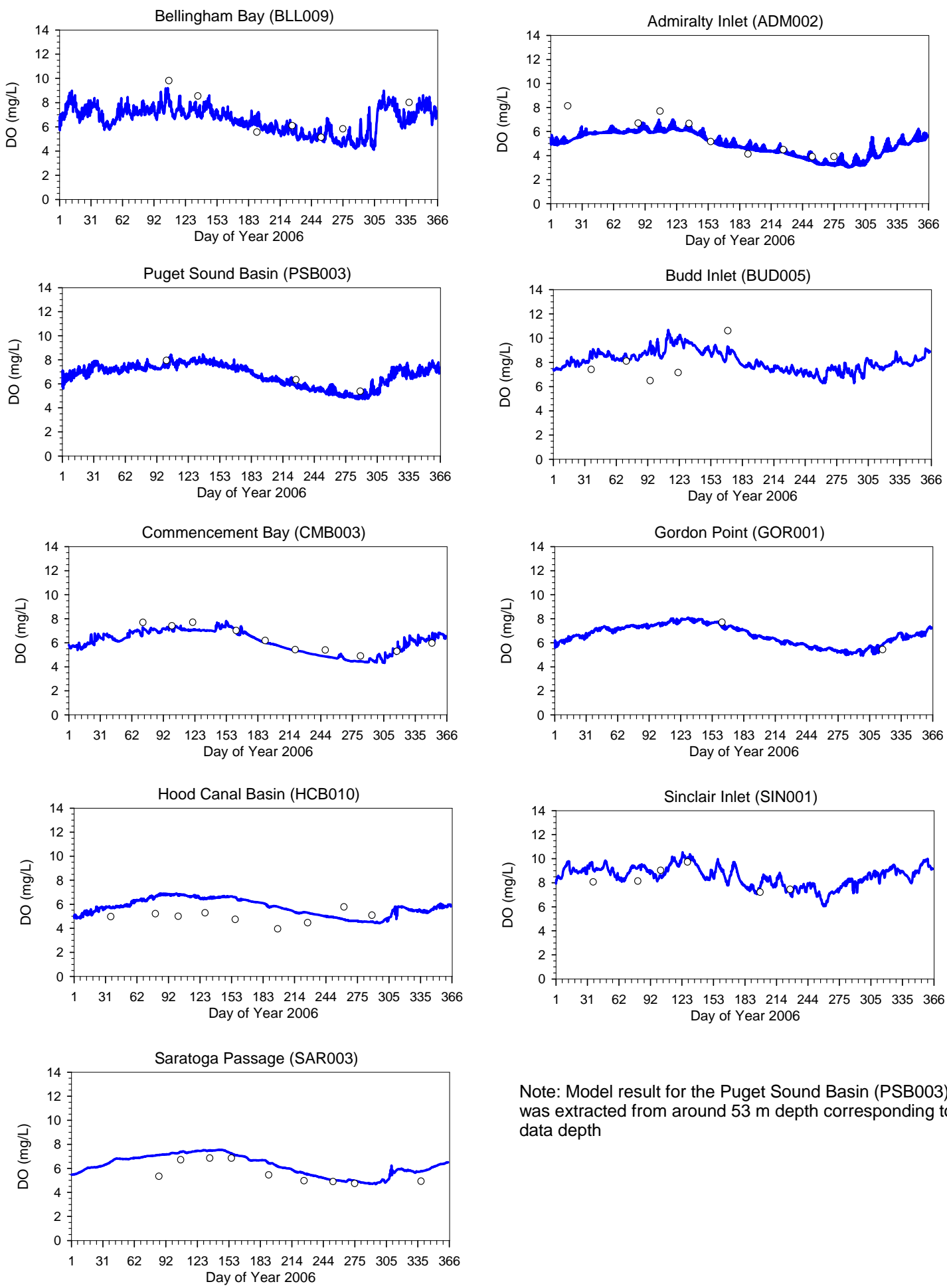

Note: Model result for the Puget Sound Basin (PSB003) was extracted from around $53 \mathrm{~m}$ depth corresponding to data depth

Figure 3.12. Dissolved Oxygen Time History Comparison of Measured Bottom Data with Model Results for Year 2006 


\subsection{Model Error Statistics}

Error statistics for key biogeochemical variables - algal biomass (chlorophyll a), DO, nitrate+nitrite, and phosphate are provided in Table 3.4. As discussed in section 3.1, exceptionally high levels of algal biomass measured at the Budd Inlet station were not captured adequately in the model simulations and were not included in the error table. The error statistics indicate that predicted algal growth and DO concentration in the model are biased lower than the observed data. The root mean square (RMS) errors for DO vary between 1-2 mg/L. Simulated nitrate+nitrite levels are higher than observed, but consistent with the lower uptake associated with lower than observed simulated algae growth. The mean RMS error and bias for nitrate + nitrite are $4.78 \mu . \mathrm{mol} / \mathrm{L}$ and $2.38 \mu . \mathrm{mol} / \mathrm{L}$ respectively, which are approximately $16 \%$ and $10 \%$ of the peak variation of nitrate + nitrite $(0-30 \mu . \mathrm{mol} / \mathrm{L})$. Phosphate concentrations are low and results show a match with data with $<1 \mu . \mathrm{mol} / \mathrm{L}$ of RMS error and bias at all stations.

Ecology performed an extended assessment of model performance at 36 stations distributed throughout the model domain (https: $/ / \mathrm{maps}$. google.com/maps/ms?msid=216293825509105801339.0004b5a5c0745b005d4d7\&msa=0). This collection of stations included the 9 used for model development and calibration (i.e., Table 3.4) as well as 27 others that were only used as part Ecology's independent model evaluation. The evaluation focused on overall performance of the coupled hydrodynamic + water quality model plus site-specific performance at key locations. Aggregated goodness-of-fit parameters for key variables are provided in Figure 3.13. Additional evaluation products, including:

- Goodness-of-fit statistics for additional variables,

- Time series, profile plots, time-depth plots and of key variables at all stations, and

- Monthly plan-view maps

can be downloaded from the project website (https://fortress.wa.gov/ecy/spsdos/salish_sea/index.html).

The current calibration appears to capture and accurately represent many large scale patterns of variability in both hydrodynamics and water quality. That said, there are localized areas where model performance could be improved with additional refinements and/or focused study. For example, deepwater dissolved oxygen predictions in the southernmost reaches of Hood Canal and Lynch Cove (stations HCB003, HCB004, and HCB007) are still much too high and may have to be improved with additional targeted effort depending on the scenario results. 
Table 3.4. Biogeochemical model calibration error statistics at selected locations in Puget Sound (2006)

Table 3.4 (a) Model calibration error statistics for Algal chlorophyll $a$

\begin{tabular}{|c|c|c|c|c|c|}
\hline Region & Location & ID & RMSE $(\mu \mathrm{g} / \mathrm{L})$ & $\operatorname{Bias}(\mu \mathrm{g} / \mathrm{L})$ & SD $(\mu \mathrm{g} / \mathrm{L})$ \\
\hline South & Dana Passage & DNA001 & 2.72 & -0.98 & 2.59 \\
\hline South & Gordon Point & GOR001 & 1.76 & -0.72 & 1.62 \\
\hline Central & Commencement Bay & CMB003 & 1.96 & 0.05 & 2.01 \\
\hline Central & Sinclair Inlet & SIN001 & 5.11 & -2.44 & 4.63 \\
\hline Central & West Point & PSB003 & 4.52 & -0.72 & 4.5 \\
\hline Hood Canal & Hood Canal North & HCB010 & 8.95 & -3.27 & 8.61 \\
\hline Whidbey Basin & Saratoga Passage & SAR003 & 4.97 & 0.49 & 5.08 \\
\hline SJdF & Admiralty Inlet Entrance & ADM002 & 1.88 & 1.13 & 1.55 \\
\hline \multirow[t]{2}{*}{ Bellingham Bay } & Bellingham Bay & BLL009 & 5.32 & 0.39 & 5.43 \\
\hline & & Mean & 4.13 & -0.67 & 4.00 \\
\hline \multicolumn{6}{|c|}{$\begin{array}{l}\text { Output compared with discrete surface chlorophyll samples } \\
\text { RMSE = root mean square error; Bias = mean of paired differences (modeled }- \text { observed); } \\
\mathrm{SD}=\text { standard deviation of paired differences (modeled }- \text { observed) }\end{array}$} \\
\hline
\end{tabular}

Table 3.4 (b) Model calibration error statistics for dissolved oxygen (DO)

\begin{tabular}{|c|c|c|c|c|c|}
\hline Region & Location & ID & RMSE (mg/L) & Bias $(\mathrm{mg} / \mathrm{L})$ & $\mathrm{SD}(\mathrm{mg} / \mathrm{L})$ \\
\hline South & Dana Passage & DNA001 (SS03) & 1.14 & -0.43 & 1.05 \\
\hline South & Gordon Point & GOR001 (SS66) & 0.88 & -0.75 & 0.46 \\
\hline Central & Commencement Bay & CMB003 & 0.81 & -0.63 & 0.51 \\
\hline Central & Sinclair Inlet & SIN001 & 1.52 & -0.55 & 1.42 \\
\hline Central & West Point & PSB003 & 1.14 & -0.91 & 0.68 \\
\hline Hood Canal & Hood Canal North & HCB010 & 1.13 & 0.28 & 1.09 \\
\hline Whidbey Basin & Saratoga Passage & SAR003 & 0.86 & 0.21 & 0.83 \\
\hline SJdF & Admiralty Inlet Entrance & ADM002 & 1.42 & -0.94 & 1.06 \\
\hline \multirow[t]{2}{*}{ Bellingham Bay } & Bellingham Bay & BLL009 & 1.25 & -0.71 & 1.03 \\
\hline & & Mean & 1.14 & -0.43 & 1.05 \\
\hline \multicolumn{6}{|c|}{$\begin{array}{l}\text { Output compared with } 0.5 \mathrm{~m} \text { binned Winkler-adjusted DO measurements from full water column CTD profiles. } \\
\text { RMSE = root mean square error; Bias = mean of paired differences (modeled - observed); } \\
\mathrm{SD}=\text { standard deviation of paired differences (modeled - observed) }\end{array}$} \\
\hline
\end{tabular}


Table 3.4 (c) Model calibration error statistics for nitrate + nitrite $\left(\mathrm{NO}_{3}+\mathrm{NO}_{2}\right)$

\begin{tabular}{|c|c|c|c|c|c|}
\hline Region & Location & ID & $\begin{array}{c}\text { RMSE } \\
(\mu . \mathrm{mol} / \mathrm{L})\end{array}$ & $\begin{array}{c}\text { Bias } \\
(\mu . \mathrm{mol} / \mathrm{L})\end{array}$ & $\begin{array}{c}\text { SD } \\
(\mu . \mathrm{mol} / \mathrm{L})\end{array}$ \\
\hline South & Dana Passage & DNA001 & 7.14 & 4.29 & 5.71 \\
\hline South & Gordon Point & GOR001 & 3.57 & 2.86 & 2.86 \\
\hline Central & Commencement Bay & CMB003 & 3.57 & 0.71 & 3.57 \\
\hline Central & Sinclair Inlet & SIN001 & 8.57 & 6.43 & 5.71 \\
\hline Central & West Point & PSB003 & 4.29 & 1.43 & 3.57 \\
\hline Hood Canal & Hood Canal North & НCB010 & 7.86 & 3.57 & 7.14 \\
\hline Whidbey Basin & Saratoga Passage & SAR003 & 5.00 & 0.71 & 5.00 \\
\hline SJdF & Admiralty Inlet Entrance & ADM002 & 2.86 & 0.71 & 2.86 \\
\hline \multirow[t]{2}{*}{ Bellingham Bay } & Bellingham Bay & BLL009 & 0.13 & 0.71 & 10.00 \\
\hline & & Mean & 4.78 & 2.38 & 5.16 \\
\hline \multicolumn{6}{|c|}{$\begin{array}{l}\text { Output compared with discrete } \mathrm{NO}_{3}+\mathrm{NO}_{2} \text { samples } \\
\mathrm{RMSE}=\text { root mean square error; Bias = mean of paired differences (modeled }- \text { observed); } \\
\mathrm{SD}=\text { standard deviation of paired differences (modeled }- \text { observed) }\end{array}$} \\
\hline
\end{tabular}

Table 3.4 (d) Model calibration error statistics for phosphate $\left(\mathrm{PO}_{4}\right)$

\begin{tabular}{|c|c|c|c|c|c|}
\hline Region & Location & ID & $\begin{array}{c}\text { RMSE } \\
(\mu . \mathrm{mol} / \mathrm{L})\end{array}$ & $\begin{array}{c}\text { Bias } \\
(\mu . \mathrm{mol} / \mathrm{L})\end{array}$ & $\begin{array}{c}\text { SD } \\
(\mu . \mathrm{mol} / \mathrm{L})\end{array}$ \\
\hline South & Dana Passage & DNA001 (SS03) & 0.32 & 0.323 & 0.32 \\
\hline South & Gordon Point & GOR001 (SS66) & 0.32 & 0.000 & 0.32 \\
\hline Central & Commencement Bay & CMB003 & 0.32 & 0.000 & 0.32 \\
\hline Central & Sinclair Inlet & SIN001 & 0.65 & 0.646 & 0.65 \\
\hline Central & West Point & PSB003 & 0.32 & 0.000 & 0.32 \\
\hline Hood Canal & Hood Canal North & HCB010 & 0.65 & 0.000 & 0.65 \\
\hline Whidbey Basin & Saratoga Passage & SAR003 & 0.65 & 0.000 & 0.65 \\
\hline SJdF & Admiralty Inlet Entrance & ADM002 & 0.32 & 0.323 & 0.32 \\
\hline \multirow[t]{2}{*}{ Bellingham Bay } & Bellingham Bay & BLL009 & 0.65 & 0.32 & 0.65 \\
\hline & & Mean & 0.47 & 0.18 & 0.47 \\
\hline \multicolumn{6}{|c|}{$\begin{array}{l}\text { Output compared with discrete } \mathrm{PO}_{4} \text { samples. } \\
\mathrm{RMSE}=\text { root mean square error; Bias = mean of paired differences (modeled }- \text { observed); } \\
\mathrm{SD}=\text { standard deviation of paired differences (modeled }- \text { observed) }\end{array}$} \\
\hline
\end{tabular}


RMSE: $1.196(n=60224)$

RMSE: $0.071(n=1369)$
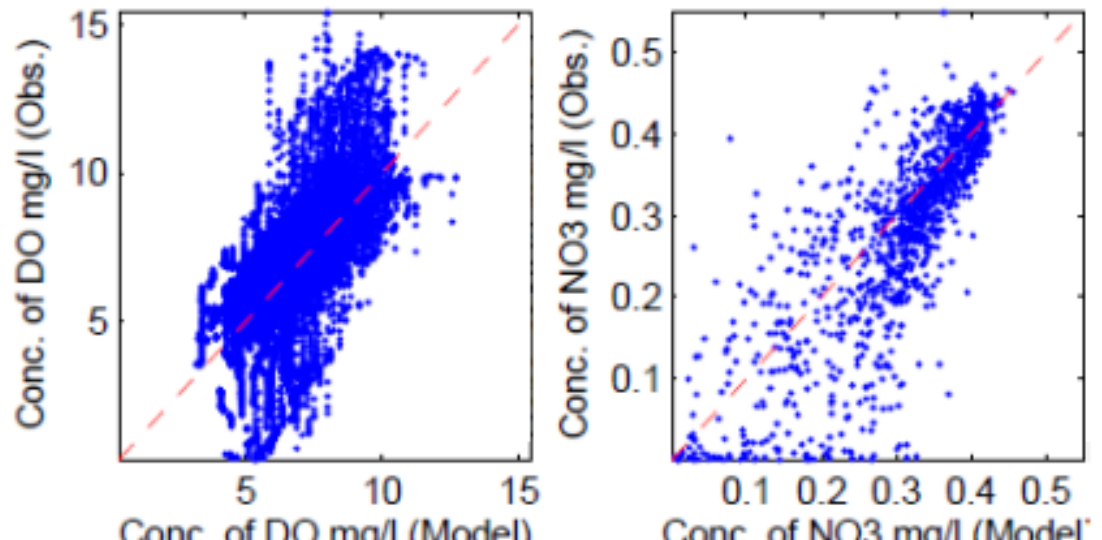

RMSE: $0.911(n=68045)$

Conc. of NO3 mg/l (Model'.

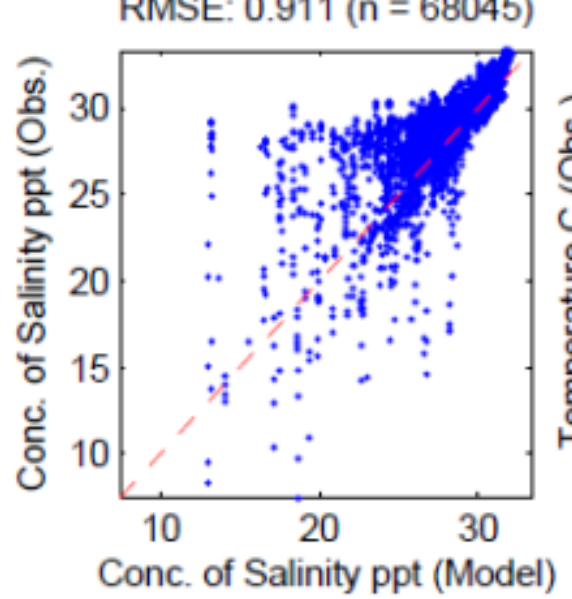

RMSE: $0.649(n=68045)$

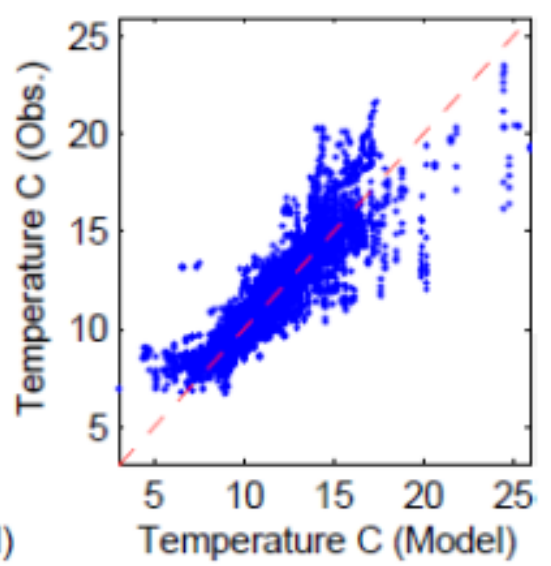

Figure 3.13. Aggregated goodness-of-fit statistics for Dissolved Oxygen (DO, mg/L), Nitrate+Nitrite (NO3, mg/L), Salinity (PPT), and Temperature (deg C) for 36 stations distributed throughout model domain. 


\subsection{Summary and Discussion of Model Limitations}

\subsection{Summary of Model Development}

In this study, an offline intermediate-scale water quality model for Puget Sound and the Northwest Straits (now known as the Salish Sea) was developed using the scalar transport scheme from the FVCOM model, coupled to the biogeochemical code of CE-QUAL-ICM. The coupling was done in an offline mode where the hydrodynamic computations are conducted independent of water quality in a stand-alone application. The previously computed hydrodynamic solution was read by the linkage code to conduct water quality constituent transport and kinetics. The model of Puget Sound developed and presented in this report simulates 19 state variables and simulates key biogeochemical processes observed in the region, including phytoplankton bloom dynamics, nutrient uptake and remineralization, and the impacts of boundary and point source loadings on DO. The model was calibrated using observed water quality data (algal carbon, nutrients, and dissolved oxygen) for 2006.

Model setup and calibration focused on tidally driven circulation and transport. Oceanic, river, and wastewater treatment plant boundary conditions were incorporated to establish baseline and background concentrations of nutrients, such as nitrate + nitrite, ammonium, and orthophosphate, which are integral to the simulation of algal dynamics and can affect DO levels. Following sensitivity tests to identify the key parameters, calibration focused on matching the spatial and temporal patterns at nine stations throughout Puget Sound representing a range of environments.

This water quality model of Puget Sound, set up and calibrated at an intermediate scale, simulates seasonal algal bloom dynamics and DO levels in Puget Sound resulting from nutrient loads from natural and human sources within the basin and exchanges with the Pacific Ocean. The salient features of this Puget Sound Water Quality Model are as follows.

- The model consists of 9,052 grid nodes and 13,976 elements in the horizontal plane and 10 sigmastretched layers in the vertical direction. The average element size is $1,760 \mathrm{~m}$.

- The model is driven by tides, river inflows, and meteorological forcing (wind and net heat flux).

- The model domain includes the entire Salish Sea, including runoff from Canadian watersheds. However, the primary area of interest is Puget Sound, interior to Admiralty Inlet.

- The model includes two open boundaries: one is at the entrance of the Strait of Juan de Fuca, and the other at the north end of Georgia Strait. Water surface elevations specified at the boundaries are based on predicted tides using XTide based on NOAA algorithms. Water quality (nutrients, algal carbon, and dissolved oxygen), salinity and temperature open boundary conditions were specified using quarterly (water quality) and monthly (salinity and temperature) profiles obtained from the DFO with data gaps filled using data from JEMS. Chlorophyll $a$ data were converted to algal carbon concentrations.

- A total of 164 freshwater inflows (19 gauged rivers, 45 watershed discharges, and 99 wastewater treatment discharges) are included in the model. Nutrient loads are included for each stream that enters the model. 
- Meteorological forcing was obtained from the University of Washington WRF model datasets reanalyzed using a representative site north of Seattle (Triple Junction station) representative of the water surface and not a land surface.

- The model was run in parallel mode on a 184-core cluster computer. A 1-year model run with 35 computation cores and 19 state variables requires about 24 hours in real time.

The model simulates phytoplankton primary production and surface water DO and nutrient dynamics in Puget Sound based on comparisons to observed data. All deeper basins of Puget Sound show a common biological behavior and response, which are different from the highly productive shallow subbasins. The fjordal subbasins within Puget Sound exhibit well-defined patterns that are consistent with classic fjord theory and are clearly distinguishable from the other basins. Incorporation of all these types of estuaries into a single framework is challenging but feasible through the approach and framework selected for this development.

\subsection{Model Limitations and Uncertainty}

Establishment of a comprehensive water quality (biogeochemical) model for any waterbody occurs through continuing process of improvement through sensitivity analysis, parameter adjustment, and model refinement. One of the first efforts to simulate biogeochemical balance over the entire Salish Sea domain using a numerical model, the model generates stable solutions and matches the observed data. The model can be applied to answer the broad water-quality management question of whether human sources of nutrients in and around Puget Sound are broadly affecting water quality, which will be conducted over the coming months. The model is optimized to the deep fjordal subbasins; performance is lower in the shallow subbasins such as Budd Inlet, Sinclair Inlet, and Bellingham Bay. Because algal growth is under predicted in these regions, the model may not be capable of identifying impairments even if they exist. Further refinements could improve performance in shallow bays. Depending on the findings, the model also may be used to quantify how much nutrient reduction is necessary to reduce human impacts in sensitive areas.

All models have limitations and uncertainties that depend on the project objectives and scope, available data, and site specific complexities. The model in its current configuration is expected to answer the broad water quality management question of whether human sources of nutrients in and around Puget Sound are significantly impacting water quality and, if so, how much nutrient reduction is necessary to reduce human impacts in sensitive areas. To address this question, it is possible to apply the model with known boundary values (as currently set up from a previously selected year such as 2006 to establish the baseline conditions. The management questions may then be answered with this tool through scenarios and sensitivity analyses relative to the established baseline.

Specific limitations related to data availability and model capability are listed below.

1. In its current configuration, the sediment oxygen demand has been incorporated with spatial variation but all other benthic nutrient fluxes are specified uniformly over the entire model domain. It is clear that parts of Puget Sound such as the southernmost regions of Hood Canal and parts of South Puget Sound have higher levels of benthic activity and could be a source of nutrients.

2. Heat flux is based on scaling of data from a single node point of the WRF meteorological data set for the Puget Sound region. This limits the ability to simulate spatial variability in sea surface 
temperatures and wind forcing. This could affect local mixing events and response, particularly in sheltered subbasins such as Hood Canal and Whidbey Basin.

3. The model response (algal growth and nutrient uptake) in the shallow subbasins of Budd Inlet and Sinclair Inlet, and likely other shallow inlets, is underestimated. In addition to reasons such as spatial variability and differences relative to the deeper parts of Puget Sound discussed previously, inadequate grid resolution in these subbasins resulting in excessive flushing could also be a factor. Additional refinement could improve the biological response in these basins.

4. The model predictions, particularly in the deeper waters of Puget Sound, are strongly dependent on the Pacific Ocean water quality (at the Neah Bay boundary in the Strait of Juan de Fuca) and the quality of outflow of water from Georgia Straits (affected correspondingly by the boundary near Johnstone Strait). Also, in the current model configuration, the boundary conditions include the measured effect of upwelling. Therefore, ability to predict response to future upwelling events over the continental shelf is not built in.

5. The available data on phytoplankton community structure and primary production data, including carbon concentrations, are very limited in Puget Sound. This limits the calibration process, particularly the ability to capture the influence of phytoplankton carbon on dissolved oxygen. We have utilized two species of algae (diatom and dinoflagellates) to re-create the spring and summer bloom peaks. However, without specific data on each algal type, the model relies on best professional judgment to adjust the phytoplankton succession.

6. Collecting phytoplankton concentrations for the entire euphotic zone, not just the very surface layers, would greatly increase the utility of this dataset because, in many regions, deep chlorophyll a maxima are important (Steinbuck et al. 2010), and these will not necessarily be well represented without appropriate data and recalibration. (In situ fluorescence profiles do exist; however, they have not yet been sufficiently calibrated for use in comparison to model results. Also they will likely be affected by daytime fluorescence quenching which will significantly bias near-surface fluorescence estimates of phytoplankton biomass)

7. Zooplankton data were not available for this calibration effort. As a result, zooplankton was simulated as a predation rate, which is a function of algal biomass and temperature. This is a common approach.

8. Due to the monthly time interval in measured data, the model cannot provide insight into finer-scale algal bloom dynamics. Therefore, higher temporal resolution dynamics, including wind-driven upwelling that alters dissolved oxygen, and nutrient concentrations in deeper waters of Puget Sound on a weekly to monthly scale, cannot be checked against measured data.

9. Sediment diagenesis is available in the model formulation but has not been incorporated. Therefore, along with spatial variations, temporal variations of benthic fluxes are not considered in this effort.

10. A total of 99 wastewater point sources are included. The effect of the mass loading of nutrient and carbon from the point sources on DO kinetics is included. However, the model does not simulate nearfield plume dynamics, including buoyancy effects. Instead, the four largest point sources (METRO West Point, METRO South King, Tacoma Central, and Chambers Creek) were introduced at the plume-trapping depth, based on information provided by King County and the Department of Ecology. However the model is capable of addressing farfield effects from the cumulative inputs from all wastewater treatment plants and rivers. 
11. Combined sewer overflow (CSO) discharges are not included in this stage of model development. Stormwater loads may be underestimated because the multiple linear regression is based on river data that may not isolate Puget Lowland developed lands.

12. Although model resolution is sufficiently fine to resolve the shoreline, islands, and river mouths, it was established at an intermediate scale to allow year-long simulations in a reasonable time frame. The limited horizontal resolution requires the model bathymetry to be smoothed, especially in the narrow long basins. This adjustment has a strong effect on residence times in the narrow and shallow inner basins of Puget Sound such as Lynch Cove, Budd Inlet, Sinclair Inlet and the finger inlets of South Puget Sound. The result is that the bottom waters are flushed out faster in the model than reality and results in higher surface DO to be mixed over entire water column.

\subsection{Recommended next steps}

The model is sufficiently calibrated for application to a series of scenarios. These scenarios include potential changes associated with climate cycles, climate change, and population growth in the Puget Sound regions.

In addition, the model could be used to evaluate whether current human sources of nutrients cause violations of the state water quality standards for dissolved oxygen. Two fundamental questions if violations occur now are how widespread and how frequently they occur. The model may be used to explore whether any violations occur throughout Puget Sound or whether they are confined to individual bays and inlets. In addition, the model may be used to evaluate whether these are frequent and persistent or sporadic in nature. Future scenarios, including the effects of climate change and population growth, will address the same questions through the year 2070. If current nutrient sources are not causing violations, then the model can inform when they might be expected to become a problem with current management approaches.

If the current or future scenarios only identify problems in the shallow basins, then additional model development may be needed to refine these regions. 


\subsection{References}

Clean Water Act. 1987. Water Pollution Control Foundation (WPCF): "The Clean Water Act of 1987." Joan M. Kovalic et al. Alexandria, VA, 1987. ISBN 978-0-943244-40-2.

Babson AL, M Kawase, and P MacCready. 2006. Seasonal and interannual variability in the circulation of Puget Sound, Washington: A box model study. Atmosphere-Ocean 44(1):29-45.

Banas, NS. 2009. Controls on Primary Production in a New, Midcomplexity, Biophysical Model of Hood Canal. A poster presented at the Coastal Estuarine Research Federation $20^{\text {th }}$ biennial conference, Estuaries and Coastal in a changing world, held in Portland Oregon. 1-5 November 2009.

Kawase M and B Bahng. 2011. Biogeochemical modeling of hypoxia in a fjord estuary: Hood Canal, Washington. Hood Canal Dissolved Oxygen Program, Integrated Assessment and Modeling Report Chapter 3.8. Available from http://hoodcanal.washington.edu/news-docs/publications.jsp?perPage=13.

Bienfang PK and PJ Harrison. 1984. Sinking-rate response of natural assemblages of temperate and subtropical phytoplankton to nutrient depletion. Marine Biology 83:293-300.

Bernhard AE and ER Peele (1997) Nitrogen limitation of phytoplankton in a shallow embayment in northern Puget Sound. Estuaries 20: 759-769.

Bowie GL, WB Mills, DB Porcella, CL Campbell, JR. Pagenkopf, GL Rupp, KM. Johnson, PWH Chan, SA Gherini, and CE Chamberlin. 1985. Rates, Constants, and Kinetics Formulations in Surface Water Quality Modeling. EPA/600/3-85/040, Environmental Research Laboratory, Office of Research and Development, U.S. Environmental Protection Agency, Athens, Georgia. Available from http://www.ecy.wa.gov/programs/eap/models/rates_and_constants/index.html.

Bunch BW, CF Cerco, MS Dortch, BH Johnson, and KW Kim. 2000. Hydrodynamic and Water Quality Model Study of San Juan Bay Estuary. ERDC TR-00-1, U.S. Army Engineer Research and Development Center, Vicksburg, Mississippi. Available from http://www.dtic.mil/cgibin/GetTRDoc?AD=ADA378533\&Location=U2\&doc=GetTRDoc.pdf.

Cannon GA. 1983. An Overview of Circulation in the Puget Sound Estuarine System, NOAA Technical Memorandum ERL PMEL-48.

Cerco CF and T Cole. 1994. Three-Dimensional Eutrophication Model of Chesapeake Bay. Technical Report EL-94-4, U.S. Army Corps of Engineers, Engineer Research and Development Center, Waterways Experiment Station, Vicksburg, Mississippi.

Cerco CF and T Cole. 1995. User's Guide to the CE-QUAL-ICM Three-Dimensional Eutrophication Model, Release Version 1.0. EL-95-15, U.S. Army Corps of Engineers, Engineer Research and Development Center, Waterways Experiment Station, Vicksburg, Mississippi. Available from http://el.erdc.usace.army.mil/elpubs/pdf/tre195-15.pdf 
Cerco CF, BW Bunch, AM Teeter, and MS Dortch. 2000. Water Quality Model of Florida Bay. Technical Report ERDC/EL TR-00-10, U.S. Army Corps of Engineers, Engineer Research and Development Center, Vicksburg, Mississippi. Available from http://el.erdc.usace.army.mil/elpubs/pdf/trel00-10.pdf.

Chen C, H Liu, and RC Beardsley. 2003. "An unstructured, finite-volume, three-dimensional, primitive equation ocean model: Application to coastal ocean and estuaries." Journal of Atmospheric and Oceanic Technology 20:159-186.

Cokelet ED, RJ Stewart, and CC. Ebbesmeyer. 1990. The Annual Mean Transport in Puget Sound. NOAA Technical Memorandum ERL PMEL-92, Pacific Marine Environmental Laboratory, Seattle, Washington

Cole TM and EM Buchak. 1995. CE-QUAL-W2: A Two-Dimensional, Laterally Averaged, Hydrodynamic and Water Quality Model, Version 2.0 - User Manual. Instruction Report EL-95-1, U.S. Army Corps of Engineers, Engineer Research and Development Center, Waterways Experiment Station, Vicksburg, Mississippi. Available from http://www.dtic.mil/cgi$\underline{\text { bin/GetTRDoc?AD=ADA298467\&Location=U2\&doc=GetTRDoc.pdf. }}$

Connell L and M Jacobs. 1998. Anatomy of a bloom: Heterosigma carterae in Puget Sound - 1997. In Puget Sound Research '98 Proceedings. Puget Sound Water Quality Action Team, Olympia, Washington.

Cox JM, CC Ebbesmeyer, CA Coomes, JM Helseth, LR Hinchey, GA Cannon, and CA Barnes. 1984. Synthesis of Current Measurements of Puget Sound, Washington-Volume I: Index of Current Measurements Made in Puget Sound from 1908-1980 with Daily and Record Averages for Selected Measurements. NOAA Technical Memorandum NOS OMS 3, U.S. Department of Commerce, National Oceanic and Atmospheric Administration, National Ocean Service, Rockville, Maryland. Available from http://environmentalengineer.com/docs/water_bodies/puget_sound/noaa/current measurements in puget_sound 19081980 v1.pdf.

Cox JM, CC Ebbesmeyer, CA Coomes, LR Hinchey, JM Helseth, GA Cannon, and CA Barnes. 1981. Index to Observations of Currents in Puget Sound, Washington, from 1908 to 1980. NOAA Technical Memorandum OMPA-5, U.S. Department of Commerce, National Oceanic and Atmospheric Administration,

Ebbesmeyer CC and CA Barnes. 1980. Control of a fjord basin's dynamics by tidal mixing in embracing sill zones. Estuarine and Coastal Marine Science 11:311-330.

Ebbesmeyer CC, CA Coomes, JM Cox, JM Helseth, LR Hinchey, GA Cannon, and CA Barnes. 1984. Synthesis of Current Measurements in Puget Sound, Washington - Volume 3: Circulation in Puget Sound: An Interpretation Based on Historical Records of Currents. NOAA Technical Memorandum NOS OMS 5, U.S. Department of Commerce, National Oceanic and Atmospheric Administration, 
National Ocean Service, Rockville, Maryland. Available from

http://docs.lib.noaa.gov/noaa documents/NOS/OMS/TM NOS OMS/nos oms 5.PDF.

Eppley RW, JN Rogers, and JJ McCarthy. 1969. Half-saturation constants for uptake of nitrate and ammonium by marine phytoplankton. Limnology and Oceanography 14(6):912-920.

Flater D. 1996. “A brief introduction to XTide.” Linux Journal 32:51-57.

Gregg M C and L J Pratt. 2010. Flow and hydraulics near the sill of hood canal, a strongly sheared, continuously stratified fjord. J. Phys. Oceanogr., 40, 1087-1105.

Harrison PJ, Mackas DL, Frost BW, MacDonald RW, Crecelius EA. 1994. An assessment of nutrients, plankton, and some pollutants in the water column of Juan de Fuca Strait, Strait of Georgia and Puget Sound, and their transboundary transport. In:Wilson RCH, Beamish RJ, Airkens F, Bell J, editors. Review of the marine environment and biota of Strait of Georgia, Puget Sound, and Juan de Fuca Strait: proceedings of the BC/Washington symposium on the marine environment, Jan 13 and 14, 1994. Can Tech Rep Fish Aquat Sci; 1994. p. 138-72.

Herndon J and WP Cochlan. 2007. Nitrogen utilization by the raphidophyte Heterosigma akashiwo: Growth and uptake kinetics in laboratory cultures. Harmful Algae 6:260-270.

Holbrook JR, RD Muench, DG Kachel, and C Wright. 1980. Circulation in the Strait of Juan de Fuca: Recent Oceanographic Observations in the Eastern Basin. NOAA Technical Report ERL 412-PMEL 33

Horner RA, JR Postel, C Halsban d-Lenk, JJ Pierson, G Pohnert, and T Wichard. 2005. Winter-spring phytoplankton blooms in Dabob Bay, Washington. Progress in Oceanography 67(3-4):286-313.

Jassby A and T Platt. 1976. Mathematical formulation of the relationship between photosynthesis and light for phytoplankton. Limnology and Oceanography 21: 40-547.

Kim T and T Khangaonkar. 2011. An Offline Unstructured Biogeochemical Model (UBM) for Complex Estuarine and Coastal Environments. Environmental Modelling \& Software 31 (2012) 47-63

Kirk JTO. 1994. Light and Photosynthesis in Aquatic Ecosystems. 2nd edition. Cambridge University Press,Cambridge, United Kingdom.

Khangaonkar T, Z Yang, T Kim, and M Roberts. 2011. Tidally Averaged Circulation in Puget Sound Sub-basins: Comparison of Historical Data, Analytical Model, and Numerical Model. Journal of Estuarine Coastal and Shelf Science, Volume 93, Issue 4, 20 July 2011, Pages 305-319.

Klausmeier CA, E Litchman, T Daufresne, and SA Levin. 2004. Optimal N:P stoichiometry of phytoplankton. Nature 429:171-174.

Krembs, C. 2012. Marine Water Condition Index. Washington State Department of Ecology. Washington State Department of Ecology, Olympia. Publication No. 12-03-013. http://spapps/sites/biblio/Summary\%20Pages/EAP/2012/1203013.html 
Large WG, Pond S (1981) Open ocean momentum flux measurements in moderate to strong winds. $J$ Phys Oceanogr 11:324-336

McAllister CD. 1970. Zooplankton rations, phytoplankton mortality, and the estimation of marine production. p. 419-457; in JH Steele. 1970. Marine Food Chains. International Council for the Exploration of the Sea, University of California Press. 552 p.

Mohamedali T, Roberts M, Sackmann BS, and Kolosseus A. 2011. Puget Sound dissolved oxygen model: nutrient load summary for 1999-2008. Washington State Department of Ecology, Olympia, Washington. Publication No. 11-03-057. https://fortress.wa.gov/ecy/publications/SummaryPages/1103057.html

Moore, SK, NJ Mantua, J A Newton, M Kawase, M J Warner, and JP Kellogg. 2008. A descriptive analysis of temporal and spatial patterns of variability in Puget Sound oceanographic properties.

Estuarine, Coastal and Shelf Science, 80 (2008) 545-554.

Newton JA and K Van Voorhis. 2002. Seasonal Patterns and Controlling Factors of Primary Production in Puget Sound's Central Basin and Possession Sound. Washington State Department of Ecology, Olympia, Washington. Publication No. 02-03-059. https://fortress.wa.gov/ecy/publications/SummaryPages/0203059.html

Newton JA, AL Thomson, LB Eisner, GA Hannach, and SL Albertson. 1995. Dissolved oxygen concentrations in Hood Canal: Are conditions different than forty years ago? In Puget Sound Research '95 Proceedings, pp. 1002-1008. Puget Sound Water Quality Authority, Olympia, Washington.

Newton JA, M Edie, and J Summers. 1998. Primary productivity in Budd Inlet: Seasonal patterns of variation and controlling factors. In Puget Sound Research '98 Proceedings, pp. 132-151. Puget Sound Action Team, Olympia, Washington.

Newton JA, SL Albertson, K Van Voorhis, C Maloy, and E Seigel. 2002. Washington State Marine Water Quality, 1998 through 2000. Washington State Department of Ecology, Olympia, Washington. Publication No. 02-03-056. https://fortress.wa.gov/ecy/publications/SummaryPages/0203056.html

Newton J, C Bassin, A Devol, M Kawase, W Ruef, M Warrner, D Hannafious, and R Rose. 2007. Hypoxia in Hood Canala: An overview of status and contributing factors. Presented to the 2007 Georgia Basin Puget Sound Research Conference, March 26-29, 2007, Vancouver, British Columbia, Canada.

Odum EP. 1971. Fundamentals of Ecology. 3rd edition. W. B. Saunders Co., Philadelphia.

Rattray M Jr and JH Lincoln. 1955. Operating characteristics of an oceanographic model of Puget Sound. Transactions, American Geophysical Union 36(2):251-261.

Rensel JEJ. 2007. Fish kills from the harmful alga Heterosigma akashiwo in Puget Sound: Recent blooms and review. Rensel Associates Aquatic Sciences, Arlington, Washington. Available from www.whoi.edu/fileserver.do?id=39383\&pt=2\&p=29109.

Roberts M, J Bos, and S Albertson. 2008. South Puget Sound Dissolved Oxygen Study Interim Data Report. Washington State Department of Ecology, Olympia, Washington. Publication No. 08-03-037. https://fortress.wa.gov/ecy/publications/SummaryPages/0803037.html 
Ruef W, A Devol, S Emerson, J Dunne, J Newton, R Reynolds, and J Lynton. 2003. Insitu and remote monitoring of water quality in South Puget Sound: The ORCA time-series. Presented to the 2003 Georgia Basin-Puget Sound Research Conference, Vancouver, BC March 31-April 3, 2003.

Sackmann B. 2009a. Quality Assurance Project Plan - Puget Sound Dissolved Oxygen Modeling Study: Large-scale Model Development. Washington State Department of Ecology, Olympia, Washington. Publication No. 09-03-103. https://fortress.wa.gov/ecy/publications/SummaryPages/0903103.html

Sackmann B. 2009b. Quality Assurance Project Plan - Puget Sound Dissolved Oxygen Modeling Study: Intermediate-scale Model Development. Washington State Department of Ecology, Olympia., Washington. Publication No. 09-03-110. https://fortress.wa.gov/ecy/publications/SummaryPages/0903110.html

Smayda TJ. 1997. Harmful algal blooms: Their ecophysiology and general relevance to phytoplankton blooms in the sea. Limnology and Oceanography 42(5, part 2):1137-1153. Available from http://www.aslo.org/lo/toc/vol_42/issue_5_part_2/1137.pdf.

Steinbuck JV, A Genin, S G Monismith, JR Koseff, R Holzman, and R Labiosa. 2010. Turbulent mixing in fine-scale phytoplankton layers: Observations and inferences of layer dynamics. Continental Shelf Research 30(5):442-455.

Snover AK, PW Mote, L Whitely Binder, AF Hamlet, and NJ Mantua. 2005. Uncertain Future: Climate Change and its Effects on Puget Sound. Climate Impacts Group, Center for Science in the Earth System, Joint Institute for the Study of the Atmosphere and Oceans, University of Washington, Seattle.

Strom, S. L., M.A. Brainard, J.L. Holmes, Olson, M. B. 2001. Phytoplankton blooms are strongly impacted by microzooplankton grazing in coastal North Pacific waters. Marine Biology, pp 355-368, v138, No 2.

Thomann R. V., and J. A. Mueller (1987). Principles of Surface Water Quality Modeling and Control. Harper and Row, Inc., New York

Tillman DH, CF Cerco, MR Noel, JL Martin, and J Hamrick. 2004. Three-Dimensional Eutrophication Model of the Lower St. Johns River, Florida. Technical Report ERDC/E1 TR-04-13, U.S. Army Corps of Engineers, Engineer Research and Development Center, Waterways Experiment Station, Vicksburg, Mississippi.

Winter DF, K Banse, and GC Anderson. 1975. The dynamics of phytoplankton blooms in Puget Sound, a fjord in the northwestern United States. Marine Biology 29:139-176.

Yang Z, T Khangaonkar, R Labiosa, and T Kim. 2010. Puget Sound Dissolved Oxygen Modeling Study: Development of an Intermediate-Scale Hydrodynamic Model. PNNL-18484, Pacific Northwest National Laboratory, Richland, Washington. 
This page is purposely left blank 


\section{Appendix A}

\section{Development and Evaluation of a Coupled Hydrodynamic}

(FVCOM) and Water Quality Model (CE-QUAL-ICM) 
This page is purposely left blank 
Estuarine and Coastal Modeling. Proceedings of the 11 th International Conference. November 4-6, 2009, Seattle, WA, Edited by M. L. Spaulding, Sponsored by Coasts, Oceans, Ports, and Rivers Institute (COPRI) and American Society of Civil Engineers (ASCE). pp 373-388

\title{
Development and Evaluation of a Coupled Hydrodynamic (FVCOM) and Water Quality Model (CE-QUAL-ICM)
}

\author{
Taeyun Kim ${ }^{1 *}$, Rochelle G. Labiosa ${ }^{1}$, Tarang Khangaonkar ${ }^{1}$, Zhaoqing Yang ${ }^{1}$, Changsheng Chen $^{2}$, \\ Jianhua $\mathrm{Qi}^{2}$, and Carl Cerco ${ }^{3}$
}

\begin{abstract}
Recent and frequent fish-kills in waters otherwise known for their pristine high quality, created increased awareness and urgent concern regarding potential for degradation of water quality in Puget Sound through coastal eutrophication caused by increased nutrient loading. Following a detailed review of leading models and tools available in public domain, FVCOM and CE-QUAL-ICM models were selected to conduct hydrodynamic and water quality simulations for the fjordal waters of Puget Sound. A high resolution hydrodynamic model of Puget Sound has already been developed and tested. The objective of this effort was to develop an associated sophisticated water quality model of Puget Sound to help nearshore restoration managers and planners in the management of nutrient loading to Puget Sound. In this study we present a one-way coupling of FVCOM hydrodynamic solution to CE-QUAL-ICM water quality kinetics. The coupled model uses FVCOM model grid and transport solution scheme to conduct water quality kinetic calculations in CE-QUAL-ICM. Through this approach, it is possible to construct the linked model with sufficient resolution in the nearshore region to address dynamics of water quality state variables in the complex coastline, multiple tidal channels, tidal flats, and a deep fjord such as Puget Sound. In this paper, we demonstrate the scalar transport and water quality module tests (a propagated pulse, diffused plumes, a BOD/oxygen sag, and phytoplankton/nutrients reactions) and compare model results with their analytical solutions as part of model validation.
\end{abstract}

\section{Introduction}

Washington State Department of Ecology (Ecology) in collaboration with U.S. Environmental Protection Agency (EPA) and Pacific Northwest National Laboratory (PNNL) has initiated the development of a water quality model of Puget Sound, Washington, to evaluate the effects of current and potential future nutrient loads on dissolved oxygen levels in Puget Sound. This project was initiated as part of the Ecology and EPA mandate under the federal Clean Water Act to manage pollution to meet Washington State water quality standards. The Puget Sound Water Quality model developed through this project is expected to answer questions such as (a) Are human sources of nutrients in and around Puget Sound significantly impacting water quality? (b) How much do we need to reduce human sources of nutrients to protect water quality in Puget Sound? PNNL is leading the development of the hydrodynamic and water quality models for use by the agencies to evaluate the effect of human sources of

\footnotetext{
${ }^{1}$ Coastal Ocean Dynamics and Ecosystem Modeling Group, Marine Science Laboratory, PNNL

${ }^{2}$ University of Massachusetts-Dartmouth

${ }^{3}$ U.S. Army Engineer Research and Development Center

* Corresponding author: Tel: + 1-206-528-3056; Fax: + 1-206-528-3552; E-mail : taeyun.kim@pnl.gov
} 
nutrients on Dissolved Oxygen (DO) across Puget Sound and to define potential Puget Sound wide nutrient management strategies and decisions.

Puget Sound is a large estuarine system bounded by 2,597 miles of complex shoreline, consists of several subbasins and has many large estuaries with distinct properties of their own. There is considerable interest in the circulation and transport in the entire region spanning the U.S. and Canadian waters for the assessment of fish migration patterns and pathways. There is also an interest in understanding the effect of nutrient loads entering Puget Sound from Canadian waters. The circulation in this estuary shows distinct fjordal three dimensional (3D) characteristics with mean outflow in the surface layers and inflow in the lower layers induced by density stratification due to freshwater discharge and surface heat exhange. The model selected must therefore be capable of simulating 3D baroclinic circulation, accommodate complex shorelines with multiple islands, and sharp change in bathymetry to deep fjordal depths of Puget Sound. The currents are also known to be affected by local winds. To meet the project objectives, the model selected must also have the ability to simulate full eutrophication kinetics including the ability to incorporate point sources, address multiple algal groups, nutrients cycling, and include sediment oxygen demand and biochemical oxygen demand processes.

A number of coastal ocean models such as CH3D, POM, EFDC, ECOM_si, and ROMS, RMA10, ADCIRC, QUODDY, UnTrim, FVCOM, ELCIRC, and others (Sheng, 1983; Blumberg and Mellor, 1987; Luettich and Westerink, 1991; Hamrick, 1992; Blumberg, 1993; Lynch and Naimie, 1993; Haidvogel et al., 2000; Casulli and Walters, 2000; Chen et al., 2003; Zhang et al., 2004) are capable of addressing the above performance requirements and were considered as part of the model selection process. The models were ranked based on various selection criteria and additional weight was placed on the ability to address the project goals of developing a tool for nutrient management actions for the Puget Sound waterbody. In consultation with an independent Technical Advisory Committee with representatives from a number of local stakeholders, PNNL and Ecology selected FVCOM and CEQUAL-ICM for the development of hydrodynamic and water quality models of Puget Sound. The models would be developed using an intermediate grid scale such that year-long simulations could be conducted efficiently and yet include the details to properly resolve significant water quality processes in the estuary. The approach selected calls for FVCOM model to generate the hydrodynamic solution to be used for conducting water quality calculations in an off line mode using CE-QUAL-ICM kinetics.

The development of the FVCOM and CE-QUAL-ICM linkage for the application to Puget Sound is presented in this paper. We provide a brief description of FVCOM and CE-QUAL-ICM as well and describe how these models were coupled as part of this effort. Furthermore, we provide validation tests that were conducted as part of quality assurance and quality control for the linkage code. Specifically, tests for scalar transport and water quality module consisting of a propagated pulse, far-field effluent plume dilution, a Biochemical Oxygen Demand (BOD)/DO sag, and phytoplankton and nutrients reactions were conducted. The results were compared with their analytical solutions as part of the validation.

\section{Methodology}

FVCOM

The Finite-Volume Coastal Ocean Model (FVCOM) was developed by Chen et al. (2003). FVCOM solves the 3-D momentum, continuity, temperature, salinity, and density equations in an integral 
form by computing fluxes between non-overlapping, horizontal, and triangular control volumes. The governing equations are in the following (Chen et al., 2003):

$$
\begin{gathered}
\frac{\partial u}{\partial x}+\frac{\partial v}{\partial y}+\frac{\partial w}{\partial z}=0 \\
\frac{\partial u}{\partial t}+u \frac{\partial u}{\partial x}+v \frac{\partial u}{\partial y}+w \frac{\partial u}{\partial z}=-\frac{1}{\rho_{0}} \frac{\partial P}{\partial x}+f v+\frac{\partial}{\partial z}\left(K_{m} \frac{\partial u}{\partial z}\right)+F_{u} \\
\frac{\partial v}{\partial t}+u \frac{\partial v}{\partial x}+v \frac{\partial v}{\partial y}+w \frac{\partial v}{\partial z}=-\frac{1}{\rho_{0}} \frac{\partial P}{\partial y}-f u+\frac{\partial}{\partial z}\left(K_{m} \frac{\partial v}{\partial z}\right)+F_{v} \\
\frac{\partial P}{\partial z}=-\rho g \\
\frac{\partial S}{\partial t}+u \frac{\partial S}{\partial x}+v \frac{\partial S}{\partial y}+w \frac{\partial S}{\partial z}=\frac{\partial}{\partial z}\left(K_{V} \frac{\partial S}{\partial z}\right)+F_{S} \\
\frac{\partial T}{\partial t}+u \frac{\partial T}{\partial x}+v \frac{\partial T}{\partial y}+w \frac{\partial T}{\partial z}=\frac{\partial}{\partial z}\left(K_{V} \frac{\partial T}{\partial z}\right)+F_{T}
\end{gathered}
$$

where $\mathrm{u}, \mathrm{v}$, and $\mathrm{w}$ are the velocity components in the horizontal $\mathrm{x}$ - and $\mathrm{y}$-directions and in the vertical zdirection, respectively; $\mathrm{t}$ is the time; $\mathrm{P}$ is the pressure; $\mathrm{g}$ is the gravitational acceleration; $\mathrm{f}$ is the Coriolis acceleration parameter; $F_{u}$ and $F_{v}$ are the horizontal momentum diffusion terms in the $\mathrm{x}$ - and $\mathrm{y}$-direction; $\rho$ is the density; $\mathrm{S}$ is the salinity; $\mathrm{T}$ is the temperature; $\mathrm{F}_{\mathrm{S}}$ and $\mathrm{F}_{\mathrm{T}}$ are the horizontal salt and thermal diffusion terms; and $\mathrm{K}_{\mathrm{m}}$ and $\mathrm{K}_{\mathrm{v}}$ are the vertical eddy viscosity and diffusivity coefficients. This finitevolume approach of solving the primitive Navier Stokes equations combines the advantages of finiteelement methods for flexibility in handling complex shorelines and the superior ability of finite difference methods for simple discrete structures and computation efficiency. A sigma-stretched coordinate system is utilized in the vertical plane to better represent the irregular bathymetry. Unstructured triangular cells are used in the lateral plane. The model employs many schemes for vertical and horizontal mixing, such as the Mellor Yamada level 2.5 turbulent closure scheme, the Smagorinsky scheme, etc. The model has been successfully applied to simulate hydrodynamics and transport processes in lakes and estuaries (Chen et al. 2003; Zheng et al. 2003; Yang and Khangaonkar, 2009).

\section{CE-QUAL-ICM}

CE-QUAL-ICM was originally developed as the eutrophication model for Chesapeake Bay by Cerco and Cole (1994) and has been applied to a number of lakes and estuaries (Cerco and Cole, 1994; Bunch, et al., 2000; Cerco et al., 2000; Tillman, et al., 2004). The model is composed of 32 state variables including multiple algae, carbon, multiple zooplankton, phosphorus, nitrogen, silica, and DO. The model also incorporates aquatic vegetation, benthic deposit feeders and a predictive sub-model to calculate interactive fluxes of DO and nutrients between sediment and water column. The model does not compute hydrodynamic information such as flows, water elevation, and diffusion coefficients, and therefore relies on hydrodynamic solutions computed externally by other models. The model solves the threedimensional mass-conservation equation for a control volume, allowing it to use structured and unstructured grids. The governing equation is as follows (Cerco and Cole, 1994): 


$$
\frac{\partial V_{j} C_{j}}{\partial t}=\sum_{k=1}^{n} Q_{k} C_{k}+\sum_{k=1}^{n} A_{k} D_{k} \frac{\partial C}{\partial x_{k}}+\sum S_{j}
$$

where $V_{j}$ is volume of $j^{\text {th }}$ control volume $\left(\mathrm{m}^{3}\right), C_{j}$ is concentration in $j^{\text {th }}$ control volume $\left(\mathrm{gm} / \mathrm{m}^{3}\right), Q_{k}$ is volumetric flow across flow face $k$ of $j^{\text {th }}$ control volume $\left(\mathrm{m}^{3} / \mathrm{see}\right), C_{k}$ is concentration in flow across flow face $\mathrm{k}\left(\mathrm{gm} / \mathrm{m}^{3}\right), A_{k}$ is area of flow face $\mathrm{k}\left(\mathrm{m}^{2}\right), \mathrm{D}_{\mathrm{k}}$ is diffusion coefficient at flow face $\mathrm{k}\left(\mathrm{m}^{2} / \mathrm{sec}\right), \mathrm{n}$ is number of flow faces attached to $\mathrm{j}^{\text {th }}$ control volume, $S$ is external loads and kinetic sources and sinks in $\mathrm{j}^{\text {th }}$ control volume $(\mathrm{gm} / \mathrm{sec}), \mathrm{t}$ is temporal coordinate, and $\mathrm{x}$ is spatial coordinate.

\section{Linkage Development}

The conversion of CE- QUAL-ICM into the unstructured grid version based on FVCOM framework was conducted by University of Massachusetts, Dartmouth team. PNNL compiled, debugged, modified, tested the linkage code, and is currently applying it to water bodies in the Pacific Northwest.

There are two approaches that are typically followed in coupling hydrodynamics and water quality models. One approach is Direct Coupling in which the two model codes are merged into a single executable program being passed hydrodynamic information to water quality code at each time-step. Another approach is Indirect Coupling in which whole simulation outputs from the hydrodynamic model are saved and used to drive the water quality kinetics. Most hydrodynamic models such as EFDC, CH3D, ROMS, and FVCOM, have sophisticated water quality modules built-in through direct coupling (Sheng and Chen, 1992; Baretta, et al., 1995; Park et al., 1995; Peeters et al., 1995). The RMA10/RMA11 models are an exception where hydrodynamic solution computed by RMA10 is read externally by RMA11 for conducting water quality calculations. Advantage of direct coupling is that water quality calculations may be conducted without having to save large hydrodynamic solution files there by reducing the storage and read/write computational burden, and ensuring accurate mass flux. However, large computational resources are needed if long duration (multi-year) simulations are desired for water quality as simulation time steps typically used in coupled codes are generally small due to stability limitations. To overcome this, many researchers have applied CH3D and EFDC models in the decoupled or indirectly coupled mode with stand alone water quality simulation programs such as WASP (DiToro et al., 1983) and CE-QUAL-ICM (Cerco and Cole 1994).

Although in principle CE-QUAL-ICM supports an unstructured grid system, its use with hydrodynamic information generated by FVCOM is complicated as it requires the creation of complex geometry, mapping of hydrodynamic files, interpolating scalar or vector information, and specifying flow and diffusivity at mesh faces to ensure mass transport and fluxes are captured correctly. In the linkage code developed here, the transport calculations are conducted in FVCOM framework and water quality calculations are conducted using CE-QUAL-ICM kinetics. This approach allows that FVCOM and CE-QUAL-ICM linkage code employs the FVCOM mesh and fluxes directly without any modifications, and then continues to conduct eutrophication kinetics using the 32 scalar variables. The linkage code may use larger computational time steps than hydrodynamic model time steps, resulting in saving the computational time. In addition, Indirect Coupling permits more economical sensitivity testing of the individual models than Direct Coupling. 
Indirect Coupling approach developed for FVCOM and CE-QUAL-ICM consists of using previously computed FVCOM hydrodynamic solution on an FVCOM triangular sigma-stretched mesh in NetCDF format. First the linkage code reads FVCOM mesh information from the NetCFD file, followed by hydrodynamic information such as velocity, diffusivities, open boundary flux, water level, salinity, and temperature. The linkage code then reads in external loads from open boundaries, river boundaries, point, and non-point sources. The information includes loading of water quality state variables as either in mass or flux loading. Once these data are loaded, water quality calculations are conducted in two steps. In step 1, kinetic equations of water quality state variables are solved using the source and sink information along with horizontal transport. In step 2, vertical transport calculations are completed. Once calculations are completed, the solution is written out for all variables at each node. A schematic flow diagram of the linkage code is provided in Figure 1.

In the next section, we provide a demonstration of the linkage code through validation tests using well known examples of physical and biological processes such as transport of a pulse, effluent plume dilution, a BOD/oxygen sag, and phytoplankton/nutrients reaction runs. The FVCOM and CE-QUAL-ICM linkage model results for the listed tests were compared with their corresponding analytical solutions. 


\section{Linkage of FVCOM and CE-QUAL-ICM}

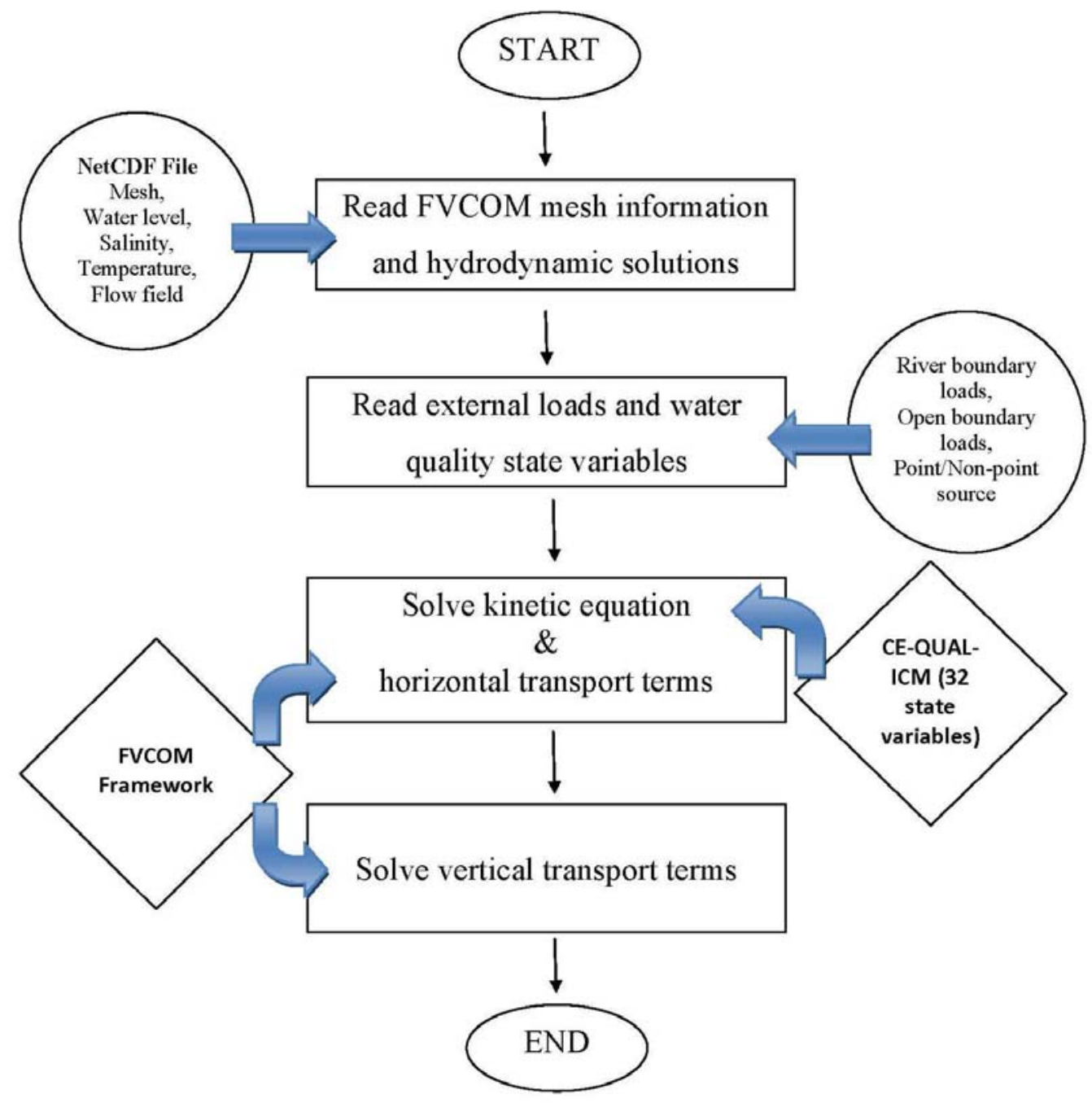

Figure A1. Schematic of linkage between FVCOM and CE-QUAL-ICM.

\section{Case Studies}

Pulse Test

We used a long channel with 40,000 m long, $100 \mathrm{~m}$ wide and 3 meter deep. The mesh has 1592 triangular elements and 1000 nodes for the pulse test. The horizontal resolution was 25 and 200 meters in $\mathrm{x}$ and $\mathrm{y}$-direction, respectively (Figure 2). Three uniform layers were employed. Initial concentration was set to 0 except the initial concentration of the pulse which was set to 20 units and $4000 \mathrm{~m}$ long. The 
channel was driven by a constant flow in x-direction with a constant velocity of $2 \mathrm{~m} / \mathrm{sec}$. Figure 3 shows that the model results agree well with the analytical solutions. For a traveling pulse with $2 \mathrm{~m} / \mathrm{s}$ velocity, the shape of the pulse was maintained reasonably well even after 4 hours of travel time.

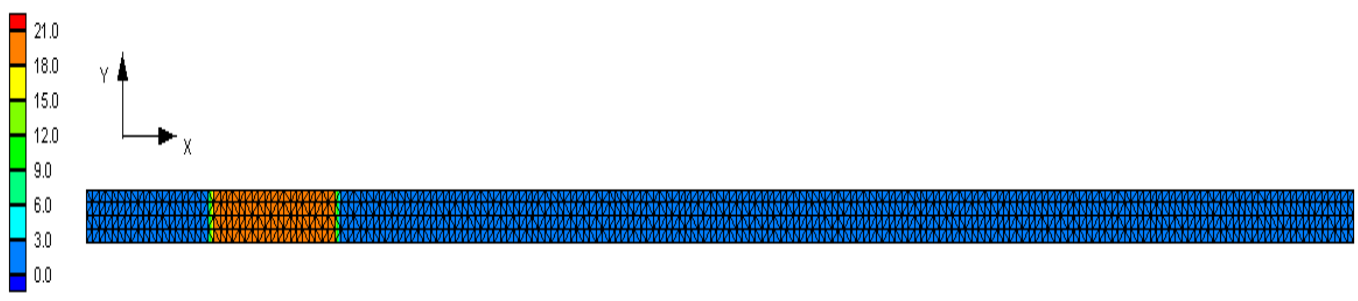

Figure A 2. FVCOM mesh and initial concentration used for the pulse test.

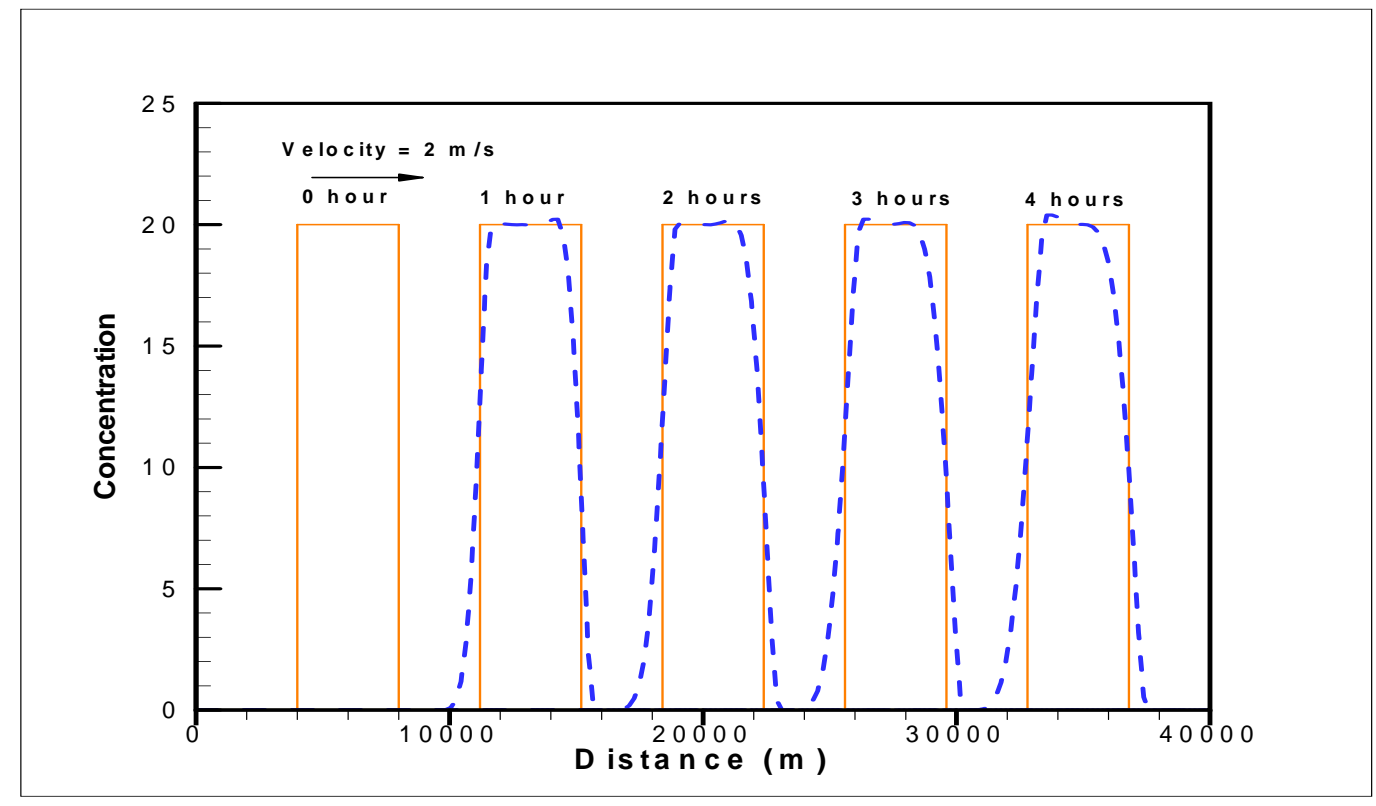

Figure A 3. A pulse test results (Dotted line - model results; solid line - analytic solution).

\section{Plume Test}

To conduct a plume test, we used a channel with 10,000 m long, $1020 \mathrm{~m}$ wide and 15 meter deep which has 50,000 triangular elements and 25,551 nodes. The horizontal resolution was 20 meters and three 5-meter layers were employed in the water column. Initial concentration was set to 0 , and the flow was uniform in the x-direction with a constant velocity of $2 \mathrm{~cm} / \mathrm{sec}$. The plume source is located at the 
center of left side of the channel with a concentration of 20 (Figure 4). To evaluate the quality of model results, we used an analytical solution corresponding to the plume test (Stommer, 1949; Brooks, 1960; Stacey et al., 2000).

$$
C(x, 0)=C_{0} \operatorname{erf}\left(\left[\frac{2}{3}\left(\left[\frac{(2-n) \beta x}{b}+1\right]^{2 / 2(2-n)}-1\right)\right]^{-1 / 2}\right)
$$

where $\mathrm{C}$ is the centerline concentration due to horizontal dispersion, $\mathrm{C}_{0}$ is a uniform source of width $\mathrm{b}$ centered at $\mathrm{y}=0, \beta=12 \varepsilon_{0} / \mathrm{U}_{\mathrm{b}}, \varepsilon_{0}$ is a constant of proportionality, $\mathrm{U}$ is a velocity, and $\mathrm{n}$ is a coefficient ( $\mathrm{n}=0$ for turbulent dispersion and $n=4 / 3$ for horizontal oceanic dispersion). As can be seen in Figure 5 , the model results have a good agreement with the analytic solutions. The fit is dependent on the specified value of $\varepsilon_{0}$ and could be improved by adjusting this parameter.

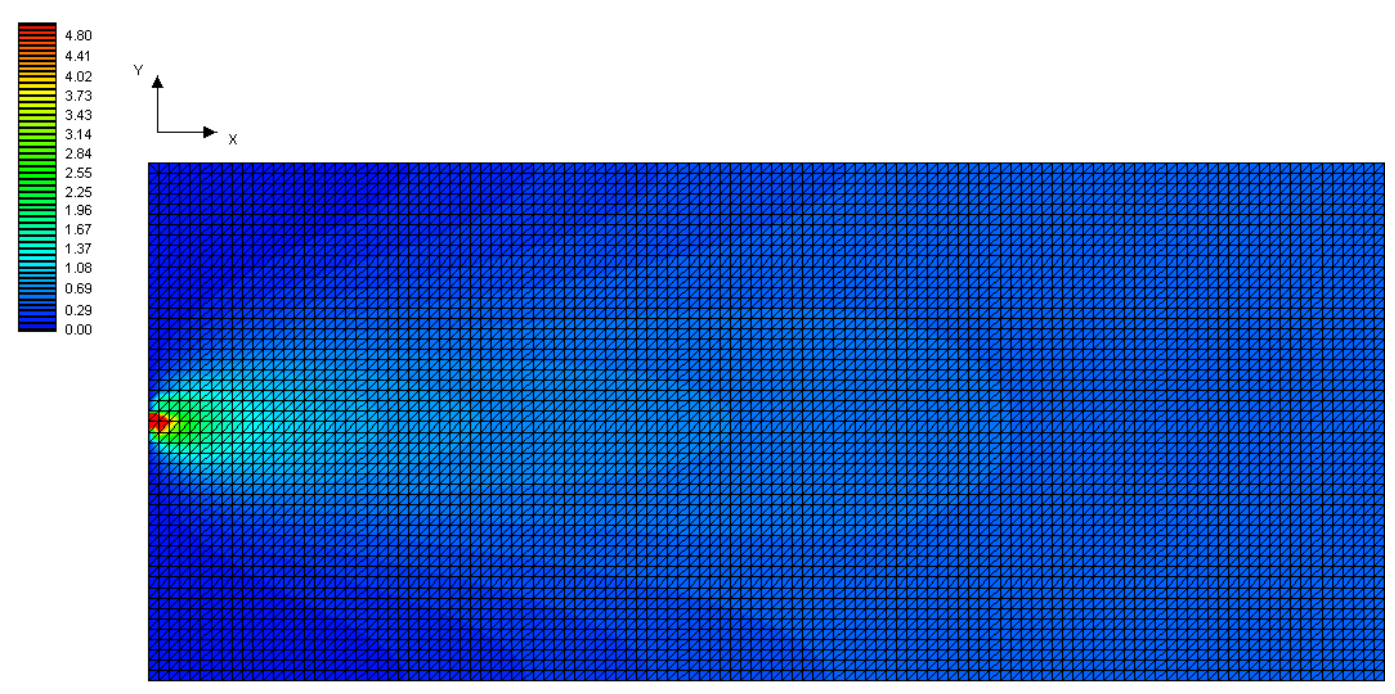

Figure A 4. Model grid and simulated surface plume concentration in the plume test. 


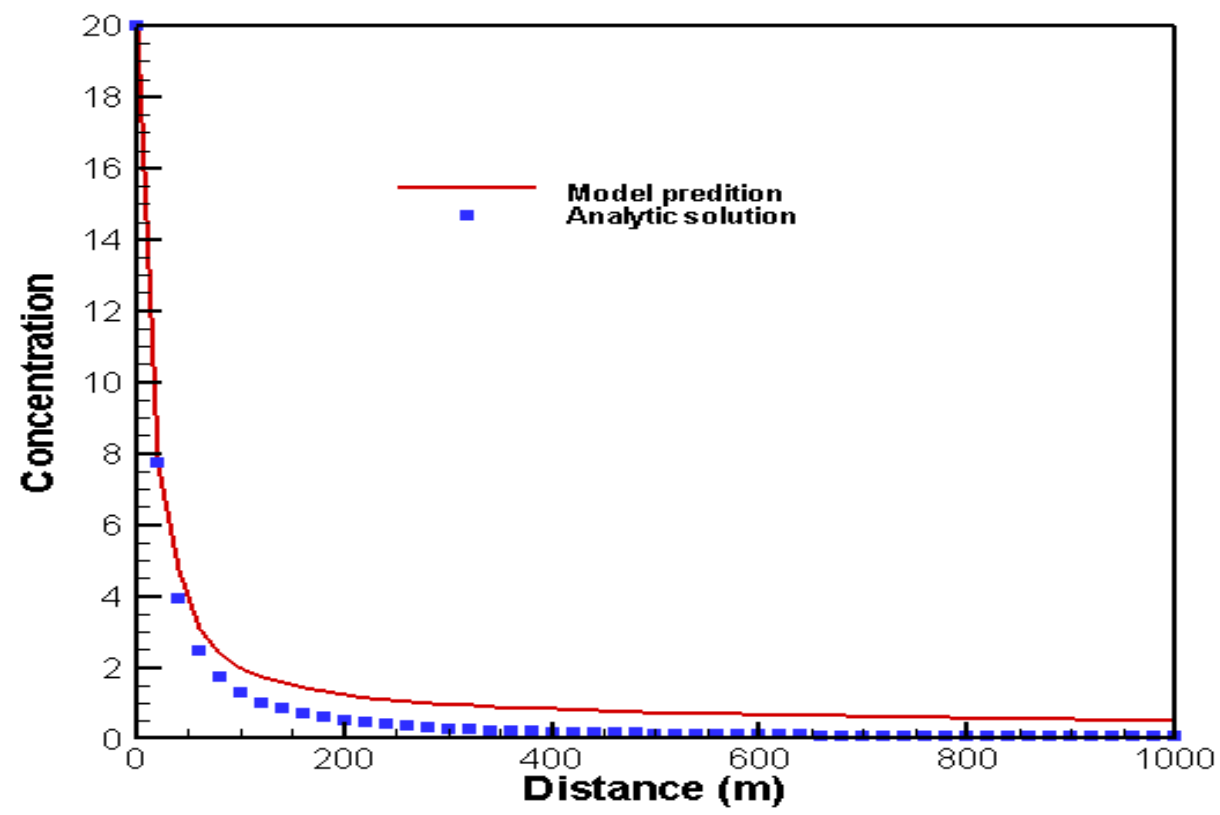

Figure A 5. Plume concentrations of analytic solution and model results along the centerline of the channel.

BOD/DO sag Test

The classic "Streeter-Phelps" model in terms of the oxygen "sag" was used to validate the performance of the linkage. We conducted a simulation of a stream with point sources of BOD. As can be seen in Figure 6, we employed a channel with 10,000 $\mathrm{m}$ long, 1,000 $\mathrm{m}$ wide and 3 meter deep which has 640 triangle elements and 369 nodes. Three 1-meter layers and the flow in the x-direction with a constant velocity of $2 \mathrm{~cm} / \mathrm{sec}$ was used. The model simulation was conducted until the stream reached a steadystate. The model included oxidation of BOD and reaeration of DO. The analytic solution of BOD/DO drawdown test is as follows (Chapra, 1997):

$$
\begin{gathered}
B O D=B O D_{0} e^{-\frac{k_{r}}{U} x} \\
D O=D O_{s}-\left[\left(D O_{s}-D O_{0}\right) e^{-\frac{k_{a}}{U} x}+\frac{k_{d} B O D_{0}}{k_{a}-k_{r}}\left(e^{-\frac{k_{r}}{U} x}-e^{-\frac{k_{a}}{U} x}\right)\right]
\end{gathered}
$$

where $\mathrm{BOD}_{0}$ is $\mathrm{BOD}$ at $\mathrm{t}=0, \mathrm{k}_{\mathrm{r}}$ is a removal rate, $\mathrm{U}$ is the velocity, $\mathrm{DO}_{\mathrm{s}}$ is oxygen saturation concentration, $\mathrm{DO}_{0}$ is $\mathrm{DO}$ at $\mathrm{t}=0$, and $\mathrm{k}_{\mathrm{a}}$ is a reaeration rate. The good agreement between the model results and the analytic solutions confirms the validation of the linkage between FVCOM and CE-QUALICM (Figure 7). 


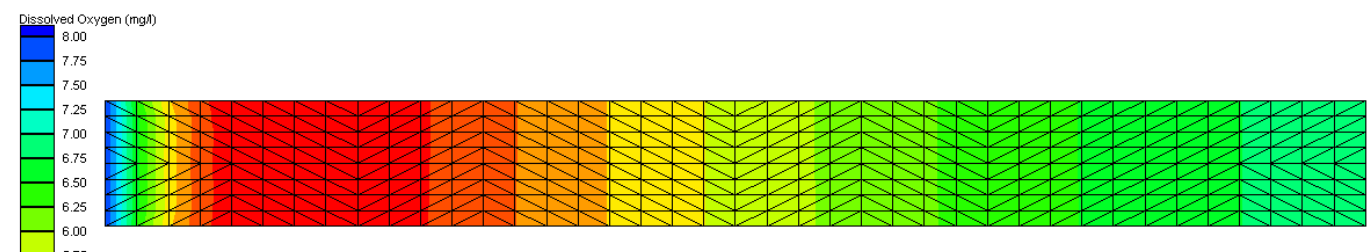

Figure A 6. A mesh and DO contour of the BOD/DO sag test.

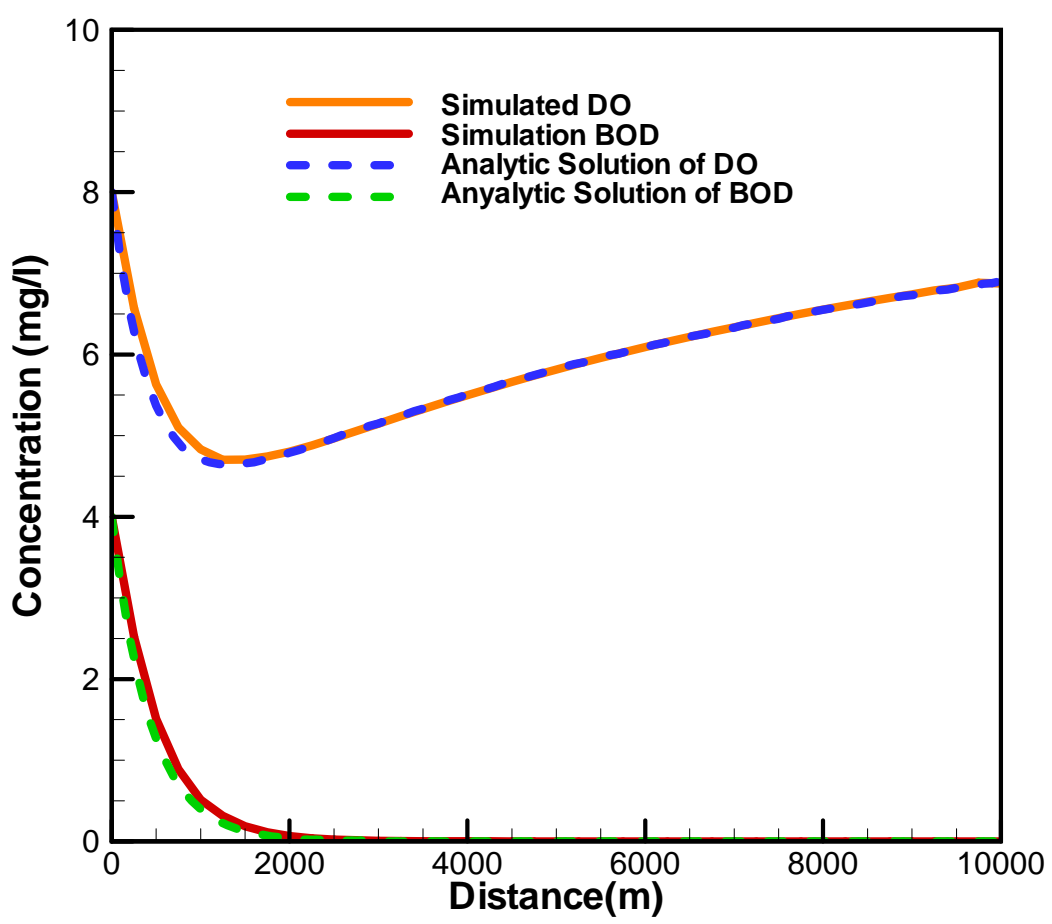

Figure A 7. BOD/DO concentrations of analytic solutions and model results along the centerline.

\section{Algal Growth and Nutrient Drawdown}

For the fourth test, we used the simplified stream phytoplankton model using an assumption that the travel time of stream nutrient should be the order of less than 10 days. This ensures that the phytoplankton biomass does not have enough time to reach the maximum growth rate, and thus the growth rate of the phytoplankton becomes a dominant factor in relatively short stream system (Thomann and Mueller, 1987). To simulate simplified stream phytoplankton growth and nutrient drawdown, we created a hydrodynamic model set-up with the stream length of $10,000 \mathrm{~m}$ long and constant stream flow of 2 $\mathrm{cm} / \mathrm{sec}$. The travel time of stream nutrient therefore was less than 6 days. For the simplified test of algal growth and nutrient drawdown, phytoplankton growth rate is limited by only inorganic nitrogen, and so light attenuation becomes constant and inorganic phosphorus is neglected. The algal growth rate and biomass are governed by the following equations. 


$$
\begin{gathered}
U \frac{d P}{d x}=\frac{d P}{d t}=G(N) P \\
G(N)=\min \left\{\frac{N O_{3}}{H_{N}+N O_{3}}\right\}
\end{gathered}
$$

where $U$ is a stream velocity, $P$ is phytoplankton, $G(N)$ is a growth rate of the phytoplankton, $H_{N}$ is a halfsaturation constant, and $\mathrm{NO}_{3}$ is nitrate-nitrite. The linkage successfully captures the increase in phytoplankton biomass and decrease in nitrate-nitrite concentration. The comparison between model results and analytical solution is presented in Figure 8.

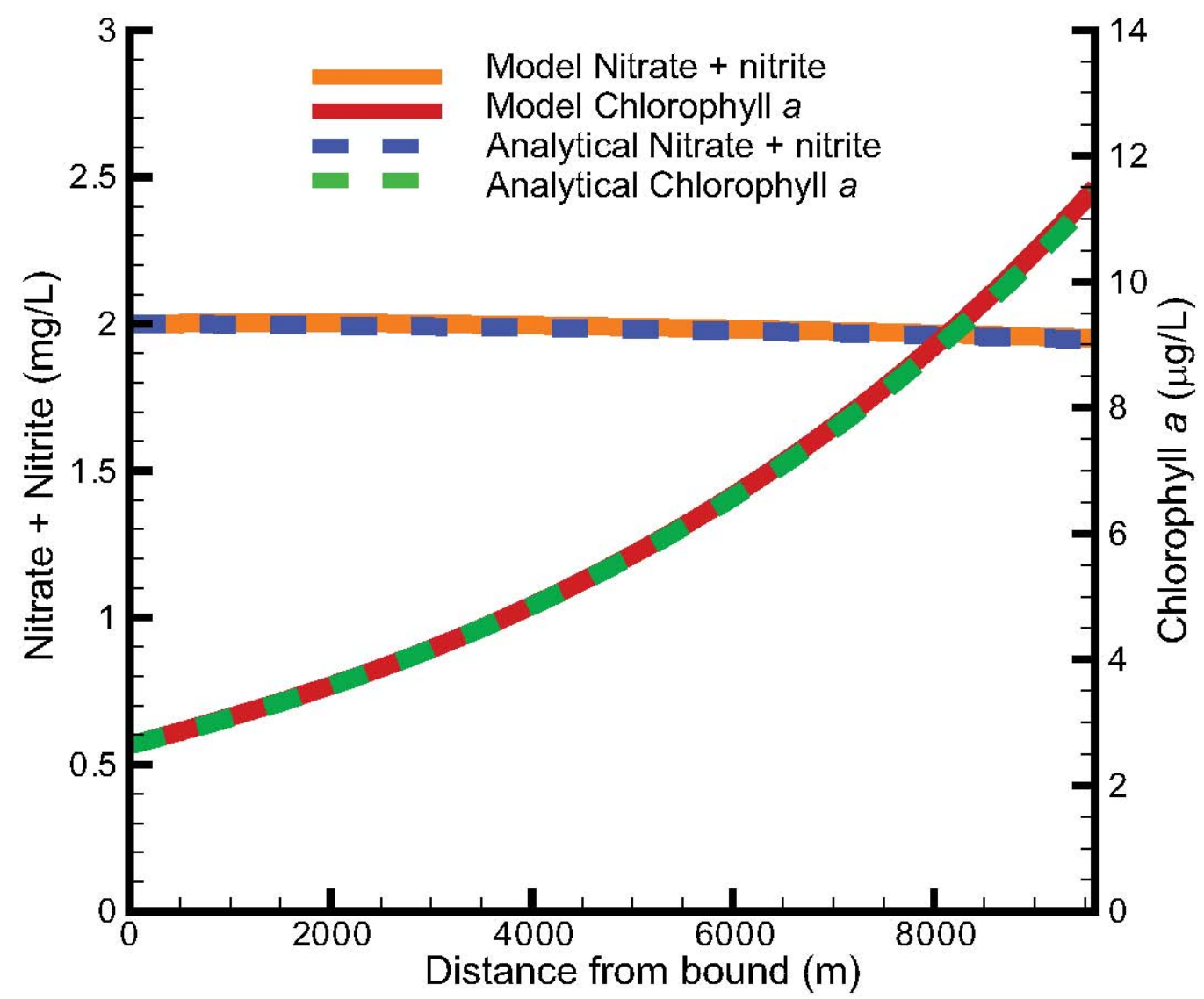

Figure A 8. Algal growth and nutrient drawdown along the centerline.

\section{Conclusion and Discussion}

A water quality modeling system consisting of coupled FVCOM and CE-QUAL-ICM models was developed for the application to Puget Sound. The modeling system has been validated by comparison of model results to analytical solutions for four well known tests such scalar transport of a propagated pulse, plume dispersion, a BOD/oxygen sag, and phytoplankton/nutrients reactions. The model results showed good agreement with the analytical solutions for the four tests. The FVCOM and CE-QUAL-ICM linkage code is considered sufficiently validated therefore can be applied to evaluate the effect of human-caused nutrient enrichment on DO Puget Sound. 


\section{Acknowledgement}

This research was funded by the Washington State Department of Ecology, USEPA, PNNL, and DOE EERE program. University of Massachusetts (UMASS) and Army Corps Engineering contributed to the initial development of the linkage of FVCOM and CE-QUAL-ICM and their support and encouragement is highly appreciated.

\section{References}

Baretta, J.W., Ebenhoh, W., and Ruardij, P. (1995) "The European regional seas ecosystem model, a complex marine ecosystem model." Netherlands Journal of Sea Research, 33, 233-246.

Blumberg, A.F. (1993). “A primer of ECOM-si.” Technical report, HydorQual, Inc., Mahwah, New Jersey.

Blumberg, A.F., and Mellor, G.L. (1987). "A description of a three-dimensional coastal ocean circulation model.” IN: Heaps, N. (Ed.), Three-Dimensional Coastal Ocean Models, American Geophysical Union, Washington, DC.

Bunch, B.W., Cerco, C.F., Dorth, M.S., Johnson B.H., and Kim, K.W. (2000). "Hydrodynamic and water quality model of San Juan Bay estuary.” Technical Report ERDC TR-00-1, U.S. Army Corps of Engineer.

Brooks, N.H. (1960). "Diffusion of sewage effluent in an ocean-current." Proceeding of First International Conference on Waste Disposal in the Marine Environment, UC-Berkeley.

Casulli, V. and Walters, R.A. (2000). "An unstructured grid, three-dimensional model based on the shallow water equations." International Journal for Numerical Methods in Fluids, 32, 331-348.

Cerco, C.F., Bunch, B.W., Teeter, A.M., and Dorth, M.S. (2000). "Water quality model of Florida Bay." Technical Report ERDC/EL TR-00-10, U.S. Army Corps of Engineer.

Cerco, C. and Cole, T. (1994). "Three-dimensional eutrophication model of Chesapeake Bay." Technical Report EL-94-4, US Army Corps of Engineer.

Chapra, S.C. (1997). "Surface water-quality modeling.” McGraw-Hill, pp. 844.

Chen C., Liu, H., and Beardsley, R.C. (2003). “An Unstructured, Finite-Volume, ThreeDimensional, Primitive Equation Ocean Model: Application to Coastal Ocean and Estuaries." $J$. Atm. \& Oceanic Tech., 20, 159-186.

DiToro, D.M, Fitzpatrick, J.J., Thomann, R.V., and Hydroscience, Inc. (1983). "Documentation for water quality analysis simulation Program (WASP) and model verification program (MVP).” U.S. EPA Ecological Research Series. EPA-600/3-81-044. 
Estuarine and Coastal Modeling. Proceedings of the 11 th International Conference. November 4-6, 2009, Seattle, WA, Edited by M. L. Spaulding, Sponsored by Coasts, Oceans, Ports, and Rivers Institute (COPRI) and American Society of Civil Engineers (ASCE). pp 373-388

Haidvogel, D.B., Arango, H.G., Hedstrom, K., Beckmann, A., Malanotte-Rizzoli, P., and Shchepetkin, A.F. (2000). "Model evaluation experiments in the North Atlantic Basin, simulation in nonlinear terrainfollowing coordinates." Dynamics of Atmospheres and Oceans, 32, 239-281.

Hamrick, J.M. (1992). “A three-dimensional environmental fluid dynamics computer code: Theoretical and computational aspects." The College of William and Mary, Virginia Institute of Marine Science, Special Report 317.

Luettich, R.A. and Westerink, J.J. (1991). "A solution for the vertical variation of stress, rather than velocity, in a three-dimensional circulation model." International Journal for Numerical Methods in Fluids, 12, 911-928.

Lynch, D.R. and Naimie, C.E. (1993). "The $\mathrm{M}_{2}$ tide and its residual on the outer banks of the Gulf of Maine.” Journal of Physical Oceanography, 23, 2222-2253.

Mote, P.W. and N.J. Mantua. 2002. Coastal upwelling in a warmer future. Geophysical Research Letters 29(23):53-1-53-4.

Park, K., Kuo, A.Y., Shen, J., and Hamrick, J.M. (1995) “A three-dimensional hydrodynamiceutrophication model (HEM-3D): description of water quality and sediment process submodels." Special Report in Applied Marine Science and Ocean Engineering No.327. School of Marine Science Virginia Institute of Marine Science, College of William and Mary, Gloucester Point, VA 23062.

Peeters , J.C.H., Los, F.J., Jansen, R., Haas, H.A., Peperzak, L., and de Vries, I. (1995). "The oxygen dynamics of the Oyster Ground, North Sea. Impact of eutrophication and environmental conditions." Ophelia, 42, 257-288.

Sheng, Y.P. (1983). "Mathematical modeling of three-dimensional coastal currents and sediment dispersion: model development and application." Coastal Engineering Research Center Tech. Rep. CERC-TR-83-2. U.S. Army Corps of Engineers.

Sheng, Y.P., and Chen, X.J. (1992) “A three-dimensional numerical model of hydrodynamics, sediment transport and phosphorus dynamics in Lake Okeechobee: theory, model development, and documentation, spring 1989." Final Report to the South Florida Water Management District, Coastal and Oceanographic Engineering Department, University of Florida, Gainesville, Florida.

Stommer, H. (1949). "Horizontal diffusion due to oceanic turbulence." Journal of Marine Research, 8 (3), 199-225.

Stacey, M.T., Cowen, E.A., Powell, T.M., Dobbins, E., Monismith, S.G., and Koseff, J.R. (2000). "Plume dispersion in a stratified, near-coastal flow: measurements and modeling." Continental Shelf Research, 20, 637-663.

Tillman, D.H., Cerco, C.F., Noel, M.R., Martin, J.L., and Hamrick, J. (2004). “Three-dimensional eutrophication model of the lower St. Johns River, Florida," Technical Report ERDC/El TR-04-13, U.S. Army Engineer Waterways Experiment station, Vicksburg, M.S.

Thomann, R.V. and Mueller, J.A. (1987). "Principles of surface water quality modeling and control." Harper and Row, pp. 644. 
Yang, Z. and Khangaonkar, T. (2009). "Modeling tidal circulation and stratification in Skagit River estuary using an unstructured grid ocean model.” Ocean Modelling, 28, 34-49.

Zhang, Y., Baptista, A., and Meyers, E. (2004). "A cross-scale model for 3D baroclinic circulation in estuary-plume-shelf systems: I. Formulation and skill assessment." Continental Shelf Research, 24, 2187-2214.

Zheng L., Chen, C., and Liu. H. (2003). "A Modeling Study of the Satilla River Estuary, Georgia. Part I: Flooding/Drying Process and Water Exchange over the Salt Marsh-EstuaryShelf Complex." Estuaries, 26(3), 651-669. 


\section{Appendix B}

\section{Dissolved Oxygen Profiles}

\section{Comparison of Year 2006 Monthly Profile Data with Predicted Results}


This page is purposely left blank 
$\mathrm{DO}(\mathrm{mg} / \mathrm{L})$

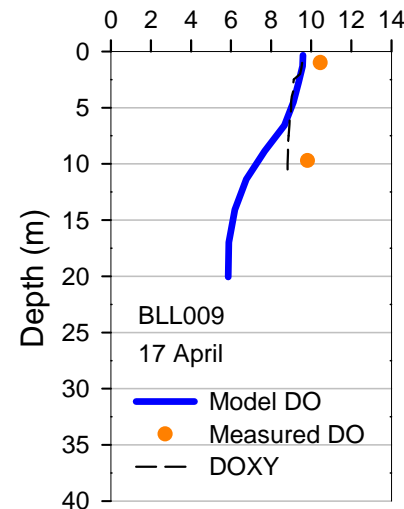

$\underset{0}{\square}$

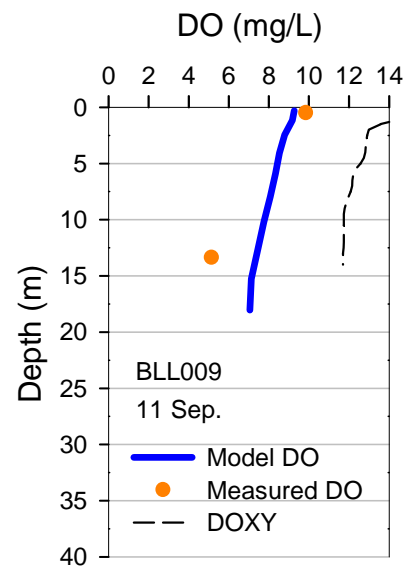

$\mathrm{DO}(\mathrm{mg} / \mathrm{L})$

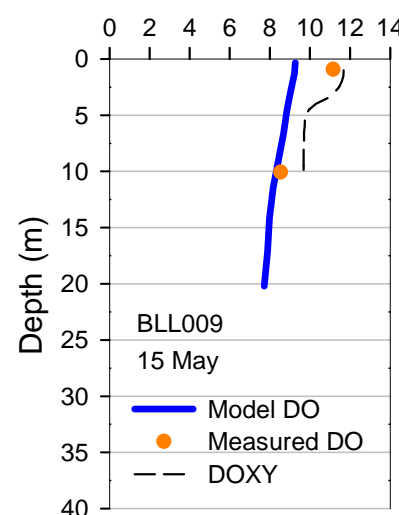

$\mathrm{DO}(\mathrm{mg} / \mathrm{L})$

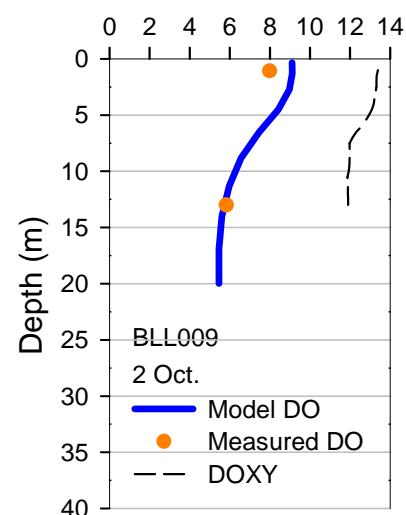

$\mathrm{DO}(\mathrm{mg} / \mathrm{L})$

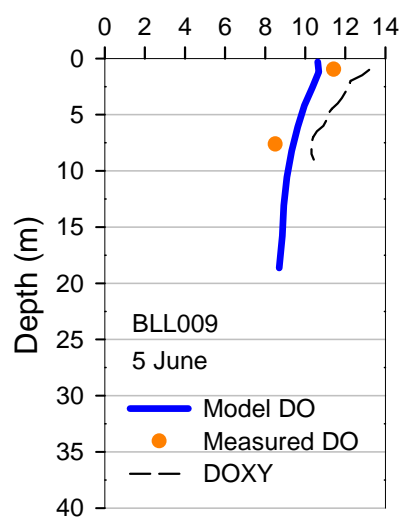

40

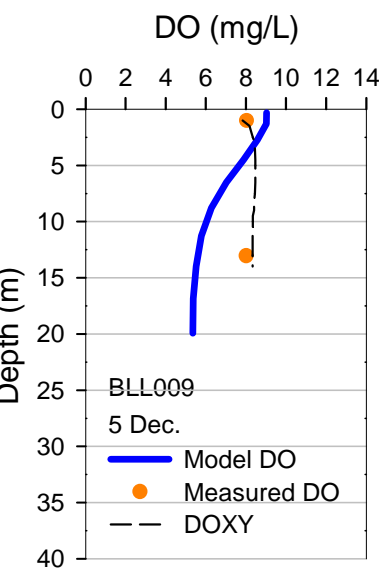

$\mathrm{DO}(\mathrm{mg} / \mathrm{L})$
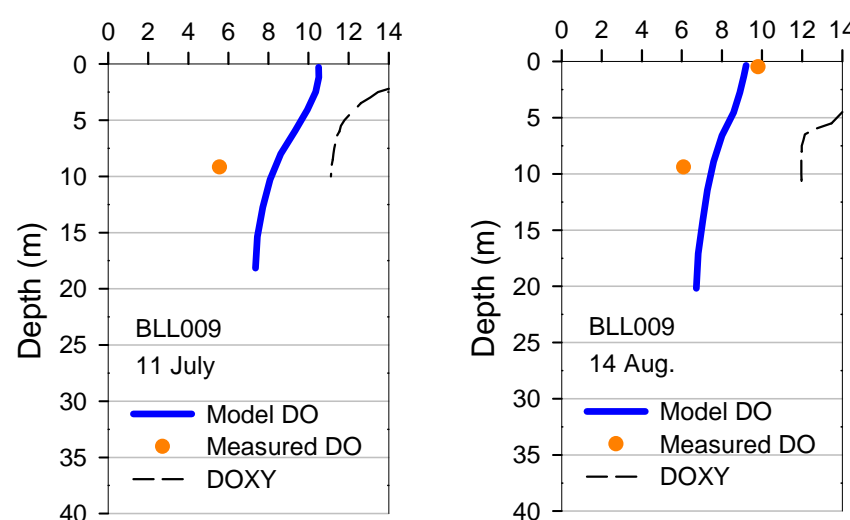

Figure B.1. Dissolved Oxygen Profiles - Bellingham Bay (BLL009). Comparison of measured DO profiles with model results for Year 2006. Circles represent the discretely measured data, and dashed black lines represent the CTD oxygen probe. 

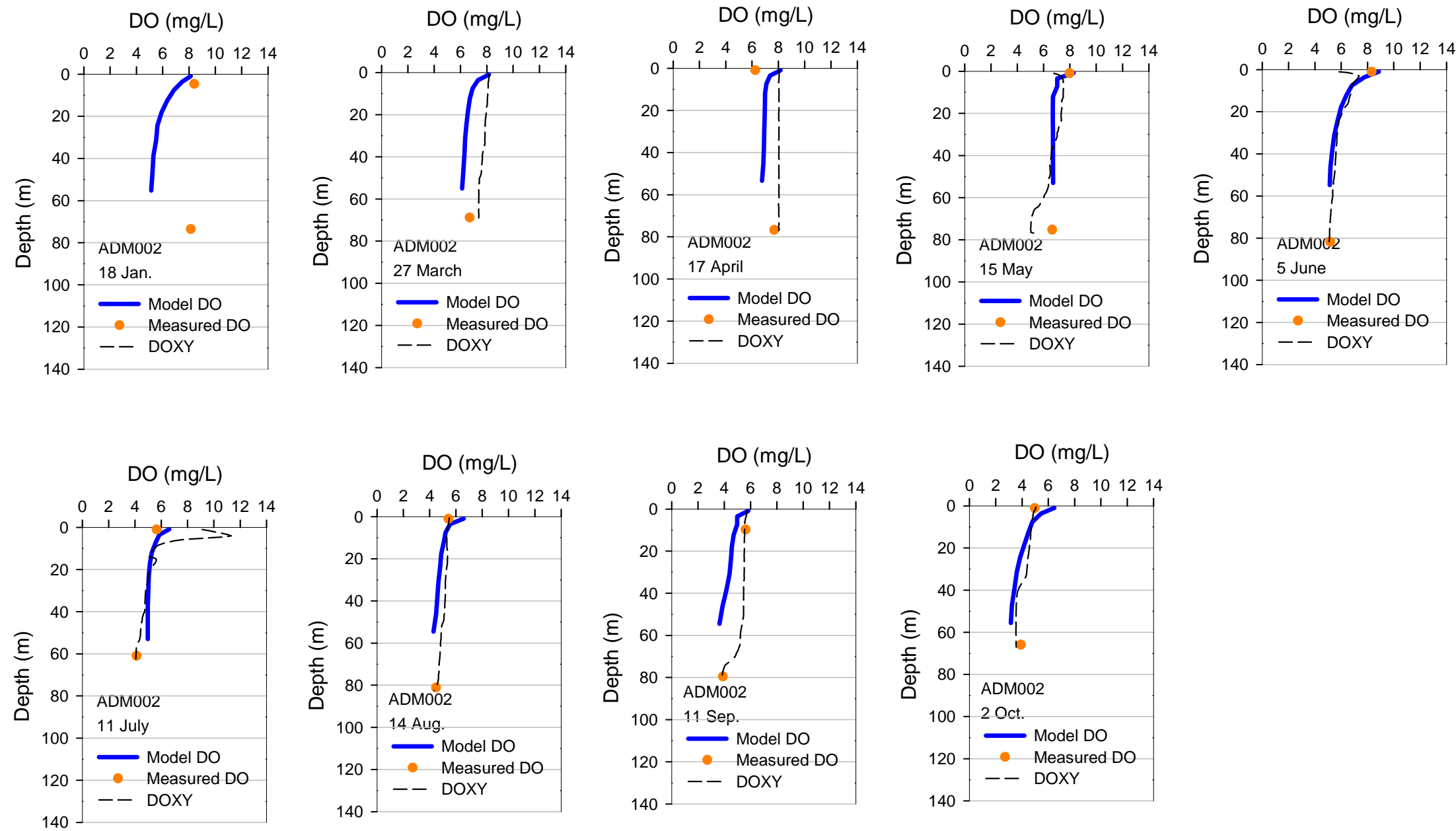

Figure B.2. Dissolved Oxygen Profiles - Admiralty Inlet (ADM002). Comparison of measured DO profiles with model results for Year 2006. Circles represent the discretely measured data, and dashed black lines represent the CTD oxygen probe. 

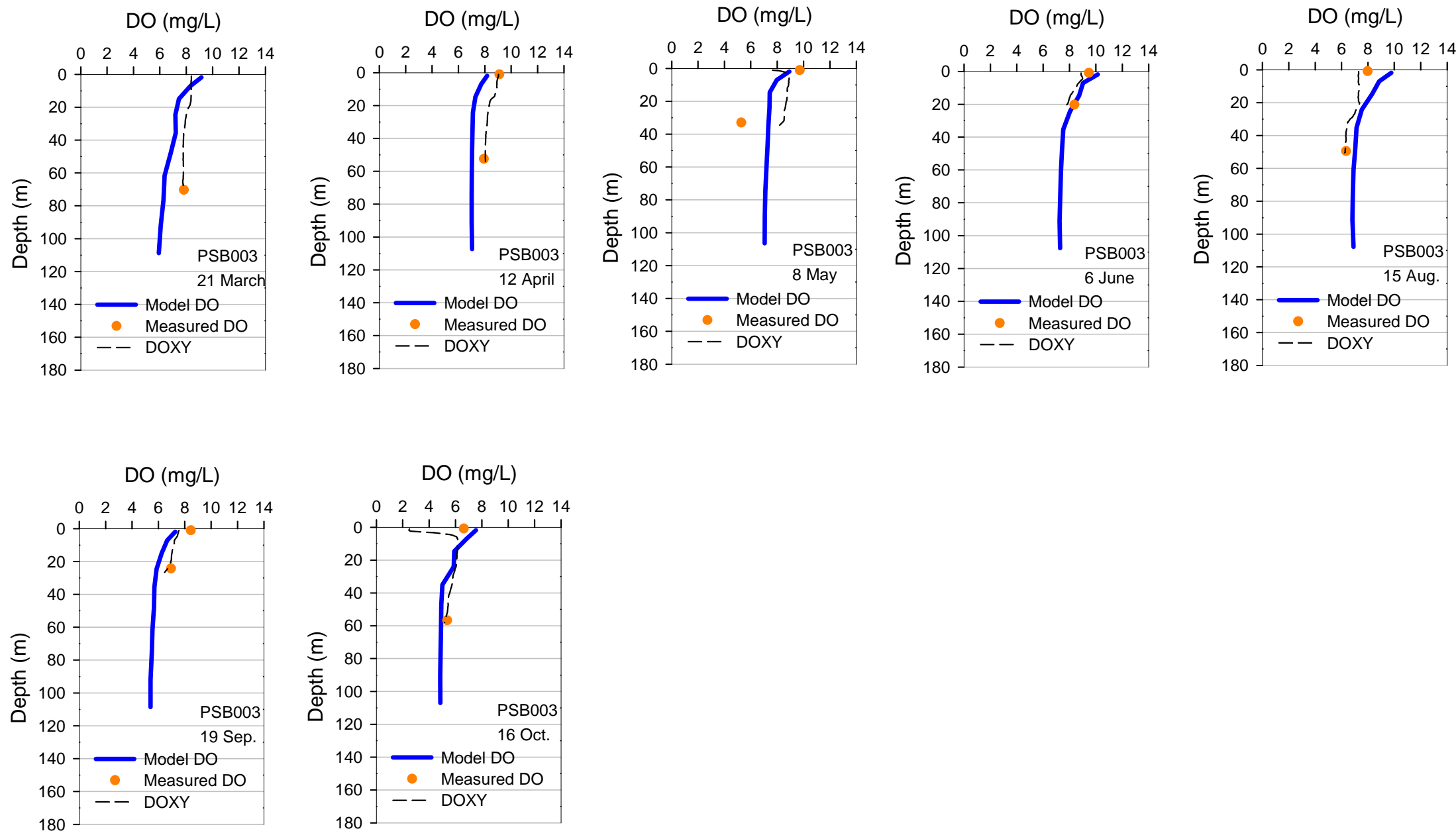

Figure B.3. Dissolved Oxygen Profiles - Puget Sound Basin (PSB003). Comparison of measured DO profiles with model results for Year 2006. Circles represent the discretely measured data, and dashed black lines represent the CTD oxygen probe. 

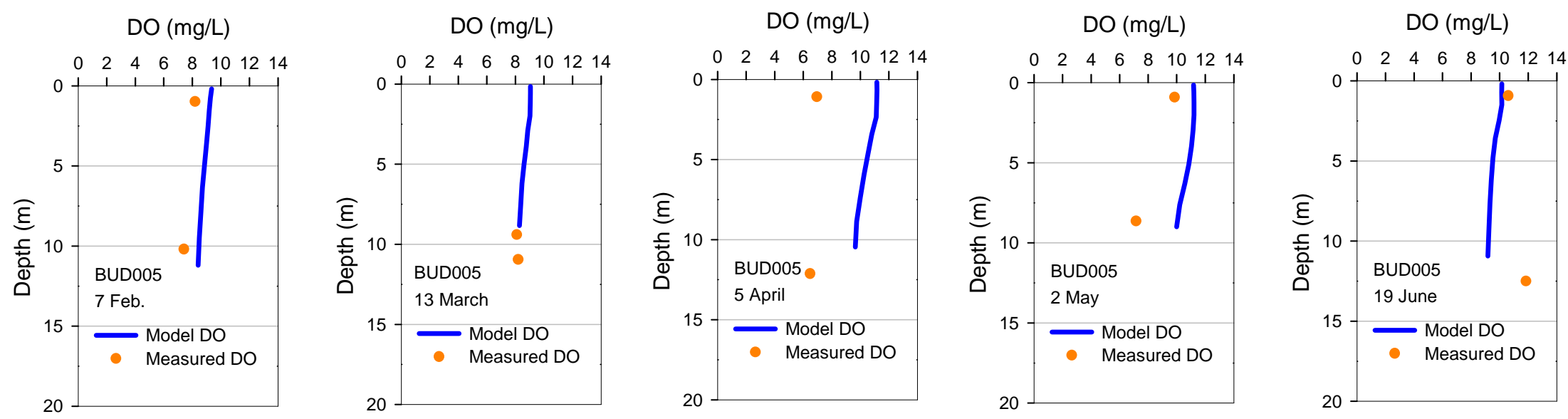

$\underset{\square}{\oplus}$
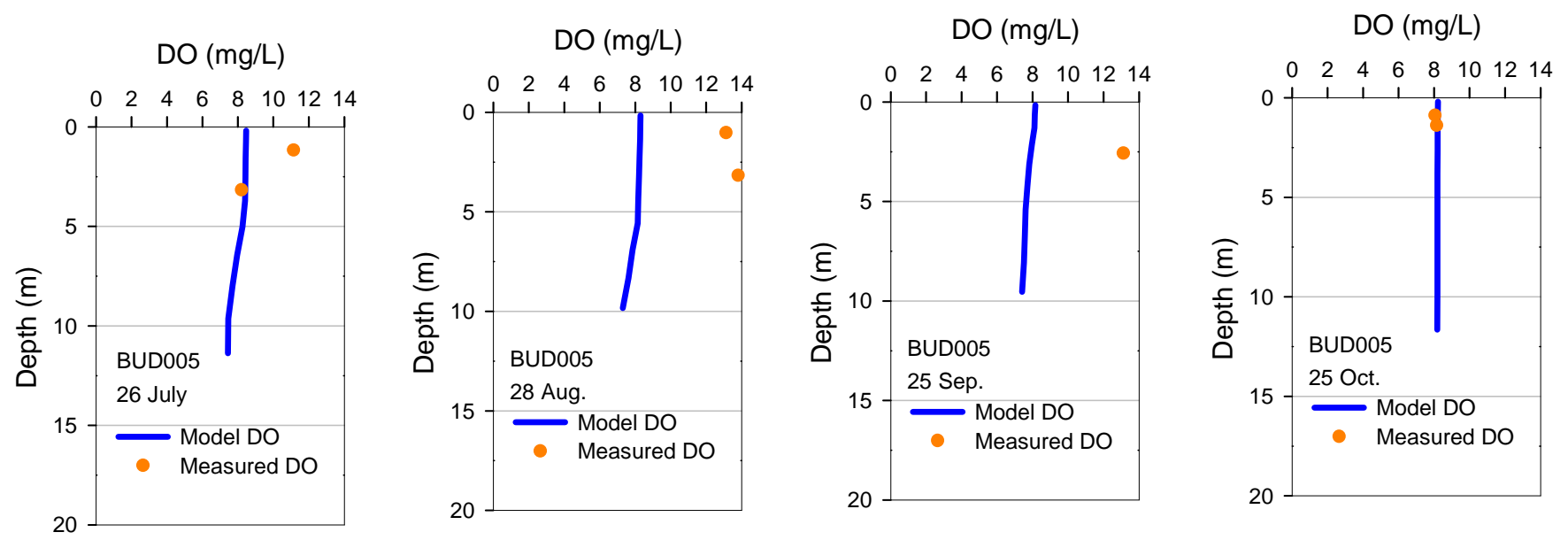

Figure B.4. Dissolved Oxygen Profiles - Budd Inlet (BUD005). Comparison of measured DO profiles with model results for Year 2006. Circles represent the discretely measured data. 

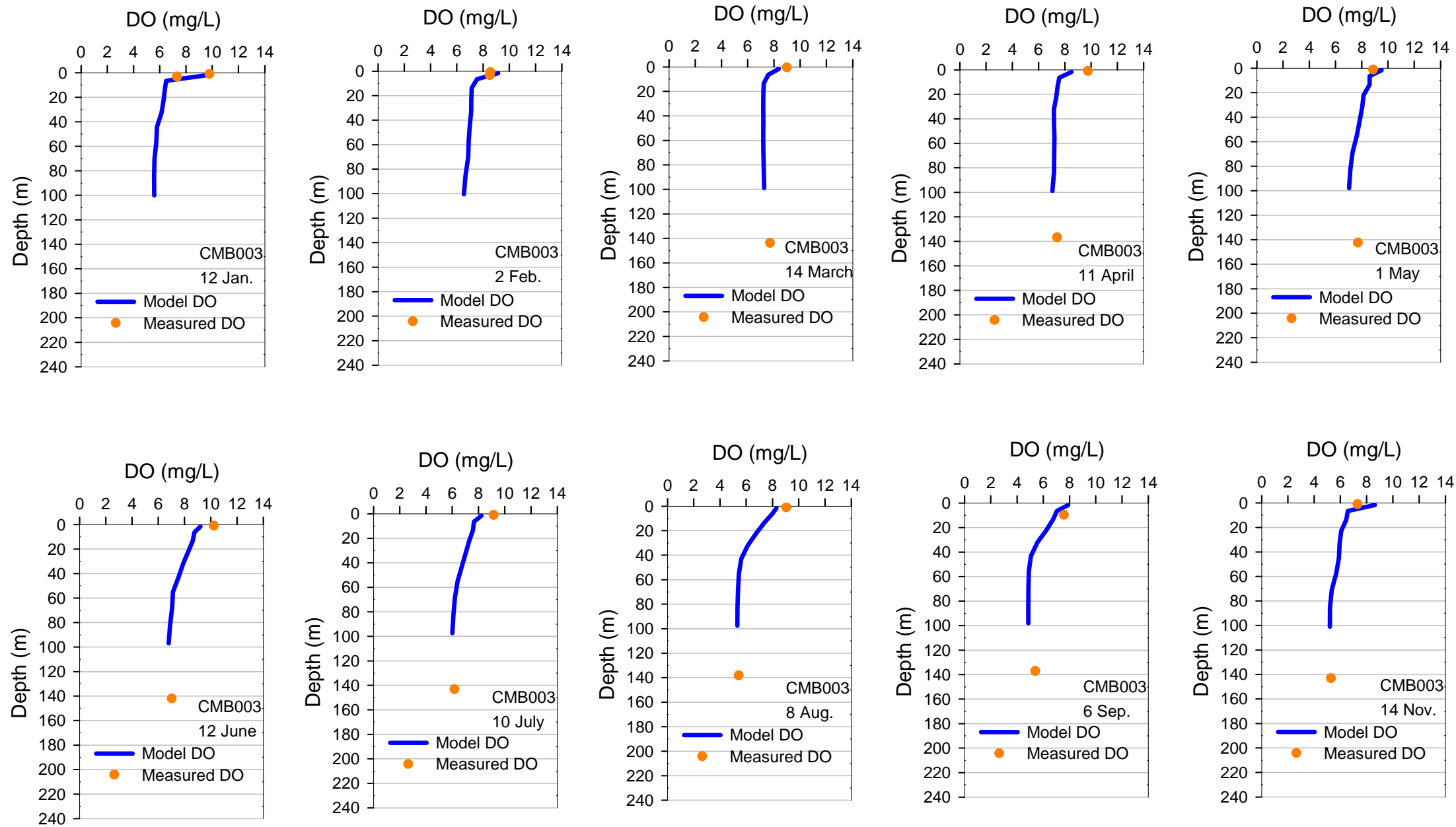

Figure B.5. Dissolved Oxygen Profiles - Commencement Bay (CMB003). Comparison of measured DO profiles with model results for Year 2006. Circles represent the discretely measured data. 
$\mathrm{DO}(\mathrm{mg} / \mathrm{L})$

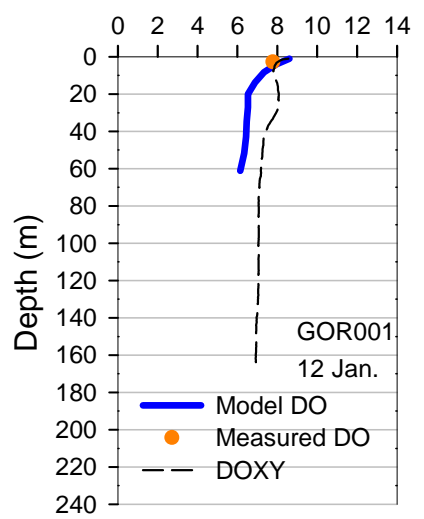

$\mathrm{DO}(\mathrm{mg} / \mathrm{L})$

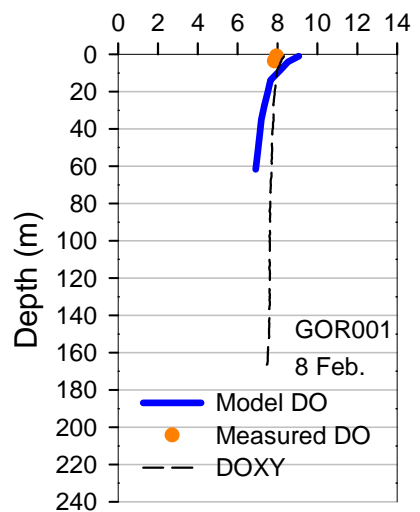

$\mathrm{DO}(\mathrm{mg} / \mathrm{L})$

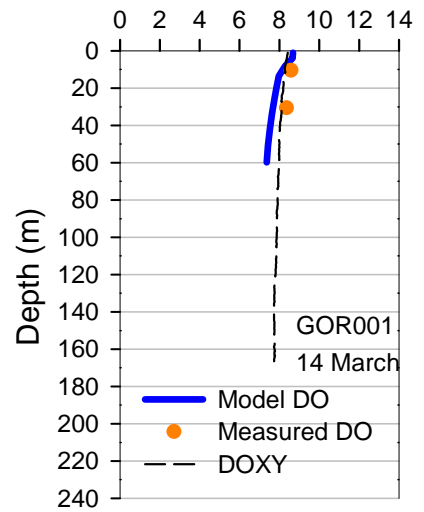

$\mathrm{DO}(\mathrm{mg} / \mathrm{L})$

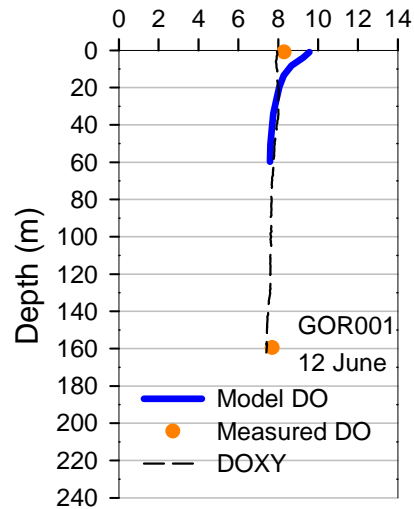

$\mathrm{DO}(\mathrm{mg} / \mathrm{L})$

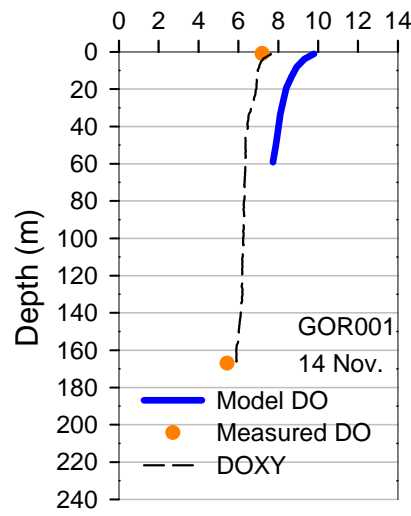

Figure B.6. Dissolved Oxygen Profiles - Gordon Point (GOR001). Comparison of measured DO profiles with model results for Year 2006. Circles represent the discretely measured data, and dashed black lines represent the CTD oxygen probe. 

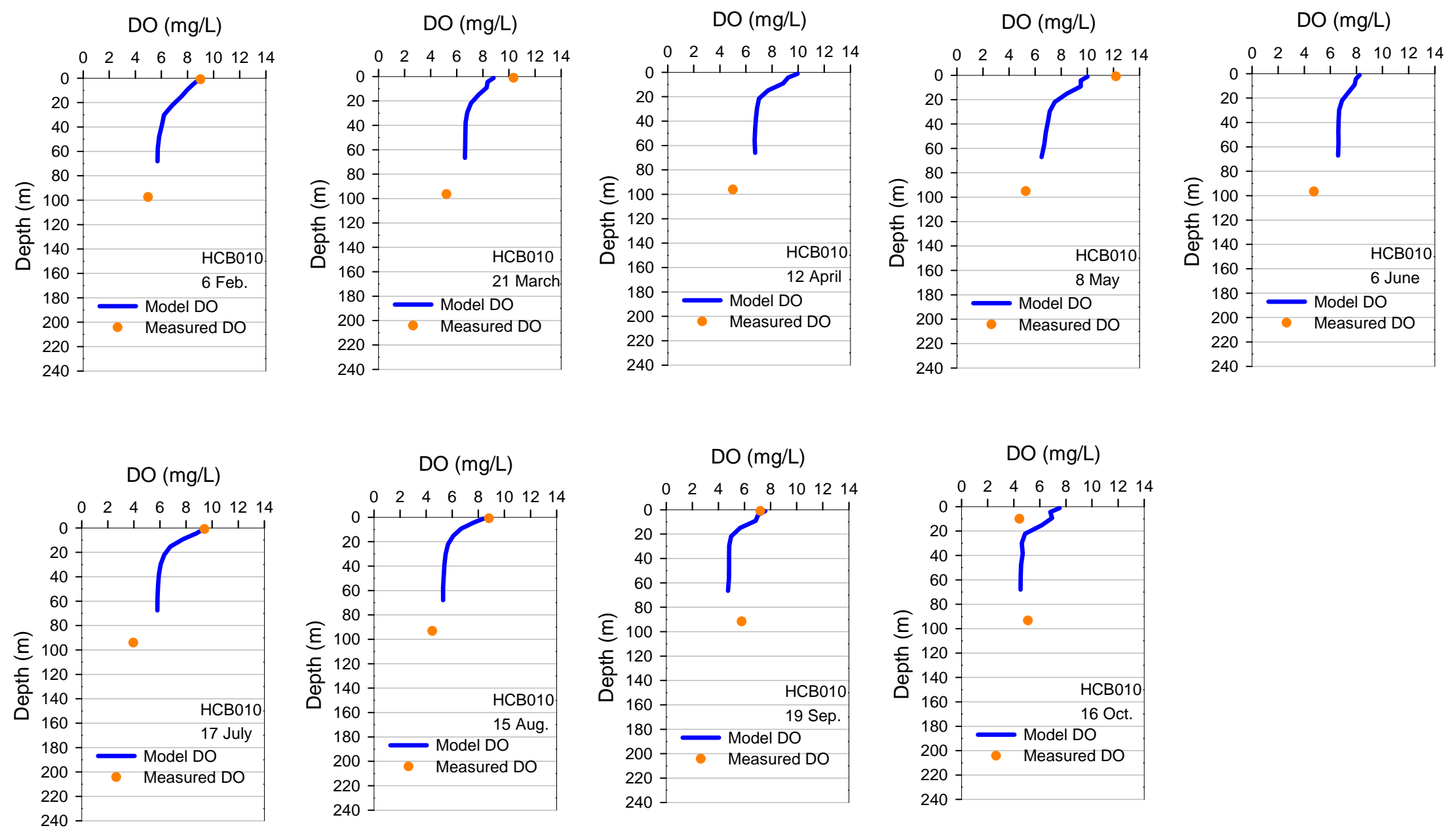

Figure B.7. Dissolved Oxygen Profiles - Hood Canal (HCB010). Comparison of measured DO profiles with model results for Year 2006. Circles represent the discretely measured data. 

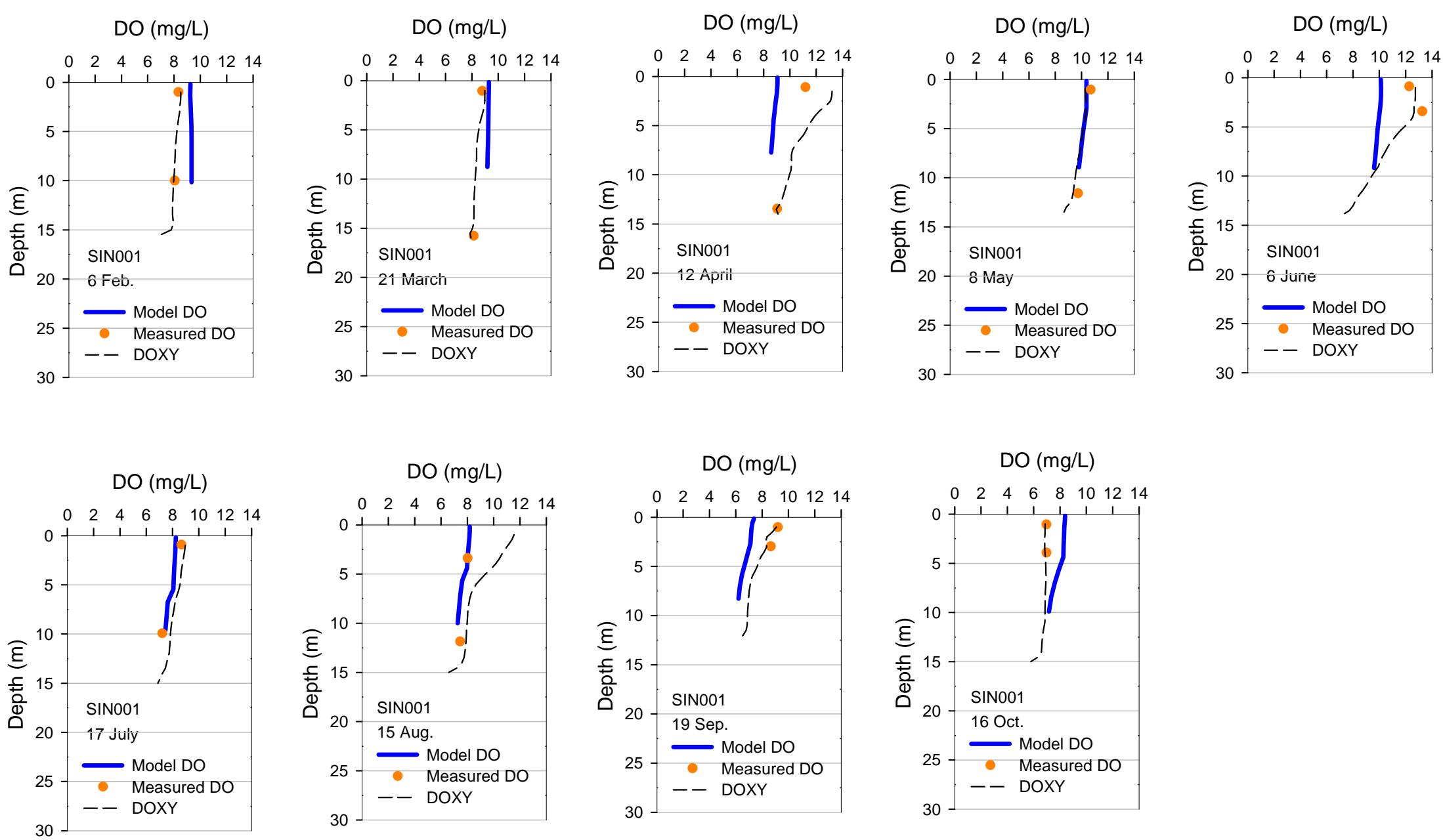

\section{$\mathrm{DO}(\mathrm{mg} / \mathrm{L})$}

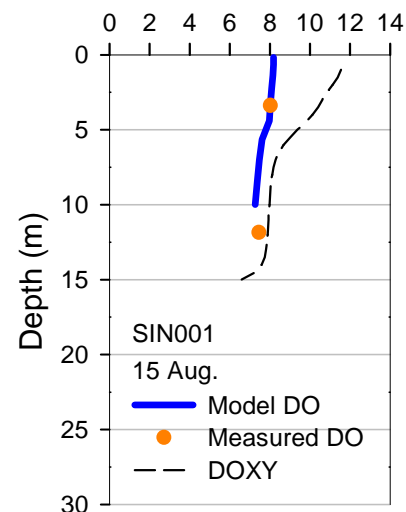

DO (mg/L)

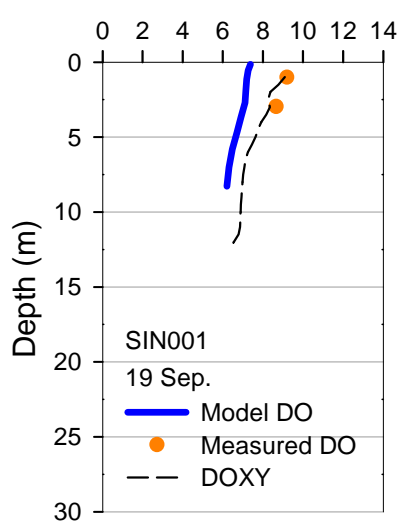

$\mathrm{DO}(\mathrm{mg} / \mathrm{L})$

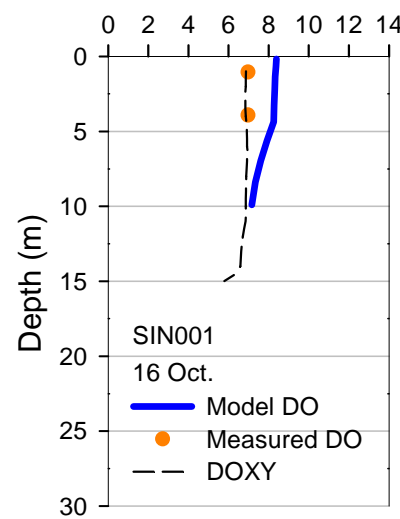

Figure B.8. Dissolved Oxygen Profiles - Sinclair Inlet (SIN001). Comparison of measured DO profiles with model results for Year 2006. Circles represent the discretely measured data, and dashed black lines represent the CTD oxygen probe. 

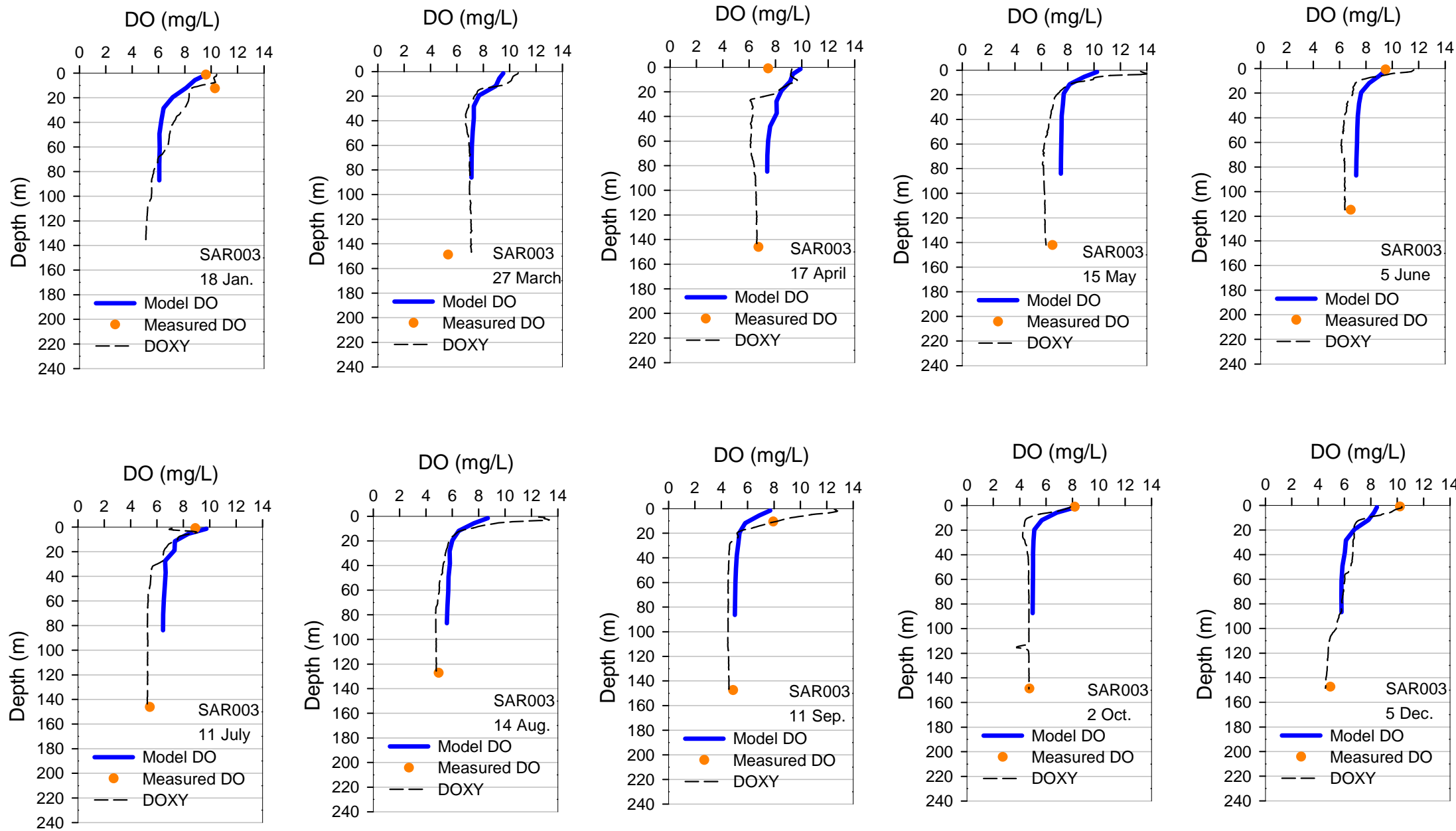

$\mathrm{DO}(\mathrm{mg} / \mathrm{L})$

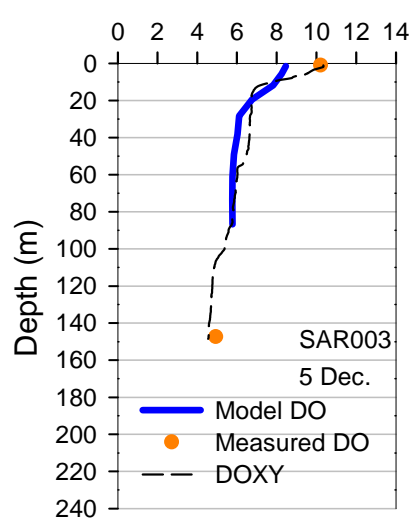

Figure B.9. Dissolved Oxygen Profiles - Saratoga Passage (SAR003). Comparison of measured DO profiles with model results for Year 2006. Circles represent the discretely measured data, and dashed black lines represent the CTD oxygen probe. 



\section{Appendix C}

(Nitrate + Nitrite) Profiles

Comparison of Year 2006 Monthly Profile Data with Predicted Results 
This page is purposely left blank 

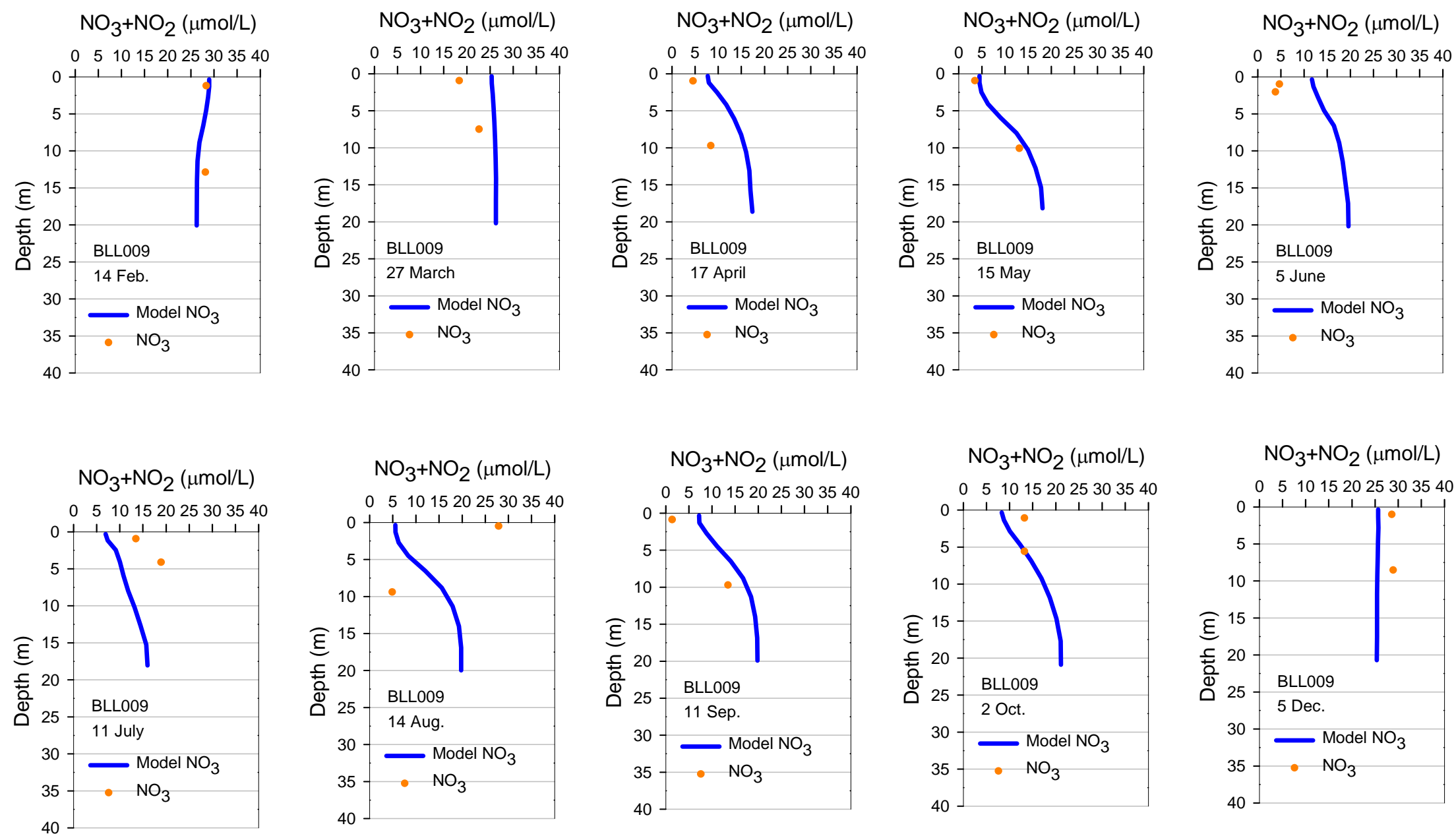

Figure C.1. (Nitrate + Nitrite) Profiles - Bellingham Bay (BLL009). Comparison of measured (nitrate + nitrite) profiles with model results for Year 2006. Circles represent the discretely measured data. 

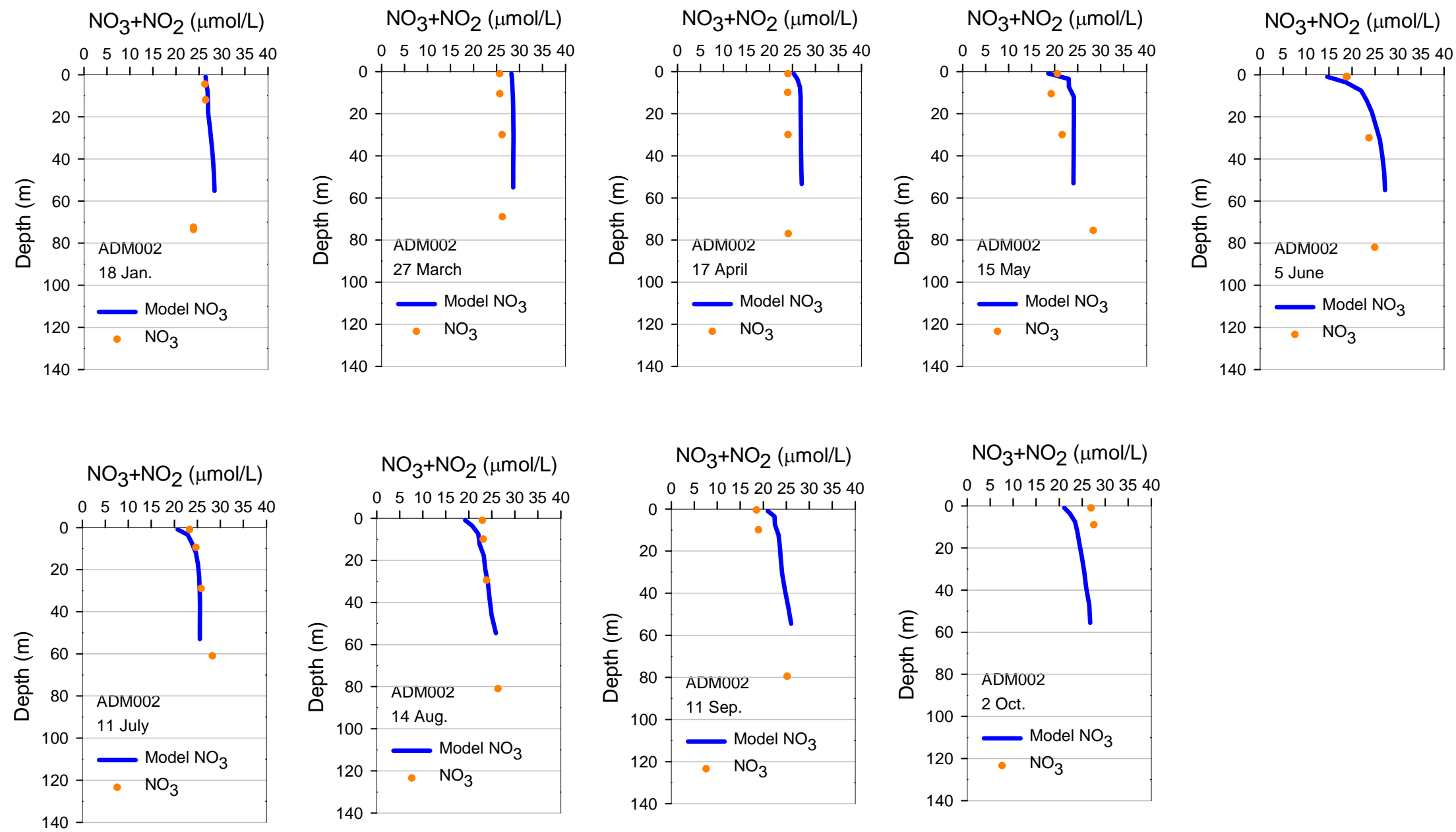

Figure C.2. (Nitrate + Nitrite) Profiles - Admiralty Inlet (ADM002). Comparison of measured (nitrate + nitrite) profiles with model results for Year 2006. Circles represent the discretely measured data. 

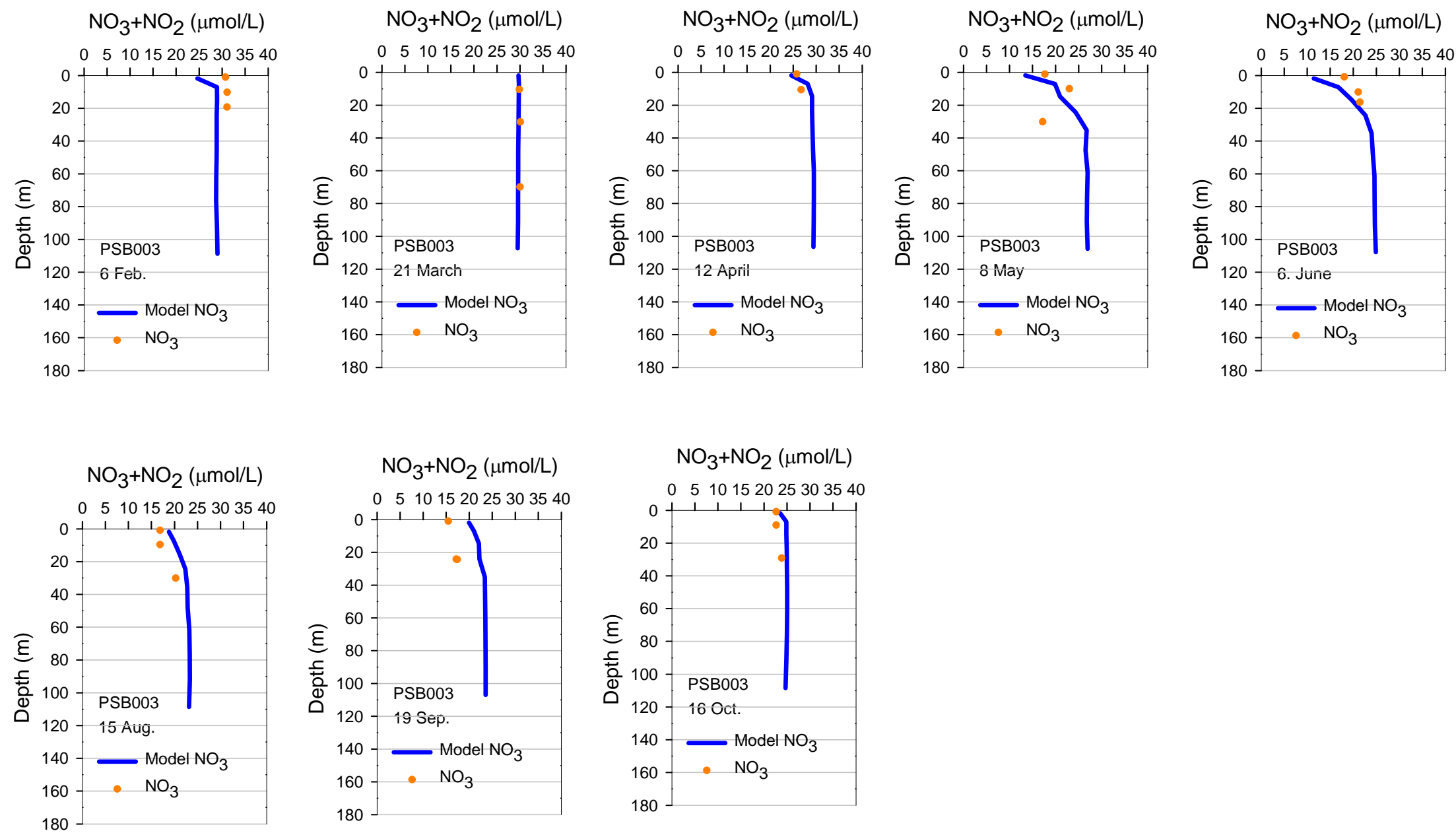

Figure C.3. (Nitrate + Nitrite) Profiles - Puget Sound Basin (PSB003). Comparison of measured (nitrate + nitrite) profiles with model results for Year 2006. Circles represent the discretely measured data. 

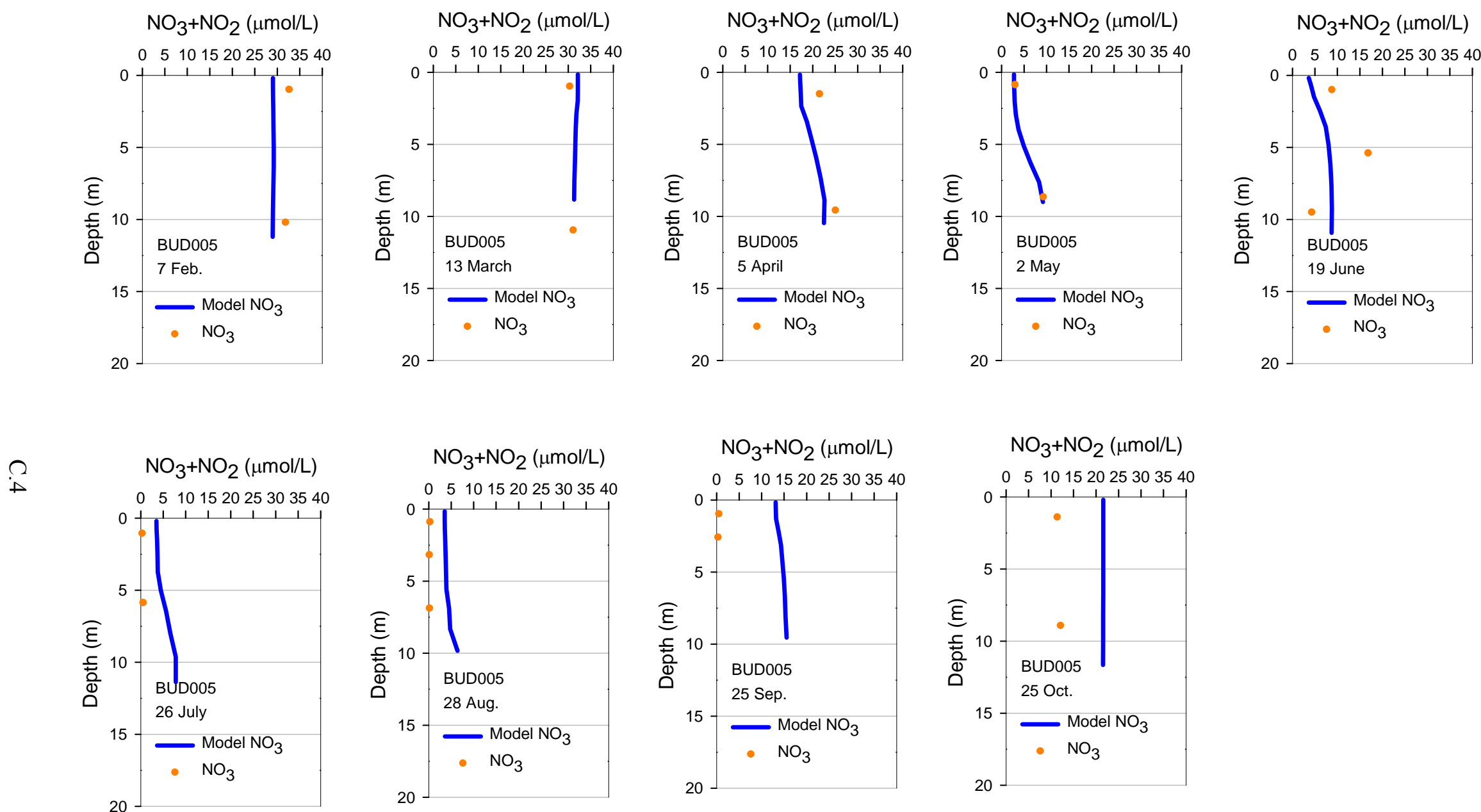

Figure C.4. (Nitrate + Nitrite) Profiles - Budd Inlet (BUD005). Comparison of measured (nitrate + nitrite) profiles with model results for Year 2006. Circles represent the discretely measured data. 

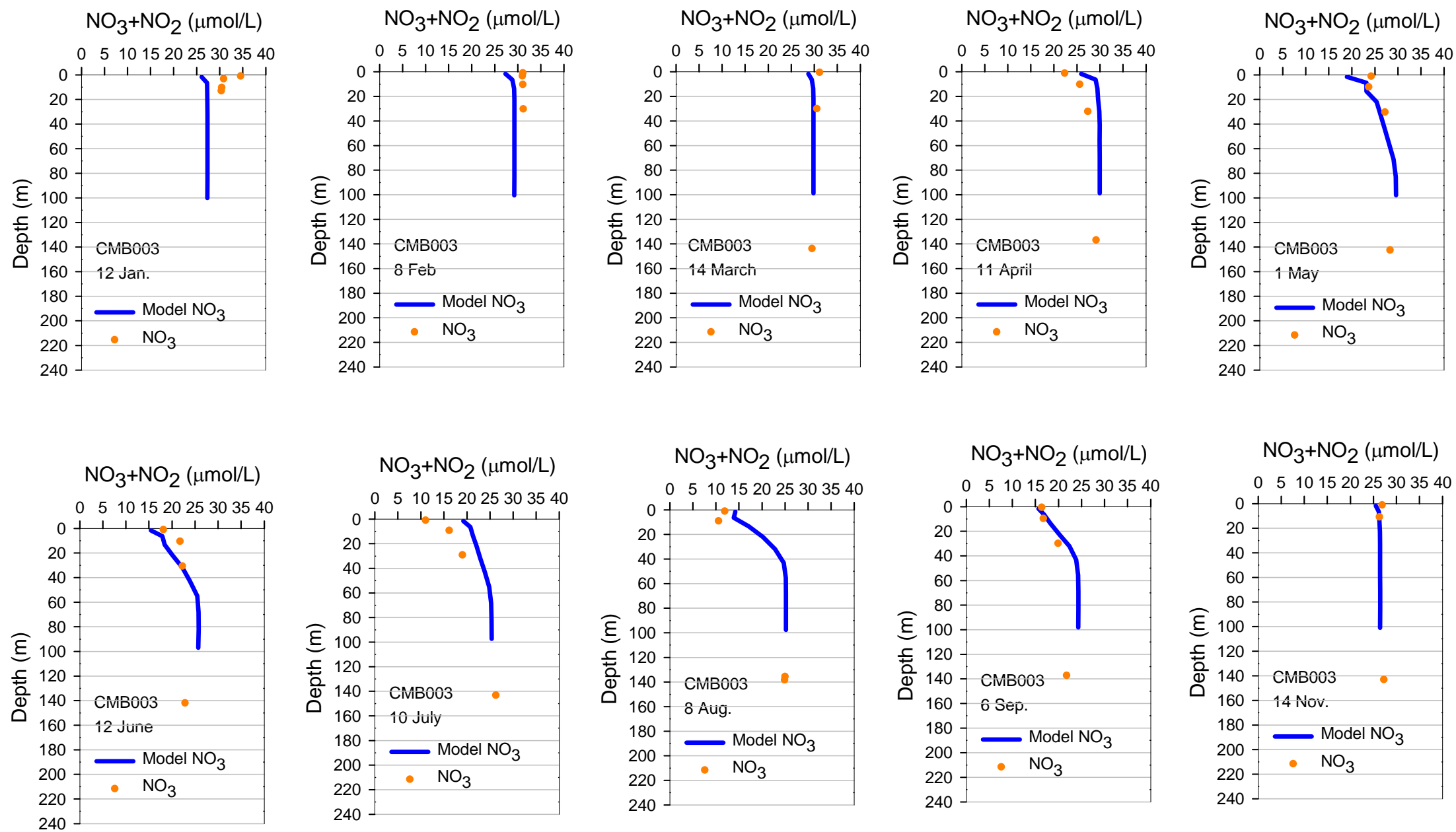

Figure C.5. (Nitrate + Nitrite) Profiles - Commencement Bay (CMB003). Comparison of measured (nitrate + nitrite) profiles with model results for Year 2006. Circles represent the discretely measured data. 

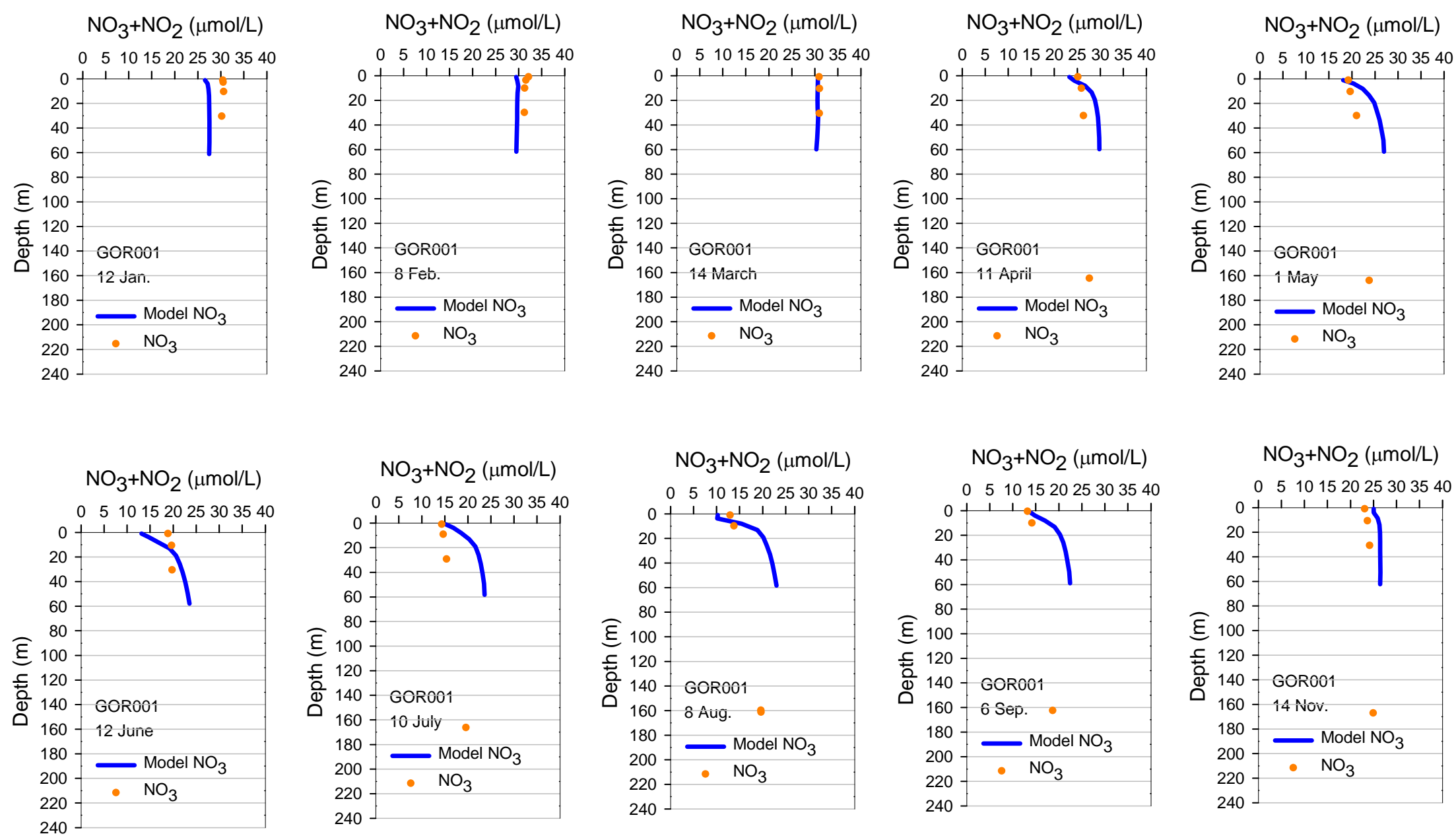

Figure C.6. (Nitrate + Nitrite) Profiles - Gordon Point (GOR001). Comparison of measured (nitrate + nitrite) profiles with model results for Year 2006. Circles represent the discretely measured data. 

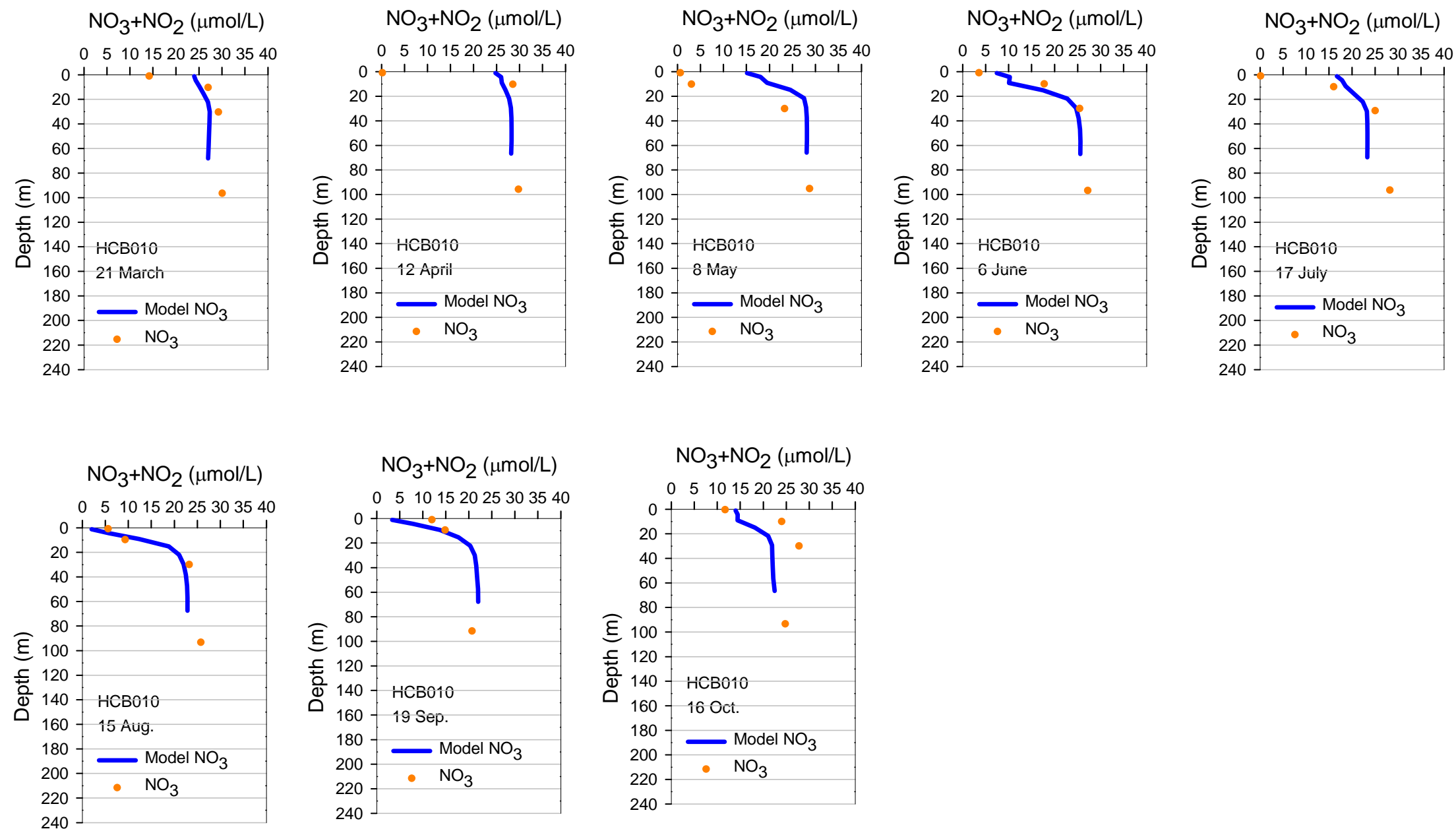

Figure C.7. (Nitrate + Nitrite) Profiles - Hood Canal (HCB010). Comparison of measured (nitrate + nitrite) profiles with model results for Year 2006. Circles represent the discretely measured data. 

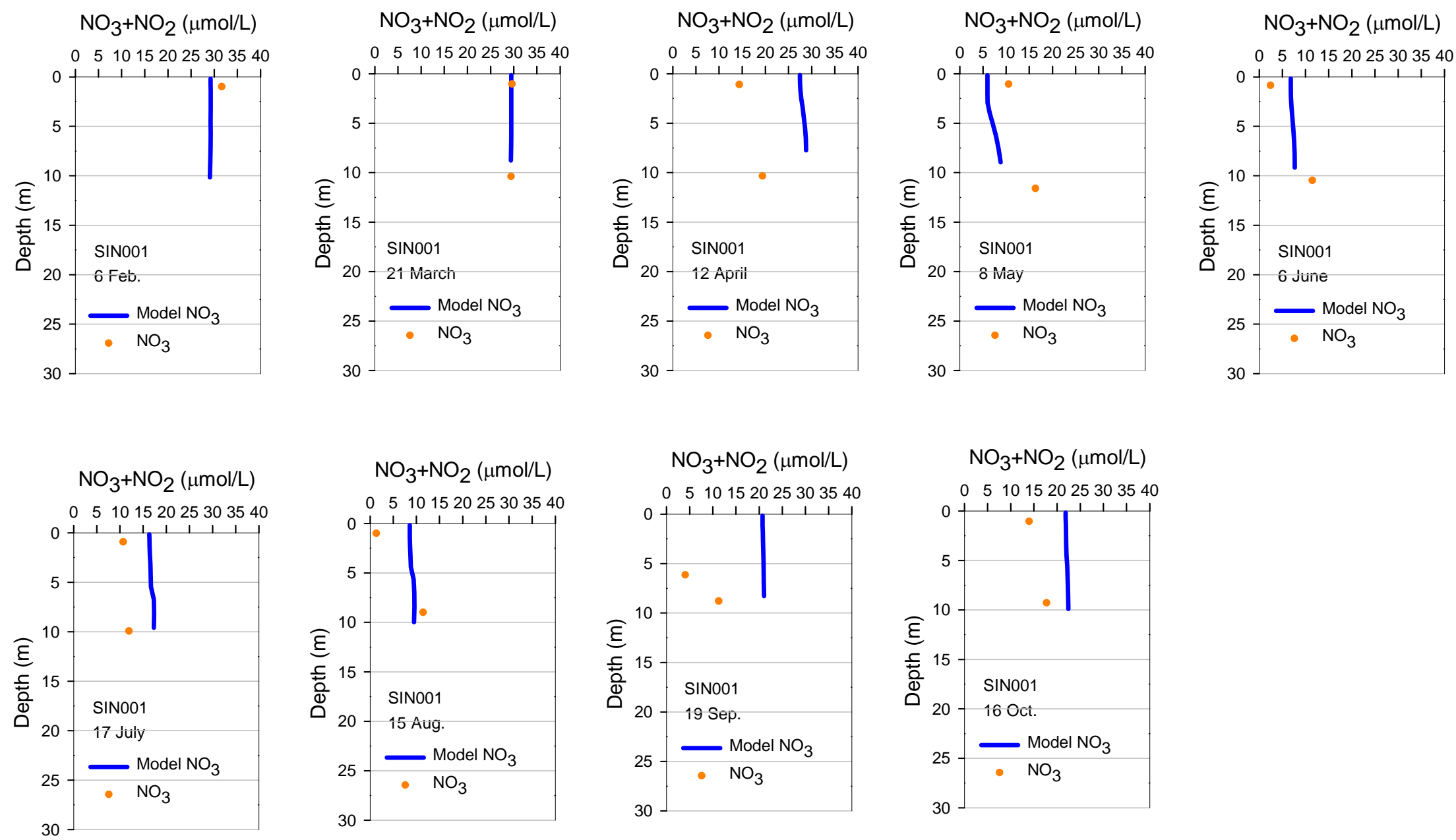

Figure C.8. (Nitrate + Nitrite) Profiles - Sinclair Inlet (SIN001). Comparison of measured (nitrate + nitrite) profiles with model results for Year 2006. Circles represent the discretely measured data. 

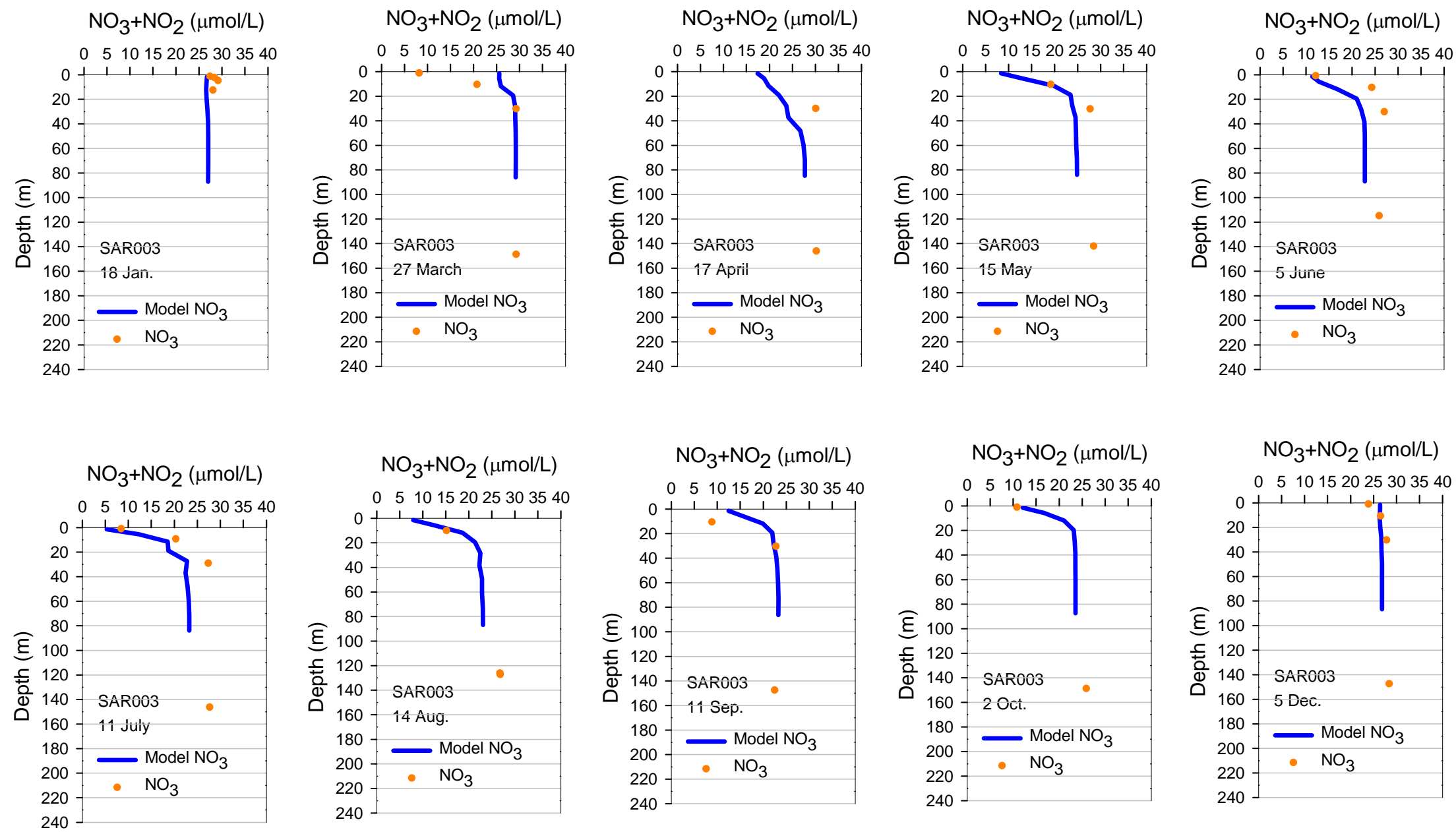

Figure C.9. (Nitrate + Nitrite) Profiles - Saratoga Passage (SAR003). Comparison of measured (nitrate + nitrite) profiles with model results for Year 2006. Circles represent the discretely measured data. 
This page is purposely left blank 


\section{Appendix D}

\section{Phosphate Profiles}

\section{Comparison of Year 2006 Monthly Profile Data with Predicted Results}


This page is purposely left blank 

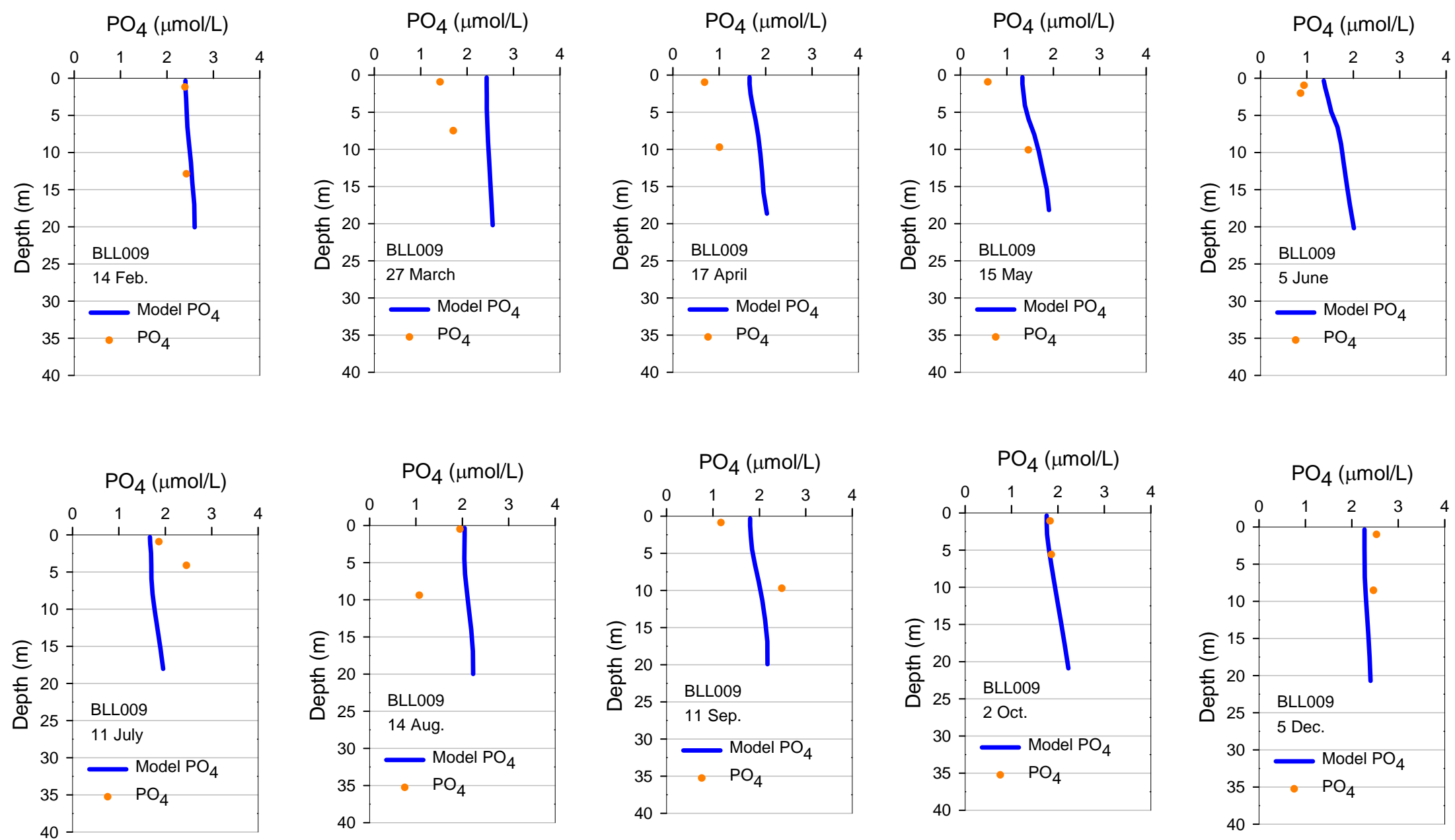

Figure D.1. Phosphate Profiles - Bellingham Bay (BLL009). Comparison of measured phosphate profiles with model results for Year 2006. Circles represent the discretely measured data. 

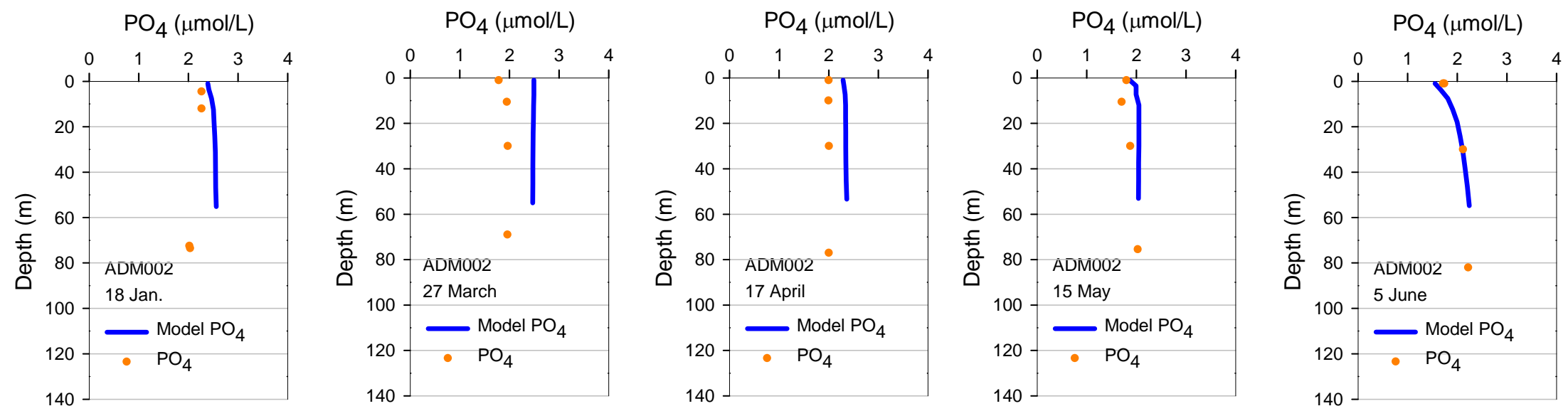

$\nabla_{i}$
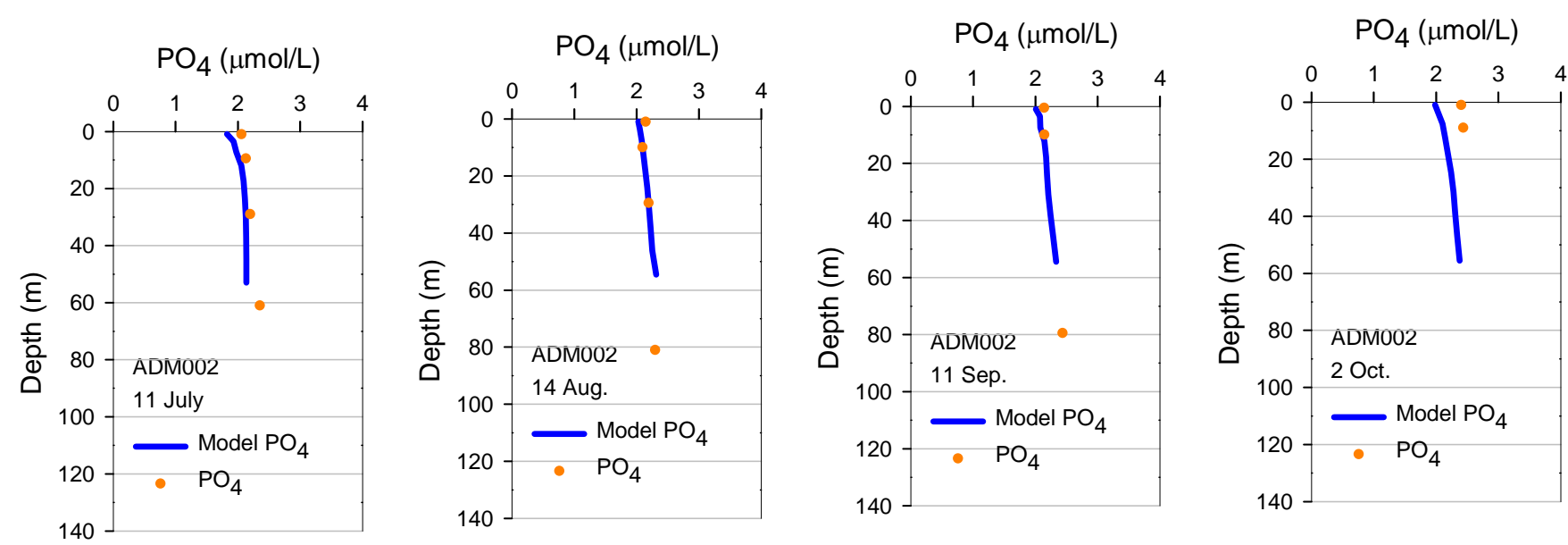

Figure D.2. Phosphate Profiles - Admiralty Inlet (ADM002). Comparison of measured phosphate profiles with model results for Year 2006. Circles represent the discretely measured data. 

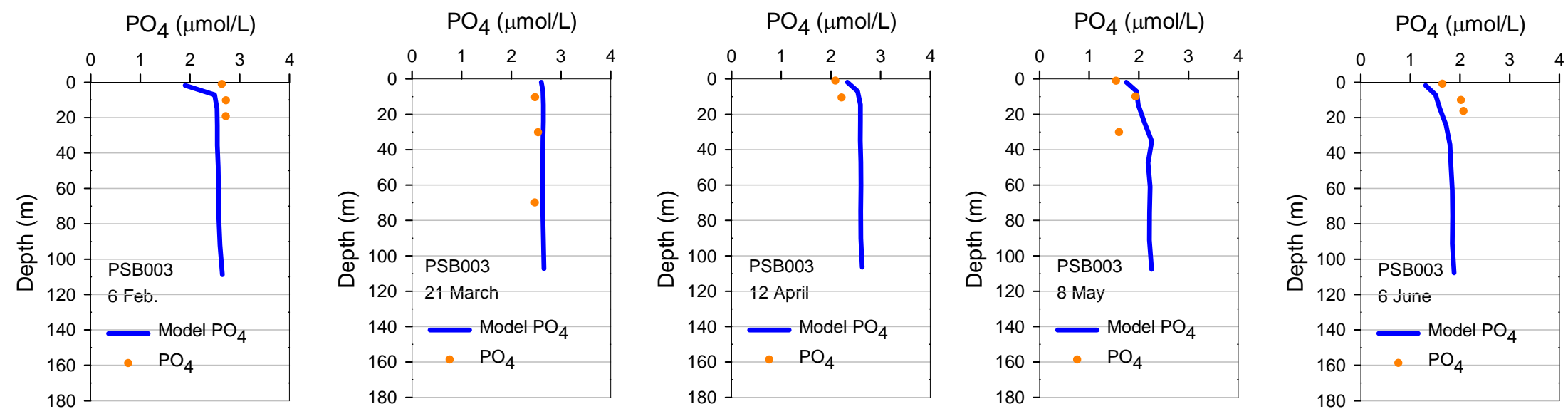

$\underset{i}{\forall}$
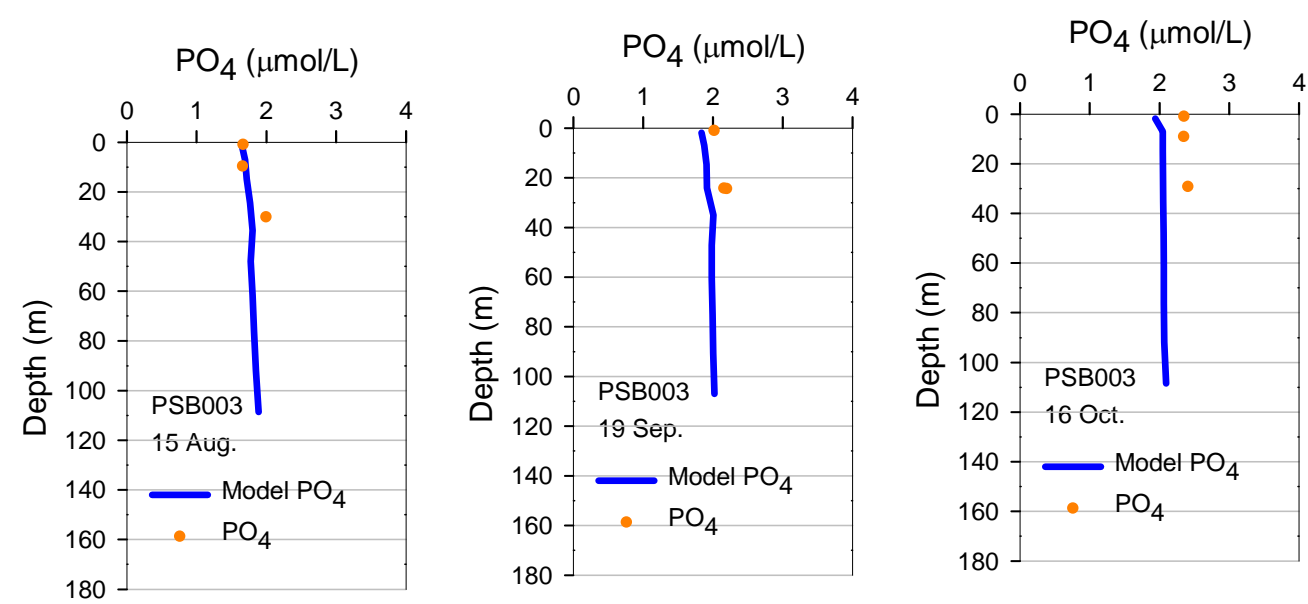

Figure D.3. Phosphate Profiles - Puget Sound Basin (PSB003). Comparison of measured phosphate profiles with model results for Year 2006. Circles represent the discretely measured data. 

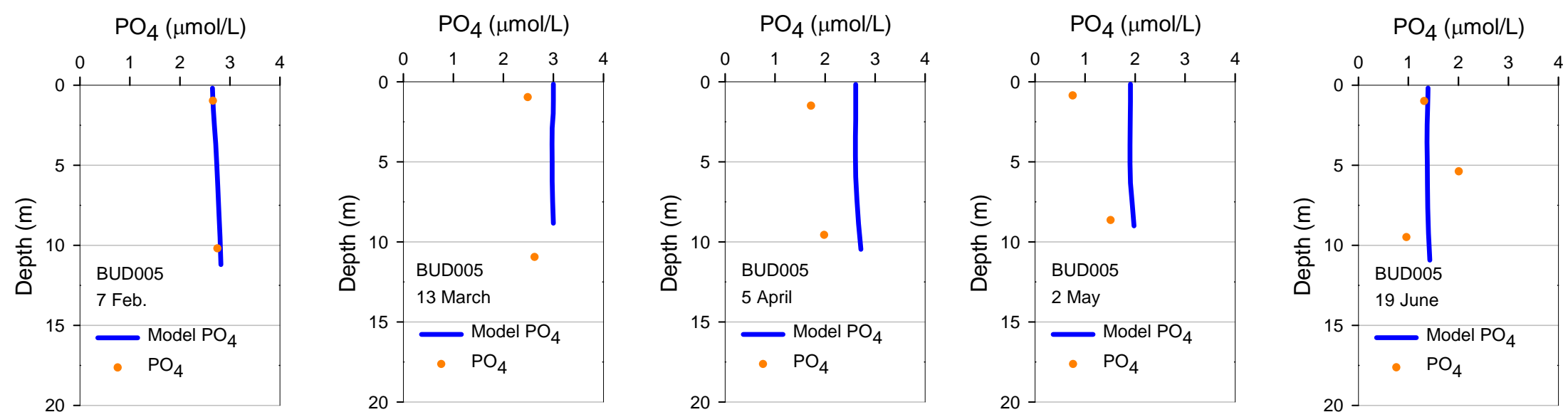

$\bullet$
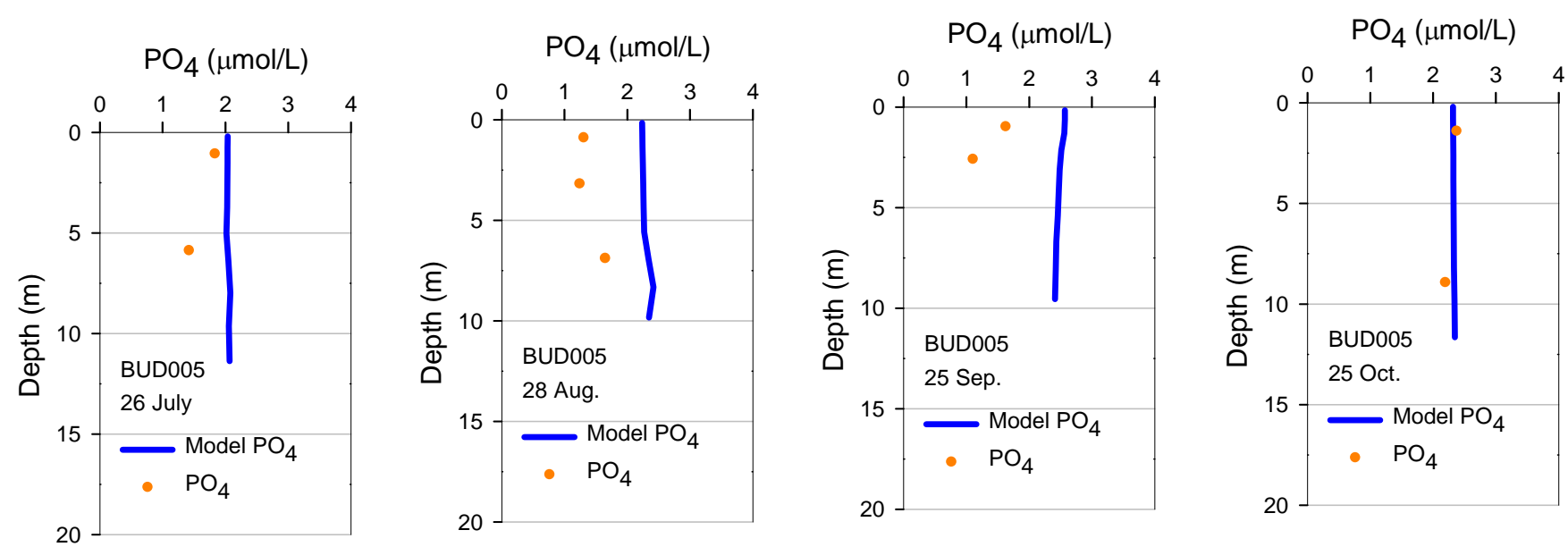

Figure D.4. Phosphate Profiles - Budd Inlet (BUD005). Comparison of measured phosphate profiles with model results for Year 2006. Circles represent the discretely measured data. 

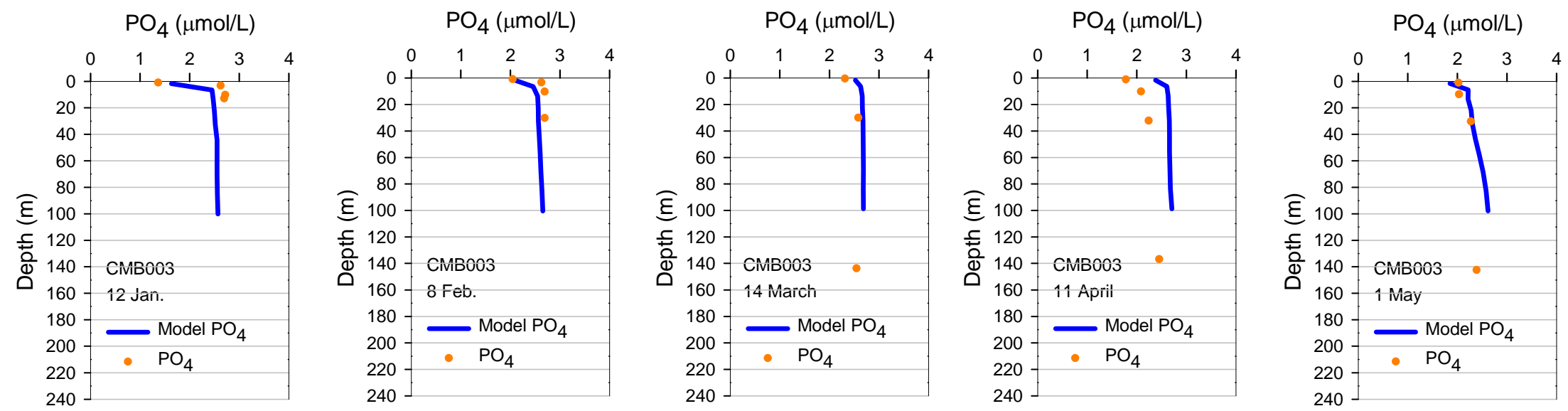

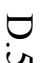
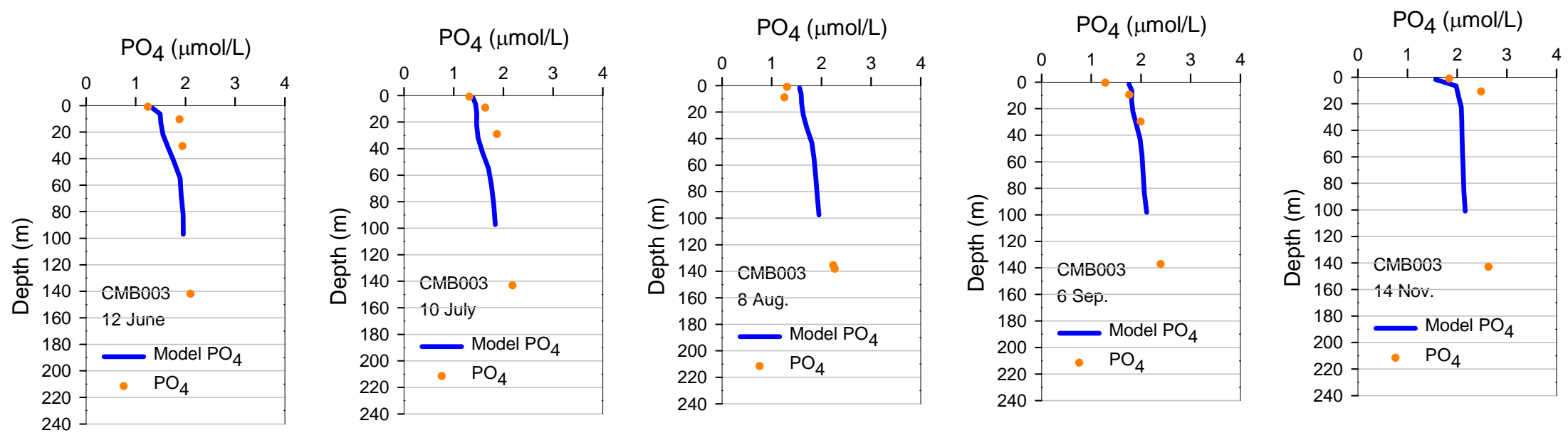

Figure D.5. Phosphate Profiles - Commencement Bay (CMB003). Comparison of measured phosphate profiles with model results for Year 2006. Circles represent the discretely measured data. 

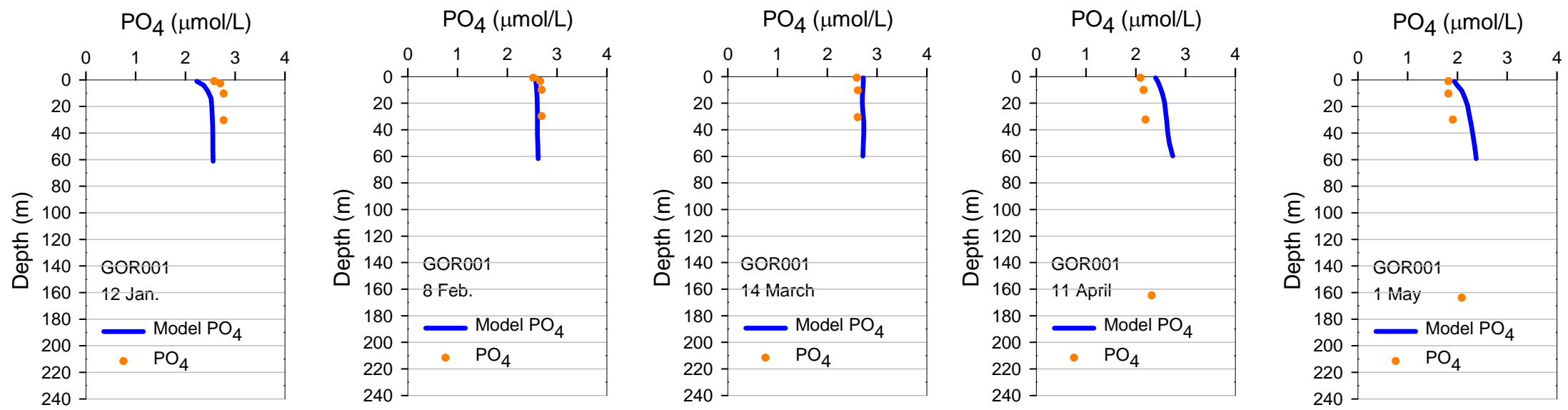

$\underset{\sigma}{\sigma}$
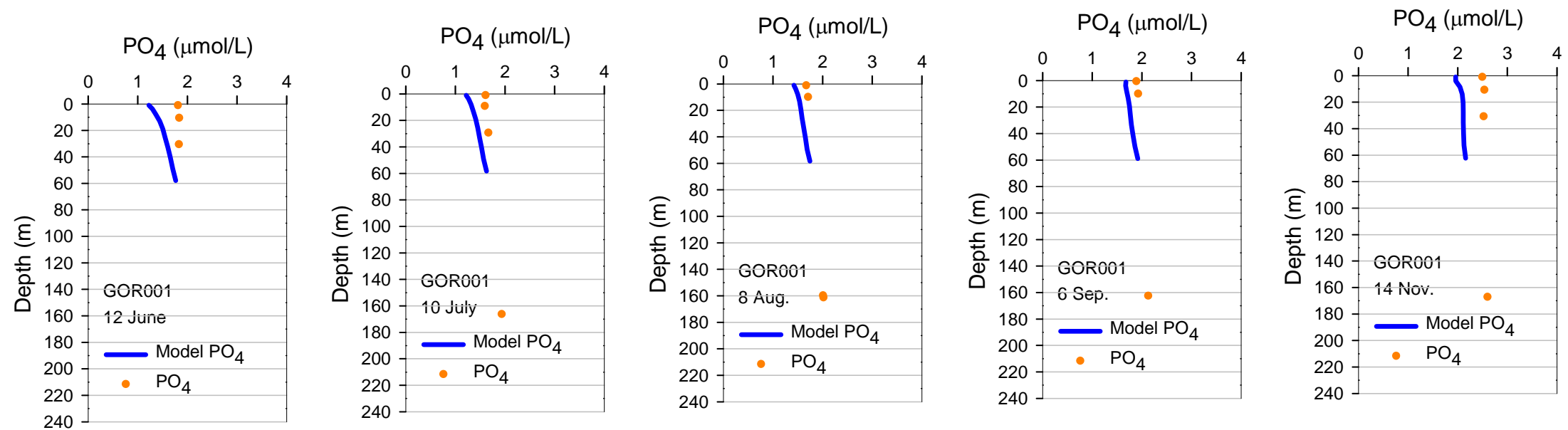

Figure D.6. Phosphate Profiles - Gordon Point (GOR001). Comparison of measured phosphate profiles with model results for Year 2006. Circles represent the discretely measured data. 

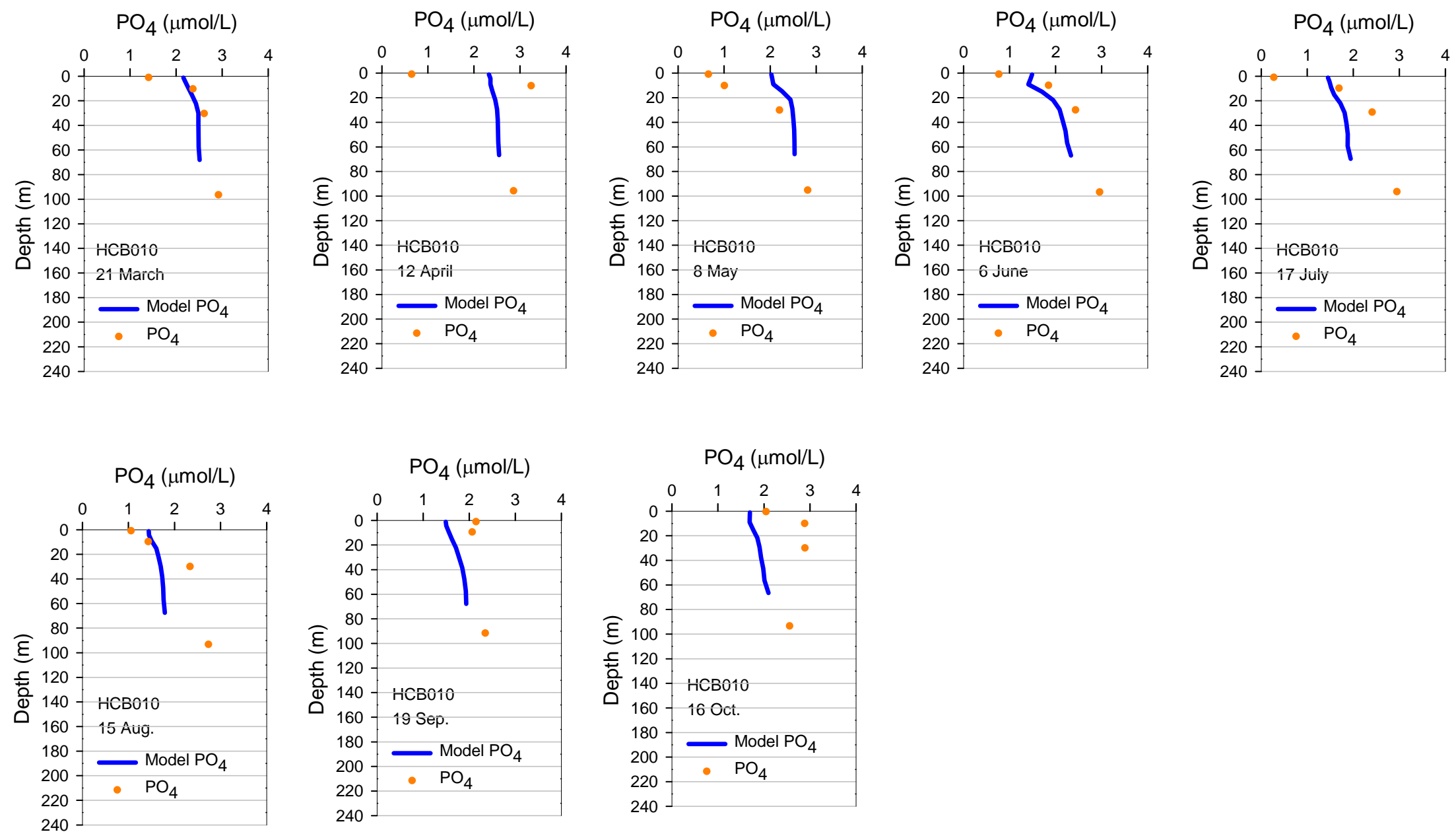

Figure D.7. Phosphate Profiles - Hood Canal (HCB010). Comparison of measured phosphate profiles with model results for Year 2006. Circles represent the discretely measured data. 

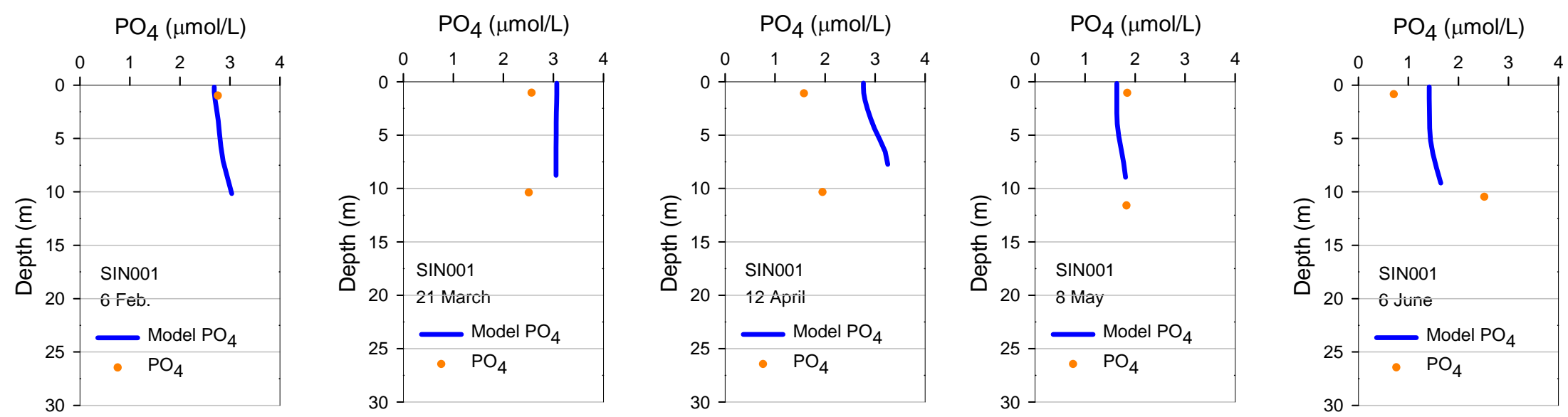

$\underset{\infty}{\bullet}$
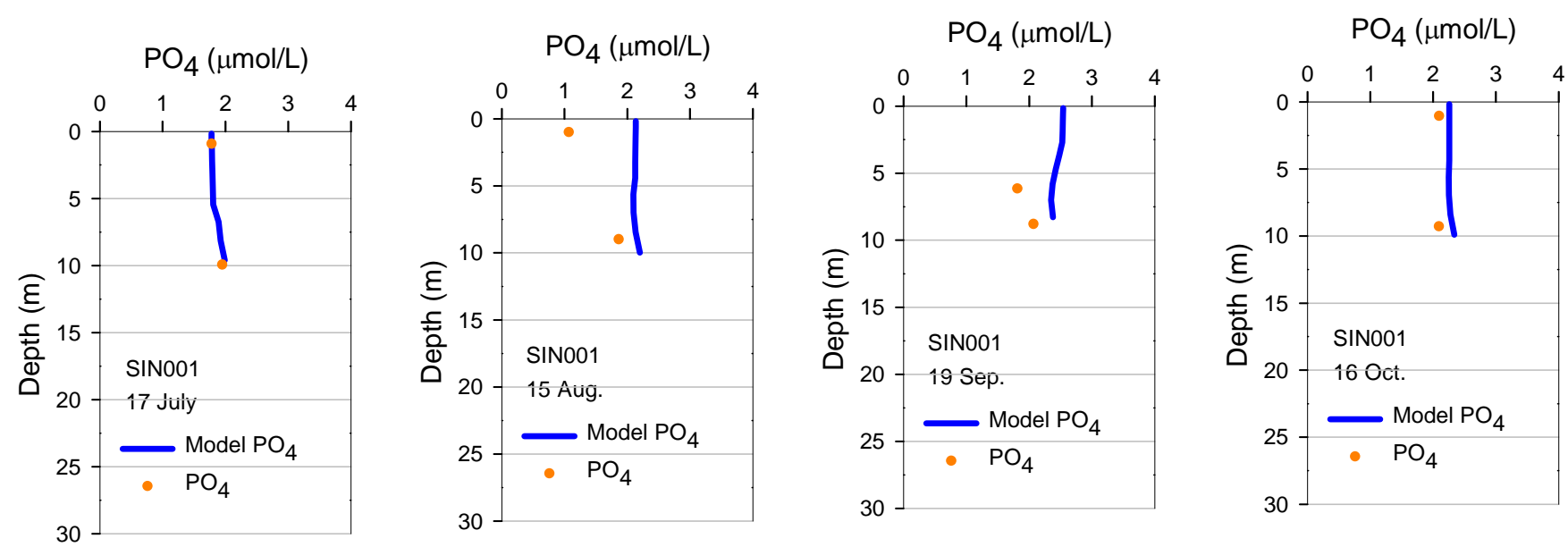

Figure D.8. Phosphate Profiles - Sinclair Inlet (SIN001). Comparison of measured phosphate profiles with model results for Year 2006. Circles represent the discretely measured data. 

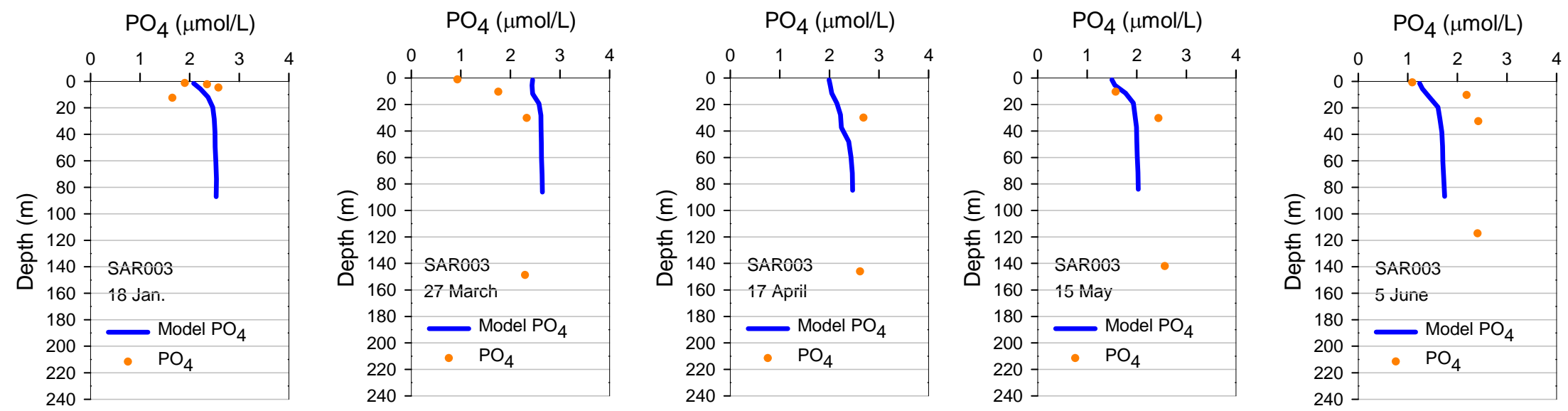

$\underset{\sigma}{\sigma}$
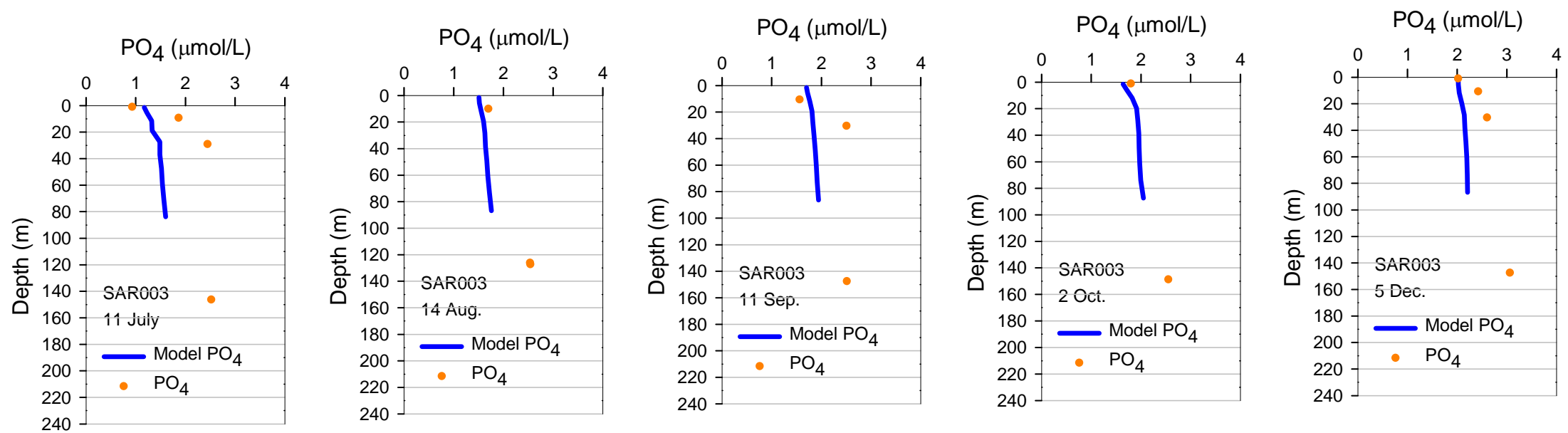

Figure D.9. Phosphate Profiles - Saratoga Passage (SAR003). Comparison of measured phosphate profiles with model results for Year 2006. Circles represent the discretely measured data. 
This page is purposely left blank 


\section{Appendix E}

\section{User Instructions and Guide - \\ Puget Sound Hydrodynamic and Water Quality Models}


This page is purposely left blank 


\section{Appendix E}

\section{User Instructions and Guide - Puget Sound Hydrodynamic and Water Quality Models}

\section{E.1 Introduction}

This document is intended to serve as a guide to an experienced coastal and oceanographic model developer who wishes to compile and run the Puget Sound Hydrodynamic and Water Quality models developed as part of this work. This guide serves as the first step toward the overall intent to transfer the models and the computer cluster to Ecology or EPA for future use in collaboration with PNNL. In its current state and at the conclusion of the Puget Sound 2.0 phase of the project, the model has been set up and calibrated using data from the Year 2006. We expect that there will be major modifications of the model setup, refinement of the boundary conditions and bathymetry, and improvement in the model parameterization in subsequent phases of this work. This Appendix simply provides model use instructions for a new user using the Puget Sound 2.0 version of the setup files. The inherent assumption is that the new user is an experienced oceanographic model developer, familiar with the Linux operating system, and has worked with FVCOM software before. The document is not designed to be a detailed user manual or a tutorial.

The following documents serve as references and provide information essential for use and application of the Puget Sound Hydrodynamic and Water Quality models developed as part of this work:

- Cerco CF and T Cole. 1995. User's Guide to the CE-QUAL-ICM Three-Dimensional Eutrophication Model, Release Version 1.0. Technical Report EL-95-15, U.S. Army Corps of Engineers, Engineer Research and Development Center, Waterways Experiment Station, Vicksburg, Mississippi.

- Chen C, RC Beardsley, and G Cowles. 2006. An Unstructured Grid, Finite-Volume Coastal Ocean Model: FVCOM User Manual. 2nd edition. SMAST/UMASSD Technical Report 06-0602, School of Marine Science \& Technology, University of Massachusetts-Dartmouth, New Bedford, Massachusetts.

- Yang Z, T Khangaonkar, R Labiosa, and T Kim. 2010. Puget Sound Dissolved Oxygen Modeling Study: Development of an Intermediate-Scale Hydrodynamic Model. PNNL-18484, Pacific Northwest National Laboratory, Richland, Washington.

- Khangaonkar T, B. Sackmann, W. Long, T. Mohamedali, and M. Roberts, 2012. Puget Sound Dissolved Oxygen Modeling Study: Development of an Intermediate Scale Water Quality Model. PNNL-20384 Rev 1

\section{E.2 Ecology-WQ Multi-processor Cluster Computer System}

A computer cluster machine built by Silicon Mechanics was acquired by Ecology and dedicated to support the development and application of the Puget Sound Hydrodynamic and Water Quality models. This machine is currently housed at PNNL's Battelle Seattle Research Center. The machine specifications are as follows. 
13. Linux Operating System

14. Number of Nodes: 1 Head/Master Node (dual quad core), including Raided Storage

22 Compute/Slave Nodes (dual quad cores, 2.0 Mhz).

This is therefore a 184-core cluster, with 16 GB of RAM and 500 GB of storage per node. It uses Intel Fortran compiler, and operates on an open source Linux Rocks Cluster Distribution.

\section{E.3 Intermediate-Scale Puget Sound Hydrodynamic Model}

An intermediate-scale 3-D hydrodynamic model for Puget Sound and the Northwest Straits was developed using the unstructured grid coastal ocean circulation modeling tool FVCOM by PNNL (Yang et al. 2010). The model simulates tidal circulation, temperature, and salinity distributions in Puget Sound and provides hydrodynamic solutions to drive the offline water quality model, which is under development as part of the project.

\section{FVCOM File Structure}

FVCOM code version 2.7 was used in Puget Sound Hydrodynamic model development. The FVCOM user's manual (Chen et al. 2006) provides instructions on how to obtain and install FVCOM files from the University of Massachusetts. It follows a strict directory structure and naming convention. Typically, a user installs FVCOM subdirectories under a project directory. An example of a project directory with FVCOM files is shown in Figure E.1.

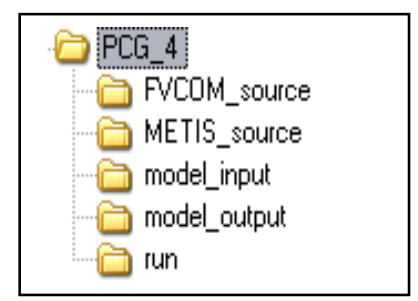

Figure E.1. FVCOM Model Directory Structure

In this example, PCG_4 is the project directory name that houses the FVCOM model and the case input files. IFVCOM_source and \METIS_source are directories containing the FVCOM source code and the METIS libraries used for domain decomposition portion of FVCOM parallelization. The \run directory contains files which control FVCOM execution. The input files containing bathymetry, inflow, tide, meteorology and other case specific initial and boundary conditions are included in $\backslash$ model_Input. Imodel_output directory is where the model output is stored. All files associated with a specific case are given a three-letter prefix. For example, lowercase letters psm (Puget Sound Model) are used to identify the case in this example. 
Key files in the respective directories associated with this model run example are listed below

Irun

- psm_run.dat

- Run control file for the Puget Sound Model. The user specifies model parameters such as external and internal model time step, frequency of output, duration of model run, number of vertical layers, and other particulars such as turbulence schemes, temperature, salinity computations etc. through this file.

- pbs_fvcom_mvapich.ib-intel.sh

- Job control script file which sets up the number of nodes/processors and the string "casename" chosen by the user. It also allows the user to specify the location of FVCOM source location of MPI libraries and specifies the case name "psm" in this example.

- hostfile

- A list of child nodes which are available to the user, to be utilizes for the job. For example the following list specifies 5 cores on node 19 are to be used on this particular model run.

- compute-0-19

- compute-0-19

- compute-0-19

- compute-0-19

- compute-0-19

Also included in the $\backslash$ run subdirectory are restart files, and short cut files for FVCOM executable, batch file for submitting multiprocessor runs, hostfile for specifying the computer nodes to be used and other miscellaneous files.

\section{linput}

- psm_uv_ini.dat

- psm_tsobc.dat

- psm_obc.dat

- psm_spg.dat

- psm_riv.dat

- psm_mc.dat

- psm_its.dat

- psm_grd.dat

- psm_dep.dat

- psm_cor.dat

- psm_bfw
Initial velocity condition

Temperature and salinity open boundary condition (time series)

Temperature and salinity open boundary condition (constant)

Sponge layer file at the open boundary

River inflow file

Meteorological loading

Initial temperature and salinity

Grid definition and connectivity

Bathymetry - depth at each node

Latitude at each node for coriolis calculations

Groundwater inflow from the bed. 


\section{loutput}

This folder includes many subfolders as shown in Figure E.2 below

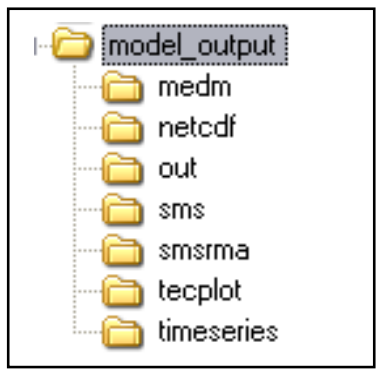

Figure E.2. Subfolders within model_output Folder

Imedm folder saves model output in binary format at the specified interval. The files have a consistent naming convention and are stored in order as

1) psm_sim0001.dat

2) psm_sim0002.dat

3) psm_sim0003.dat

4) $\ldots$

\timeseries and $\backslash$ sms subfolders include utility FORTRAN codes for post processing model result files in $\backslash$ medm.

\section{Running the Puget Sound Hydrodynamic Model}

It is assumed that the user has undergone training and is familiar with preparing the FVCOM model input files (listed in \model_input). Once all input files are ready the model run is executed by issuing the following command

“./fvcom psm" from the prompt in the \run subdirectory for a single processor execution.

For a parallel model run using multiple processors, the job file - pbs_fvcom_mvapich.ib-intel.sh file located in the Irun subdirectory is used. Typically, user edits this file to specify number of nodes and processors, indicates the location of the source code, and provides the case name (in this case psm). A parallel run is initiated using the command

“qsub pbs_fvcom_mvapich.ib-intel.sh"

\section{Post Processing of the Hydrodynamic Model Results}

After the model run is completed, typically, user navigates to $\backslash$ model_output $\backslash$ medm directory to review output files saved at the specified interval. The users may then conduct post processing. For example, the \model_output smsrma directory contains post processing utilities which help convert the 
results into a format suitable for viewing with the commercial software SMS (*.sol). This is accomplished in the following steps

- After editing and compiling the utility medm2rma.f code corresponding to the specific model particulars run the executable medm2rma by typing "./medm 2 rma" at the command prompt (note this requires editing of associated input files called by the utility to specify nodes, cells, number of layers and other case specific information). At the prompt, provide start file $=1$, increment $=1$, number of files $=$ number of files to be processed.

- The output files produced by the FVCOM model read by medm2rma program are in Imodel_output $\backslash$ medm

- The utility generates uv_layer, tsed_layer, depavg_uv, and depavg_ts - .sol files

- Transfer the *sol files to your desktop (using a utility such as WinSCP).

- Open SMS and load in PCG_4 grid file, solution files and visualize the model output. (It is assumed that the model grid was created using SMS software PCG_4.2dm is available)

Similar routines are available for processing time history and profiles at selected nodes.

\section{E.4 Puget Sound Water Quality Model (Offline Linkage to Puget Sound Hydrodynamic Model)}

This chapter provides information on how to conduct biogeochemical simulations with the Puget Sound Water Quality Model (PSWQM) using previously computed hydrodynamic solution for the same domain. We first address the structure of the PSWQM, which includes model code, model run, and FVCOM NetCDF subdirectories. After that, descriptions of the input/output files are provided. Finally, instructions on running the model and post-processing of the output files are presented.

\section{Structure of PSWQM Simulation}

The water quality model code and output directories reside in a user-created project directory, PSWQM for this example, as shown in Figure E.3.

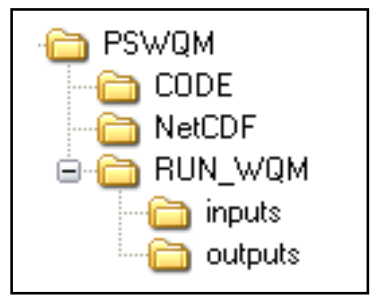

Figure E.3. PSWQM Model Directory Structure

The project directory includes model code subdirectory ((PSWQM $\backslash$ CODE), model run subdirectory

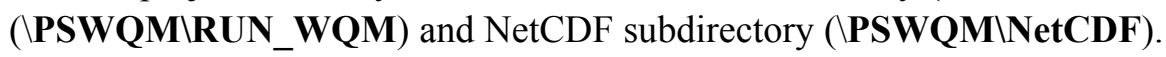

- Model code subdirectory (|PSWQM|CODE): The water quality model executable file (wqm) and the subroutine code files reside in this subdirectory. These subroutine files were coded in Fortran language and include all biogeochemical and water quality kinetics routines. If modifications are 
made or if re-compilation is needed, the user types "make" in the $\backslash$ CODE directory. A new executable file named wqm is generated.

For example:

[tykim@ecology-wq CODE]\$ make

[tykim@ecology-wq CODE] $\$$ make: ‘wqm' is up to date.

- Model run subdirectory ( $\left.\mid \boldsymbol{P S} W \mathbf{W} \backslash \mathbf{R} \boldsymbol{R} \mathbf{N} \_\boldsymbol{W Q M}\right)$ : The run control file (wqm_con.npt), job control file (pbs_linkage_mvapich.ib-intel.sh), hostfile, and input/output file subdirectories exit in this directory. The run control file is the primary file which includes information about node/element numbers, starting/ending time of simulation, time-step, location of linked input/output files, flags as indicators of the options, etc. Of many flags, ACC flag indicates of which 32 water quality state variables are active or not. The OFF implies that constituent is not activated and $\mathrm{ON}$ implies variable will be computed.

1. Temperature (OFF, b/c from FVCOM)

2. Salinity (OFF, b/c from FVCOM)

3. TSS

4. Algal 1 (Algal group 1)

5. Algal 2 (Algal group 2)

6. Algal 3 (Algal group 3)

7. Zooplankton 1 (Zooplankton - species 1)

8. Zooplankton 2 (Zooplankton species 2)

9. Labile DOC (Labile dissolved organic carbon)

10. Refractory DOC (Refractory dissolved organic carbon)

11. Labile POC (Labile particulate organic carbon)

12. Refractory POC (Refractory particulate organic carbon)

13. 13) Ammonium $\left(\mathrm{NH}_{4}\right)$

14. Nitrate + Nitrite $\left(\mathrm{NO}_{3}+\mathrm{NO}_{2}\right)$

15. Urea

16. Labile DON (Labile dissolved organic nitrogen)

17. Refractory DON (Refractory dissolved organic nitrogen)

18. Labile PON (Labile particular organic nitrogen)

19. Refractory PON (Refractory particulate organic nitrogen)

20. Total PO4 (Total phosphate)

21. Labile DOP (Labile dissolved organic phosphate)

22. Refractory DOP (Refractory dissolved organic phosphate)

23. Labile POP (Labile particulate organic phosphate)

24. Refractory POP (Refractory particulate organic phosphate)

25. Particulate inorganic $P$ (Particulate inorganic phosphate)

26. COD (Chemical oxygen demand)

27. DO (Dissolved Oxygen)

28. Particulate Silica

29. Dissolved Silica

30. "internal P group for Alga 1, Droop model" (currently off)

31. "internal P group for Alga 2, Droop model" (currently off)

32. "internal P group for Alga 3, Droop model" (currently off) 
Similar to the hydrodynamic model, the job control file (pbs_linkage_mvapich.ib-intel.sh) is a script which sets up the number of nodes/processors and the string "casename" chosen by the user. All input files are prefixed by "casename" which is "psm" in PSWQM simulation same as in the hydrodynamic model. In the hostfile, the user indicates which nodes and processors are being requested for the model simulation as in the hydrodynamic model. Note that the specified nodes/processors in the hostfile need to match the number of nodes/processor in the job control file.

- NetCDF subdirectory ( $\quad$ PSWQM $\backslash$ NetCDF): In this directory, computed FVCOM hydrodynamic solution is stored in a NetCDF format. The solution files containing velocities, boundary fluxes, free surface and water depth, temperature, and salinity, etc., are to be read by the water quality model for biogeochemical kinetic calculations. Each NetCDF hydrodynamic solution file includes 72 output snapshots, one for every 100 second (a total 2 hours hydrodynamic solution per file) designed to keep the size of each file less than 1 gig. There are 4,380 NetCDF files for the 1 year simulation. To facilitate read/write operations in Net CDF format, the NetCDF library is required which is also located in this directory.

- Input files: All input files are located in the directory ( $\mathbf{P S W Q M \backslash R U N \_ W Q M} \backslash$ inputs) which is also specified in the job control file. A description of all input files is provided below.

1. wqm_algae.dat - This input file includes algal kinetics parameters, such as algal photosynthetic rate, basal metabolic rate, base predation rate, etc.

2. settling.dat - This input file includes settling rates of algae, labile particle, refractory particle, etc. The unit is meter/day.

3. mineralization.dat - This input file includes DO/Nutrient kinetics parameters, such as nitrification rate, mineralization rate of dissolved nitrogen, hydrolysis rate of particulate nutrients, etc.

4. meteorologic.dat - This input file includes meteorological forcing such as coefficient of heat exchange, wind speed, PAR, etc.

5. psm_initial_wq_vert.dat - This input file includes initial values of water quality state variables at each node from the surface to bottom layers.

6. psm_obc_wq.dat - This input file includes time series of water quality state variable on the open boundary.

7. psm_riv_wq.dat - This input file includes time series of water quality state variable at the river boundary.

8. psm_pnt_wq.dat - This input file includes time series of water quality state variable at point sources. This includes un-gauged river loads introduced at individual nodes and waste-water treatment plant loads.

9. bfi_flux.dat - This input file includes temporally varying benthic fluxes. 
10. wqm_kei.dat - This input file includes light extinction coefficients.

11. wqm_linkage.in- This input file indicates location and time intervals of netcdf output files from the hydrodynamic model, output frequency of stations and field data for the water quality model.

- Output files: All output files are located in the directory ( $\backslash$ PSWQM $\backslash$ RUN_WQM $\backslash$ outputs). This location is also specified in the control file where model results (output files) are to be stored. A description of the output files is provided below.

1. psm_history_00001.out to psm_history_00010.out - These output files include water quality state variable results in the form of the $x-y-c$ matrix (plan view of the constituent distribution in each model layer). The data files are saved at a six hour interval. (psm_history_00001.out is the first layer or surface layer, psm_history_00010.out is the tenth layer or bottom layer)

2. psm_station.out - This output file include water quality state variable outputs in the form of time series at the water quality monitoring stations. (P1 - JEMS station north, P2 Bellingham Bay, P3 - Georgia Strait, P4 - JEMS station central, P5 - JEMS station south, P6 - Admiralty Inlet Quimper Pt., P7 - Port Townsend, P8 - Admiralty Inlet Bush Pt., P9 - Saratoga Passage, P10 - Possession Sound, P11 - Admiralty Inlet South, P12 Hood Canal, Send Creek, P13 - Sinclair Inlet, P14 - Puget Sound main basin, P15 Elliot Bay, P16 - East Passage, P17 - Hood Canal, Gt. Bend, P18 - Commencement Bay, P19 - Gordon Pt., P20 - Nisqually Reach, P21 - Dana Passage, P22 - Budd Inlet, P23 Hood Canal, Eldon, P24 - Skagit Bay, P25 - Eld Inlet) (station locations are shown in Figure E.4)

Execution and Post Processing: To run the model, the user navigates to the run directory (/PSWQM/RUN_WQM) and simply issues the command

“qsub pbs_linkage_mvapich.ib-intel.sh".

For example:

[tykim@ecology-wq RUN_WQM]\$ qsub pbs_linkage_mvapich.ib-intel.sh

The model takes approximately 24 hours to complete 1 year simulation using 5 nodes and 35 processors. The number of nodes and processors may be increased or reduced by modifying the hostfile located in the run directory. The job control file pbs_linkage_mvapich.ib-intel.sh also must be updated to reflect the updated umber of nodes and processors 


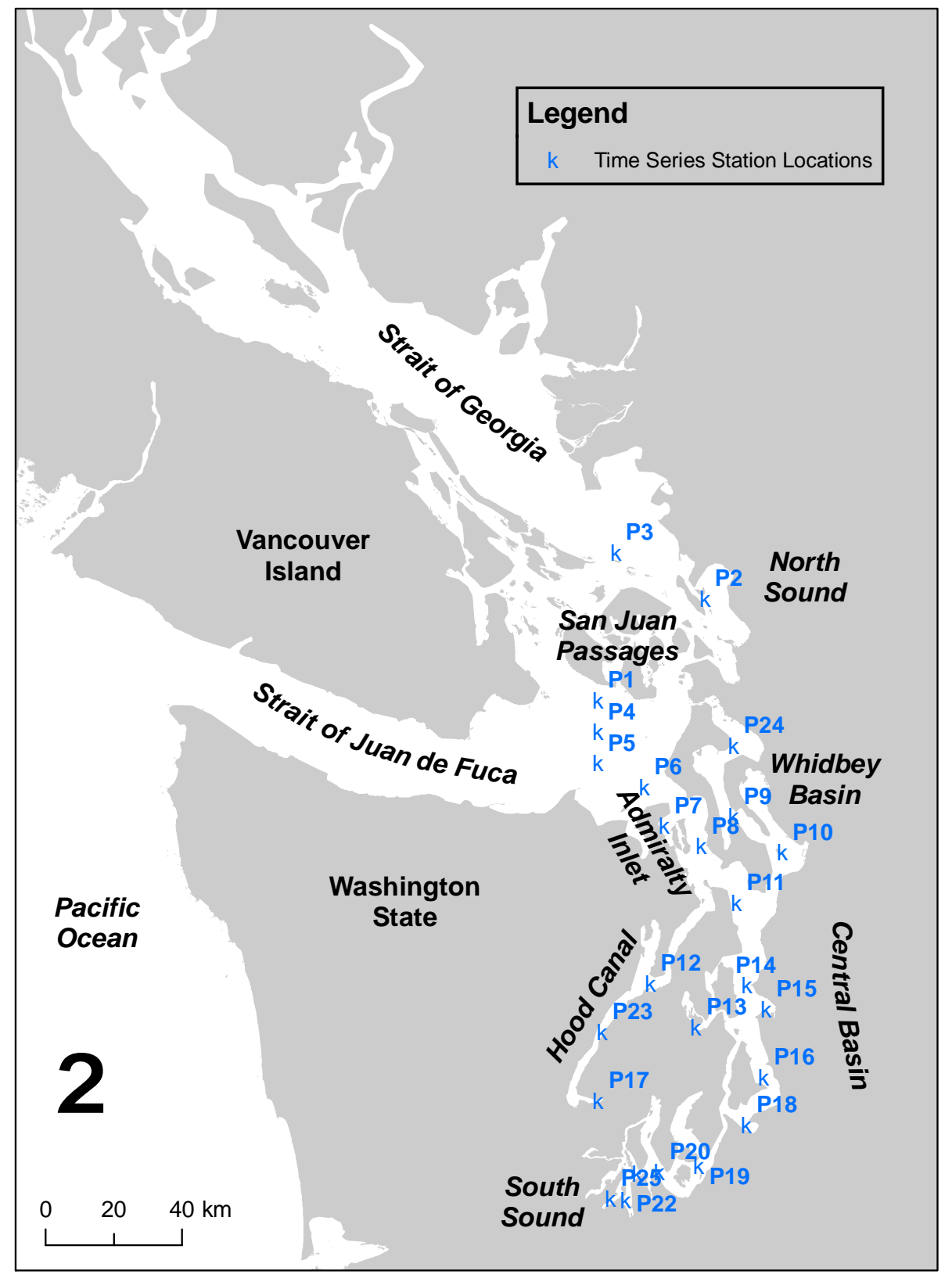

Figure E.4. Time Series Station Locations for Puget Sound Water Quality Model Output

Program wqmhis2sms.f90 is a Fortran code that can be compiled and executed to process the psm_history_xxxxx.out files and generate constituent plane view files (NUT1.dat, NUT2.dat, NUT3.dat), which can be read into SMS software and visualized as contour plots.

For example:

[tykim@ecology-wq RUN_WQM/outputs]\$ ifort -o wqmhis2sms wqmhis2sms.990

[tykim@ecology-wq RUN_WQM/outputs]\$ ./wqmhis2sms 
The station output file psm_station.out can be processed by wqmstn2tecplot.f90 or wqmstn2matlab.m to allow plotting software Tecplot to plot them. The program wqmstn2tecplot. 990 generates a series of *.plt files for selected stations and can be loaded into Tecplot and plotted against data. The program wqmstn2matlab.m can be run in MATLAB software and will plot surface and bottom value of all variables of stations listed in psm_station.out for quick inspection.

For example:

[tykim@ecology-wq RUN_WQM/outputs]\$ ifort -o wqmstn2tecplot wqmstn2tecplot.f90

[tykim@ecology-wq RUN_WQM/outputs]\$./wqmstn2tecplot 
This page is purposely left blank 


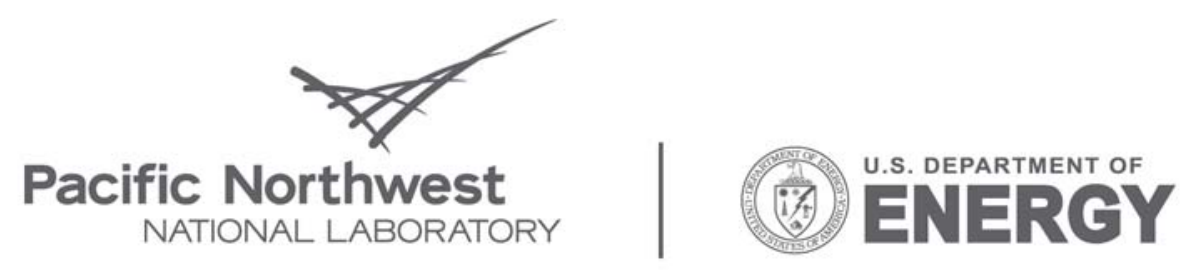

Proudly Operated by Battelle Since 1965

902 Battelle Boulevard

P.O. Box 999

Richland, WA 99352

1-888-375-PNNL (7665)

www.pnl.gov 